\title{
WestVirginiaUniversity
}

THE RESEARCH REPOSITORY @ WVU

Graduate Theses, Dissertations, and Problem Reports

2010

\section{Process Model and Control System for the Glass Fiber Drawing Process}

Songke Liu

West Virginia University

Follow this and additional works at: https://researchrepository.wvu.edu/etd

\section{Recommended Citation}

Liu, Songke, "Process Model and Control System for the Glass Fiber Drawing Process" (2010). Graduate Theses, Dissertations, and Problem Reports. 3006.

https://researchrepository.wvu.edu/etd/3006

This Dissertation is protected by copyright and/or related rights. It has been brought to you by the The Research Repository @ WVU with permission from the rights-holder(s). You are free to use this Dissertation in any way that is permitted by the copyright and related rights legislation that applies to your use. For other uses you must obtain permission from the rights-holder(s) directly, unless additional rights are indicated by a Creative Commons license in the record and/ or on the work itself. This Dissertation has been accepted for inclusion in WVU Graduate Theses, Dissertations, and Problem Reports collection by an authorized administrator of The Research Repository @ WVU.

For more information, please contact researchrepository@mail.wvu.edu. 


\title{
Process Model and Control System for the Glass Fiber Drawing Process
}

\author{
Songke Liu
}

\author{
Dissertation submitted to the \\ College of Engineering and Mineral Resources \\ at West Virginia University \\ in partial fulfillment of the requirements \\ for the degree of
}

Doctor of Philosophy

in

Mechanical Engineering

\author{
Larry E. Banta, Ph. D., Chair \\ Wade W. Huebsch, Ph. D. \\ Kenneth H. Means, Ph. D. \\ Mario Perhinschi, Ph. D. \\ Natalia A. Schmid, Ph. D. \\ Department of Mechanical and Aerospace Engineering
}

Morgantown, West Virginia

2010

Keywords: Glass Fiber; Drawing Process; Temperature Estimation; Process Control Copyright 2010 Songke Liu 


\title{
Abstract \\ Process Model and Control System for the Glass Fiber Drawing Process
}

\begin{abstract}
Songke Liu
Drawing of glass fibers is an important industrial process used for manufacture of a variety of materials ranging from optical communications cables to fiber filter media. A variety of machines exist for performing the drawing function, but all share similar problems with control of the fiber diameters and breakage of the fibers during the extrusion process. In many cases, control systems are not configured to monitor the most critical process variables-- temperature of molten glass in the furnace, but instead use only furnace crown temperature. Upsets in disturbance variables such as ambient temperature are compensated manually by operators, usually only after significant problems with fiber breakage occur. This work seeks to provide better understanding of the effects of important process variables on the key quality and production parameters such as fiber diameter and production rates, and to develop an effective control model to monitor molten glass temperature and winder speed for good production quality even if some disturbance happens.

First an analytical model of the glass fiber based primarily on Glicksman's work was developed, with the addition of a radiative heat transfer component and the addition of temperature-dependent relationships for physical properties of soda-lime glass. The model is valid for fibers in the central attenuation region, where most of fiber attenuation and breakage happens. Parametric studies have been done using the model to evaluate the effects of variation in the ambient temperature and variation of the molten glass depth in the furnace. These studies have shown that even modest changes ambient temperature and molten glass depth can generate significant changes in the final diameter of the glass fibers.

Based on those results, a state space model of the furnace has been constructed and used as the basis of a state reduced-order estimator to provide an accurate estimate of the temperature of the molten glass at the furnace bottom. A LQR controller with a reference input was applied in the model for bottom glass temperature control. A winder speed controller has been developed in parallel in order to compensate for the long time delay between application of burner firing rate changes and the response of the thermal system. Then multivariable control analysis was done on variation of ambient temperature and variation of molten glass depth. The control model
\end{abstract}


manipulates both the winder speed and the burner firing rate, bringing the process back to design conditions even if some disturbance occurs, and allows greater flexibility and more accurate quality control for the glass fiber drawing process. 


\section{Acknowledgments}

First I would like to express my high appreciation to Professor Larry E. Banta, for both his patient guidance and deep insight in helping completing the present work and providing me a chance to study under his supervision at West Virginia University. I am also indebted him a lot to his invaluable support in my difficult time.

Very special thank goes to my family. My lovely wife, Huiying Zhu, has been a great supporter, for her care, love, and cooking that has kept me fat and healthy all these year. I am eternally grateful to my beloved mother, who always prays for me. Love and care from my parents-in-law, my friends are strong support to finish my research here. Again thank them all.

Funding for this research was provided by the National Energy Technology Laboratory. I would thank Dr. Wade W. Huebsch, Dr. Kenneth H. Means, Dr. Mario Perhinschi and Dr. Natalia A. Schmid for their support, suggestion and participation in this research. 


\section{Nomenclature}

A Area of the section through which heat flows by conduction, $\mathrm{m}^{2}$

$\mathrm{A}_{1} \quad$ Radiation area, $\mathrm{m}^{2}$

$\mathrm{a}_{1}, \mathrm{a}_{2}$ Two coefficients in Glickman's temperature and viscosity model,28.7415, and $0.9827 \times 10^{-2} \mathrm{degF}^{-1}$ respectively

$\mathrm{c}_{\mathrm{p}} \quad$ Specific heat, $\mathrm{J} /(\mathrm{kg} * \mathrm{~K})$

$E=\frac{\overline{v_{f}}}{\overline{v_{o}}} \quad$ Extension ratio

F $\quad$ Rate of flow, $\mathrm{g}^{*} \mathrm{~h}^{-1}$

$\mathrm{F}_{12} \quad$ Shape factor

$\mathrm{F}_{\mathrm{ST}} \quad$ Surface tension force, $\mathrm{N}$

$\mathrm{f}_{1}, \mathrm{f}_{2}, \mathrm{f}_{3} \quad$ Fulcher constant, in my cases $-2.66,4545,489.75$ respectively

g Gravity onstant, 9.8Nkg

$\mathrm{H} \quad$ Height of glass above the nozzle, $\mathrm{m}$

H' Distance from the molten glass top surface to the point where I calculate, $m$

h Coefficient of heat transfer, $\mathrm{J} /\left(\mathrm{sec}^{*} \mathrm{~K}^{*} \mathrm{~m}^{2}\right)$

$\overline{h_{c}} \quad$ Average convective heat transfer coefficient, $\mathrm{W} /\left(\mathrm{m}^{2} * \mathrm{~K}\right)$

$\mathrm{I}_{1}, \mathrm{I}_{2} \quad$ Intensity of the light entering at the first boundary, intensity of the light arriving at the second boundary $\mathrm{J}$

$\mathrm{I}_{\mathrm{o}, \lambda} \quad$ Original intensity of the light entering the material at the wavelength $\lambda, \mathrm{J}$

$\mathrm{I}_{\mathrm{x}, \lambda} \quad$ Remaining intensity of the light at $\mathrm{x}$ distance at the wavelength $\lambda, \mathrm{J}$ 
k Thermal onductivity of he material, $\mathrm{W} /(\mathrm{m} * \mathrm{~K})$

$\mathrm{k}_{\mathrm{f}} \quad$ Thermal conductivity evaluated at the average of the wall and free-stream temperature, $\mathrm{W} /\left(\mathrm{m}^{*} \mathrm{~K}\right)$

$\mathrm{k}_{\mathrm{s}} \quad$ Thermal conductivity of a solid material, $\mathrm{W} /(\mathrm{m} * \mathrm{~K})$

L Length of the cylindrical section, mm; or nozzle length, mm

$\mathrm{l}$ Total length $o$ he tube $\mathrm{n}$ the $\mathrm{x}$ diection, $\mathrm{m}$

$\Delta \mathrm{P} \quad$ Pressure difference between the two ends, $\mathrm{mmHg}$

$\mathrm{q}_{\mathrm{c}} \quad$ Rate of heat transfer by convection, $\mathrm{W}$

$\mathrm{R} \quad$ Internal radius of the tube in Poiseuille's law, mm; nozzle radius, or the radius of the nozzle bore in its narrowest cylindrical section, $\mathrm{mm}$

R' Ratio of gavity frce $\mathrm{t}$ the sirface ension

$\mathrm{r} \quad$ Radius of glass fibers where I calculate, $\mathrm{mm}$

$\mathrm{r}_{\mathrm{o}} \quad$ Cone radius on the glass fiber profile, $\mathrm{mm}$

$\mathrm{T} \quad$ Temperature of the fiber at its surface, Kelvin

$\mathrm{T}_{\mathrm{m}} \quad$ Crystallization temperature, Kelvin

$\mathrm{T}_{\mathrm{o}} \quad$ Temperature at the cone radius $\mathrm{r}_{0}$, Celsius

$\mathrm{T}_{\infty} \quad$ Ambient Temperature, Kelvin

$\Delta \mathrm{T} \quad$ Difference between the surface temperature and a temperature of the fluid $\mathrm{T}_{\infty}$ at some specified location (usually far away from the surface), $\mathrm{K}$

$\mathrm{t} \quad$ Thickness of the glass, $\mathrm{cm}$

V Volume of the liquid, flowing in the time unit, $\mathrm{cm}^{3}$; or free stream airflow velocity, $\mathrm{m} / \mathrm{s}$; or velocity of glass fibers, $\mathrm{m} / \mathrm{s}$ 


$\begin{array}{ll}\mathrm{V}_{\mathrm{o}} & \text { Flow rate in the nozzle, } \mathrm{cm}^{3} / \mathrm{sec} \\ \mathrm{V}_{\mathrm{L}} & \text { Winder speed, } \mathrm{m} / \mathrm{sec} \\ v & \text { Kinematic viscosity of air } \mathrm{cm}^{2} / \mathrm{s} \\ \bar{v} & \text { Mean fluid velocity along the length of the tube, } \mathrm{cm} / \mathrm{sec} \\ \overline{v_{f}} & \text { Pulling velocity } \mathrm{m} / \mathrm{sec} \\ \overline{v_{o}} & \text { Average inlet velocity, } \mathrm{m} / \mathrm{sec} \\ \mathrm{w} & \text { Mass rate of flow, } \mathrm{kg} / \mathrm{sec} \\ \mathrm{x} & \text { Direction of fow }\end{array}$

\section{Greek symbols}

a Absorption coefficient of the glass, $\mathrm{cm}^{-1}$

$\gamma_{\mathrm{T}} \quad$ Surface tension coefficient, $\mathrm{N} / \mathrm{m}$

$\varepsilon_{1} \quad$ Emissivity of the grey surface

$\eta \quad$ Dynamic fluid viscosity in the nozzle, Pa*sec

$\eta$ ' Dynamic fuid viscosity, cPs or enti-Poisseuille’s

$\eta_{0} \quad$ Dynamic fluid viscosity in the nozzle, $\mathrm{Pa}$ *sec

$\theta \quad$ Angle between the tangent to the jet surface, and the axial direction in the r-z plane, radian

$\mu \quad$ Constant of proportionality, absolute viscosity, Pa*sec

$\mu_{\text {o,b }} \quad$ Coefficients in the temperature dependent viscosity model

$\mu_{o} \quad$ Absolute viscosity, poise

$\rho \quad$ Density of glass, $2.4755 \times 10^{3} \mathrm{~kg} / \mathrm{m}^{3}$ in my case

$\sigma \quad$ Stefan-Boltzmann constant, $5.67 \times 10^{-8} \mathrm{~W} / \mathrm{m}^{2} * \mathrm{~K}^{4}$

$\sigma_{0} \quad$ Stress from the winder, Pascal 
$\sigma_{\lambda} \quad$ Optical thickness for the material at wavelength $\lambda, \mathrm{cm}$

$\tau \quad$ Shear stress, Pascal

$\Phi \quad$ Voluminal laminar stationary flow rate of an incompressible uniform viscous liquid, $\mathrm{mm}^{3} / \mathrm{sec}$

\section{Subscripts}

( ) $\mathrm{BP} \quad$ Conditions at the bushing plate

()$_{\mathrm{E}} \quad$ Conditions at the upper boundary of the one-dimensional region

( ) Conditions at the nozzle exit plane

( ) $\quad$ Conditions in the air far from the jet surface 


\section{Table of Contents}

1. INTRODUCTION

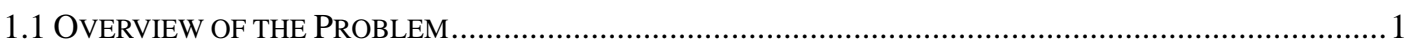

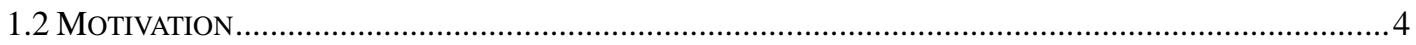

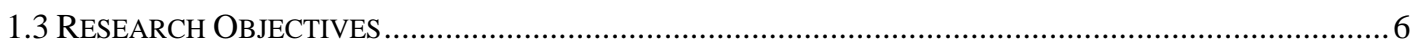

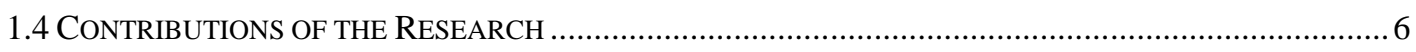

2. LITERATURE REVIEW ................................................................................................................

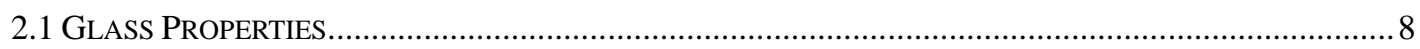

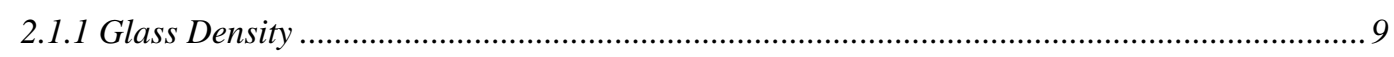

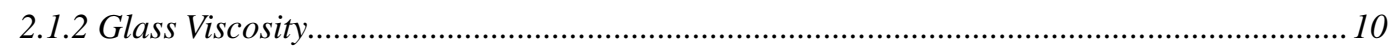

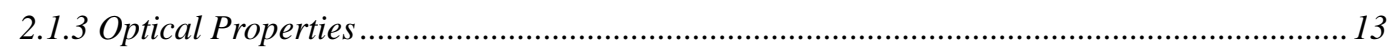

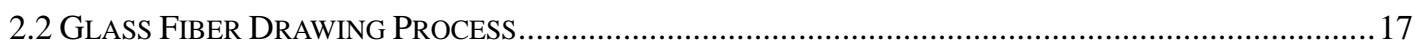

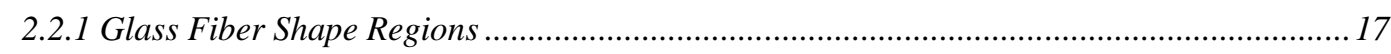

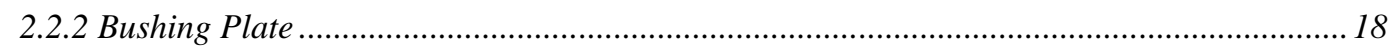

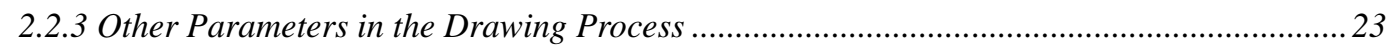

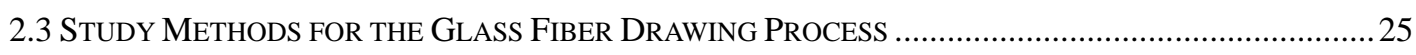

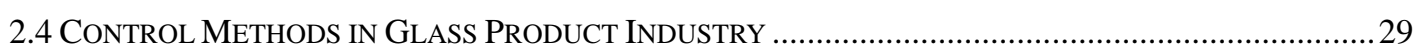

3. TECHNICAL APPROACH .........................................................................................................33

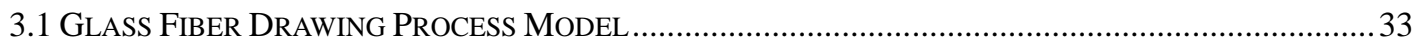

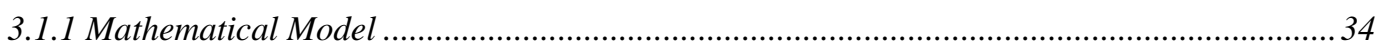

3.1.1.1 Forced Convection in Heat Transfer ............................................................................. 34

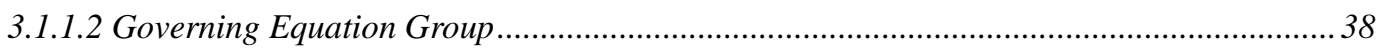

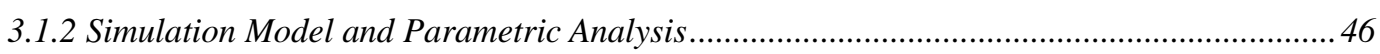

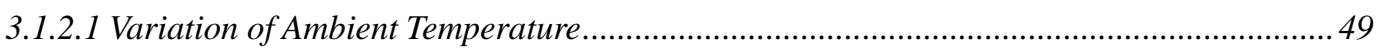

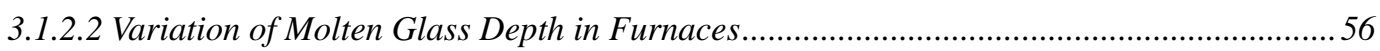

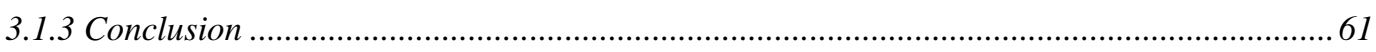

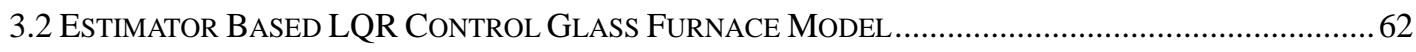

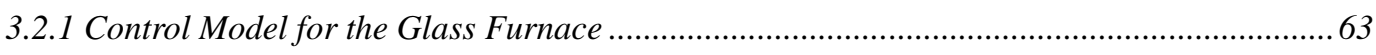

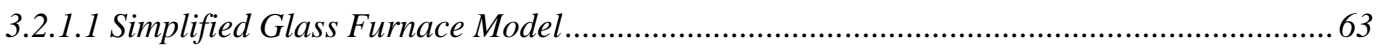

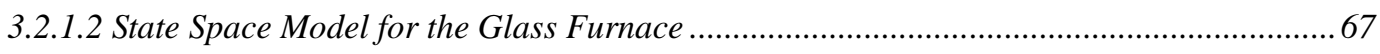

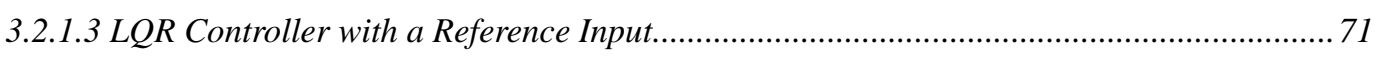

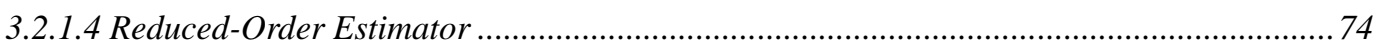

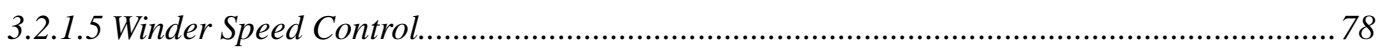

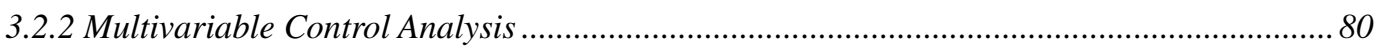

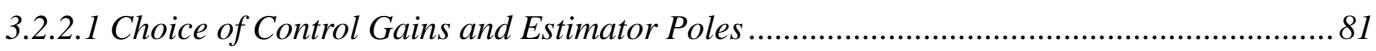


3.2.2.2 Ambient Temperature Variation .88

3.2.2.3 Molten Glass Depth Variation. .96

4. CONCLUSIONS AND FUTURE WORK 101

BIBLIOGRAPHY 103

APPENDIX A. COMPARISON OF CONDUCTION, RADIATION AND FORCED CONVECTION IN THE CENTRAL ATTENUATION REGION. 107

APPENDIX B COMPARISON OF GRAVITY FORCE WITH SURFACE TENSION. 113 APPENDIX C PARAMETRIC ANALYSIS FOR THE GLASS FIBER MODEL IN THE DRAWING PROCESS 117

APPENDIX D BLACK BODY SPECTRUM CALCULATION IN OUR MODEL 124 APPENDIX E ASSUMPTION FOR CONSTANT GLASS MASS FLOW RATE AND CONSTANT MOLTEN GLASS DEPTH IN SIMULATION. 130 APPENDIX F DIFFERENTIAL EQUATIONS FOR OUR FIBER GLASS FURNACE MODEL .134 APPENDIX G METHODS OF CHOOSING CONTROL GAINS AND ESTIMATOR POLES IN OUR MODEL 136 APPENDIX H EFFECT OF SETTING FOR THE SATURATION BLOCK IN THE SIMULINK $^{\mathrm{TM}}$ MODEL TO THE FUEL FLOW RATE PLOT. 142 APPENDIX I M FILE FOR THE MULTIVARIABLE CONTROL MODEL FOR FIBER GLASS FURNACE SYSTEMS IN MATLAB ${ }^{\text {TM }}$ 144 


\section{Table of Figures}

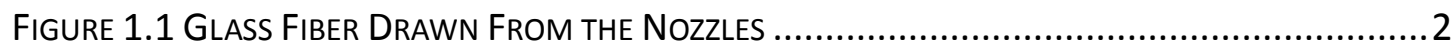

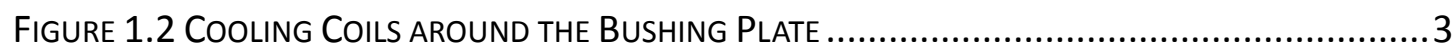

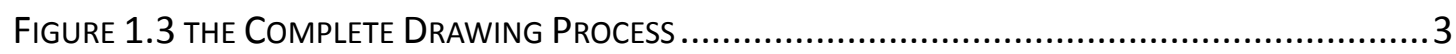

Figure 2.1 Density of SOdA-LIME GlasS AS A Function of ITS TEMPERATURE [TOOLEY] .............10

Figure 2.2 Viscosity of Glass at Various Temperatures (DATA of Lillie AND Babcock). A,

SODA-LIME-SILICA GLASS; B, LEAD GLASS; C, BOROSILICATE GLASS [TOOLEY] ........................11

Figure 2.3 Viscosity CuRVES of SOdA-LIME-SILICA GLASSES SHOWING Fit WITH FulCher Equation

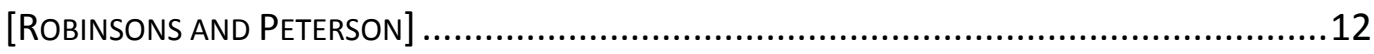

Figure 2.4 Spectral AbSorption Coefficients of Window Glass [Gardon] .......................14

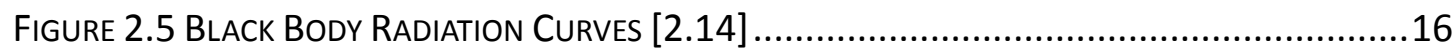

Figure 2.6 Black Body Radiation CURVES at 2100K With Non-PREhEated AIR ....................16

Figure 2.7 Absorption Spectra of Wool Fiber Glass Measured at 550,1000 and 1400oC (A,

B), And Temperature Dependences of Absorption Coefficient Measured at 1.1,2.5,2.8

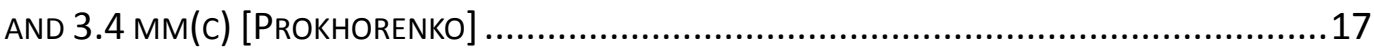

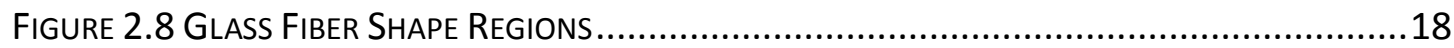

Figure 2.9 A Nozzle in a Base Plate of a Bushing Showing the Meniscus during

ATtENUATION OF THE GLASS INTO FIBER [LoeWENSTEIN] .............................................19

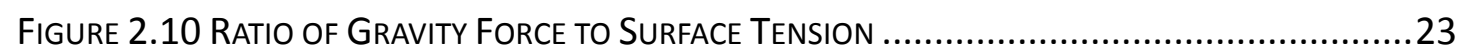

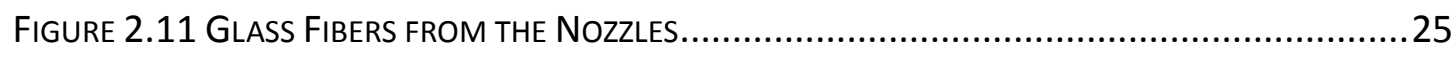

Figure 2.12 POLYFloW Results, at a DraW Ratio of 1:19,024, Show ExCELlent Agreement

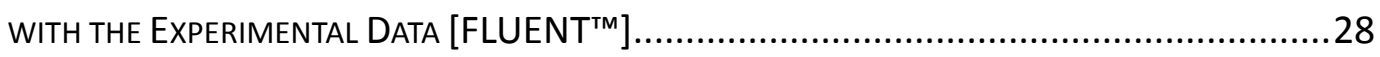

Figure 2.13 the Hybrid Fuzzy-PI Control Structure [Moon And LeE] ...............................30

Figure 2.14 Cascade Control Structure for the Furnace Temperatures [WertZ] ..............31

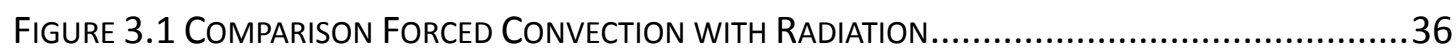

Figure 3.2 Comparison of the Experimental Data and Prediction CurVes [XIONg] ..............42

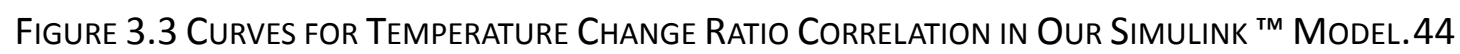

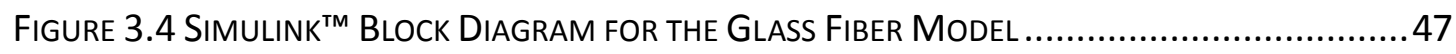

Figure 3.5 Glass Fiber Diameter (LEFT AXIS) AND SURFACE TEMPERATURe (RIGHT AXIS) AS

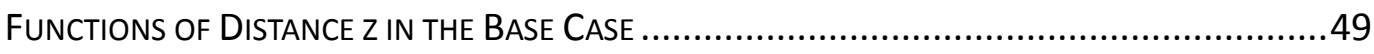

Figure 3.6 Fiber RADIUS VS Z DistANCE (THE FIRST PART OF THE WHOLE PLOT, 300K) .................49

Figure 3.7 Radius vs Z At Different AMbient Temperatures ..........................................53

Figure 3.8 Fiber Temperature vs Z at Different Ambient Temperatures (1) ........................53

Figure 3.9 Fiber Temperature vs Z at Different Ambient Temperatures (2) ......................54

Figure 3.10 Effect of Ambient Temperature on Fiber Diameter and Production Rate.......55 
Figure 3.11 Central Region Length Changes With Ambient Temperatures. 55

Figure 3.12 Winder Speed RequiRed to Keep Final Fiber Diameter at $30 \mu \mathrm{M}$ in Ambient

TEMPERATURE VARIATION. .56

Figure 3.13 Fiber Temperature vs Z at Different Glass Depths (1) ...................................58

Figure 3.14 Fiber Temperature vs Z At Different Glass Depths (2)....................................59

Figure 3.15 Radius vs Z AT FIVE Different Glass DePTHS .................................................59

Figure 3.16 Effect of Glass DePTH IN THE FuRnACE ......................................................60

Figure 3.17 Central Region Length Changes with Molten Glass Depths .........................60

Figure 3.18 the Winder speed Required to Keep Final Fiber Diameter at 30um in Molten

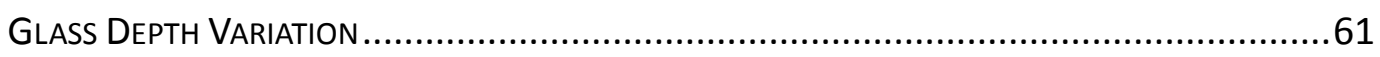

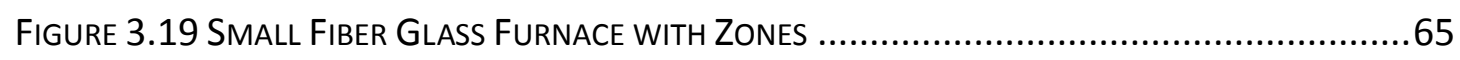

Figure 3.20 Testing Picture from the Mikron Infrared Camera ...................................67

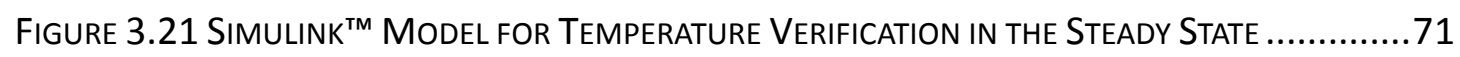

Figure 3.22 linear Quadratic Set-point Control With State Feedback [3.9].......................73

Figure 3.23 THE LQR Control PART WITH A ReFERENCE INPUT ...........................................73

Figure 3.24 ERror Response of the Reduced-ORder Estimator With the Pole Vector EP0..77

Figure 3.25 THE LQR CONTROL MOdel WITH A ReFERENCE INPUT AND AN EstimatoR ................78

Figure 3.26 THe LQR Controller With WINDER SPEed Control.........................................8

Figure 3.27 Tdg With the Control Gain K2 AND the Estimator Pole EP1.........................84

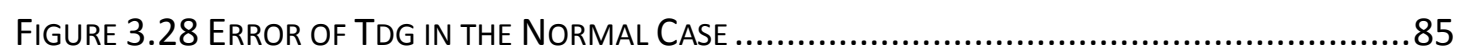

Figure 3.29 Tdg, Fuel Flow Rate and Winder Speed in the Normal CaSe (1) .....................85

Figure 3.30 Tdg, Fuel Flow Rate and Winder Speed in the Normal CaSe (2) .....................86

Figure 3.31 Tdg, Fuel Flow Rate and Winder Speed in Normal Case (3) ...........................86

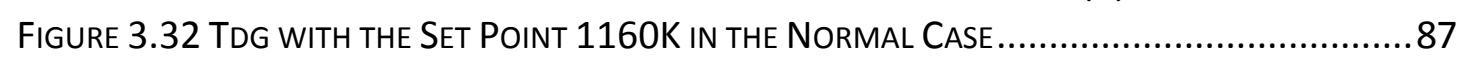

Figure 3.33 Tdg With the Set Point 1190K IN THe Normal CASE.....................................8

Figure 3.34 Tdg in Ambient Temperature Change CASe 1 K2 X1 .....................................90

Figure 3.35 Tdg in Ambient Temperature Change CASe 2 K2 X1 .....................................91

Figure 3.36 Tdg in Ambient Temperature Change Case 3 K2 X1 (1) Figure 3.37 Tdg IN

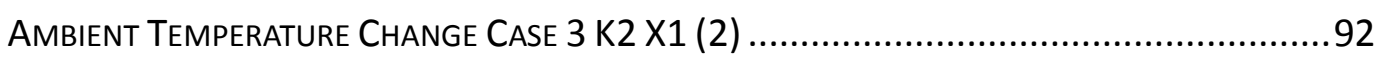

Figure 3.38 Tdg,T $\infty$,Fuel Flow Rate and Winder Speed in Ambient Temperature Change

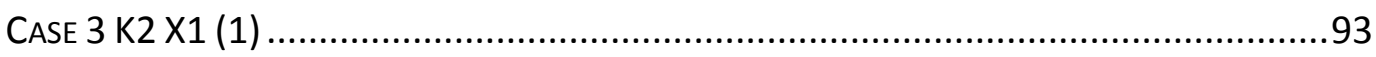

Figure 3.39 Tdg,T $\infty$,Fuel Flow Rate And Winder Speed in Ambient Temperature Change

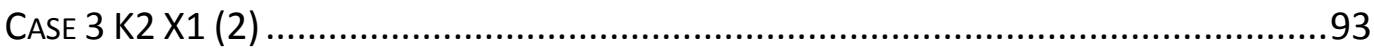

Figure 3.40 Tdg,T $\infty$,Fuel Flow Rate and Winder Speed in Ambient Temperature Change

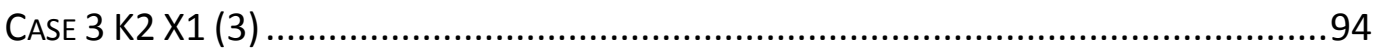

Figure 3.41 Tdg, T $\infty$,Fuel Flow Rate and Winder Speed in Ambient Temperature Change

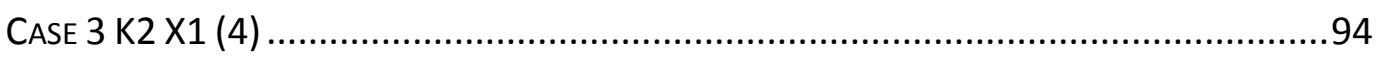

Figure 3.42 Tdg In Ambient Temperature Change CASe 4 K2 X1 (1) ...................................95

Figure 3.43 Tdg In Ambient Temperature Change CASe 4 K2 X1 (2) ................................96

Figure 3.44 Tdg In Molten Glass Depth Change CASE 1 K2 X1 .........................................98

Figure 3.45 Tdg, Fuel Flow Rate in Molten Glass Depth Change CaSe 1 K2 X1(1) ............98

Figure 3.46 Tdg, Fuel Flow Rate in Molten Glass Depth Change Case 1 K2 X1(2) .............99

Figure 3.47 Tdg, Fuel Flow Rate in Molten Glass Depth Change CaSe 1 K2 X1(3).............99

Figure 3.48 Tdg In Molten Glass Depth Change CASE 2 K2 X1 .....................................100 


\section{List of Tables}

Table 2.1 Key Temperature Points in Different Types of Glass [2.5],[2.6],[2.7],[2.8] ........12

Table 3.1 Parameters in Variation of Ambient Temperatures .......................................52

Table 3.2 TAble 3.2 Parameters in Variation of Molten Glass DePTH ...............................58

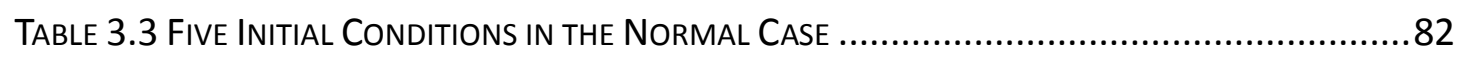

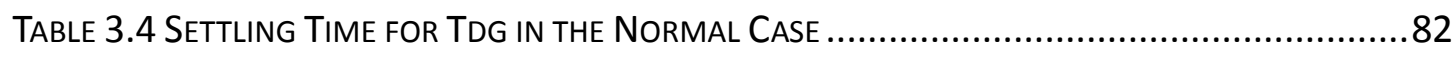

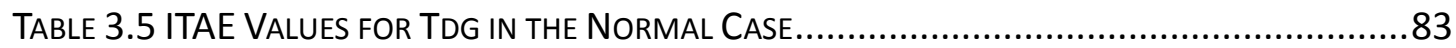




\section{Introduction}

\subsection{Overview of the Problem}

There are two main processes in the manufacture of fiberglass filters. The first one is the drawing process, which is studied in this thesis. The second process, expansion and curing will not be considered here. In the drawing process, glass cullet is melted in a small furnace situated above a spinning drum, called a winder. Molten glass is drawn through many small holes in a metal or ceramic plate, to form fibers which are wound around the winder. Please check Figure 1.1 and 1.2. In most applications, the furnace traverses back and forth along the axis of the drum, so the fibers form a spiral winding on the winder. Please check Figure 1.3. The speed of the traverse controls the pitch of the spiral, which is important in determining the characteristics of the filter when it is expanded.

In the production process, there are typically hundreds of glass fibers being drawn simultaneously to a winder. If one of them breaks, it will stick to others and cause other fibers to break, and eventually cause the process to be stopped and manually restarted. At the beginning, glass fibers come from the nozzles on the bushing plate as 
a liquid. As they are being drawn down to the winder, their temperature drops down very quickly, which makes the glass change from liquid to a transition phase, to a solid. At the same time, the diameters of glass fibers are reduced from the size of a nozzle to the size of a single human hair. This imposes both tensile and thermal stresses on the glass fibers.

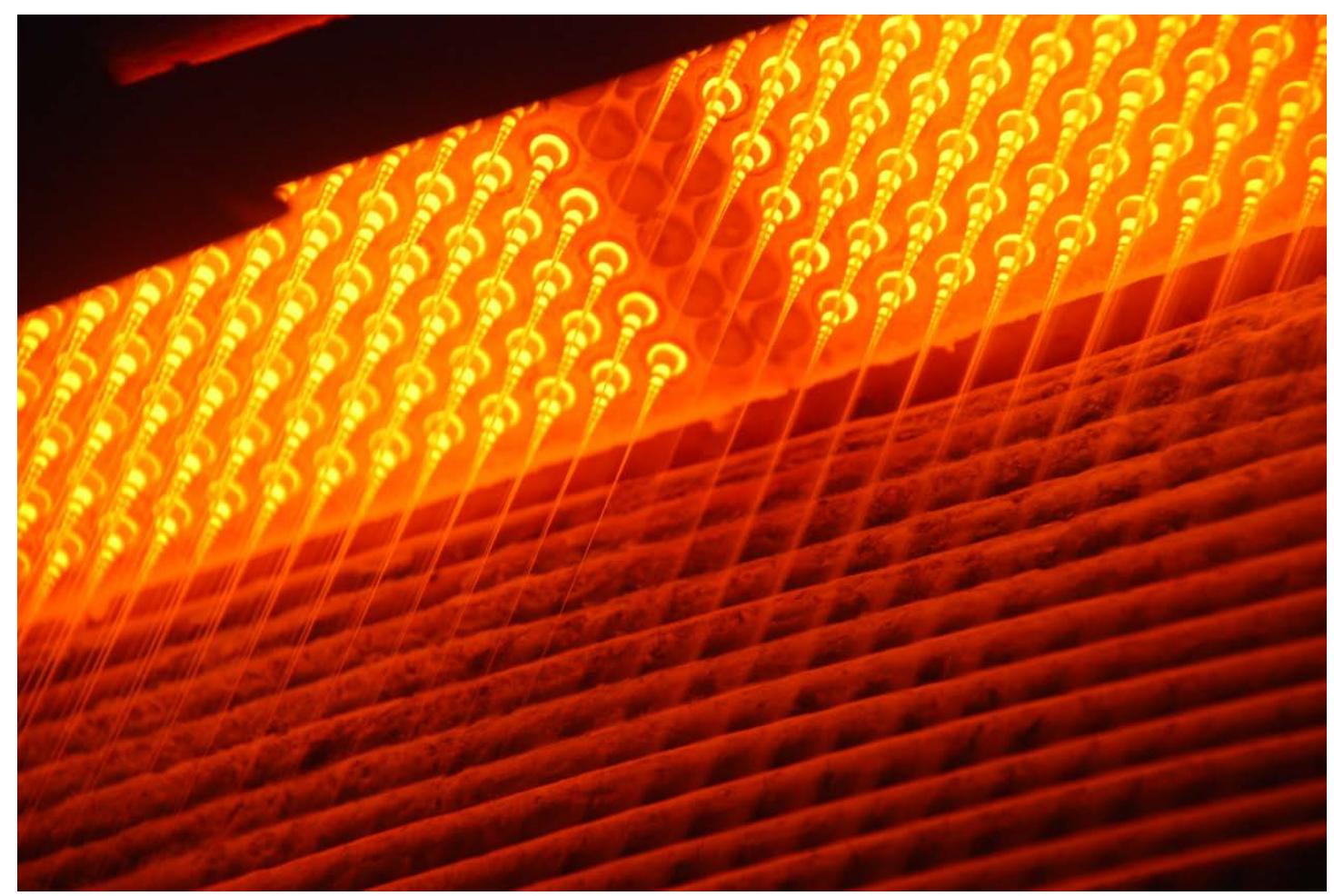

Figure 1.1 Glass Fiber Drawn From the Nozzles 


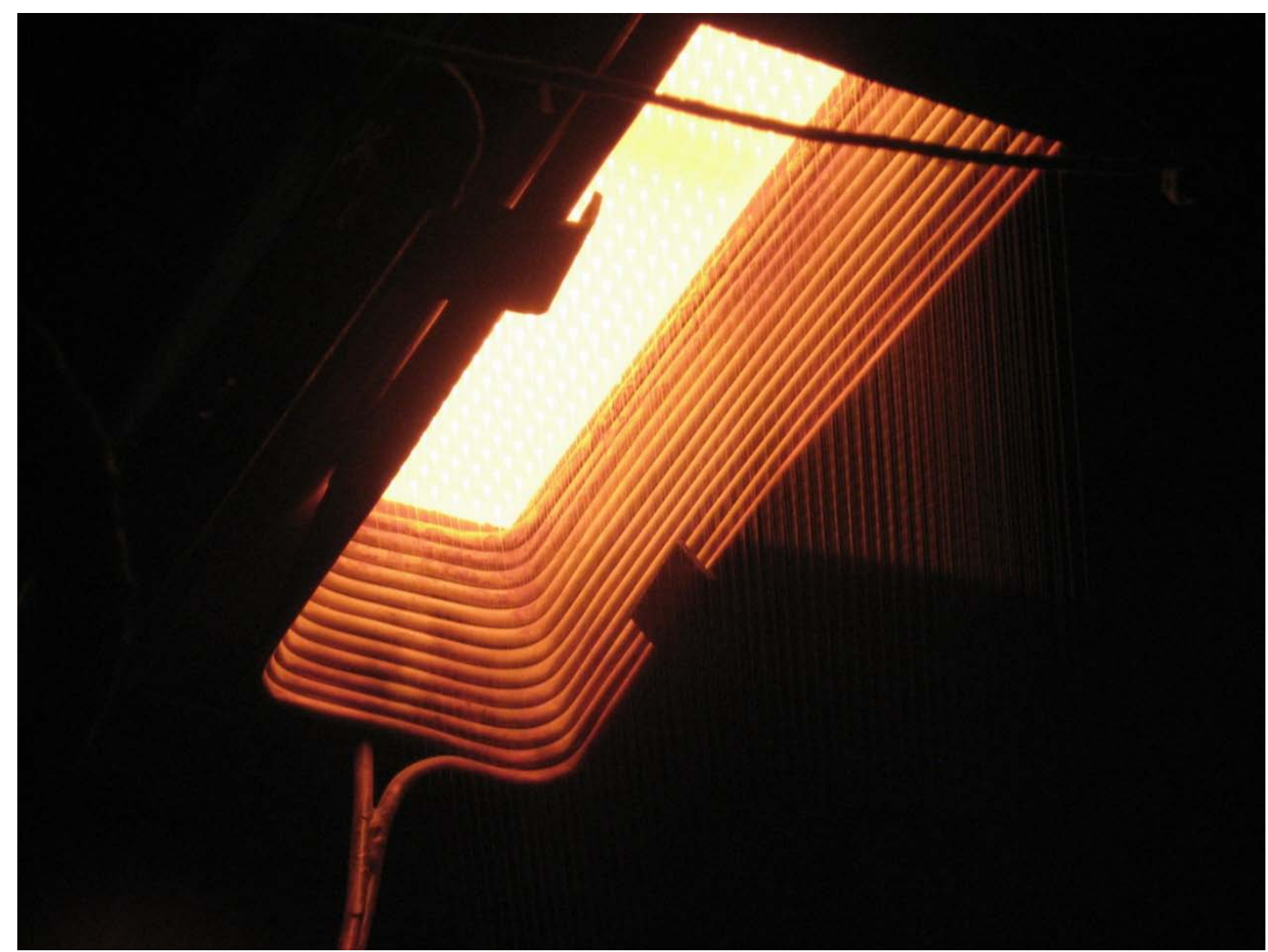

Figure 1.2 Cooling Coils around the Bushing Plate

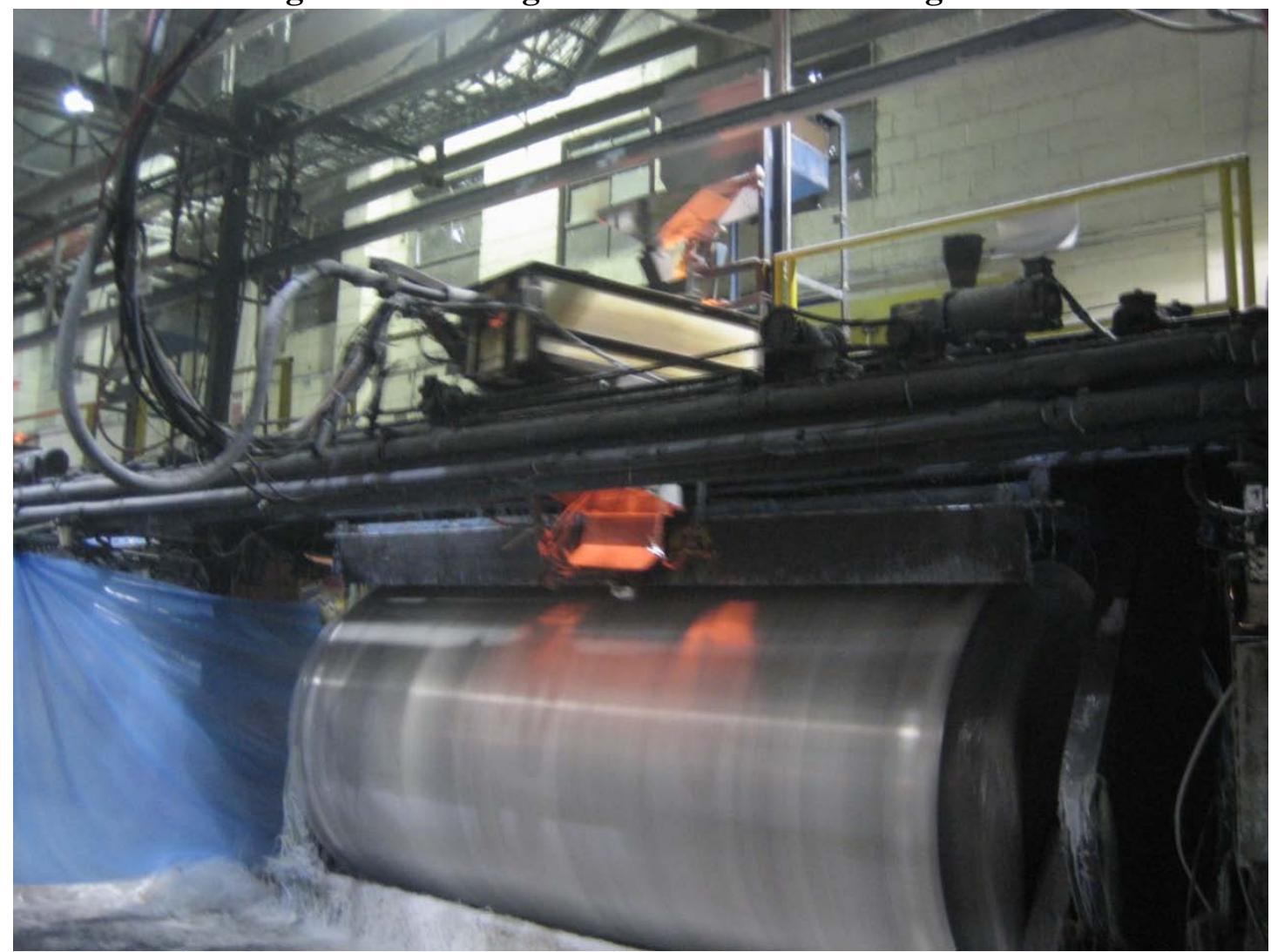

Figure 1.3 the Complete Drawing Process 
There are several key process parameters in the drawing process: the furnace temperature, the ambient temperature, the cooling water flow rate, the winder speed, molten glass depth in the furnace, and the final diameter of glass fibers. The furnace temperature is kept around $904^{\circ} \mathrm{C}(1177 \mathrm{~K})$ in order to melt the cullet and remove bubbles from the liquid glass. It is also the initial temperature for glass fibers. The furnace temperature and the ambient temperature play important roles in heat transfer. The mass flow rate of glass through the nozzles in the bushing plate is a function of glass depth in the furnace, nozzle length and diameter, and glass viscosity, which is a strong function of the temperature. The mass flow rate of glass has nothing to do with the winder speed, however the final fiber diameter is a function of both the glass mass flow rate and the winder speed.

\subsection{Motivation}

In the production of continuous fibers, the drawing process is sensitive to conditions like ambient temperature, molten glass depth in the furnace, drawing speed, glass temperature and others. If some disturbance happens, instabilities occur which cause variations in the final diameter and interruption of the process when the glass fibers break. The object company annually produces a significant amount of waste that cannot be recycled. The waste is mostly due to glass fiber breakage during the drawing process. Once one filament breaks, it will gather more liquid glass at the end of the filament and become big enough to stick to others so that many more filaments break. At the same time, the furnace is still moving and working and molten glass still 
drops down until a worker cuts the waste off and resets fibers again. It always takes several minutes to get the process back to normal. The waste can't be recycled and has to be sent to landfills. Obviously frequent fiber breakage decreases the production efficiency, wastes a lot of resources and increases the cost.

In addition, a lot of product is scrapped after the mats are expanded in the second process. Some of the problems are created by broken fibers, but others can be from incorrect fiber diameter or other problems associated with the drawing process.

Currently, the object company only depends on experiential parameters in process control, and fiber breakage happens frequently. There is no effective method to control the glass temperature to the set point value, not to mention to conserve energy during the process. They also lack a quantitative understanding of the other important process parameters like molten glass depth, ambient temperature, winder speed and how those contribute to the process.

To solve those problems and improve reliability of the drawing process and quality of final product, it is necessary to design some control schemes to control glass temperature in the furnace and other important process parameters like winder speed. First, it is of crucial importance to study the relationships among the key process parameters and the product quality. Based on a good understanding of the dynamics relating the various process parameters to each other and to product quality and process reliability, an effective control scheme can be developed to control glass temperatures in the furnace and the winder speed. Then, parametric analysis will be carried on when some disturbance happens like ambient temperature changes or 
molten glass depth changes.

\subsection{Research Objectives}

There are four main objectives in our research:

1. Build a computer model for glass fibers in the drawing process

2. Use the model to perform parametric studies to predict the influence of various key process parameters on fiber diameter, fiber temperature as a function of position, stresses in the fiber and possible mechanisms for fiber breakage.

3. Based on the results of parametric analysis for glass fiber drawing process model, develop an effective multivariable control model.

4. Performance parametric analysis when some disturbance happens like ambient temperature changes or molten glass depth changes.

\subsection{Contributions of the Research}

1. This research mainly focuses on modeling glass fiber production and controlling the drawing process effectively. Little work in this field has been reported in the literature. One of the reasons is that research projects in this field have been done by private companies and are considered proprietary. The extent and quality of modeling efforts for this industry are essentially unknown. It is also true that not all fiber products are manufactured in the same way. For example, fiberglass for insulation is produced in an entirely different manner. However, enough applications exist for the drawing process described here to make this study relevant and 
important.

2. Glicksman has done some research on glass fiber drawing process by using differential analysis only in the central region [1.1]. Purnode has built a CFD model and done some two-dimensional finite element analysis of glass fiber forming in all the jet regions by using Polyflow ${ }^{\mathrm{TM}}$ [1.2]. In this research, both a mathematic model and a computer model are used to simulate a single fiber to study the drawing process. The experimental forming conditions simulated by Glicksman and Purnode are different from those in this research. Second, it is not clear that all of the boundary conditions and assumptions used by the prior authors apply to the present case. Parametric studies using the new model will be performed in order to understand and control those key process parameters better.

3. Current industrial control processes are almost universally based on single loop PID control, or at best combinations of several single-loop controllers linked in a nested loop scheme. The glass fiber spinning process is actually a more complex problem with multiple inputs and several important state variables. This work will use modern control methods including state estimator and LQR control to improve product quality and process throughput. Based on the control model, multivariable control analysis is performed to obtain the desired molten glass temperature near to the bushing plate when common disturbances occur such as changes in ambient temperature or molten glass depth in the furnace. At the same time, winder speed will be controlled to ensure the final diameter of glass fibers. 


\section{Literature Review}

\subsection{Glass Properties}

Morey defines glass as follows:

"A glass is an inorganic substance in a condition which is continuous with, and analogous to, the liquid state of that substance, but which, as a result of a reversible change in viscosity during cooling, has attained so high a degree of viscosity as to be for all practical purposes rigid .’[2.1]

The outward appearance of glasses is essentially solid-like. The density, the mechanical properties, and the thermal properties of glasses are similar to those of the corresponding crystals. However, unlike crystals, glasses do not have a sharp, well-defined melting point. Unlike most crystals, glasses do not cleave in preferred directions. In the absence of applied forces and internal stresses, glasses are essentially isotropic [2.2]. Consider a small volume of material at a high temperature in liquid form. The melting point of the corresponding crystal $\mathrm{T}_{\mathrm{m}}$ may be defined at which an infinitely small amount of crystals is in thermodynamic equilibrium with the liquid. Under suitable condition, crystallization happens when temperature is at or below $\mathrm{T}_{\mathrm{m}}$. If crystallization does not occur below $\mathrm{T}_{\mathrm{m}}$, the liquid mass moves into the super-cooled liquid state. As cooling continues, the molecules become less 
and less mobile, i.e., the viscosity of the system rapidly increases. Such high viscosity tends to prevent devification, which results in no crystallization in cooling molten glass to room temperature. The material at low temperature is in a seemingly rigid condition as a solid. This is the glassy state. So glass is also defined as "a non-crystalline solid” or "an amorphous solid” [2.2].

\subsubsection{Glass Density}

Glass density mainly depends on its chemical composition. From Tooley(v1) [2.3], at $20^{\circ} \mathrm{C}$ the density of the Soda-lime glass for windows is $2.53 \mathrm{~g} / \mathrm{cm}^{3}$, container glass is $2.46 \mathrm{~g} / \mathrm{cm}^{3}$, plate glass is $2.50 \mathrm{~g} / \mathrm{cm}^{3}$ and heavy lead glass is $3.20 \mathrm{~g} / \mathrm{cm}^{3}$.Also the density of glass is a function of its temperature. From Figure 2.1 [2.3] (reproduced from Tooley, v1 Page 24), it can be seen that when the temperature increases; the glass density will decrease a little bit, and there are two linear sections in the relation of the temperature and the density. 


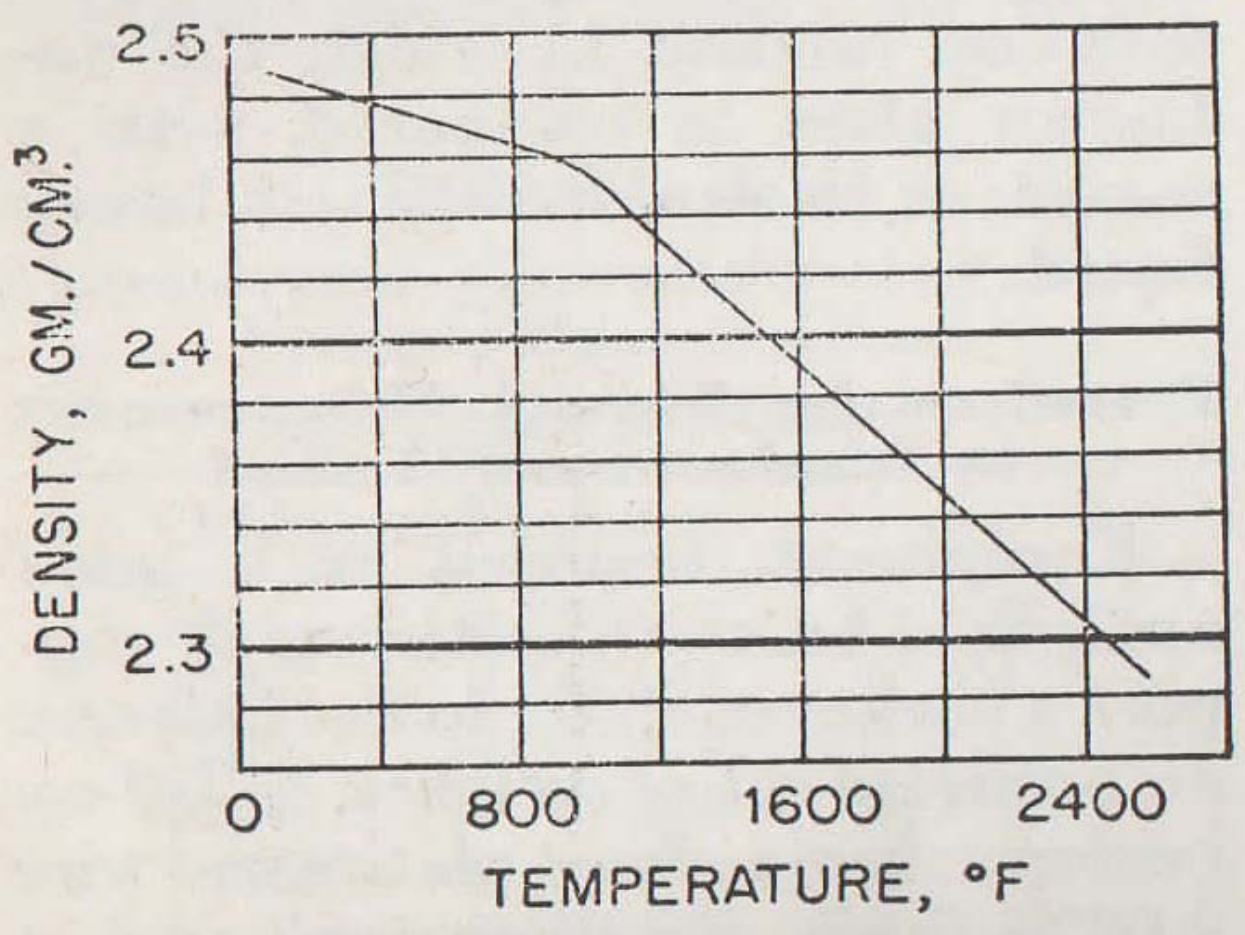

Figure 2.1 Density of Soda-lime Glass as a Function of its Temperature [Tooley]

\subsubsection{Glass Viscosity}

Generally, for gas, the viscosity increases as its temperature rises; for liquid as its temperature rises, the viscosity decreases. Figure 2.2 shows viscosity curves for three types of glasses, soda-lime-silica glass, lead glass, borosilicate glass as given by Babcock [2.4] (reproduced from Tooley v1 page 39). Note the logarithmic scale for the viscosity, showing that the viscosity is a very strong function of temperature. The approximate working point temperatures for those glasses are shown in this figure. Also key temperature points for those three types of glass in Figure 2.2 are shown in Table 2.1. Figure 2.3 shows the viscosity curves of soda-lime-silica glass with the strain point, annealing point and softening point [2.3] (reproduced from Tooley v1 page 40). 


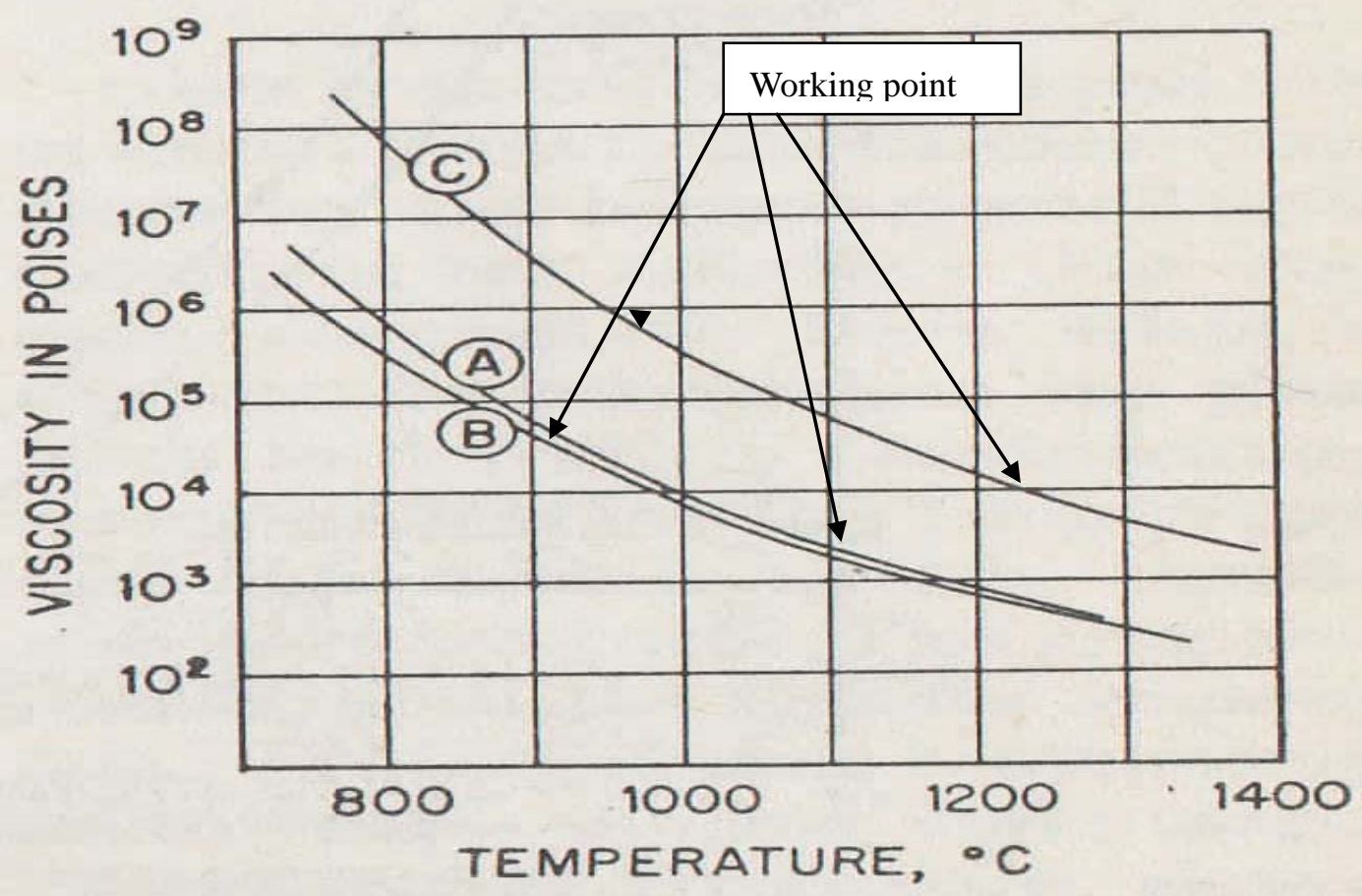

Figure 2.2 Viscosity of Glass at Various Temperatures (data of Lillie and Babcock). A, Soda-lime-silica glass; B, Lead glass; C, Borosilicate glass [Tooley]

\begin{tabular}{|l|l|l|l|l|}
\hline Glass Type & $\begin{array}{l}\text { Strain Point } \\
\text { (Celsius) }\end{array}$ & $\begin{array}{l}\text { Annealing } \\
\text { Point } \\
\text { (Ce1sius) }\end{array}$ & $\begin{array}{l}\text { Softening } \\
\text { Point } \\
\text { (Ce1sius) }\end{array}$ & $\begin{array}{l}\text { Working Point } \\
\text { (Celsius) }\end{array}$ \\
\hline Lead Glass (B) & 444.0 & 467.0 & 603.0 & 800.0 \\
\hline $\begin{array}{c}\text { Soda-Lime } \\
\text { Glass (A) }\end{array}$ & 514.0 & 546.0 & 726.0 & 1100.0 \\
\hline $\begin{array}{c}\text { Borosilicate } \\
\text { Glass (C) }\end{array}$ & 510.0 & 565.0 & 820.0 & $1,252.0$ \\
\hline
\end{tabular}


Table 2.1 Key Temperature Points in Different Types of Glass

[2.5],[2.6],[2.7],[2.8]

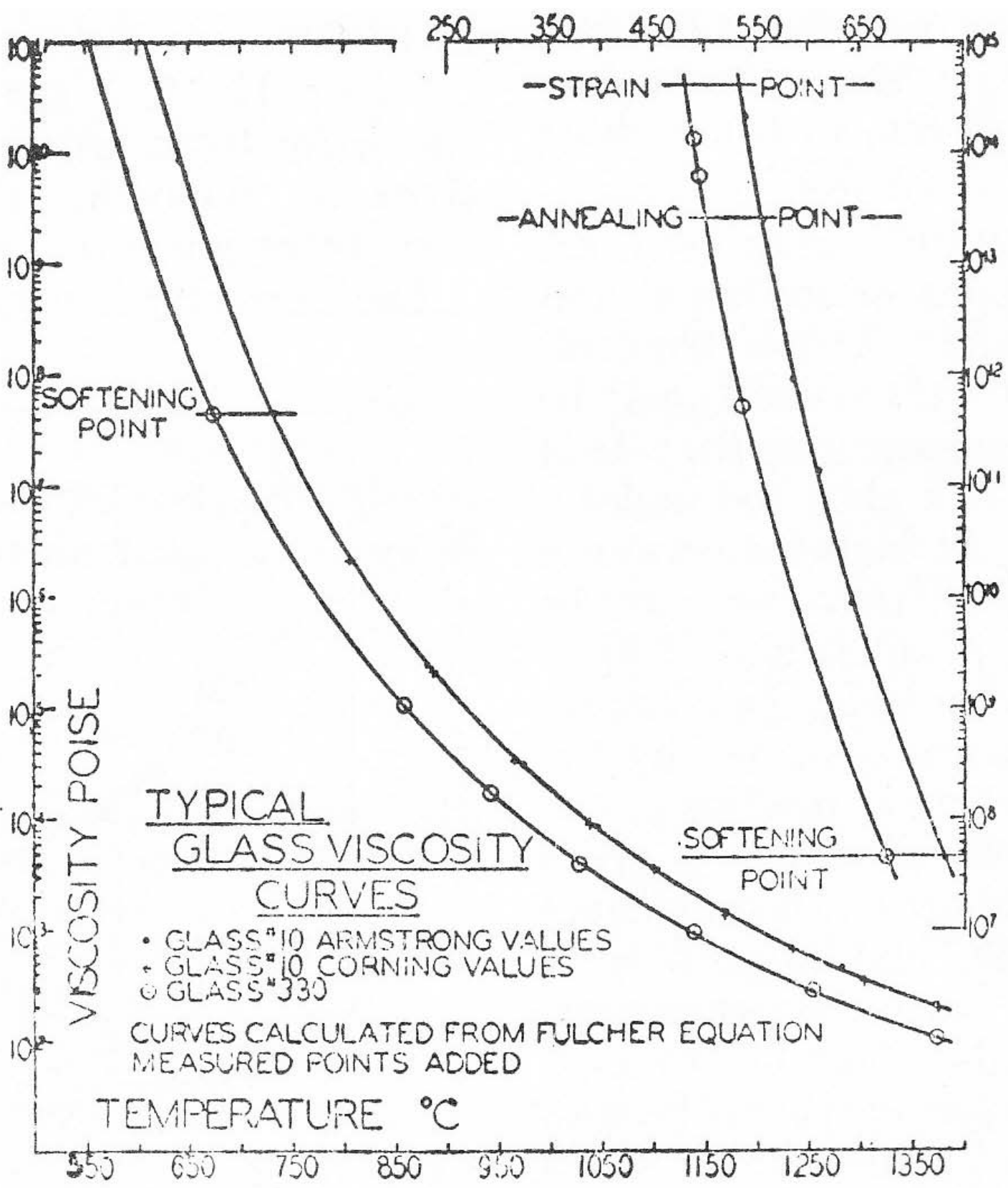

Figure 2.3 Viscosity Curves of Soda-lime-silica Glasses Showing Fit with Fulcher Equation [Robinsons and Peterson]

There are several models of the temperature dependence of glass viscosity. The basic one is the exponential model:

$$
\mu(T)=\mu_{o, b} \exp (-b T)
$$

This is an empirical model that usually works for a limited range of temperatures [2.9]. The Arrhenius law is a simple, but remarkably accurate, formula for the 
temperature dependence of the viscosity. Glicksman (1968) suggested some coefficients and used it to calculate glass viscosity [1.1], and Purnode (1998) also used it in his calculations [2.10]:

$$
\mu=\mu_{o} \exp z\left[-\left(T-T_{o}\right)\right]=\mu_{o} \exp \left(a_{1}-a_{2} T\right)
$$

The Fulcher Law is another model for the temperature dependence of liquid viscosity. It is used mainly for glass [2.11]. From Tooley, the Fulcher Law is probably the best of these on the basis of simplicity and usefulness [2.1]. So in this research, the Fulcher law is used in all of the models. The Fulcher model says that:

$$
\mu(T)=10^{-f 1+\frac{f 2}{T-f 3}}
$$

According to the composition of glass fibers from Superior Fiber, coefficients of the Fulcher Law, $f_{1}, f_{2}$ and $f_{3}$ are carefully chosen so that calculation results from the Fulcher Law model agree with the viscosity and temperature experimental data from Superior Fiber.

\subsubsection{Optical Properties}

Optical properties are the most important characteristics of glass. From Gardon [2.12], even transparent materials are practically opaque to radiation of some wave lengths. For example, all silicate glasses are practically opaque to radiation having a wave length longer than about $4.5 \mu$ m,so they are more or less transparent to $70 \%$ of the radiation from a black body at $1000^{\circ} \mathrm{C}$ [2.12]. Glicksman defined that the optical thickness is the monochromatic absorption coefficient times a typical dimension, i.e., the jet radius [1.1]. 


$$
\sigma_{\lambda}=t \alpha
$$

According to Figure 2.4 [2.12] (reproduced from Gardon), Glicksman thought in the one-dimensional region the optical thickness is much less than unity for wavelengths less than 4.5 microns, and much greater than unity for wavelengths above 4.5 microns. Glicksman concluded that radiation from the surface of glass fibers is mainly from the light whose wavelength is above 4.5 microns, while radiation from the interior volume of glass fibers is mainly from the light whose wavelength is less than 4.5 micron, and radiation from surface is much more than that from the volume.

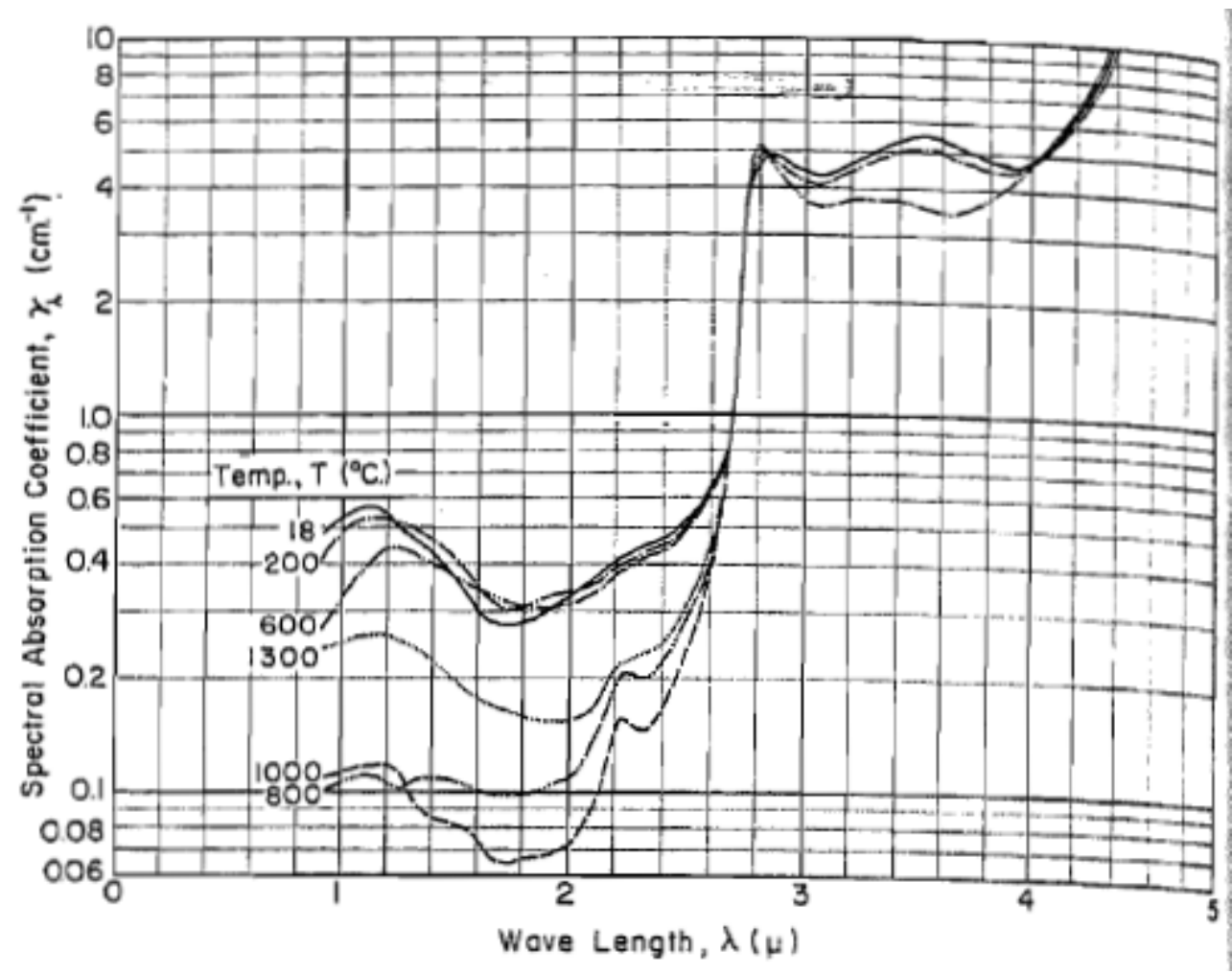

Figure 2.4 Spectral Absorption Coefficients of Window Glass [Gardon]

The general definition of optical thickness from Encyclopedia of Laser Physics and Technology is "The optical thickness of a light-absorbing medium is the inverse intensity absorption coefficient, i.e., the propagation length over which the optical 
power is reduced to 1/e (about 37\%) of its original value." The intensity of light remaining can be calculated by the formula:

$$
I_{x, \lambda}=I_{o, \lambda} \exp \left(-x / \sigma_{\lambda}\right)
$$

where $\sigma_{\lambda}$ is the optical thickness for the material at wavelength $\lambda$ [2.13]. Tooley introduced some definitions of glass optical properties [2.3]. "Under constant conditions the absorption coefficient of light of specified wavelength by a given glass varies with thickness as follows:

$$
\alpha=\frac{\ln \left(I_{1} / I_{2}\right)}{t}
$$

The absorption coefficient a varies with temperature, thermal history, and wavelength of light, and is normally independent of thickness.

For a given thickness, the bigger the optical density is, the more the energy is absorbed in the material.

From above equations, we can get the relation between $\alpha$ and $\sigma_{\lambda}$ :

$$
\sigma_{\lambda}=1 / \alpha
$$

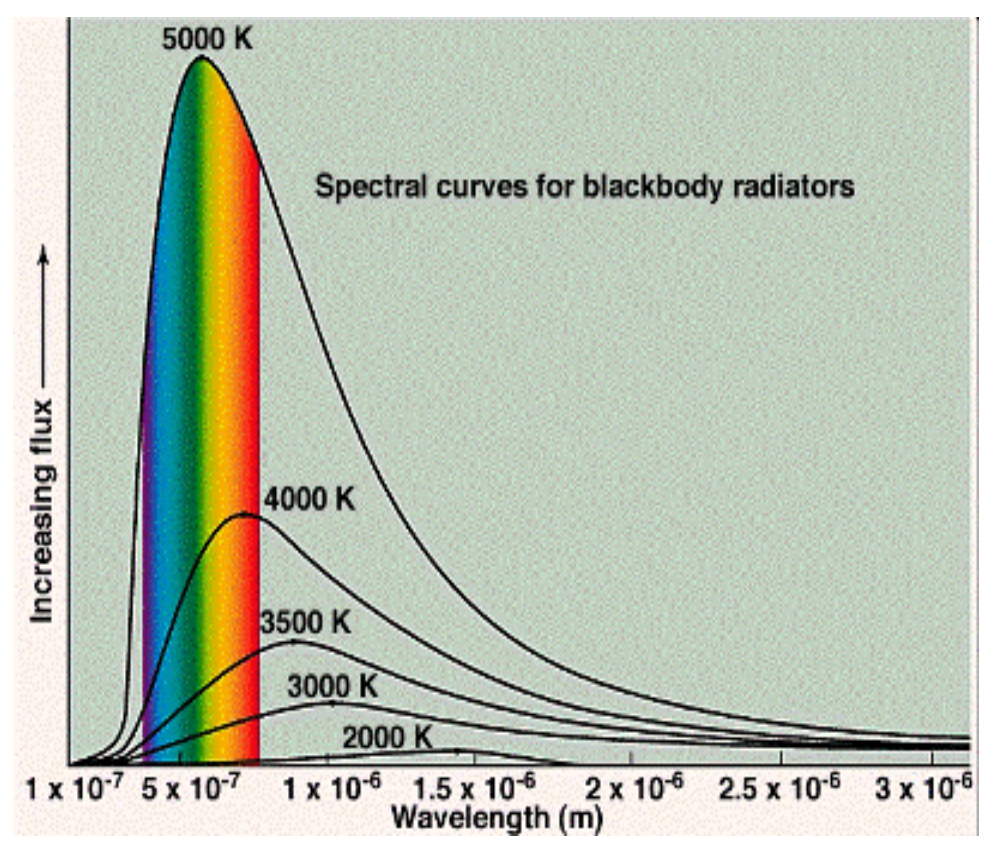


Figure 2.5 Black Body Radiation Curves [2.14]

In Figure 2.5 black body radiation spectrum (reproduced from [2.14]), it is obvious that at the temperature of a glass furnace (around $1200 \mathrm{~K}$ ), the plot is much flatter than the one at $3000 \mathrm{~K}$, which means that most of the energy is spread across a very broad spectrum of wavelengths.

A Matlab ${ }^{\mathrm{TM}}$ program was developed to calculate the black body spectrum at 2100K with non-preheated air, which was the condition in my case. Figure 2.6 shows the plot. Please check the appendix D for details of the program.

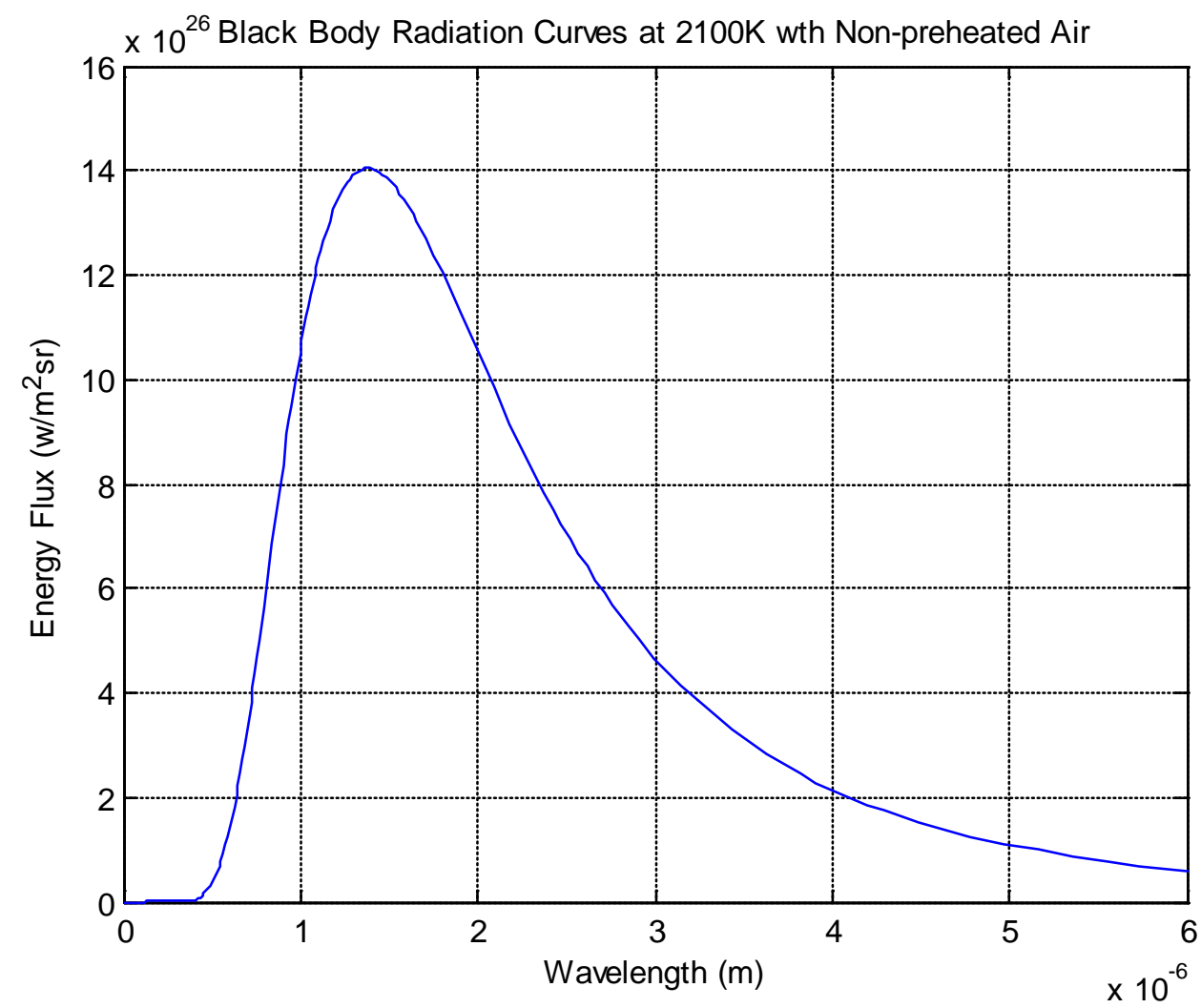

Figure 2.6 Black Body Radiation Curves at 2100K with Non-preheated Air

Prokhorenko studied commercial glasses predisposed to quick irreversible changes at high temperatures recently, and got the data on high-temperature 
absorption spectra in the wavelength range 0.6-3.8 $\mu \mathrm{m}$ at temperatures from about 500 to $1600^{\circ} \mathrm{C}$ measured for six typical commercial glasses( wool fiber glass, E-glass, white container glass, color TV panel glass, low-expansion borosilicate glass, and float glass) [2.15]. Figure 2.7 (reproduced from Prokhorenko) shows the data for the wool fiber glass.

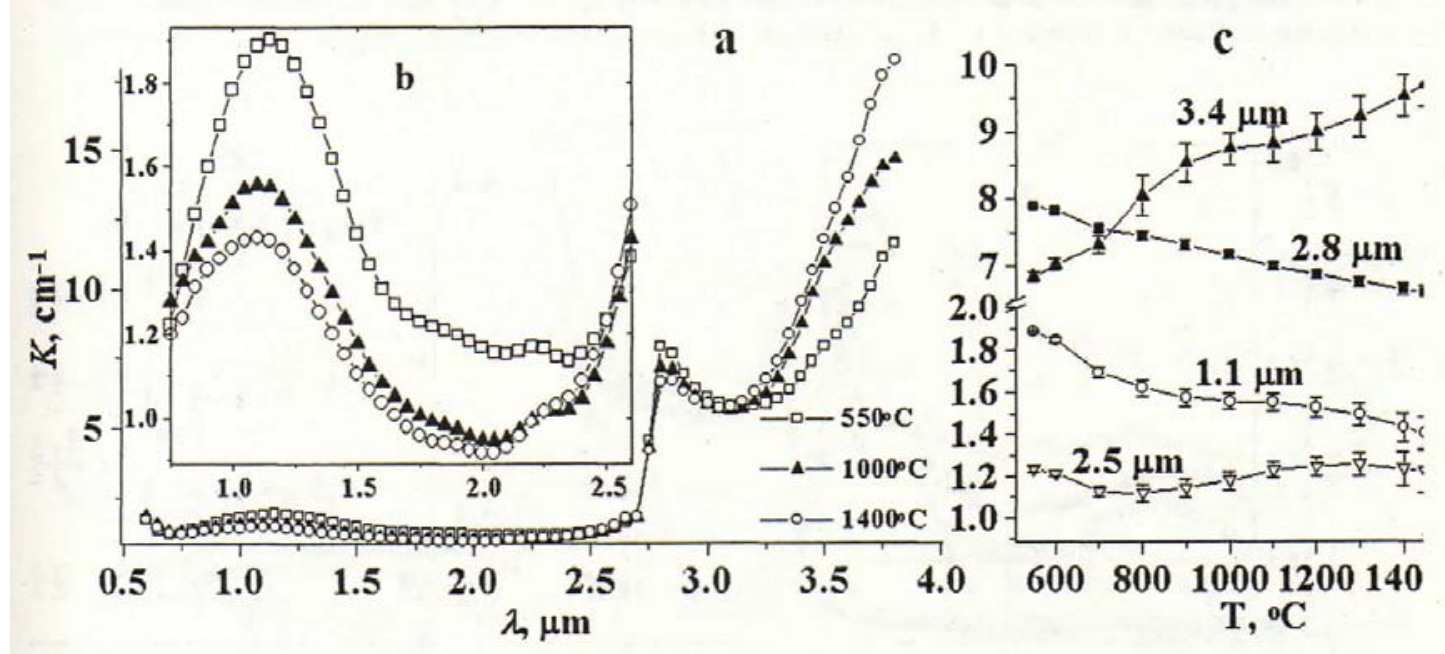

Figure 2.7 Absorption Spectra of Wool Fiber Glass Measured at 550,1000 and 1400oC (a, b), and Temperature Dependences of Absorption Coefficient Measured at 1.1,2.5,2.8 and 3.4 $\mu \mathrm{m}(\mathrm{c})$ [Prokhorenko]

\subsection{Glass Fiber Drawing Process}

\subsubsection{Glass Fiber Shape Regions}

Glicksman (1968) defined three jet regions in the glass fiber drawing process: the upper, central, and constant radius regions [1.1]. Based on his definition, similar definitions were given in this research. Please see Figure 2.8 for details. The upper meniscus region is the part from the nozzle to where the $d_{0} / d z$ equals -0.1 . In this region, molten glass has just emerged from the furnace at high temperature. The 
central attenuation region is the place where most of the attenuation of the fiber happens. At the end of this region, the glass fiber is attenuated to the final size of the product. The remaining part is called the constant radius region, where the variation of the fiber radius is very small.

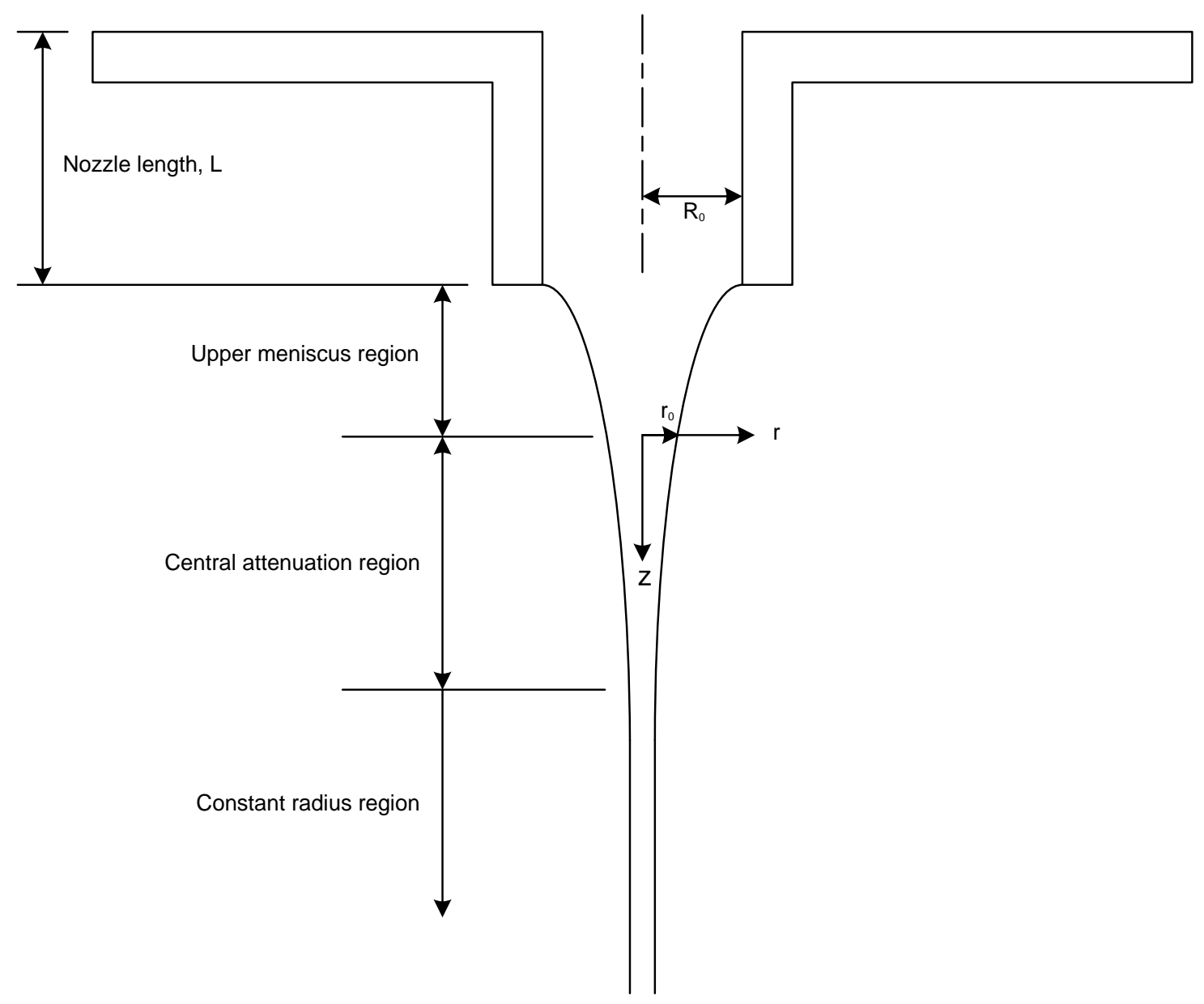

Figure 2.8 Glass Fiber Shape Regions

\subsubsection{Bushing Plate}

Glass fibers are made by the rapid attenuation of drops of molten glass extruded through nozzles formed in a bushing plate. The bushing plate is a rectangular-shaped alloy plate at the bottom of the furnace. In the object company, the bushing plate has 
294 nozzles, each with a diameter of $4.27 \mathrm{~mm}$. The bushing plate is intended to provide a uniform temperature among fibers and to allow the production of many fibers of the same diameter. The molten glass exiting the nozzles is rapidly cooled and attenuated, and takes on the shape of a meniscus immediately below the nozzle. The fibers are stretched to their desired diameter by a drawing force created by winding the fibers around a rotating drum. Figure 2.9 [2.16] (reproduced from Loewenstein, page 92) shows the nozzle, the meniscus and the rapid attenuation of the fiber diameter.

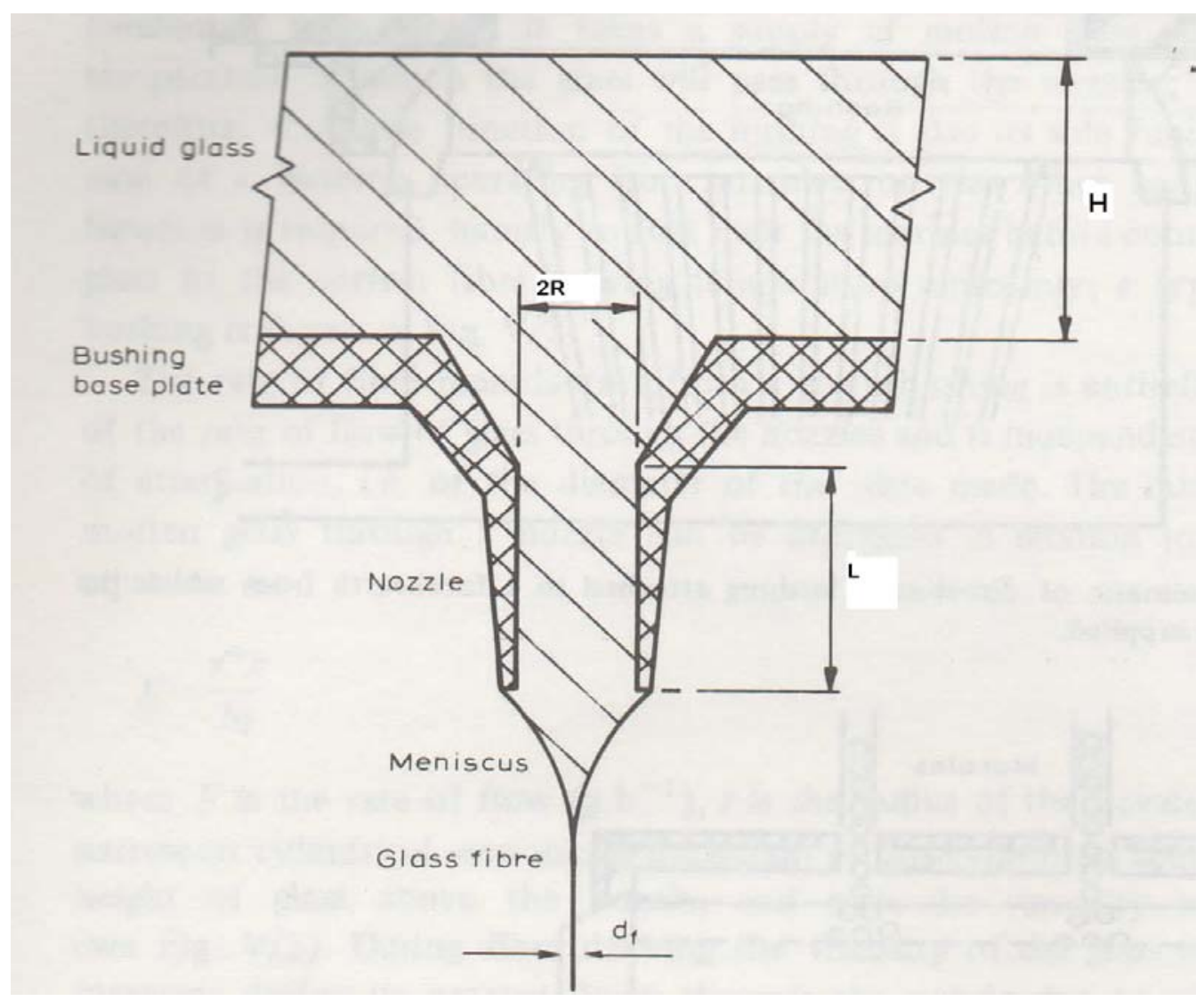

Figure 2.9 A Nozzle in a Base Plate of a Bushing Showing the Meniscus during Attenuation of the Glass into Fiber [Loewenstein]

Loewenstein concluded that the rate of fiber manufacture from a given bushing is entirely a function of the rate of flow of glass through the nozzles and is independent 
of the rate of attenuation, i.e. the final diameter of the fiber [2.16]. His idea was that the molten glass flow rate through a nozzle has nothing to do with the drawing force from the drum, and can be described by

$$
F \propto \frac{R^{4} H}{L \eta}
$$

where $\mathrm{R}$ is the radius of the nozzle bore in its narrowest cylindrical section, $\mathrm{mm}$; $\mathrm{H}$ is the height of glass above the nozzle, mm; L is length of this cylindrical section, mm; $\eta$ is the dynamic fluid viscosity in the nozzle, $\mathrm{Pa} *$ sec.

Poiseuille’s Law (or Hagen-Poiseuille Law) is the physical law concerning the voluminal laminar stationary flow $\phi$ of an incompressible uniform viscous liquid through a cylindrical tube with constant circular cross-section. It may be expressed in the following form [2.17]:

$$
\phi=\frac{d V}{d t}=\bar{v} \pi R^{2}=\frac{\pi R^{4}}{8 \eta}\left(\frac{-\Delta P}{\Delta x}\right)=\frac{\pi R^{4}}{8 \eta} \frac{|\Delta P|}{l}
$$

where $\mathrm{l}$ is the total length of the tube in the $\mathrm{x}$ direction, $\mathrm{mm}$; $\mathrm{R}$ is radius of nozzles, $\mathrm{cm} ; \quad \eta \quad$ is the dynamic fluid viscosity in the nozzle, $\mathrm{Pa}$ *sec.

In the industrial glass fiber drawing process, the more general situation is that glass fibers are pulled by a drawing force produced by the rotating drum in order to get the desired final diameters of the glass fibers. In that situation, the Hagen-Poiseuille Law has been applied by many researchers to calculate the molten glass mass flow rate through the nozzle. Siegel and Grundy used the Hagen-Poiseuille Law to calculate the glass mass flow rate through the nozzle in their US patent No.5015867 [2.18]. Hearle agreed with Loewenstein, whose idea was that the rate of 
fiber production at the nozzle is a function of the rate of flow of glass, not the rate of attenuation, which only determines final diameter of the fiber [2.19]. Based on the Hagen-Poiseuille Law, Rekhson concluded the flow rate through the nozzles is higher in the middle of the bushing plate and lower on the periphery when the glass melt is cooler at the walls of the bushing and hotter in the middle. Rekhson modified the Hagen-Poiseuille equation and obtained his volume flow rate equation through a nozzle [2.20]:

$$
V_{o}=\left(\rho g H^{\prime}+\sigma_{o}\right) R^{4} /\left[8 L \eta_{o}\left(1+\frac{3 \pi R}{8 L}\right)\right]
$$

where $V_{o}$ is the flow rate in the nozzle, $\mathrm{cm}^{3} / \mathrm{s} ; \sigma_{o}$ is stress from the winder, $\mathrm{Pa}$; $\mathrm{H}^{\prime}$ is the distance from the molten glass top surface to the point where it is calculated, $\mathrm{m}$.

Rekhson defined the pressure difference in Equation 2-10 as the sum of the fluid static pressure and the stress from the drum, while most of the researchers including Loewenstein and Hearle insist that only fluid static pressure is counted in the pressure difference. So the situation around the nozzles needs to be studied in order to get the right explanation of the $\Delta \mathrm{P}$.

Since molten glass is the laminar fluid, and the drawing force depends on the surface tension to pull the glass down, the gravity force $\left(\rho g \mathrm{H}^{*} \mathrm{~S}\right)$ was compared with the surface tension at several cross sections of the fiber. Commercial glasses possess surface-tension values at $1200^{\circ} \mathrm{C}$ which usually lie in the range of about 245 to 320 dynes per $\mathrm{cm}$. The temperature coefficient is usually from -0.02 to $-0.04[2.3]$ (Tooley, v1, Page 36). So the ratio of gravity force to the surface tension can be expressed as: 


$$
R^{\prime}=\frac{\rho g H \pi r^{2}}{2 \gamma_{T} \pi r \cos \theta}=\frac{\rho g H r}{2 \gamma_{T} \cos \theta}
$$

where $\gamma_{T}$ is the surface tension coefficient, $\mathrm{N} / \mathrm{m}$.

Several assumptions were made for the relationship between $\mathrm{T}$ and radius of glass fibers, and for the relationship between $\mathrm{T}$ and the distance from the nozzle in the cone region. Under these assumptions, the ratio of gravity to the surface tension was calculated at several cross sections for glass temperature ranging from $600^{\circ} \mathrm{C}$ to $1100^{\circ} \mathrm{C}$. Nearly the same result was obtained for the different scenarios. As the glass fiber cools and is also attenuated, the magnitude of the surface tension increases relative to the gravity force. This relationship is shown in Figure 2.10. However, the volume rate of flow through the nozzle is determined by the forces acting on the glass very near the nozzle, i.e., at the left side of the plot. Clearly, the mass flow through the nozzle is thus dominated by the static pressure force and the effect of the drawing force can be neglected with only minor error in calculating nozzle flow. Details of the assumed temperature and fiber radius as functions of $\mathrm{z}$ can be found in Appendix B. 


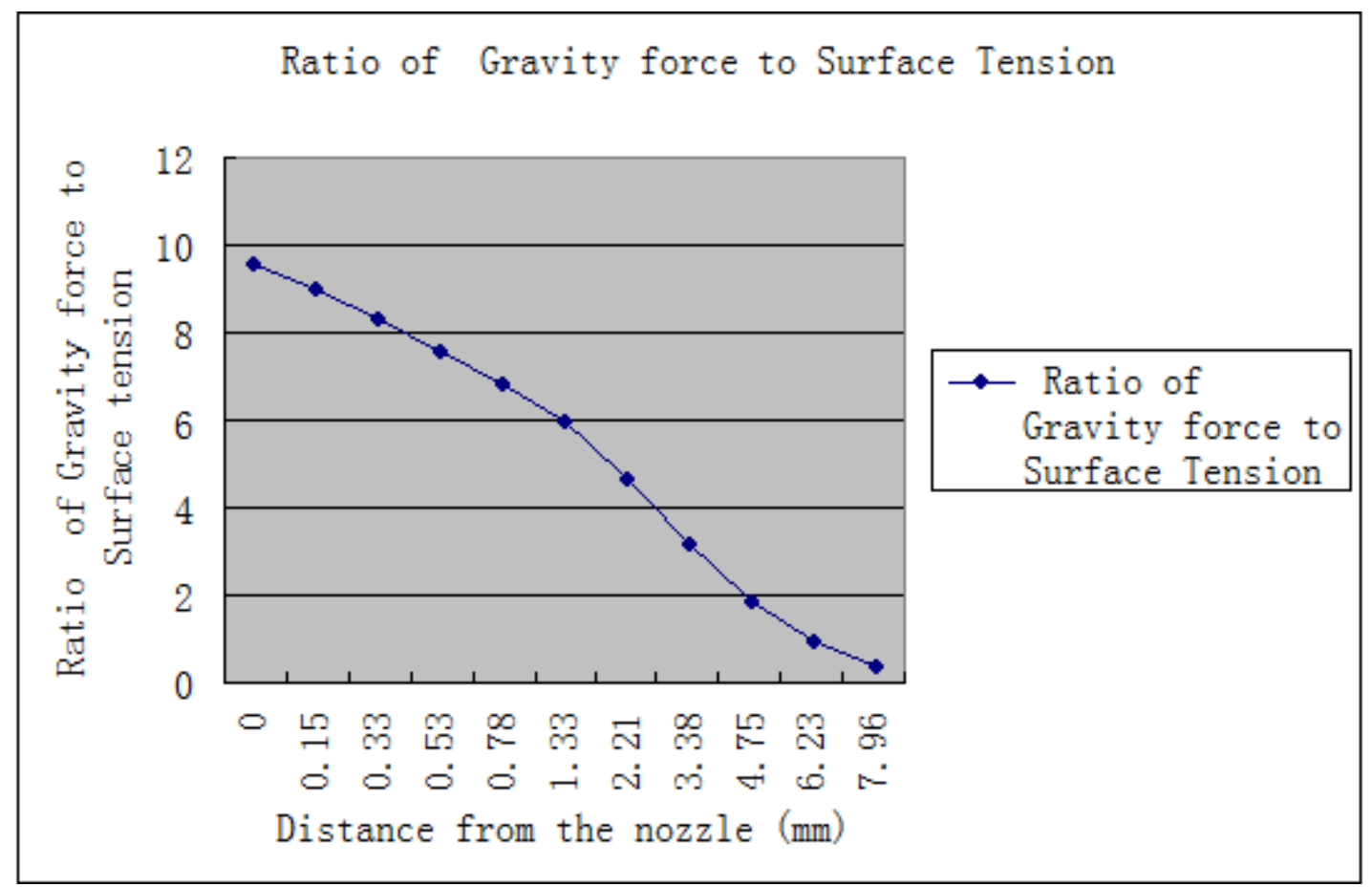

Figure 2.10 Ratio of Gravity Force to Surface Tension

\subsubsection{Other Parameters in the Drawing Process}

In order to get the desired final diameter, a drum is used to pull the glass fibers down and around itself with high speed. The winding speed or the rate of the attenuation only determines the final diameters of the fibers. In our case, the winding speed is $13.6 \mathrm{~m} / \mathrm{sec}$.

Below the bushing plate there is a hood extending about $0.1 \mathrm{~m}$, moving with furnace. Inside the hood, there are cooling water coils around the glass strands drawn from the nozzles. Chilled water runs in these coils to help cool the fibers by radiation. Please check Figure 1.2.

Rekhson proposed that variations in the bushing plate temperature can cause the glass flow rate through the nozzles to vary. This would in turn increase fiber breakage rates. 
“The colder tips on the periphery yield shorter and stiffer cones, which leads to a higher stress and therefore higher break rates.” [2.20].

So the cooling water flow rate must be optimized to keep the breakage rate low and also to reduce diameter variation of glass fibers. Special binders are sprayed on the glass fibers when they are in the drawing process. It sticks them together for later processes and dyes them in different colors according to the customer's requirements. There is some evidence that fiber breakage may be caused by excessive binder being “slung” off the drum by the centripetal acceleration.

Gas bubbles are also found in the pictures of glass fibers, as shown in Figure 2.11. As the fibers are attenuated, it is possible that bubbles or other inclusions in the glass could cause weak spots in the fiber and fiber breakage.

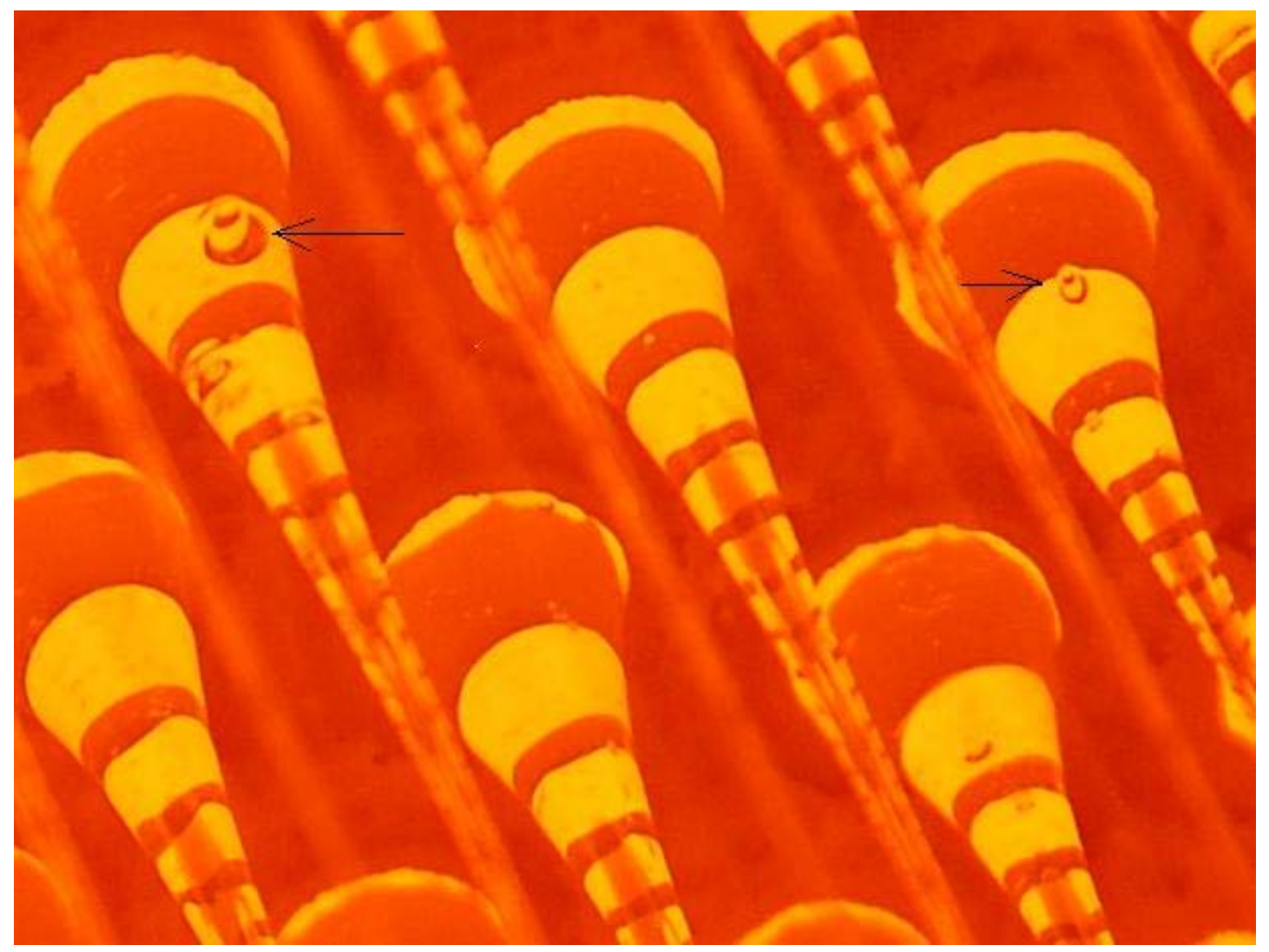




\section{Figure 2.11 Glass Fibers from the Nozzles}

\subsection{Study Methods for the Glass Fiber Drawing Process}

Many people studied the glass fiber drawing process in different ways so far, especially to reduce the fiber breakage and strengthen fibers.

Gas bubbles always cause some breakage in glass fibers. Anderegg thought that although the solubility of most gases in glass increases as the temperature falls, there is a tendency for dissolved gases to collect around any solid impurities in fluid glass. Although any large gas bubbles would decrease in size as the melt solidified, they would still remain to cause further discontinuities. He mentioned that the strength of glass was reduced by discontinuities but, by thorough melting and proper methods of attenuation, the effect is greatly reduced so that high strengths are produced with glass fibers [2.21]. In the field of high-speed coating of optical waveguide fibers, Paek made progress not only in the drastic increase of the line speed but also in the improvement of the transmission loss and strength characteristics of the high-speed coated fibers [2.22]. The processing of a glass fiber-reinforced polypropylene in the presence of a chemical blowing agent was found to dramatically reduce the occurrence of fiber breakage during processing within an injection molding machine [2.23]. Some work has been done by Anderson on the equations for the quenching time of fibers in terms of fiber velocity, outside radius and flow rate because he believed the quenching time is an important factor in the high strength phenomenon of glass fibers [2.24]. 
A prediction of the temperature distribution in the jet is important since some people, like Otto [2.25], have suggested that the strength of glass fibers is determined by the rate at which the fiber cools as it is being formed. A similar opinion was given by Bateson. The tension in the fiber as it is drawn is also believed to influence the final strength of the fiber [2.26]. Bartenev paid attention to the nature of the surface layer of glass fibers which is responsible for the high strength, and discussed the strength and structure of flawless and commercial glass fibers [2.27].

Glicksman (1968) applied the differential method to analyzing the glass fiber drawing process, and defined three jet regions in the drawing process as Figure 2.6 shows. His one-dimensional steady state analysis in the central jet region is in good agreement with experimental results [1.1]. Petrie and Denn (1976) considered an isothermal, inertialess Newtonian fiber drawing, and concluded that the extension ratio $E=\frac{\overline{v_{f}}}{\overline{v_{o}}}=20.2$ (where $\overline{v_{f}}$ is pulling velocity and $\overline{v_{o}}$ is average inlet velocity) is approximately a critical draw ratio [2.28]. But this number is much smaller than the one in our case (about $E=100$ ). Shah and Pearson (1972) determine the drawing process to be unconditionally stable when there is sufficiently high convective heat transfer at the fiber surface [2.29]. Studies have been done by Mashkar and Shah (1977) which proved that heat transfer stabilizes fiber drawing, while surface tension destabilizes it [2.30]. Denn et al. (1975) [2.31], Shultz (1987)[2.32], Wang and Forrest (1994)[2.33] have studied the process using viscoelastic fluid models. Gupta et al. (1996) thought that viscoelasticity has a destabilizing effect on the process [2.34]. 
Most of those earlier theoretical approaches were mainly one-dimensional. However, from Glicksman's definition of jet regions, one-dimensional theory is only valid in the central jet region, not in the upper jet region. A two-dimensional steady-state numerical analysis of the fiber forming process (Purnode and Rubin, 1998) showed good agreement with experiments of Glicksman [2.10]. They use the finite element method to simulate the process in Polyflow ${ }^{\mathrm{TM}}$.

Purnode (2000) extended his work by examining the unsteady behavior of glass fiber forming with a finite element transient algorithm. He simulated a time-periodic transition which results in fiber diameter variation and possibly leads to fiber failure. Purnode investigated several flow rates and process conditions. The fiber diameter in the axial (draw) direction was compared with the experimental data in the literature [2.35]. Purnode's results and their agreement with experimental data are shown in Figure 2.12 [2.36] (reproduced from FLUENT ${ }^{\mathrm{TM}}$ ). His analysis also indicates that convective heat transfer is shown to have a stabilizing effect on the process whereas surface tension has an unstabilizing effect [2.35]. 


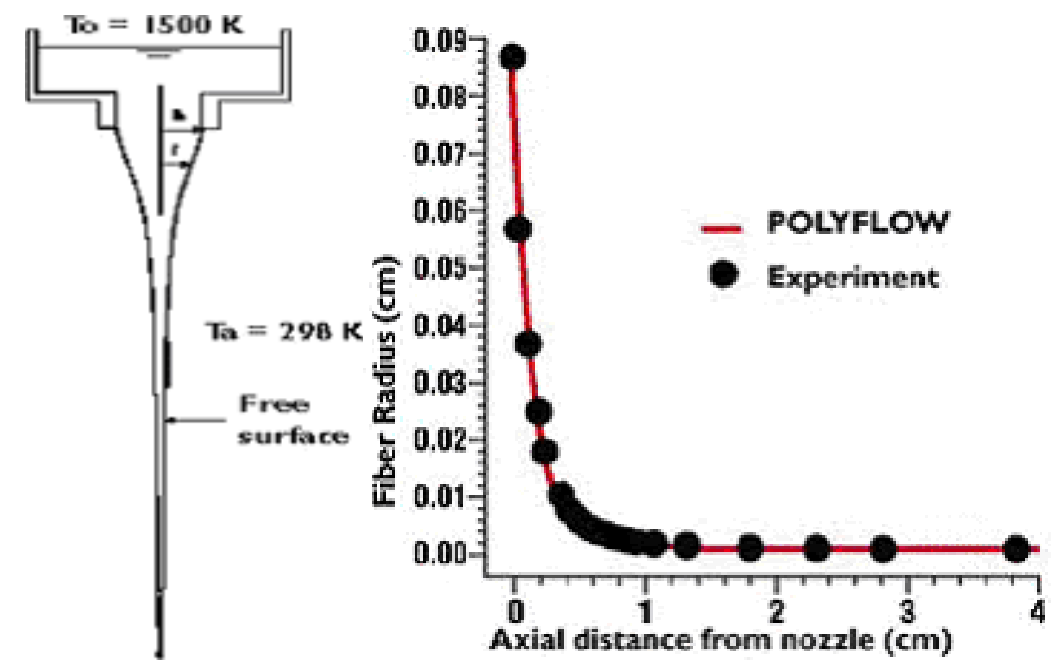

Figure 2.12 POLYFLOW Results, at a Draw Ratio of 1:19,024, Show Excellent Agreement with the Experimental Data [FLUENT ${ }^{\mathrm{TM}}$ ]

Following Glicksman’s one-dimensional theory, Rekhson (2004) has done some further work. He concluded that filament diameter variation and increased breakage rates were caused by temperature variations in the bushing plate based on his equation 2-10. By using the Weibull cumulative distribution function, Rekhson calculated that the probability of breakage in the central attenuation region is orders of magnitude higher than in the upper jet region. He concluded because of the cooling water's effect, the colder tips on the periphery on the bushing plate lead to a higher stress and therefore to higher breakage rates.

However, his calculated break rates are in poor agreement with literature data, while the results of his computations for cone shape and forming stress are found to be in agreement with them [2.20].

Beyond these examples, little has been published that relates to the control of the glass fiber drawing process. 


\subsection{Control Methods in Glass Product Industry}

In nearly all industrial glass forming processes, the temperature of the glass in the furnace is an important factor to ensure the quality of final glass products. So many control ideas in this field have focused on temperature control in the process.

Gough et al. discussed the application of a new predictive-adaptive controller for the control of molten glass temperature for the production of glass containers on automated molding machines [2.37]. Dzyuzer, Shvydkii and Klimychev described the specifics and control algorithms for a glass-melting furnace and analyzed methods for setting and monitoring the temperature regulation parameters in the working space. They demonstrated the advantages of using a mathematical model for the construction of an automated control system for the thermal performance of the glass-melting furnace [2.38].

Moon and Lee did a lot of work in control of temperature for a TV Glass furnace. They modeled one linear portion of the furnace with a First Order-Plus-Dead-Time (FOPDT) System and applied a PI controller to the FOPDT model. The remaining complex and nonlinear portion of the furnace dynamics was covered by a fuzzy logic system using rules collected from human experts. The PI controller and fuzzy system are combined in cascade [2.39][2.40]. As shown in Figure 2.13 (reproduced from Moon and Lee) [2.40]. They also introduced a practical application of the multi-loop control to control the temperature of a TV glass furnace. Some major input-output variables were selected and a FOPDT model was established with the process experimental data. Based on the FOPDT models, a 
multi-loop control, which was a combination of cascade and single loops, was used [2.41].

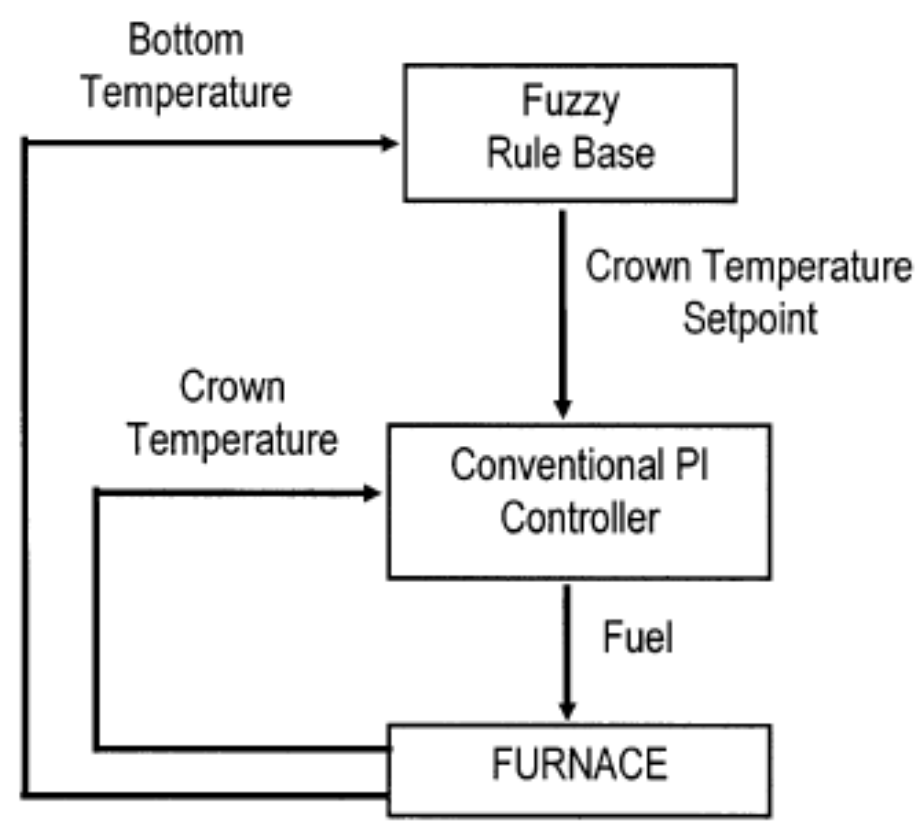

Figure 2.13 the Hybrid Fuzzy-PI Control Structure [Moon and Lee]

Wertz designed an adaptive control of the temperature of a glass furnace. He paid attention to the bottom temperature of the furnace because studies have shown evidence of a strong correlation between the glass quality (bubbles, stones) and the stability of the bottom temperature of the furnace. Also, a more stable bottom temperature allowed the furnace to be operated at a lower mean temperature, hence leading to energy savings. In order to control the bottom temperature of the furnace, a hierarchical control structure has been designed, subdividing the main control task into several subtasks operating at different time scales. 


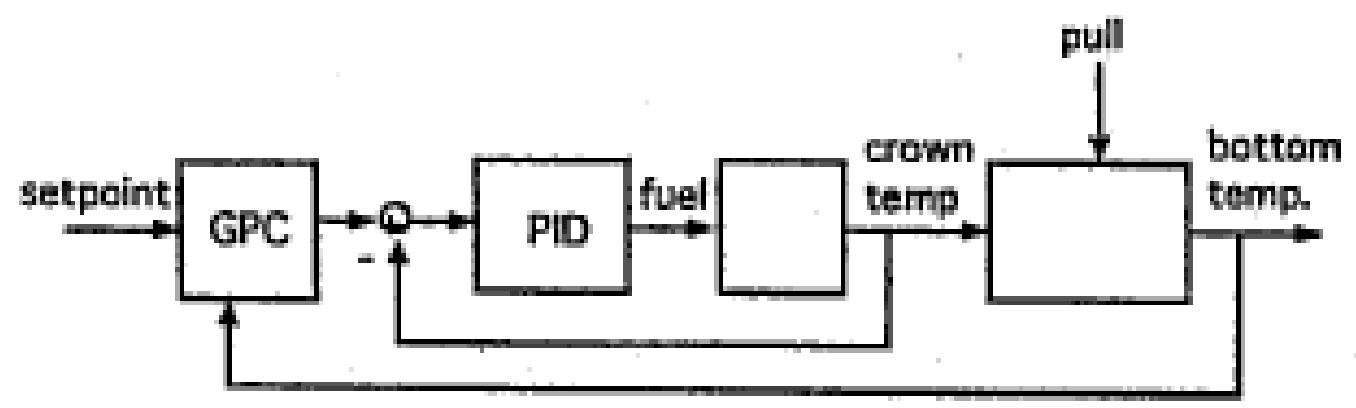

Figure 2.14 Cascade Control Structure for the Furnace Temperatures [Wertz]

Basically, the control of the bottom temperature, at the highest level of the hierarchy, was achieved by using the crown temperature as the control input. As illustrated on Figure 2.14 (reproduced from Wertz), the process that Wertz considered had a single control input (the crown temperature), a single output (the bottom temperature) and is also affected by a measurable perturbation (the pull). Then they chose the simpler ARX models in their prediction model based on an off-line identification study and built a control algorithm. Since there are changes in the process which require adaptation (e.g. change of color or change of electrical power), they added an adaptive algorithm into the control part. They were able to reduce the variation in the furnace bottom temperature without increasing the variation of the furnace crown temperature [2.42].

Holladay presented a good control method in small furnaces for batch production under some reasonable assumptions [2.43]. Instead of measuring the molten glass temperature directly, she designed an observer control systems to get good estimates of the glass temperature based on easily measured states. Firstly, she built an observer based on the combustion gas temperature, but it could not provide 
accurate estimates of glass temperature within a reasonable time. Then she designed another observer based on available measurements of combustion gas, bottom refractory, and wall refractory temperatures using the same method as for the combustion gas observer. The estimation error for this observer is only apparent during the first few minutes of the simulation. This observer is also robust to disturbance inputs and measurement noise. Morris extended Holladay’s work [2.44]. He eliminated the assumption of homogeneous glass melt and refractory temperatures, and developed a furnace model suitable for implementation with a real-time controller. A state space model of an end-fired furnace was developed in which the furnace is divided longitudinally into two zones. He divided the furnace into 24 separate volumes with the temperature of each becoming a state variable. The model included three stratification layers in the glass melt and separate zones for combustion gases and furnace walls, crown and ends. Simulations using his model showed potential fuel savings from modification of the firing strategy during melting [2.44].

Beyond these examples, little has been published that relates to multivariable control in small fiber-glass furnaces. 


\section{Technical Approach}

In order to decrease the breakage rate and control the whole drawing process stably and optimally, an effective control scheme must be developed for the process, which requires an understanding of the dynamics relating the various process parameters to each other and to product quality and process reliability. So two models are developed in this study. One is for the glass fiber drawing process, the other is for process control of the glass furnace. First, relationships among the process parameters were studied. A mathematical model for the process was developed and was examined to find the parameter interactions from equations. Then the model was developed in Matlab /Simulink ${ }^{\text {TM }}$ to do parametric analysis. Based on those results, an estimator based LQR control model was developed to control the glass temperature and winder speed for the furnaces. Multivariable control analysis has been done to ensure that even if some disturbance happens, the system can still be controlled back to the normal state.

\subsection{Glass Fiber Drawing Process Model}

To control the drawing process, it is necessary to understand and if possible to quantify how changes in disturbance parameters such as ambient temperature or molten glass height affect the process. An analytical model of the glass fiber was developed based primarily on Glicksman's work, but with the addition of a radiative 
heat transfer component and the addition of temperature-dependent relationships for physical properties of soda-lime glass.

\subsubsection{Mathematical Model}

From the previous description about glass fiber shape region, we know that there are three regions for glass fibers in the drawing process from the nozzle down to the winder, as shown in Figure 2.8. Glicksman paid attention to the central attenuation region with the reasonable assumption that the temperature distribution is one-dimensional [1.1]. Rekhson also proved it is significant to study the central attenuation region because in this region there is higher possibility for fiber breakage than other two regions [2.20]. So the model is based on the central attenuation region, which is from $\left(\frac{d r_{o}}{d z}\right)_{E}=-0.1$ to $r_{o}=r_{F I N A L}$. Forced convection and radiation are the main heat transfer methods in this model.

\subsubsection{Forced Convection in Heat Transfer}

The rate of heat transfer by convection between a surface and a fluid may be computed by the relation

$$
q_{c}=\bar{h}_{c} A \Delta T
$$

In the object company, with the winder speed of $13.6 \mathrm{~m} / \mathrm{sec}$ (149 rpm), glass fibers exchange heat energy with air by forced convection, not natural convection. Glicksman assumed that in the central attenuation region, radiation and conduction heat transfer are negligible compared to forced convection [1.1]. 
A measure of the relative importance of the thermal resistance within a solid body is the ratio of the thermal to the external resistance. This ratio can be written in dimensionless form as $\bar{h} L^{\prime} / k_{s}$, the Biot number, where $\bar{h}$ is the average unit-surface conductance, $L^{\prime}$ is a significant length dimension obtained by dividing the volume of the body by its surface area, and $\mathrm{k}_{\mathrm{s}}$ is the thermal conductivity of the solid body. In bodies whose shape resembles a plate, a cylinder, or a sphere, the error introduced by the assumption that the temperature at any instant is uniform will be less than 5 percent when the internal resistance is less than 10 percent of the external surface resistance, i.e., when $\bar{h} L^{\prime} / k_{s}<0.1[3.1]$ (Fox ,page 140).

In the central attenuation region, because the radius of the glass fiber is very small, the Biot number for glass is less than 0.1, which means the temperature distribution inside the glass fiber in the central region is pretty flat. Since both the fiber and the air are moving, heat transfer by contact is necessarily forced convection. The assumption that radiation is negligible must be verified by calculating the forced convective heat transfer coefficient and using a cylinder model to compare the energy transmitted by the forced convection and radiation. 


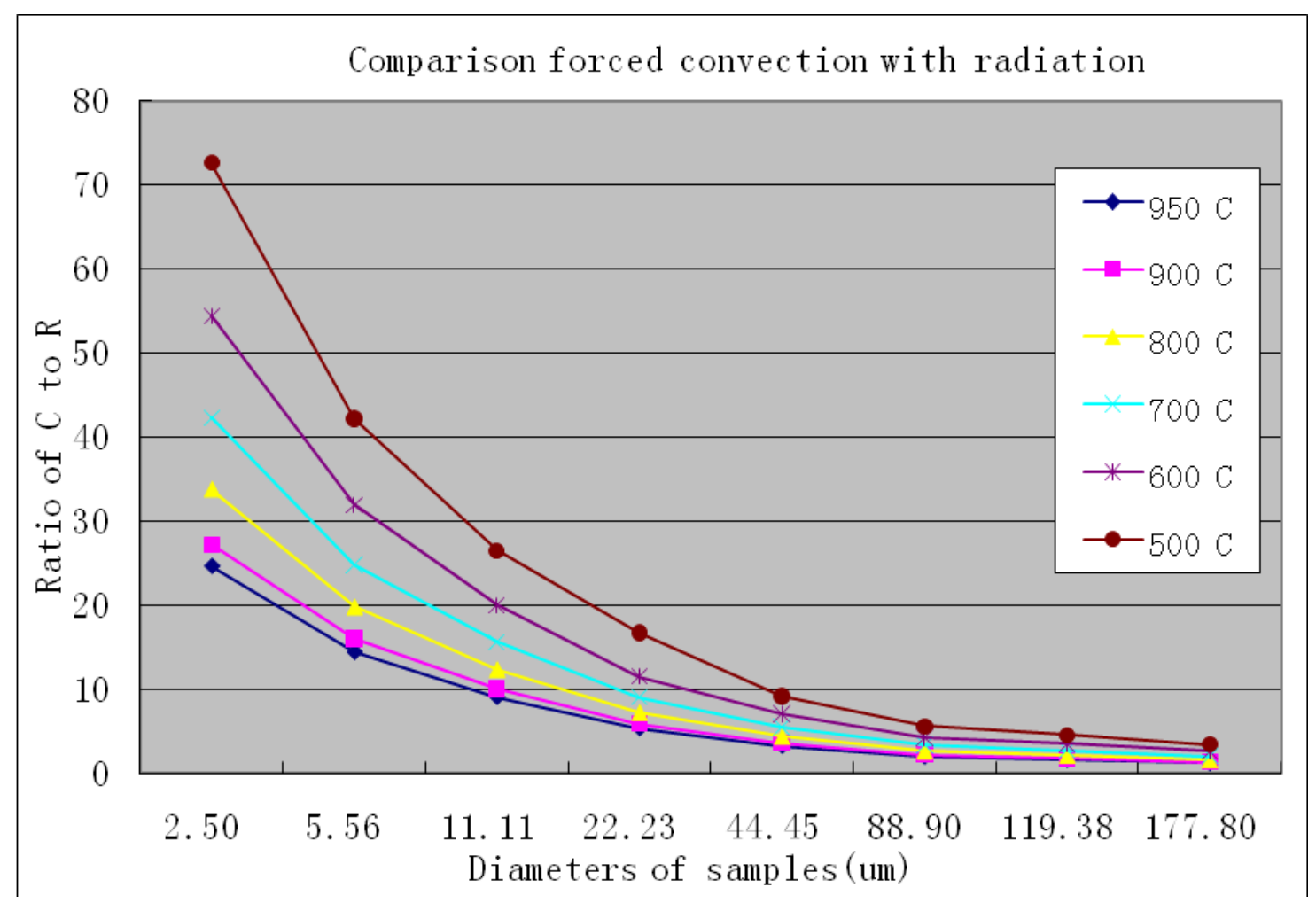

Figure 3.1 Comparison Forced Convection with Radiation

Figure 3.1 shows the result. There are six plots in the figure, parameterized by temperatures in the range of $500{ }^{\circ} \mathrm{C}$ to $950{ }^{\circ} \mathrm{C}$ from top to bottom. It is obvious that when glass fibers are the same size during the process, the high temperature one has the lower ratio of convection heat transfer to radiation. For a specific plot with a constant temperature in the figure, ratio of convection heat transfer to radiation increases when glass fibers are drawn to the final size. In our case, the final diameter of glass fiber is set to be around 30 micron, where the maximum ratio is about 12.9 at the temperature $500{ }^{\circ} \mathrm{C}$ and the minimum ratio is about 4.75 at the temperature $950{ }^{\circ} \mathrm{C}$. At the end of central attenuation region, glass fibers should be drawn to the final size and its temperature in normal status is calculated to be about $580{ }^{\circ} \mathrm{C}$ in our model, then ratio of convection heat transfer to radiation is less than 5 . Temperature at the 
starting point of the central is calculated as about $770{ }^{\circ} \mathrm{C}$ by my model when the bushing plate temperature is $900{ }^{\circ} \mathrm{C}$. In the central attenuation region, the temperature of glass fiber drops from $770{ }^{\circ} \mathrm{C}$ to $580{ }^{\circ} \mathrm{C}$ approximately. This temperature range is mainly covered by $600{ }^{\circ} \mathrm{C}$ and $800{ }^{\circ} \mathrm{C}$ plots in Figure 3.1, and the corresponding ratios of convection to radiation are 9.26 and 5.85 respectively when glass fiber diameter reaches 30 microns at the point, which is the end of the central attenuation region. Actually in the central attenuation region, the size of glass fibers decreases to final size equal to 30 microns, and their temperatures start from about $770{ }^{\circ} \mathrm{C}$ to $580{ }^{\circ} \mathrm{C}$. So in the Figure 3.1, ratio of convection to radiation region should be the area between $600{ }^{\circ} \mathrm{C}$ and $800{ }^{\circ} \mathrm{C}$ plots as top edge and down edge, 30 microns as left edge, open in the right direction. It is obvious that all the ratios in this region are smaller than 9.26 .

In addition, there is much difference between the actual situation and the situation in the calculation. In the drawing process, the air flows over the surface of glass fibers along the axial direction, while in the calculation, air was considered to flow over the surface in the direction normal to glass fibers axis. Obviously, forced convection from the direction normal to the axis is stronger than that along the axis. So actually, the ratio of the heat transferred by forced convection to the heat transferred by radiation is smaller than that shown in Figure 3.1 (Please see Appendix A Comparison of Conduction, Radiation with Forced Convection in the Central Attenuation Region for details).

Above all, this analysis shows that the radiation part should not be neglected 
compared to the forced convection part in the central attenuation region.

\subsubsection{Governing Equation Group}

All derivations described in this chapter are based on the following assumptions:

1. The region of primary interest is the central region where the fiber is drawn to its final diameter.

2. The "target" final glass fiber diameter is approximately 30 microns;

3. Radiation from the fiber is from the surface only, due to the high absorption coefficient of glass at the wavelengths of interest;

4. Tension from the drawing process is constant along the length of the fiber. This is equivalent to saying that gravitational and inertial effects are much smaller than viscous forces in the attenuation process;

For the region of interest, Glicksman has derived the governing equations as follows:

The energy equation

$$
w c_{p} \frac{d T}{d z}=-2 \pi r_{o} h\left(T-T_{\infty}\right)=-\pi k_{f} N u\left(T-T_{\infty}\right)
$$

where the $\mathrm{z}$ axis has its origin at the beginning of the central attenuation region, and is positive in the direction of the drawing process. Also, $\mathrm{w}$ is the mass flow rate (kg/sec), $c_{p}$ is the specific heat $(\mathrm{J} / \mathrm{kg}-\mathrm{K}), \mathrm{r}_{\mathrm{o}}$ is the radius of the glass fiber $(\mathrm{mm}), \mathrm{h}$ is the forced convection heat transfer coefficient $\left(\mathrm{W} / \mathrm{m}^{2}-\mathrm{K}\right), \mathrm{T}_{\infty}$ is the ambient temperature, and $\mathrm{T}$ is the temperature of the fiber at its surface, $\mathrm{k}_{\mathrm{f}}$ is thermal 
conductivity evaluated at the average of the wall and free-stream temperature $(\mathrm{W} / \mathrm{m}-\mathrm{K})$.

This equation ignores the transfer of heat to the environment by radiation. Based on the previous conclusion from Figure 3.1 and some real situation that in many applications, cooling fins or water cooled coils are used specifically to enhance the radiative cooling of the fibers, Equation 3-2 was modified to include a term for the radiation component:

$$
\begin{aligned}
& w c_{p} \frac{d T}{d z}=-2 \pi r_{o} h\left(T-T_{\infty}\right)-2 \pi r_{o} \sigma \varepsilon_{1} F_{12}\left(T^{4}-T_{\infty}^{\prime}{ }^{4}\right) \\
& =-\pi k_{f} N u\left(T-T_{\infty}\right)-2 \pi r_{o} \sigma \varepsilon_{1} F_{12}\left(T^{4}-T_{\infty}^{\prime}{ }^{4}\right)
\end{aligned}
$$

where $\mathrm{w}$ is mass rate flow, $\mathrm{kg} / \mathrm{sec}$, and in the research it is supposed to be constant; $\mathrm{c}_{\mathrm{p}}$ is specific heat, $\mathrm{J} /\left(\mathrm{kg}^{*} \mathrm{~K}\right) ; \mathrm{r}_{\mathrm{o}}$ is the cone radius of the glass fiber profile at some point, $\mathrm{mm}$; $\mathrm{h}$ is the forced convection coefficient at some point; $\sigma$ is the Stefan-Boltzmann constant, $\varepsilon_{1}$ is the emissivity of the glass, $F_{12}$ is the shape factor. The last term in this equation contains the additional variable T', which is the "ambient” temperature for radiation calculations (may be different from the air temperature used for convection).

Boundary condition: at $z=Z_{E}, T=T_{E}, r_{o}=r_{E}$.

where $\mathrm{E}$ is the point where the central attenuation region begins.

Shape factor is an important item in radiation calculation. "Since most industrial surfaces can be treated as diffuse emitters and reflectors of radiation in a heat-transfer analysis, a key problem in calculating radiation heat transfer between surfaces is to determine the fraction of the total diffuse radiation leaving one surface which is intercepted by another surface and vice versa. The fraction of diffusely 
distributed radiation leaving a surface $A_{i}$ that reaches surface $A_{j}$ is called the radiation shape factor $F_{i-j}$. The first subscript appended to the radiation shape factor denotes the surface from which the radiation emanates while the second subscript denotes the surface receiving the radiation.” [3.2] (Kreith, page 243-244).

In the drawing process, different cooling water flow rates change the temperature of the area receiving the radiation, thus increasing or decreasing radiant heat transfer from the fiber to the coils. Thus the ambient temperature for radiation can vary with the cooling water flow rates. In the case at hand, shape factor was computed based on a configuration with no fins but with rows of cooling coils surrounding the region down to about ten centimeters below the bushing plate.

Computation of the convective heat transfer coefficient is not straightforward. Many studies have been conducted for forced convection from a cylinder in crossflow, however the data for air flowing axially along a solid cylinder are sparse.

Some studies are done by blowing air axially along a constant-diameter cylinder to measure forced coefficient in experiments. Morris et al. [3.3][3.4] developed a correlation for the local convective heat transfer coefficient based on the fiber diameter, the temperature difference between the fibers and the airflow, the airflow speed and the fibers.

$$
\begin{aligned}
& h=\left(-0.0118 \times 10^{6} d+0.9057\right) \times\left(T-T_{\infty}\right)+\left(23.01 \times V-6.612 \times 10^{6} \times d+573.5\right) \\
& +V \times\left[\left(0.8452 \times 10^{12} d^{2}-111.3 \times 10^{6} d+4631\right) \times \sin ^{2}(\theta)\right]
\end{aligned}
$$

where $\mathrm{V}$ is free stream airflow velocity $(\mathrm{m} / \mathrm{s}), \mathrm{d}$ is the diameter of fibers $(\mathrm{m}), \theta$ is the angle between the airflow and the fibers (radian). Using this equation with a fiber diameter of 30 microns and drawing speed of $13.6 \mathrm{~m} / \mathrm{s}$, a forced convection 
coefficient was obtained for air flowing along the cylinder of about $1000 \mathrm{~W} / \mathrm{m}^{2}-\mathrm{K}$ to $1200 \mathrm{~W} / \mathrm{m}^{2}-\mathrm{K}$, which is consistent with results obtained by other authors. However, this equation is cumbersome to use with a continuously changing fiber diameter.

Glauert and Lighthill [3.5] assumed that the momentum boundary layer was developed from the leading edge of a stationary, infinitely long cylinder in a moving fluid. Although they didn’t derive any results for heat transfer, their application of the Von Karman-Pohlhausen techniques and their use of the non-dimensional coordinate $v z / \mathrm{Vr}^{2}$ were widely adopted in the later studies. Glicksman (1968) combined Glauert \& Lighthill's results for the shear stress with the Reynolds analogy to yield predictions for the local and average Nusselt numbers [3.6]:

$$
N u=\frac{4.3}{\ln \left(\frac{4 v Z}{V r_{o}^{2}}\right)}-\frac{12.9}{\left[\ln \left(\frac{4 v z}{V r_{o}^{2}}\right)\right]^{3}}
$$

where $v$ is the kinematic viscosity of air $\left(\mathrm{m}^{2} / \mathrm{s}\right), V$ is the velocity of glass fibers $(\mathrm{m} / \mathrm{s})$, and $r_{0}$ is the radius of the glass fiber (mm). The Prandtl number for air is taken as unity. From this estimate of $\mathrm{Nu}$, the convective heat transfer coefficient can be found from the definition of the Nusselt number,

$$
N u=\frac{2 r_{o} h}{k_{f}}
$$

Here, $h$ is the convective heat transfer coefficient $\left(W / m^{2}-K\right), k_{f}$ is the thermal conductivity of air, evaluated at the average of the wall and free-stream temperature $(\mathrm{W} / \mathrm{m}-\mathrm{K})$.

From Xiong’s Figure 3.2 “Comparison of the Experimental Data and Prediction 
Curves” [3.7], some theoretical results and some experimental results were shown and gave a range for the dimensionless correlation $x v / V d^{2}$ vs $\left(T-T_{\text {air }}\right) /\left(T_{o}-T_{\text {air }}\right) . \quad T_{\mathrm{o}}$ is the temperature of the starting point of the region, in our case, it is the temperature of the starting point for the central attenuation region. As Figure 3.3 shows, the correlation plot in my model with air kinematic viscosity $62.53 \times 10^{-6} \mathrm{~m}^{2} / \mathrm{s}$ at $400^{\circ} \mathrm{C}$ falls into the general range given by Figure 3.2, which is confirmed by some peoples' research results. In other words, the correlation about temperature change and $\mathrm{Nu}$ in our model is proved by several peoples' research results in Figure 3.2. According to the correlation $x v / V d^{2}$ vs. $\left(T-T_{\text {air }}\right) /\left(T_{o}-T_{\text {air }}\right)$, Nu was calculated by using Equation 3-5 and air thermal conductivity was set to $0.0328 \mathrm{~W} / \mathrm{mK}$ (at $120^{\circ} \mathrm{C}$ ) to calculate heat transfer from forced convection by using the energy Equation 3-3.

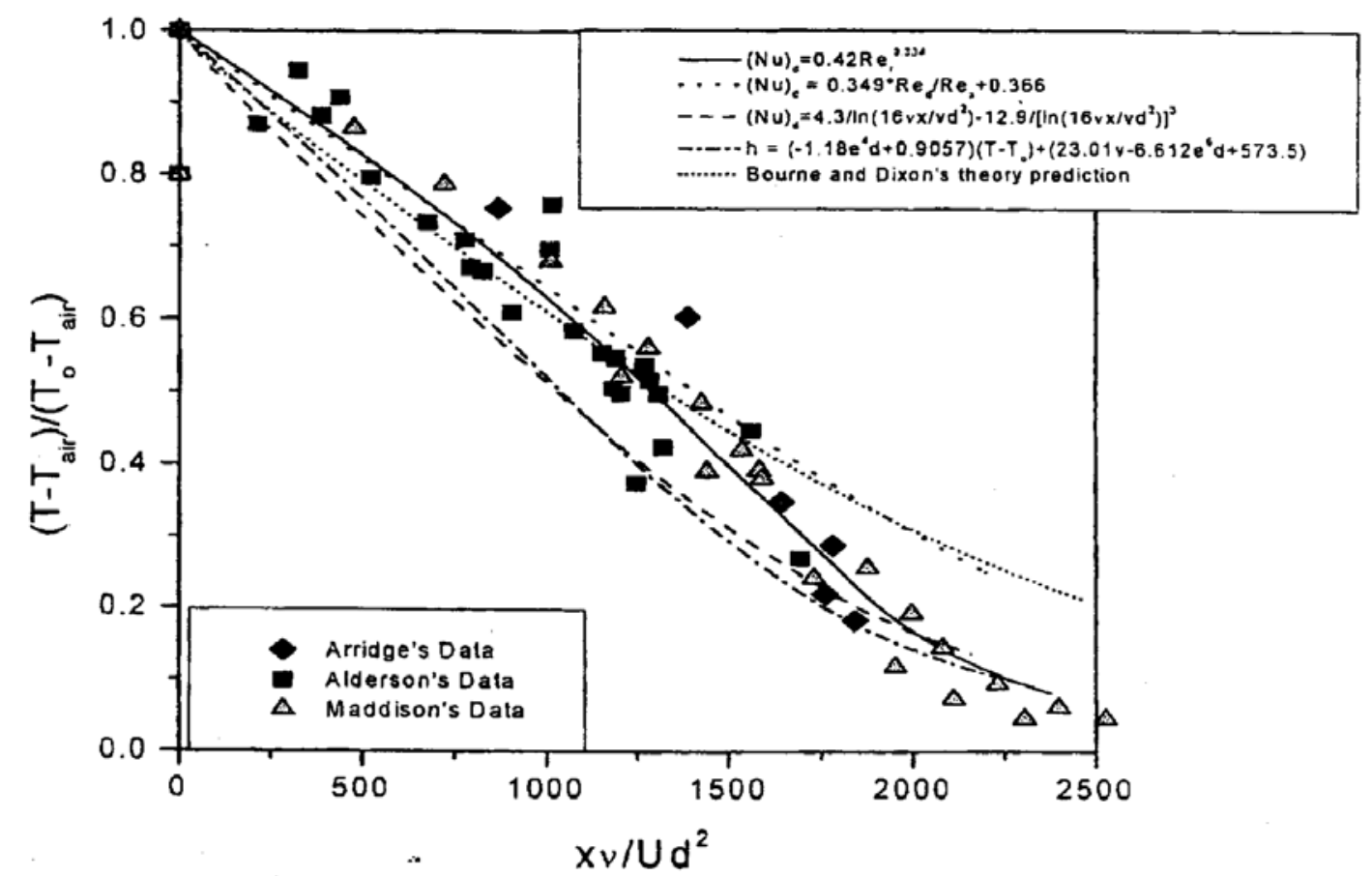

Figure 3.2 Comparison of the Experimental Data and Prediction Curves [Xiong]

Glicksman defined the central attenuation region so that momentum effects in 
the radial direction could be ignored. He also assumed that the drawing tension in the fiber is constant across the length of the fiber, i.e. that the drawing tension is much greater than gravity or inertial effects in the $\mathrm{z}$ direction. Under these assumptions, he combined the continuity and momentum equations to obtain

$$
\frac{d}{d z}\left[\frac{-6 \mu w}{\rho r_{o}} \frac{d r_{o}}{d z}+\pi r_{o} \gamma_{T} \cos \theta\right]=0
$$

Boundary conditions are as follows: at $\mathrm{z}=0, \mathrm{dr}_{\mathrm{E}} / \mathrm{dz}=-0.1, \mathrm{r}_{0}=\mathrm{r}_{\mathrm{E}}$; as $\mathrm{z} \rightarrow \infty, \mathrm{dr}_{0} / \mathrm{dz} \rightarrow$ 0 and $\mathrm{r}_{0} \rightarrow \mathrm{r}_{\text {final. }}$. Here, the subscript $\mathrm{E}$ refers to the beginning point of the central region, i.e. $z=0$. It requires expressions for viscosity, density, and surface tension as functions of temperature in order to solve Equations 3-3 and 3-7. The Fulcher law was used for the viscosity relationship and the Fulcher constants are chosen according to the glass composition in our case:

$$
\mu=10 \exp \left(-2.66+\frac{4545}{(T-489.75)}\right)
$$

where unit of T is K. Tooley [3.8] (v1, page 36) gave the following relationship for the surface tension of soda lime glass:

$$
F_{S T}=\frac{2 \pi r_{o}}{10^{3}}\left[283-0.03 \times\left(T_{o}-1200\right)\right]=2 \pi r_{o} \gamma_{T}
$$

where $r_{0}$ is the fiber radius in $m m ; F_{S T}$ is the surface tension force on the circumference of a circle with the radius $r_{0}$, in Newton; $\gamma_{T}$ is the unit surface tension per length, in Newton/ $\mu \mathrm{m}$; $\mathrm{T}_{\mathrm{o}}$ is the temperature at that point, in Celsius. 


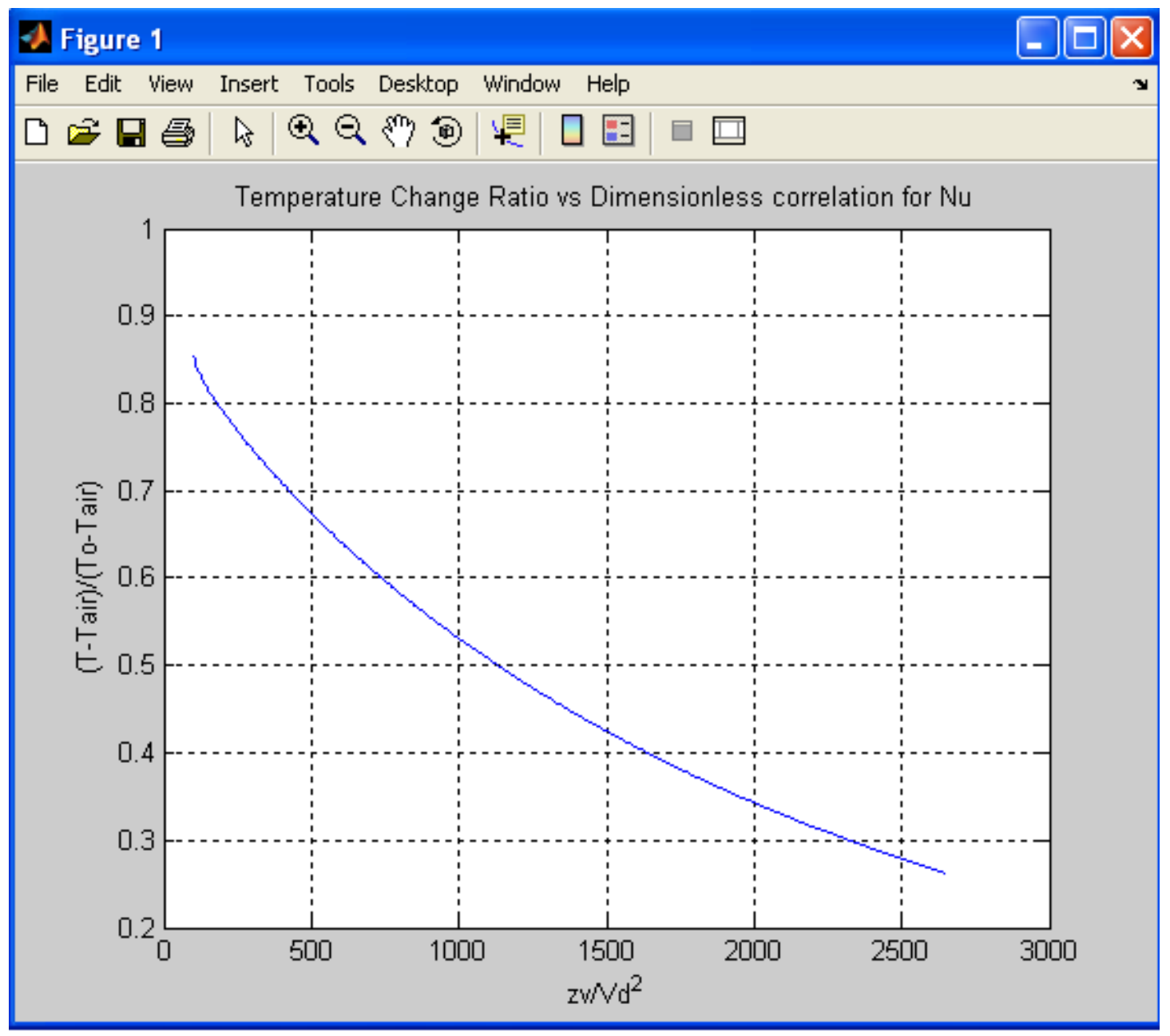

Figure 3.3 Curves for Temperature Change Ratio Correlation in Our Simulink TM Model

The mass flow rate, w was shown by Loewenstein to follow Poiseulle Law for viscous fluids, and thus becomes a function only of the glass viscosity, the nozzle diameter and the nozzle length in Equation 2-8 [2.16]. Poiseuille Law (or Hagen-Poiseuille Law) is also expressed in Equation 2-9 in detail [2.17].

$$
\phi=\frac{d V}{d t}=\bar{v} \pi R^{2}=\frac{\pi R^{4}}{8 \eta}\left(\frac{-\Delta P}{\Delta x}\right)=\frac{\pi R^{4}}{8 \eta} \frac{|\Delta P|}{L}
$$

where $\mathrm{L}$ is the length of the tube in the $\mathrm{z}$ direction in meters.

In order to solve the system of differential equations, all the boundary conditions and coefficients have to be specified, including $r_{E}$. To find $r_{E}$, pictures of glass fibers corresponding to different situations were taken, and points on the fiber 
surface were chosen. A polynomial curve was fitted to the coordinates of the points. The value of $\mathrm{r}_{\mathrm{E}}$ can be obtained from the result according to the definition of the $\mathrm{E}$ as the point where $d r_{E} / d z=-0.1$. From these calculations, $r_{E}$ was found to be $0.27 \mathrm{~mm}$ at a distance of approximately $8 \mathrm{~mm}$ below the bushing plate nozzle.

Since the tension is assumed constant over the entire length of the fiber, the momentum equation for the meniscus region allows us to make the following approximation:

$$
\left[-\frac{6 \mu w}{\rho r_{o}} \frac{d r_{o}}{d z}+\pi r_{o} \gamma_{T} \cos \theta\right]_{E} \approx\left[-\frac{6 \mu w}{\rho r_{o}} \frac{d r_{o}}{d z}+\pi r_{o} \gamma_{T} \cos \theta\right]_{B P}
$$

where the subscript BP refers to the condition at the bushing plate. At the bushing plate, the radius of the fiber is known, and the angle $\theta$ can be approximated from the photographs. $T_{0}$ at the bushing plate was measured using an infrared pyrometer and found to be approximately $900{ }^{\circ} \mathrm{C}$. With this information, the viscosity and surface tension coefficient were computed, as well as the mass flow rate and density. At point $\mathrm{E}$, the fiber radius, gradient and the angle $\theta$ are known, so Equation 3-10 can be solved iteratively to find $\mathrm{T}_{\mathrm{E}}$ using the relationships in Equation 3-8 and 3-9.

Putting the physical constants into the energy and momentum equations and simplifying them yields the following result:

the energy equation

$$
\frac{d T}{d z}=C_{1} N u_{z}\left(T-T_{\infty}\right)+C_{2} r_{o}\left(T^{4}-T_{\infty}^{\prime}{ }^{4}\right)
$$

the continuity/momentum equation: 


$$
\frac{d^{2} r_{0}}{d z^{2}}=\frac{\left[A \mu\left(\frac{d r_{0}}{d z}\right)^{2}+A \mu(\ln 10) r_{0} \frac{4545}{(T-489.75)^{2}} \frac{d r_{0}}{d z} \frac{d T}{d z}+B D \pi r_{0}{ }^{2} \frac{d r_{0}}{d z}-0.00003 \pi r_{0}{ }^{3} D \frac{d T}{d z}\right]}{\left(\mu A r_{0}+\pi r_{0}{ }^{3} B D^{3} \frac{d r_{0}}{d z}\right)}
$$

where $\mathrm{T}$ is in degrees K. For simplification, those definitions of several coefficients derived from the equations for the physical properties are shown as following:

$$
C_{1}=-\frac{\pi k_{f}}{w C p} \quad, \quad C_{2}=-\frac{2 \sigma \varepsilon \pi}{w C p}, \quad A=\frac{6 w}{\rho}, \quad B=\frac{319-0.03 T}{10^{3}}, \quad D=\cos \theta .
$$

\subsubsection{Simulation Model and Parametric Analysis}

The equations were integrated using Matlab /Simulink ${ }^{\mathrm{TM}}$. The initial conditions at the beginning of the central attenuation region are given above. The Simulink ${ }^{\mathrm{TM}}$ block diagram is shown in Figure 3.4. In Simulink ${ }^{\mathrm{TM}}$ all the blocks are functions of time, which is not indicated in the current differential equation group. So time is used to take the place of independent variable $\mathrm{Z}$ in the simulation. $\mathrm{Z}$ axis was defined that 0 point is nozzles, and positive direction is to point earth. In Simulink ${ }^{\mathrm{TM}}$ blocks, there is no boundary condition setting. For the integrator block, it has the initial condition. So the problem was solved like an initial value problem and the results from Simulink ${ }^{\mathrm{TM}}$ should be compared to the lower boundary value in equations. 


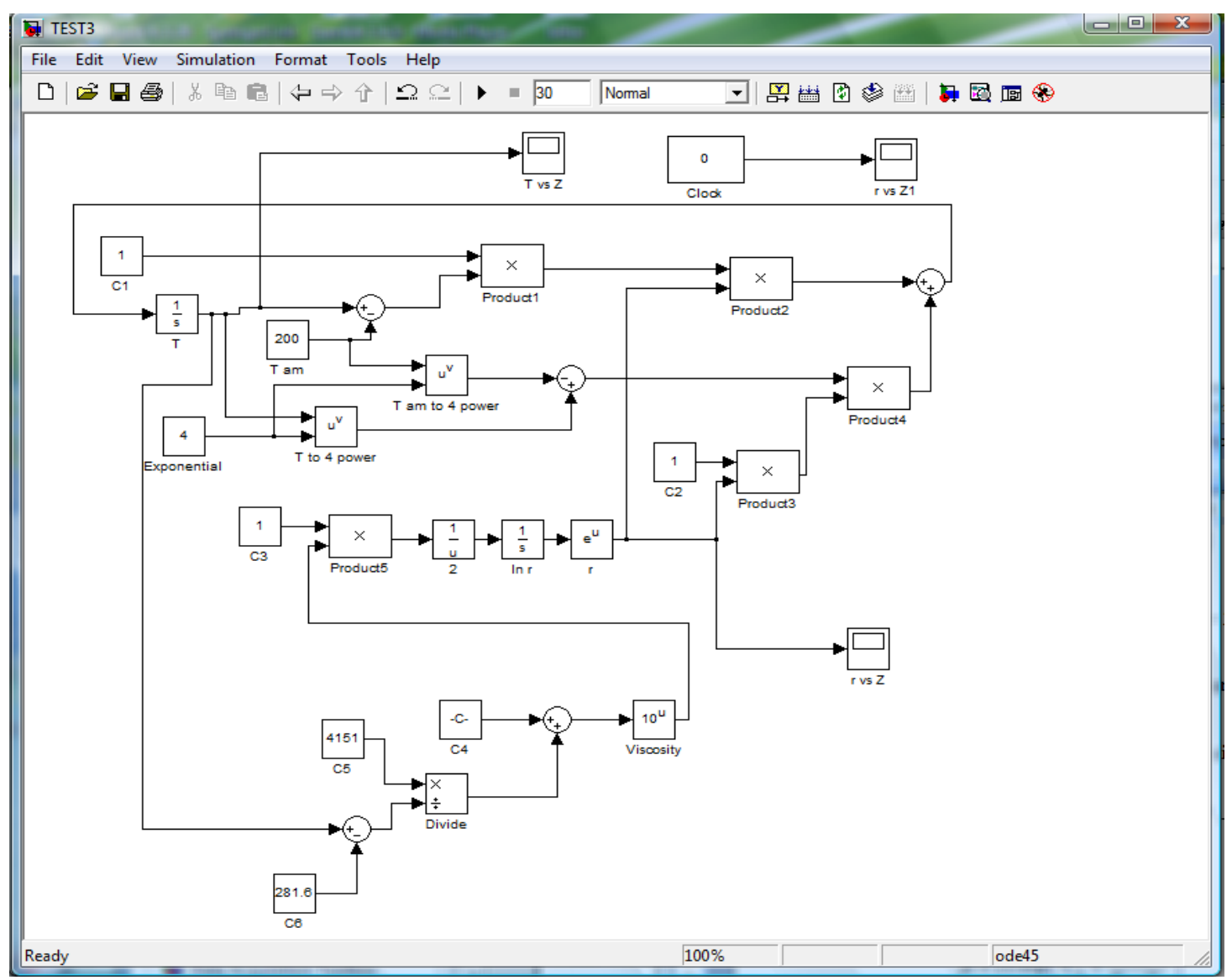

Figure 3.4 Simulink ${ }^{\mathrm{MM}}$ Block Diagram for the Glass Fiber Model

A “base case” was computed for furnace glass height of $8 \mathrm{~cm}$, drawing speed was $13.6 \mathrm{~m} / \mathrm{sec}$ and the glass mass flow rate was $2.38 \times 10^{-5} \mathrm{~kg} / \mathrm{s}$. The final radius was 15 microns. The bushing plate temperature was set at $1173 \mathrm{~K}$, and the temperature of the glass fiber at the beginning of the central region, $\mathrm{T}_{\mathrm{E}}$, was $1044 \mathrm{~K}$. The ambient temperature was set at $300 \mathrm{~K}$. Using a kinematic viscosity for air at $400^{\circ} \mathrm{C}$ of $62.53 \times 10^{-6} \mathrm{~m}^{2} / \mathrm{s}$, and air thermal conductivity $0.0328 \mathrm{~W} / \mathrm{m}-\mathrm{K}$ at $120^{\circ} \mathrm{C}$, Nusselt number and the forced convection heat transfer coefficient were calculated. The simulation found $\mathrm{r}_{\mathrm{E}}=0.000267 \mathrm{~m}$ at a distance $\mathrm{z}_{\mathrm{E}}=0.008 \mathrm{~m}$.

After $0.5 \mathrm{~s}$ simulation, the following results were obtained. At the point 0.1427 $\mathrm{m}$ away from the starting point of the central attenuation region, $\mathrm{V}=13.6221 \mathrm{~m} / \mathrm{s}$, 
$\mathrm{r}=1.5 \times 10^{-5} \mathrm{~m}, \mathrm{~T}=793.29 \mathrm{~K}$.

Figure 3.5 shows the base case fiber diameter and temperature as functions of $\mathrm{z}$. In the simulation, radius and temperature are still changing after 0.5 seconds, but if the winder speed is kept constant, the real situation is that when the glass fibers reach the final diameter calculated from the continuity equation, they will be changed to solid as they are cooled in drawing process. Because the Simulink ${ }^{\mathrm{TM}}$ model is only valid in liquid state, all the results before the final diameters became constant is right.

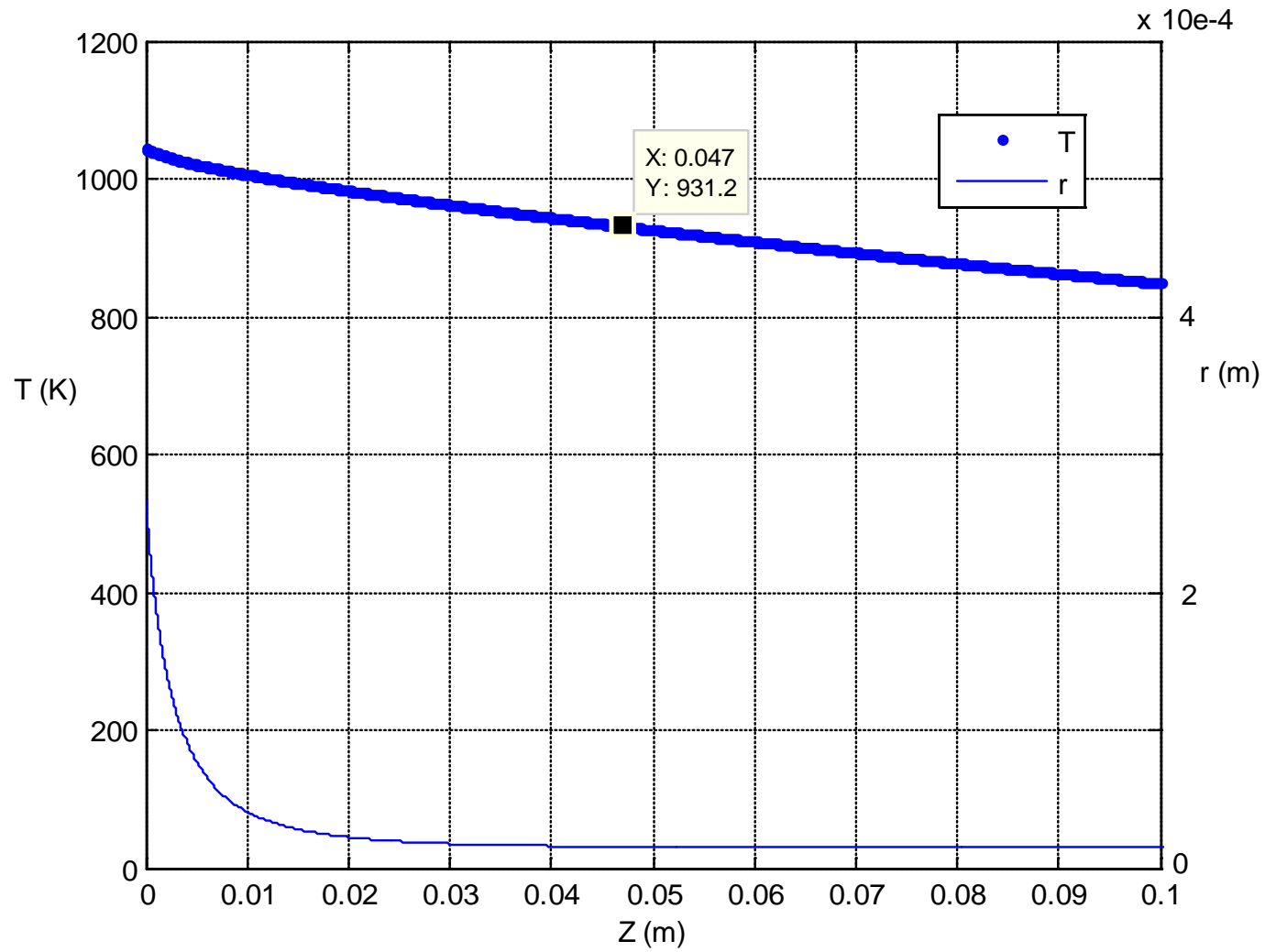


Figure 3.5 Glass Fiber Diameter (left axis) and Surface Temperature (right axis) as Functions of Distance $z$ in the Base Case

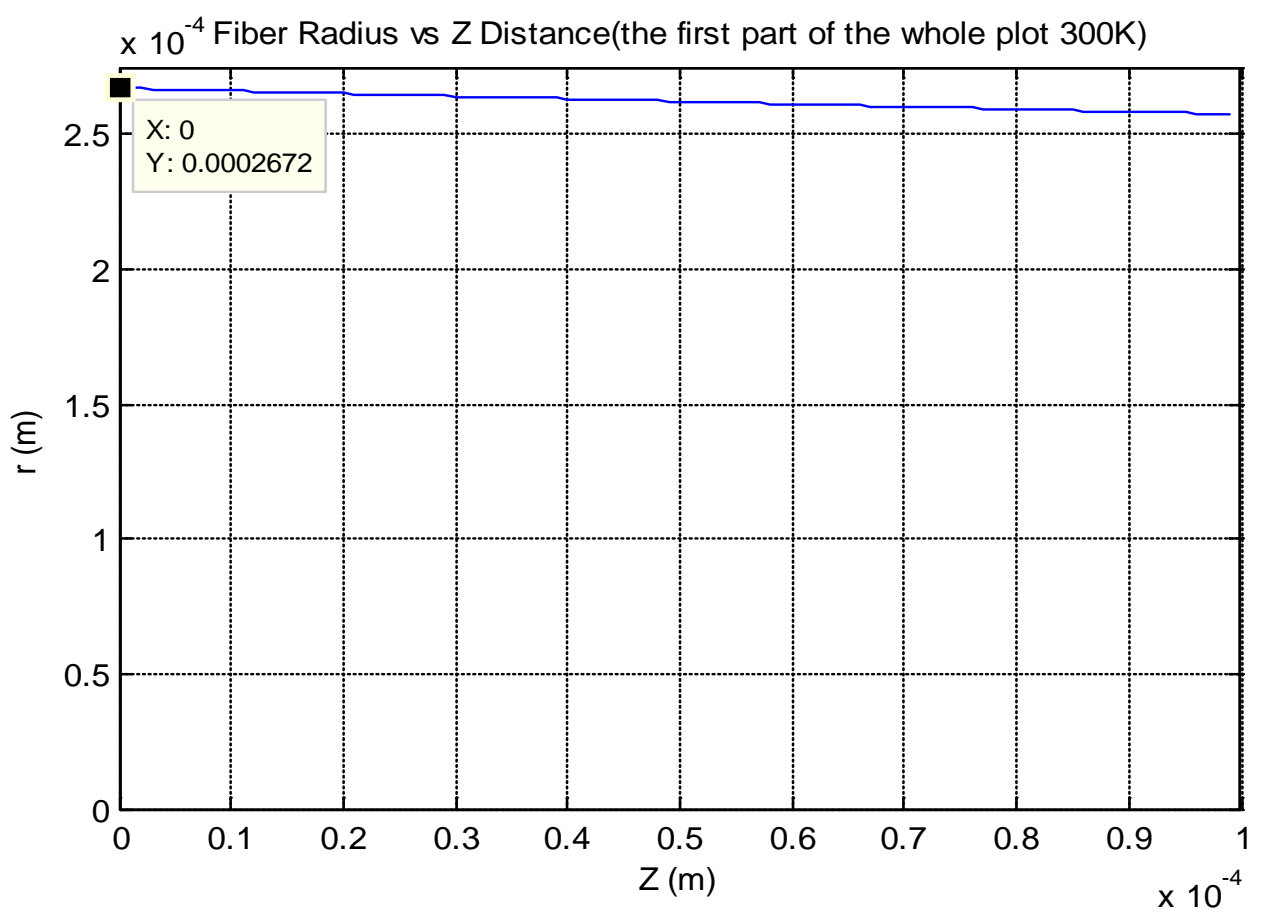

Figure 3.6 Fiber Radius vs Z Distance (the first part of the whole plot, 300K)

Parametric studies were then performed to quantify the effects of several important control and disturbance variables on the fiber diameter and fiber temperature as functions of the distance $\mathrm{z}$ along the fiber axis.

\subsubsection{Variation of Ambient Temperature}

The ambient temperature for the base case is $300 \mathrm{~K}$, but $\mathrm{T}_{\infty}$ changes significantly since the workspace is not heated except by waste process heat. Ambient temperature was varied in 5 degree increments from $285 \mathrm{~K}$ to $315 \mathrm{~K}$ to determine its effect on fiber diameter. It was assumed that these small changes in ambient temperature would produce the same change in the bushing plate temperature, since the radiation and forced convection equations have been linearized and the physical properties for air remained nearly constant over such small temperature variations. At the same time, $\mathrm{r}_{\mathrm{E}}$ 
changed in the same direction as glass flow rate did. All other parameters were the same as those in the base case.

The change in the bushing plate temperature causes the glass flow rate through the nozzle to change, since glass viscosity is a strong function of glass temperature. If the winder speed is held constant, the fiber final diameter will thus also increase with higher ambient temperature. Note that this simulation assumes that furnace firing rates are controlled by measuring the temperature of the hot gases in the furnace rather than by measuring the bushing plate temperature. Most glass furnaces control firing rate by measuring crown temperature. Even if the plant measures bushing plate temperature, the thermal capacitance of the system guarantees a time lag on the order of hours for firing rate changes to compensate for a rapid change in ambient temperature.

When ambient temperature was $305 \mathrm{~K}$, To was $905{ }^{\circ} \mathrm{C}$, so $\mathrm{T}_{\mathrm{E}}$ was $767.49{ }^{\circ} \mathrm{C}$ (1040.64 K). The glass mass flow rate was $2.6635 \times 10^{-5} \mathrm{~kg} / \mathrm{s}, \mathrm{r}_{\mathrm{E}}$ was $3.31532 \times 10^{-4} \mathrm{~m}$. The winder speed was $13.6221 \mathrm{~m} / \mathrm{s}$ (149 RPM) and according to continuity equation, the final radius was $1.5858 \times 10^{-5} \mathrm{~m}$. C1 was -4.6056 , C2 was $-1.2738 \times 10^{-5}$, A was $6.4570 \times 10^{-8}$. After $0.5 \mathrm{~s}$ simulation, at $0.1605 \mathrm{~m}, \mathrm{~V}=13.6221 \mathrm{~m} / \mathrm{s}, \mathrm{r}=1.5828 \times 10^{-5} \mathrm{~m}$, $\mathrm{T}=786.75 \mathrm{~K}$.

When ambient temperature was $310 \mathrm{~K}$, To was $910{ }^{\circ} \mathrm{C}$, so $\mathrm{T}_{\mathrm{E}}$ was $765.84{ }^{\circ} \mathrm{C}$ (1038.99 K ). The glass mass flow rate was $2.9721 \times 10^{-5} \mathrm{~kg} / \mathrm{s}, \mathrm{r}_{\mathrm{E}}$ was $3.915952 \times 10^{-4} \mathrm{~m}$. The winder speed was $13.6221 \mathrm{~m} / \mathrm{s}$ (149 RPM) and according to continuity equation, the final radius was $1.6751 \times 10^{-5} \mathrm{~m}$. C1 was -4.1274 , C2 was $-1.1416 \times 10^{-5}$, A was 
$7.2051 \times 10^{-8}$. After $0.5 \mathrm{~s}$ simulation, at $0.1800 \mathrm{~m}, \mathrm{~V}=13.6221 \mathrm{~m} / \mathrm{s}, \mathrm{r}=1.6751 \times 10^{-5} \mathrm{~m}$, $\mathrm{T}=777.67 \mathrm{~K}$.

When ambient temperature was $315 \mathrm{~K}$, To was $915{ }^{\circ} \mathrm{C}$, so $\mathrm{T}_{\mathrm{E}}$ was $762.65{ }^{\circ} \mathrm{C}$ (1035.80 K ). The glass mass flow rate was $3.3112 \times 10^{-5} \mathrm{~kg} / \mathrm{s}, \mathrm{r}_{\mathrm{E}}$ was $4.878276 \times 10^{-4} \mathrm{~m}$. The winder speed was $13.6221 \mathrm{~m} / \mathrm{s}$ (149 RPM) and according to continuity equation, the final radius was $1.7681 \times 10^{-5} \mathrm{~m}$. C1 was -3.7047 , C2 was $-1.0247 \times 10^{-5}$, A was $8.0272 \times 10^{-8}$. After $0.5 \mathrm{~s}$ simulation, at $0.205 \mathrm{~m}, \mathrm{~V}=13.6221 \mathrm{~m} / \mathrm{s}, \mathrm{r}=1.7681 \times 10^{-5} \mathrm{~m}$, $\mathrm{T}=769.92 \mathrm{~K}$.

When ambient temperature was $295 \mathrm{~K}$, To was $895{ }^{\circ} \mathrm{C}$, so $\mathrm{T}_{\mathrm{E}}$ was $773.98{ }^{\circ} \mathrm{C}$ (1047.13 K ). The glass mass flow rate was $2.1288 \times 10^{-5} \mathrm{~kg} / \mathrm{s}$, $\mathrm{r}_{\mathrm{E}}$ was $2.1239834 \times 10^{-4}$ m. The winder speed was $13.6221 \mathrm{~m} / \mathrm{s}$ (149 RPM) and according to continuity equation, the final radius was $1.4177 \times 10^{-5} \mathrm{~m}$. C1 was -5.7625 , C2 was $-1.5938 \times 10^{-5}$, A was $5.1607 \times 10^{-8}$. After $0.45 \mathrm{~s}$ simulation, at $0.1252 \mathrm{~m}, \mathrm{~V}=13.6221 \mathrm{~m} / \mathrm{s}$, $\mathrm{r}=1.4177 \times 10^{-5} \mathrm{~m}, \mathrm{~T}=801.38 \mathrm{~K}$.

When ambient temperature was $290 \mathrm{~K}$, To was $890{ }^{\circ} \mathrm{C}$, so $\mathrm{T}_{\mathrm{E}}$ was $777.34{ }^{\circ} \mathrm{C}$ (1050.49 K). The glass mass flow rate was $1.8984 \times 10^{-5} \mathrm{~kg} / \mathrm{s}, \mathrm{r}_{\mathrm{E}}$ was $1.6925 \times 10^{-4} \mathrm{~m}$. The winder speed was $13.6221 \mathrm{~m} / \mathrm{s}$ (149 RPM) and according to continuity equation, the final radius was $1.3388 \times 10^{-5} \mathrm{~m}$. C1 was -6.4618 , C2 was $-1.7872 \times 10^{-5}$, A was $4.6022 \times 10^{-8}$. After $0.35 \mathrm{~s}$ simulation, at $0.109 \mathrm{~m}, \mathrm{~V}=13.6221 \mathrm{~m} / \mathrm{s}, \mathrm{r}=1.3388 \times 10^{-5} \mathrm{~m}$, $\mathrm{T}=809.81 \mathrm{~K}$.

When ambient temperature was $285 \mathrm{~K}$, To was $885{ }^{\circ} \mathrm{C}$, so $\mathrm{T}_{\mathrm{E}}$ was $781.24{ }^{\circ} \mathrm{C}$ (1054.39 K). The glass mass flow rate was $1.6901 \times 10^{-5} \mathrm{~kg} / \mathrm{s}, \mathrm{r}_{\mathrm{E}}$ was $1.32475 \times 10^{-4} \mathrm{~m}$. 
The winder speed was $13.6221 \mathrm{~m} / \mathrm{s}$ (149 RPM) and according to continuity equation, the final radius was $1.2632 \times 10^{-5} \mathrm{~m}$. C1 was -7.2584 , C2 was $-2.0076 \times 10^{-5}$, A was $4.0971 \times 10^{-8}$. After $0.35 \mathrm{~s}$ simulation, at $0.0877 \mathrm{~m}, \mathrm{~V}=13.6221 \mathrm{~m} / \mathrm{s}, \mathrm{r}=1.2632 \times 10^{-5} \mathrm{~m}$, $\mathrm{T}=831.20 \mathrm{~K}$.

\begin{tabular}{|r|r|l|l|l|l|l|l|}
\hline $\begin{array}{l}\text { Ambient } \\
\mathrm{T}(\mathrm{K})\end{array}$ & $\mathrm{TE}(\mathrm{K})$ & $\begin{array}{l}\text { Glass } \\
\text { flow } \\
\text { rate } \\
(\mathrm{kg} / \mathrm{s})\end{array}$ & $\mathrm{rE}(\mathrm{m})$ & $\begin{array}{l}\text { Final } \\
\text { radius } \\
(\mathrm{m})\end{array}$ & $\mathrm{C} 1$ & & \\
\hline 285 & 1054.4 & $1.69 \mathrm{E}-05$ & $1.32 \mathrm{E}-04$ & $1.26 \mathrm{E}-05$ & $-7.26 \mathrm{E}+00$ & $-2.01 \mathrm{E}-05$ & $4.10 \mathrm{E}-08$ \\
\hline 290 & 1050.5 & $1.90 \mathrm{E}-05$ & $1.69 \mathrm{E}-04$ & $1.34 \mathrm{E}-05$ & $-6.46 \mathrm{E}+00$ & $-1.79 \mathrm{E}-05$ & $4.60 \mathrm{E}-08$ \\
\hline 295 & 1047.1 & $2.13 \mathrm{E}-05$ & $2.12 \mathrm{E}-04$ & $1.42 \mathrm{E}-05$ & $-5.76 \mathrm{E}+00$ & $-1.59 \mathrm{E}-05$ & $5.16 \mathrm{E}-08$ \\
\hline 300 & 1044 & $2.38 \mathrm{E}-05$ & $2.67 \mathrm{E}-04$ & $1.50 \mathrm{E}-05$ & $-5.15 \mathrm{E}+00$ & $-1.42 \mathrm{E}-05$ & $5.78 \mathrm{E}-08$ \\
\hline 305 & 1040.6 & $2.66 \mathrm{E}-05$ & $3.32 \mathrm{E}-04$ & $1.59 \mathrm{E}-05$ & $-4.61 \mathrm{E}+00$ & $-1.27 \mathrm{E}-05$ & $6.46 \mathrm{E}-08$ \\
\hline 310 & 1039 & $2.97 \mathrm{E}-05$ & $3.92 \mathrm{E}-04$ & $1.68 \mathrm{E}-05$ & $-4.13 \mathrm{E}+00$ & $-1.14 \mathrm{E}-05$ & $7.21 \mathrm{E}-08$ \\
\hline 315 & 1035.8 & $3.31 \mathrm{E}-05$ & $4.88 \mathrm{E}-04$ & $1.77 \mathrm{E}-05$ & $-3.70 \mathrm{E}+00$ & $-1.02 \mathrm{E}-05$ & $8.03 \mathrm{E}-08$ \\
\hline
\end{tabular}

Table 3.1 Parameters in Variation of Ambient Temperatures 


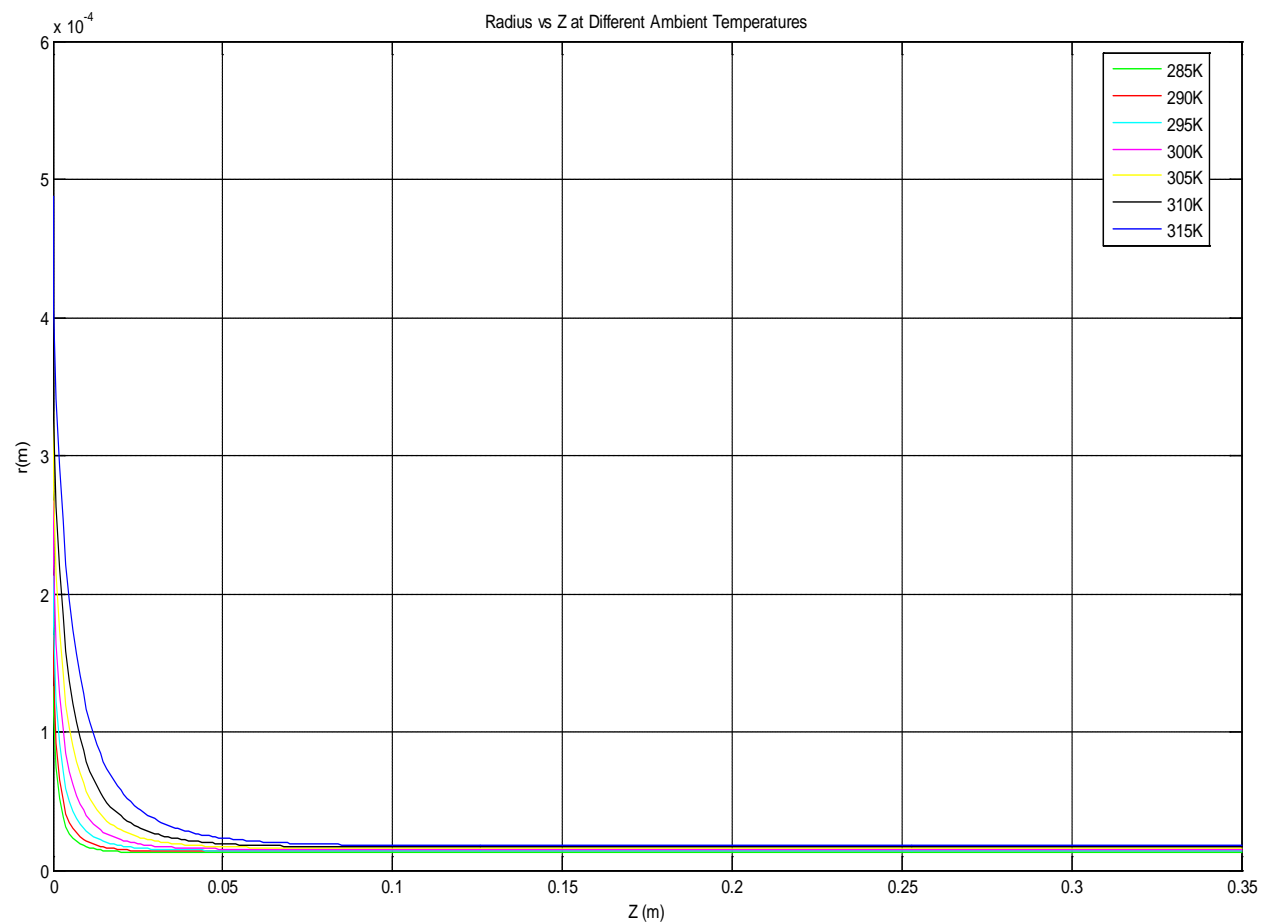

Figure 3.7 Radius vs Z at Different Ambient Temperatures

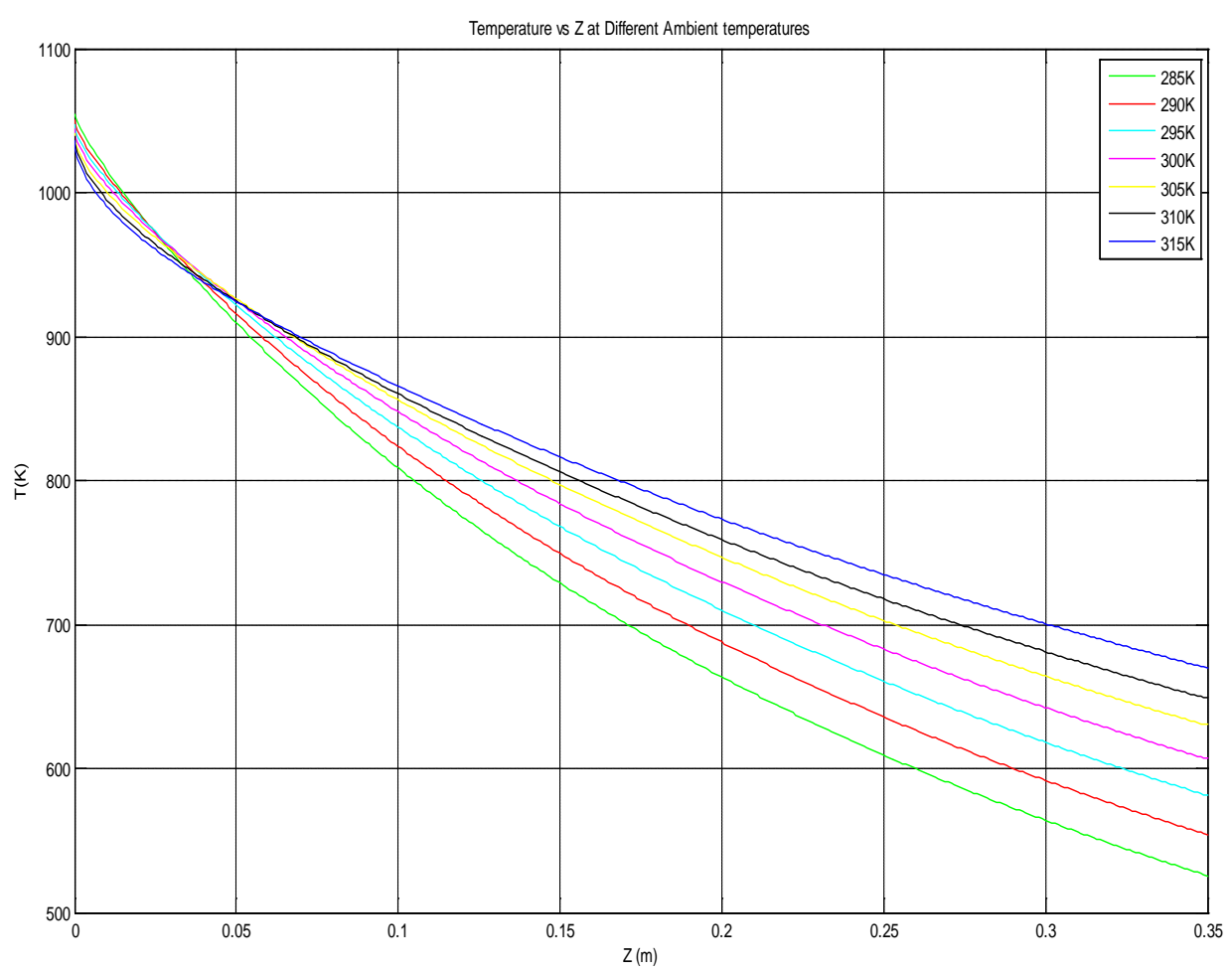

Figure 3.8 Fiber Temperature vs $\mathrm{Z}$ at Different Ambient Temperatures (1) 


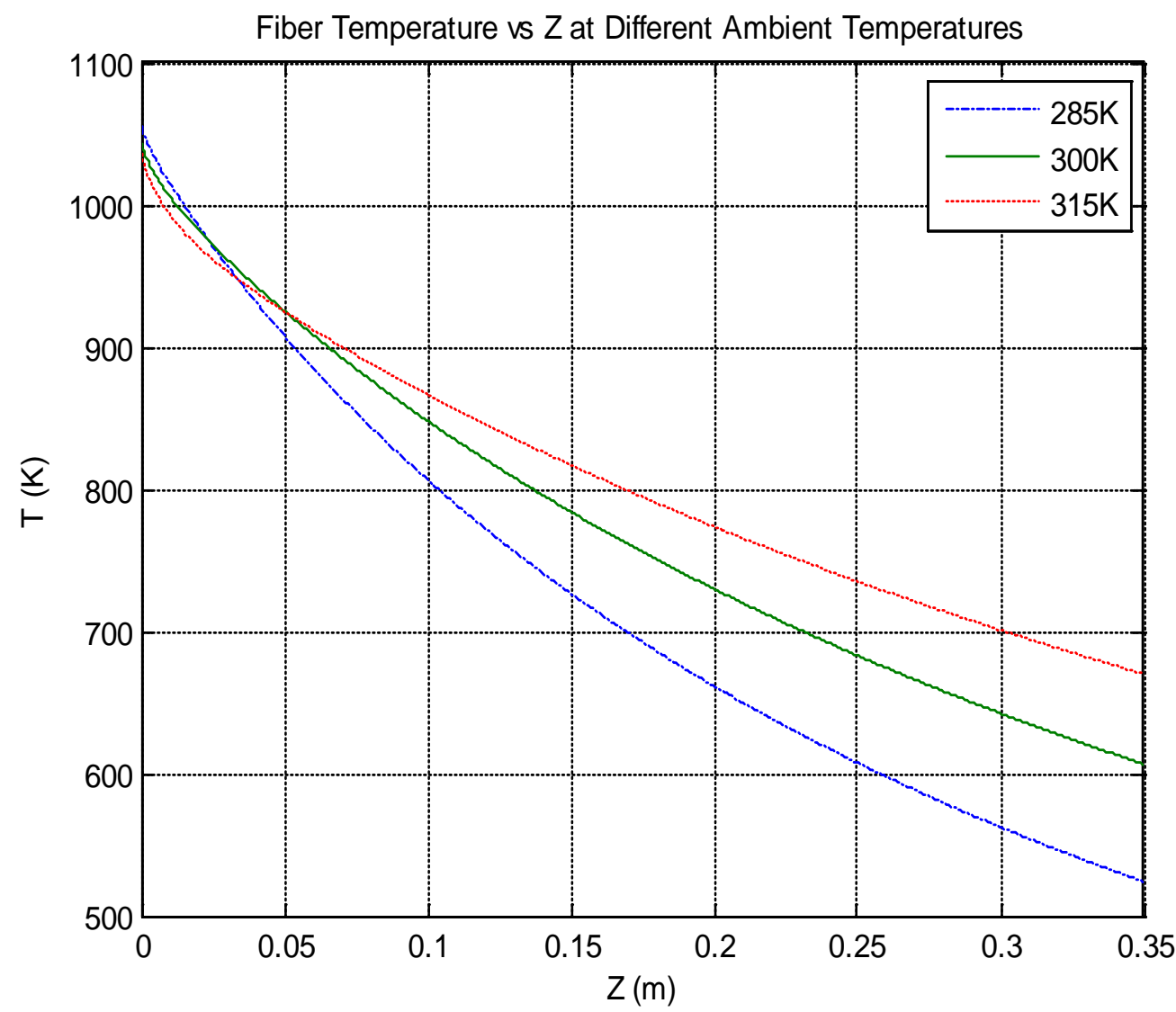

Figure 3.9 Fiber Temperature vs $\mathrm{Z}$ at Different Ambient Temperatures (2)

\section{Effect of Ambient Temperatures}

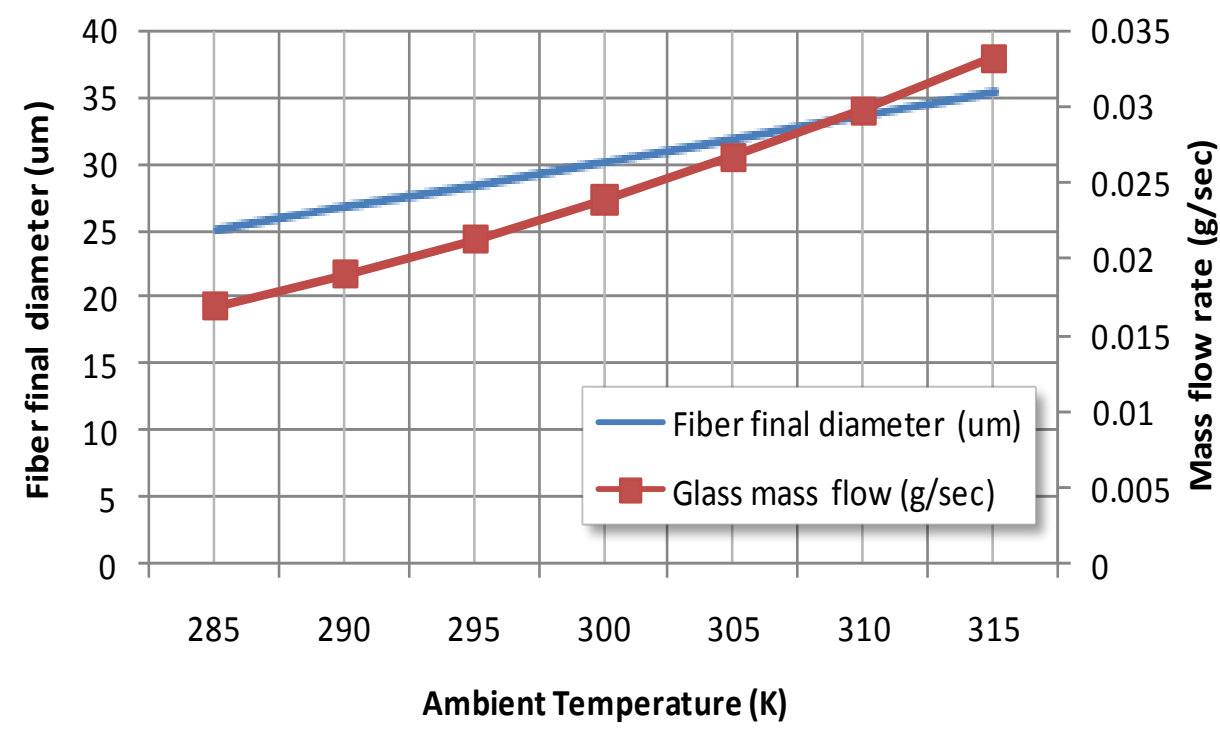


Figure 3.10 Effect of Ambient Temperature on Fiber Diameter and Production Rate

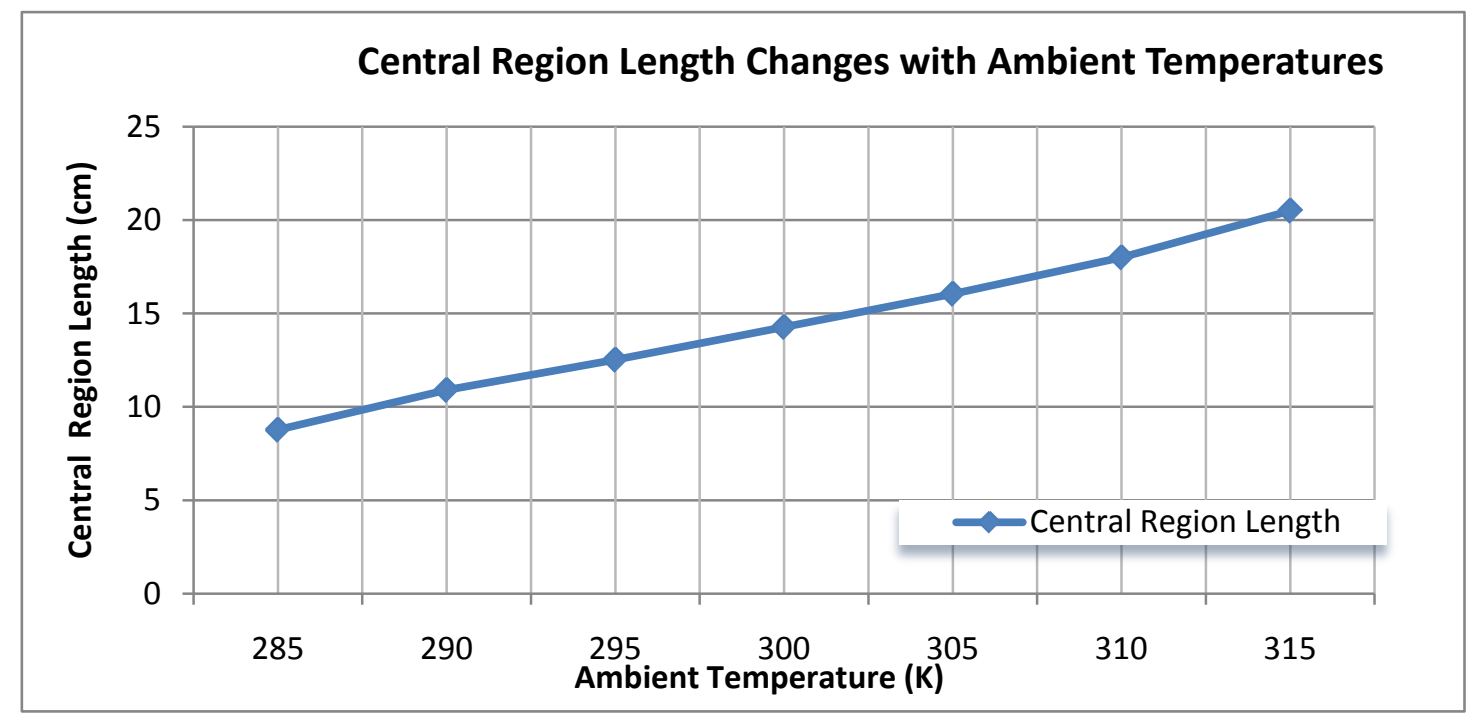

Figure 3.11 Central Region Length Changes with Ambient Temperatures

Figure 3.7 shows that the fiber radius versus $\mathrm{z}$ for various ambient temperatures. Figure 3.8 and 3.9 show the fiber temperature versus $\mathrm{z}$ for various ambient temperatures. Figure 3.10 shows the changes in glass mass flow rate and the resulting changes in fiber diameter for different ambient temperatures. Figure 3.11 shows the changes in the Central Attenuation Region length for different ambient temperatures. When ambient temperature increases, central attenuation region will also increase if there is no change for the winder speed.

It is known that the change in the bushing plate temperature causes the glass flow rate through the nozzle to change. In figure 3.10, it can be seen that if the winder speed is held constant, the fiber final diameter will thus also increase with higher ambient temperature and decrease with lower ones. However, it is desired to keep glass fiber quality during the process, even when ambient temperature changes. So it is necessary at least to keep the same final diameter for glass fibers as the one in base 
case. Since the winder speed is the key factor to control the final diameter of glass fibers, a controller was used to change the winder speed corresponding to ambient temperature changes. Figure 3.12 shows the control plot for the winder speed control when ambient temperature changes.

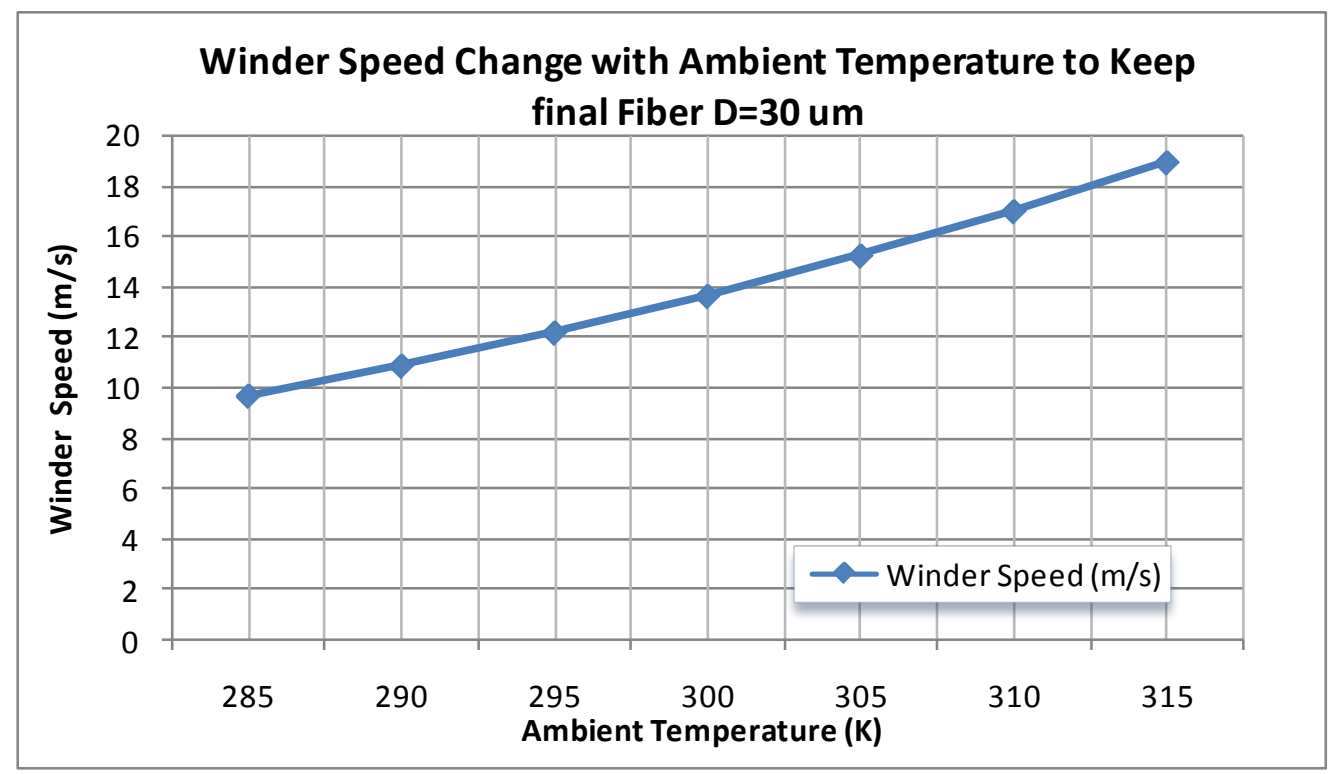

Figure 3.12 Winder Speed Required to Keep Final Fiber Diameter at 30 $\mathbf{m m}$ in Ambient Temperature Variation

\subsubsection{Variation of Molten Glass Depth in Furnaces}

In the base case, glass depth in the furnace was set at $8 \mathrm{~cm}$. Since furnace glass depth is constantly changing slightly, and since glass depth directly affects the flow rate of glass through the nozzles, a study of the furnace glass depth was also conducted. Simulations were run using furnace depths ranging from $6 \mathrm{~cm}$ to $10 \mathrm{~cm}$ in one-cm increments.

In the base case when molten glass depth was $8 \mathrm{~cm}$, after $0.5 \mathrm{~s}$ simulation, at $0.1427 \mathrm{~m}, \mathrm{~V}=13.6221 \mathrm{~m} / \mathrm{s}, \mathrm{r}=1.5 \times 10^{-5} \mathrm{~m}, \mathrm{~T}=793.29 \mathrm{~K}$. 
When molten glass depth was $9 \mathrm{~cm}$, To is $900{ }^{\circ} \mathrm{C}$, so $\mathrm{T}_{\mathrm{E}}$ was $764.07{ }^{\circ} \mathrm{C}$ (1037.22K). The glass mass flow rate was $2.6810 \times 10^{-5} \mathrm{~kg} / \mathrm{s}, \mathrm{r}_{\mathrm{E}}$ was $3.33962 \times 10^{-4} \mathrm{~m}$. Winder speed was $13.6221 \mathrm{~m} / \mathrm{s}$ (149 RPM) and according to continuity equation, the final radius was $1.5910 \times 10^{-5} \mathrm{~m}$. C1 was -4.5755 , C2 was $-1.2655 \times 10^{-5}$, A was $6.4995 \times 10^{-8}$. After 0.5 s simulation, at $0.1757 \mathrm{~m}$, $\mathrm{r}$ was $1.5910 \times 10^{-5} \mathrm{~m}$, T was $768.64 \mathrm{~K}$.

When molten glass depth was $10 \mathrm{~cm}$, To was $900{ }^{\circ} \mathrm{C}$, so $\mathrm{T}_{\mathrm{E}}$ was $758.73{ }^{\circ} \mathrm{C}$ (1031.88K). The glass mass flow rate was $2.9789 \times 10^{-5} \mathrm{~kg} / \mathrm{s}, \mathrm{r}_{\mathrm{E}}$ was $4.032531 \times 10^{-4} \mathrm{~m}$. Winder speed was $13.6221 \mathrm{~m} / \mathrm{s}$ (149 RPM) and according to continuity equation, the final radius was $1.6771 \times 10^{-5} \mathrm{~m}$. C1 was -4.1180 , C2 was $-1.1390 \times 10^{-5}$, A was $7.2217 \times 10^{-8}$. After $0.5 \mathrm{~s}$ simulation, at $0.21 \mathrm{~m}$, r was $1.6771 \times 10^{-5} \mathrm{~m}$, T was $747.48 \mathrm{~K}$.

When molten glass depth was $7 \mathrm{~cm}$, To was $900{ }^{\circ} \mathrm{C}$, so $\mathrm{T}_{\mathrm{E}}$ was $778.43{ }^{\circ} \mathrm{C}$ (1051.58K). The glass mass flow rate was $2.0853 \times 10^{-5} \mathrm{~kg} / \mathrm{s}, \mathrm{r}_{\mathrm{E}}$ was $2.048833 \times 10^{-4} \mathrm{~m}$. Winder speed was $13.6221 \mathrm{~m} / \mathrm{s}$ (149 RPM) and according to continuity equation, the final radius was $1.4031 \times 10^{-5} \mathrm{~m}$. C1 was -5.8828 , C2 was $-1.6271 \times 10^{-5}$, A was $5.0552 \times 10^{-8}$. After $0.4 \mathrm{~s}$ simulation, at $0.1115 \mathrm{~m}$, r was $1.4031 \times 10^{-5} \mathrm{~m}$, T was $822.17 \mathrm{~K}$.

When molten glass depth is $6 \mathrm{~cm}$, To was $900{ }^{\circ} \mathrm{C}$, so $\mathrm{T}_{\mathrm{E}}$ was $787.77{ }^{\circ} \mathrm{C}$ (1060.92K). The glass mass flow rate was $1.7874 \times 10^{-5} \mathrm{~kg} / \mathrm{s}, \mathrm{r}_{\mathrm{E}}$ was $1.51098 \times 10^{-4} \mathrm{~m}$. Winder speed was $13.6221 \mathrm{~m} / \mathrm{s}$ (149 RPM) and according to continuity equation, the final radius was $1.2990 \times 10^{-5} \mathrm{~m}$. C1 was -6.8633 , C2 was $-1.8983 \times 10^{-5}$, A was $4.3330 \times 10^{-8}$. After $0.35 \mathrm{~s}$ simulation, at $0.08 \mathrm{~m}$, $\mathrm{r}$ was $1.2990 \times 10^{-5} \mathrm{~m}$, T was $860.98 \mathrm{~K}$.

Figure 3.13 and 3.14 show the fiber temperature versus $\mathrm{z}$ for various glass depths. Figure 3.15 shows that the fiber radius versus $\mathrm{z}$ for various glass depths. Figure 3.16 
shows the changes in glass mass flow rate and the resulting changes in fiber diameter for different molten glass depths. Figure 3.17 shows the changes in the Central Attenuation Region length for different molten glass depths in the furnace. When molten glass depth increases, central attenuation region will also increase if there is no change for winder speed.

\begin{tabular}{|r|r|l|l|l|l|l|l|}
\hline $\begin{array}{l}\text { Molten } \\
\begin{array}{l}\text { Glass } \\
\text { Depth } \\
(\mathrm{cm})\end{array}\end{array}$ & & $\begin{array}{l}\text { Glass } \\
\text { flow } \\
\text { rate } \\
(\mathrm{kg} / \mathrm{s})\end{array}$ & $\mathrm{rE}(\mathrm{K})$ & $\begin{array}{l}\text { Final } \\
\text { radius } \\
(\mathrm{m})\end{array}$ & $\mathrm{C} 1$ & $\mathrm{C}$ & \\
\hline 6 & 1060.9 & $1.79 \mathrm{E}-05$ & $1.51 \mathrm{E}-04$ & $1.30 \mathrm{E}-05$ & $-6.86 \mathrm{E}+00$ & $-1.90 \mathrm{E}-05$ & $4.33 \mathrm{E}-08$ \\
\hline 7 & 1051.6 & $2.09 \mathrm{E}-05$ & $2.05 \mathrm{E}-04$ & $1.40 \mathrm{E}-05$ & $-5.88 \mathrm{E}+00$ & $-1.63 \mathrm{E}-05$ & $5.06 \mathrm{E}-08$ \\
\hline 8 & 1044 & $2.38 \mathrm{E}-05$ & $2.67 \mathrm{E}-04$ & $1.50 \mathrm{E}-05$ & $-5.15 \mathrm{E}+00$ & $-1.42 \mathrm{E}-05$ & $5.78 \mathrm{E}-08$ \\
\hline 9 & 1037.2 & $2.68 \mathrm{E}-05$ & $3.34 \mathrm{E}-04$ & $1.59 \mathrm{E}-05$ & $-4.58 \mathrm{E}+00$ & $-1.27 \mathrm{E}-05$ & $6.50 \mathrm{E}-08$ \\
\hline 10 & 1031.9 & $2.98 \mathrm{E}-05$ & $4.03 \mathrm{E}-04$ & $1.68 \mathrm{E}-05$ & $-4.12 \mathrm{E}+00$ & $-1.14 \mathrm{E}-05$ & $7.22 \mathrm{E}-08$ \\
\hline
\end{tabular}

Table 3.2 Table 3.2 Parameters in Variation of Molten Glass Depth

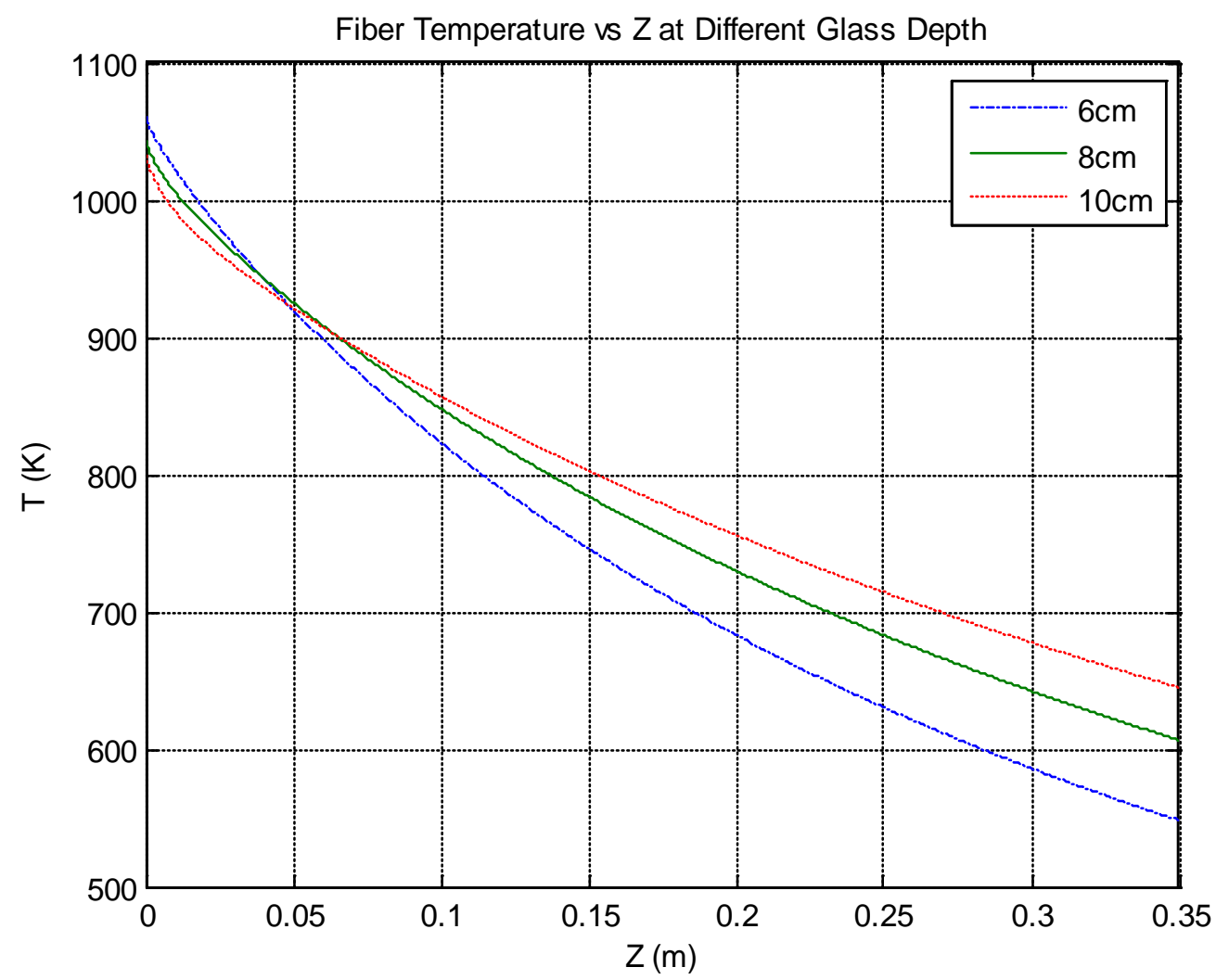

Figure 3.13 Fiber Temperature vs Z at Different Glass Depths (1) 


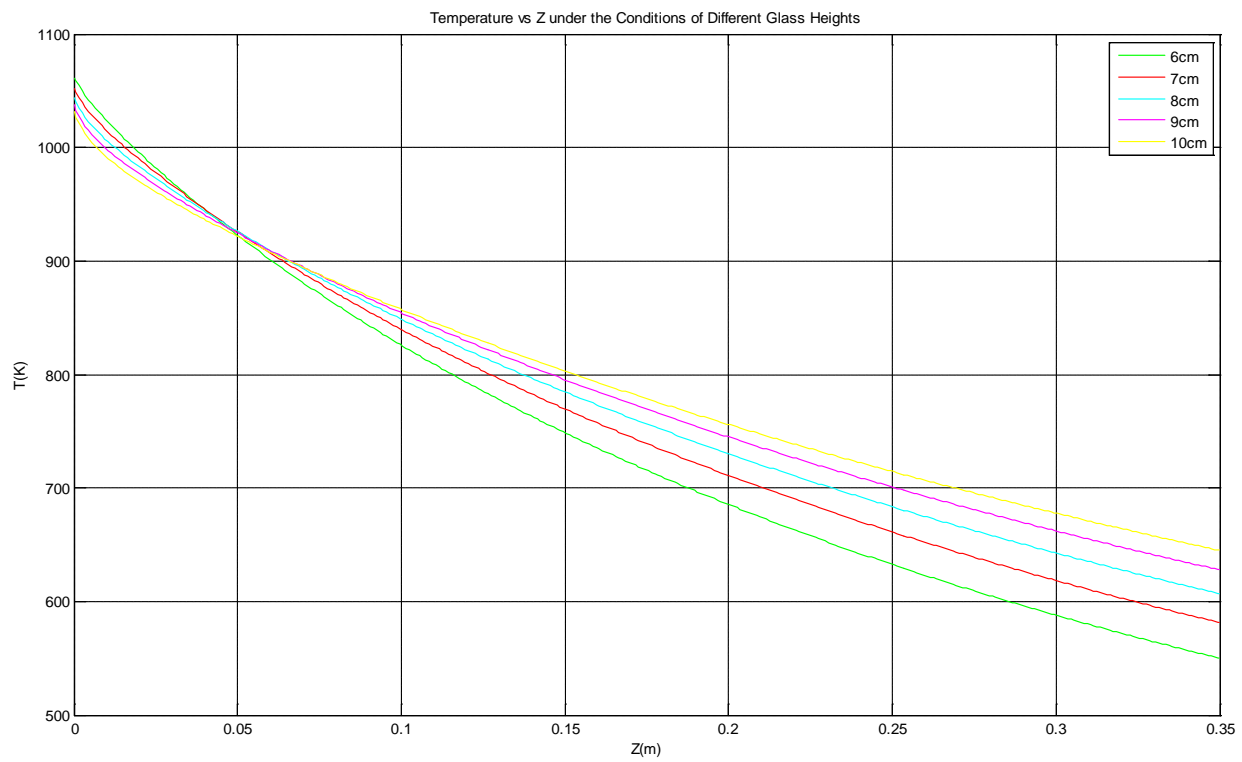

Figure 3.14 Fiber Temperature vs Z at Different Glass Depths (2)

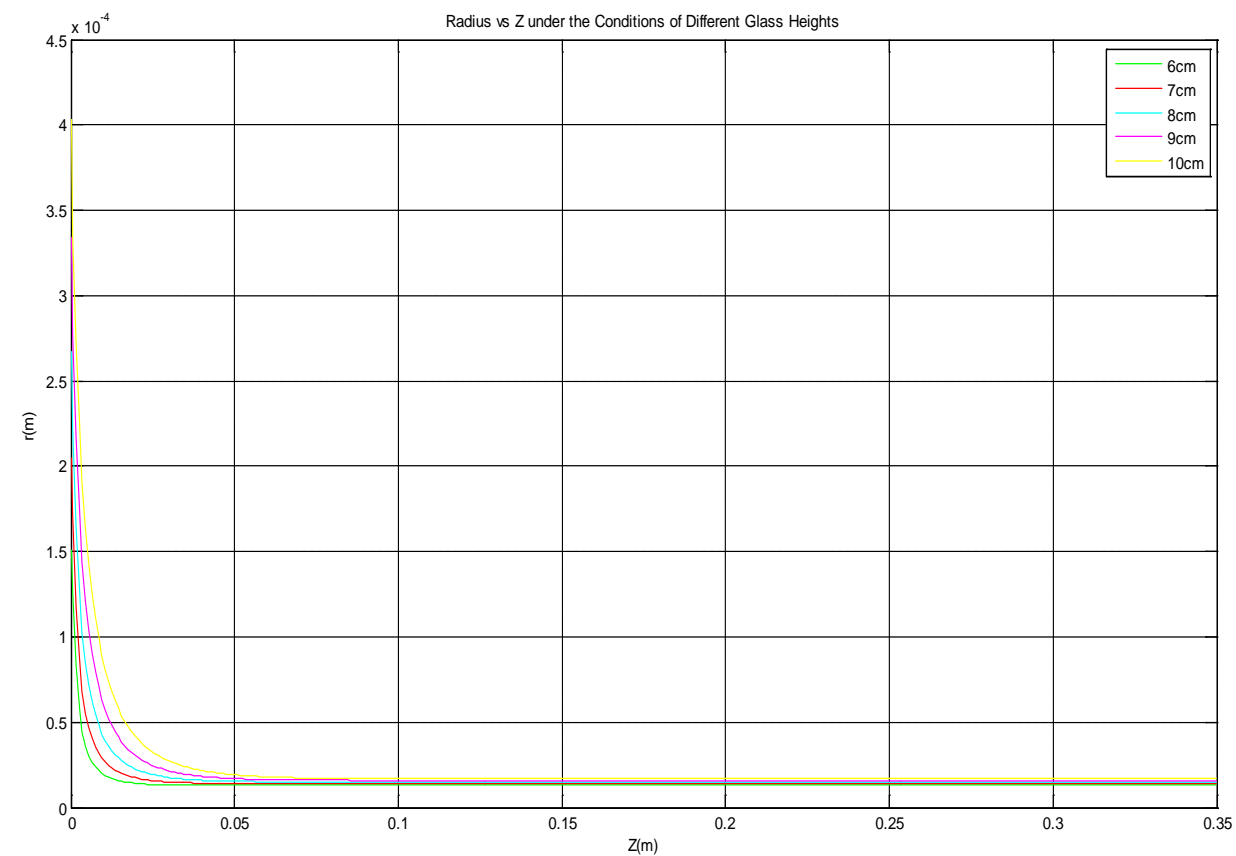

Figure 3.15 Radius vs Z at five Different Glass Depths 


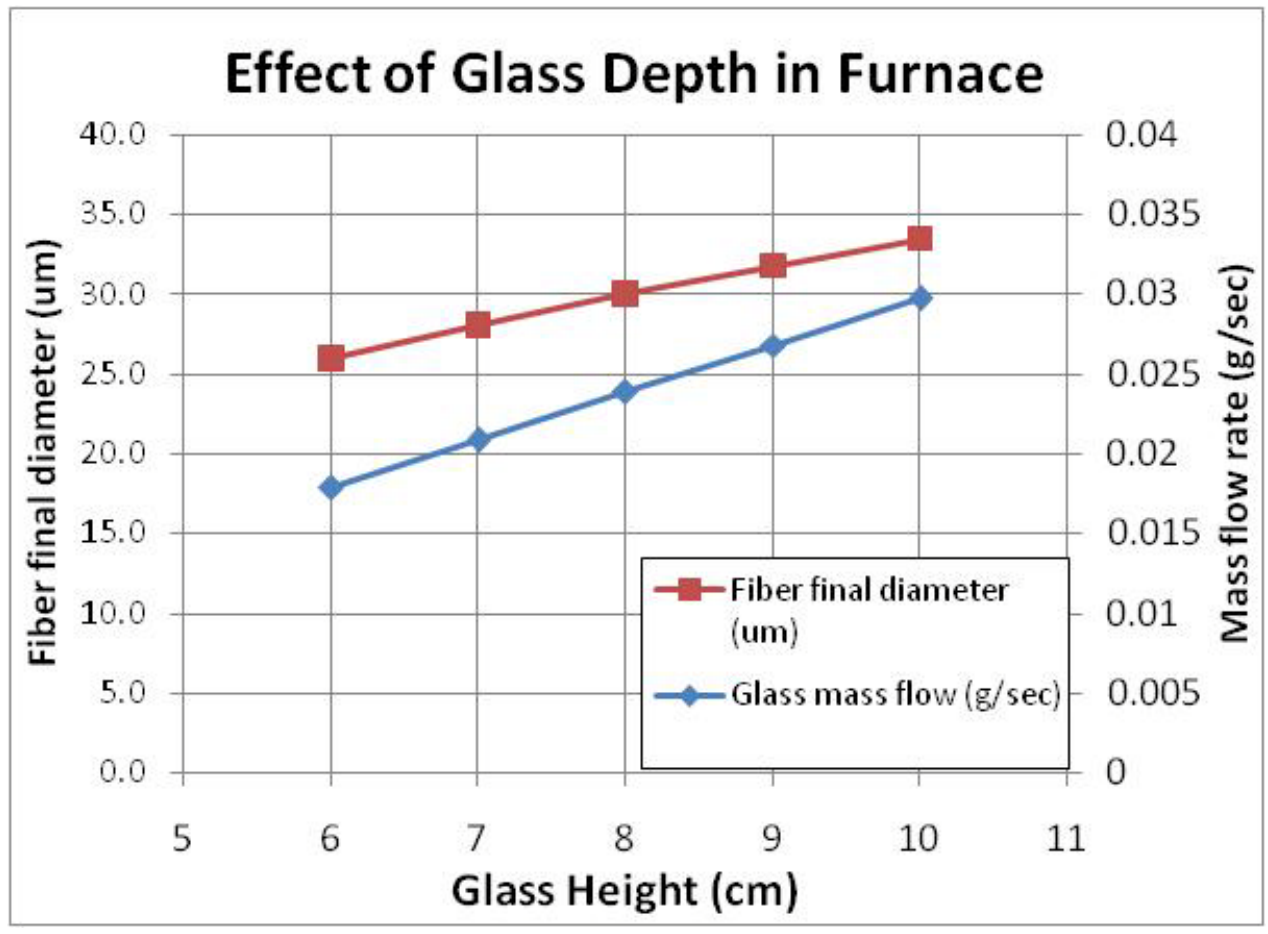

Figure 3.16 Effect of Glass Depth in the Furnace

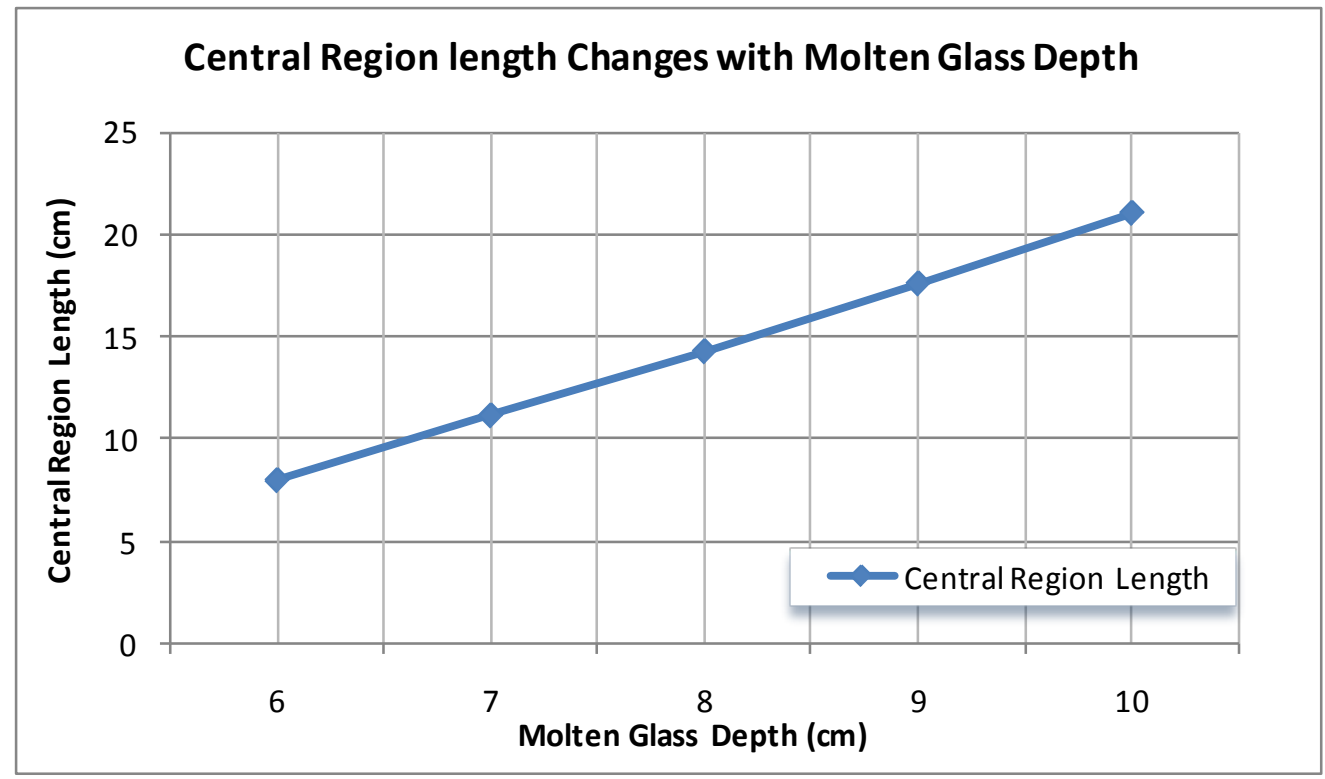

Figure 3.17 Central Region Length Changes with Molten Glass Depths

It is assumed that when molten glass depth changes, the bushing plate keeps the same temperature as the one in base case. While the change in molten glass depth caused the glass flow rate through the nozzle to change, which can be seen in Figure 3.16 clearly. Also in Figure 3.16, when winder speed was held constant as $13.6 \mathrm{~m} / \mathrm{s}$, the fiber final diameter increased with higher molten glass depths or decreased with 
lower ones. In order to keep glass fiber quality during the process, even when molten glass depth changes, it is necessary to keep the same final diameter for glass fibers as the one in base case. Since winder speed is the key factor to control the final diameter of glass fibers, a controller was used to change winder speed corresponding to molten glass depth changes. Figure 3.18 shows the control plot for winder speed control when molten glass depth changes.

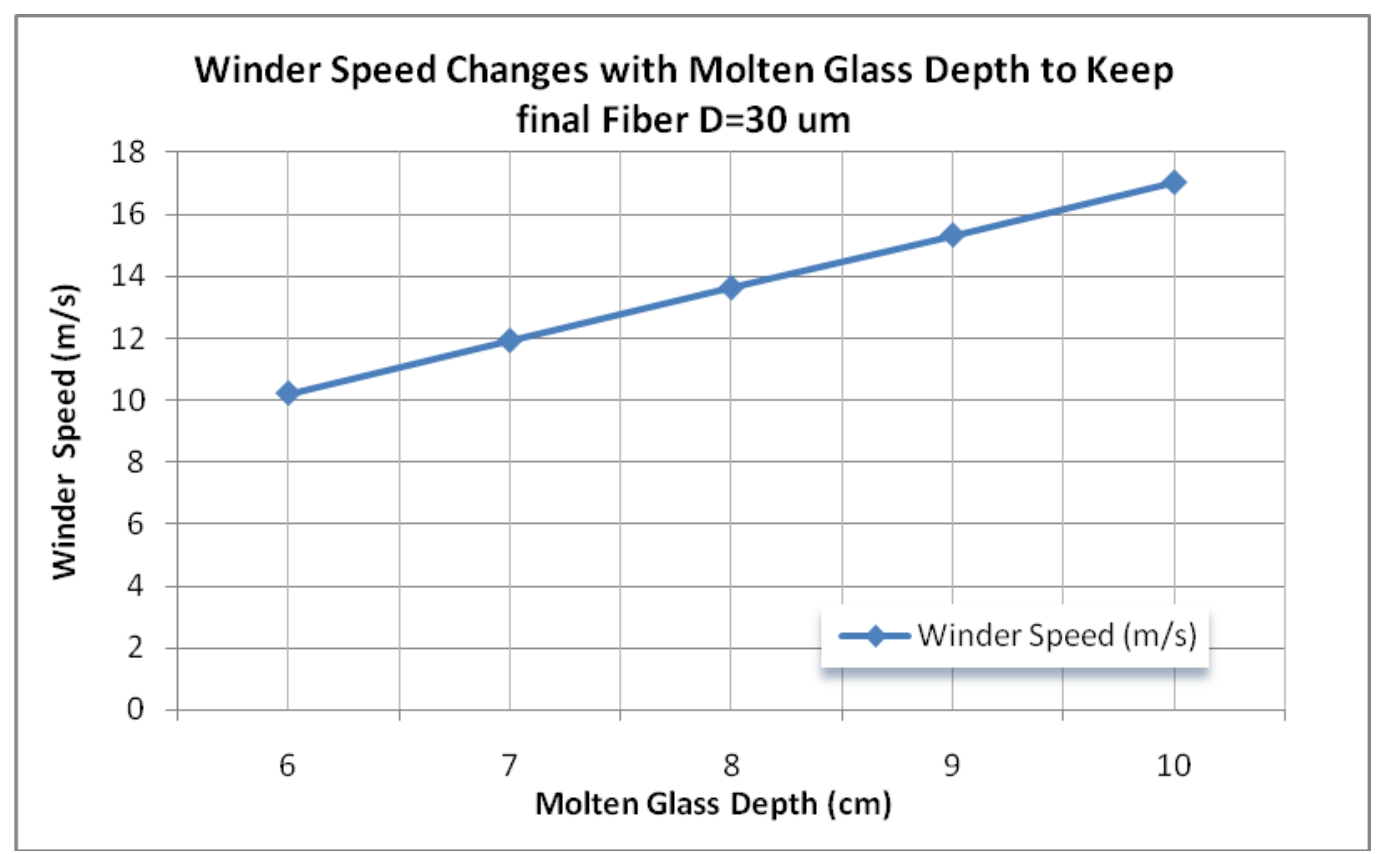

Figure 3.18 the Winder speed Required to Keep Final Fiber Diameter at 30um in Molten Glass Depth Variation

\subsubsection{Conclusion}

Parametric analysis has been done in variation of ambient temperature and molten glass depth, and the detailed plots are shown in Appendix C. These studies have shown that even modest changes in ambient temperature can generate significant changes in the diameter of the glass fiber. Variations in the depth of the molten glass 
in the furnace can have similar effects on the fiber diameter. Fortunately, it is proved that it could be relatively easy to compensate for these disturbances by controlling the speed of the winder.

For example, when ambient temperature increases, and the winder speed is constant, glass mass flow rate and the final diameter increase. At the same time, the central attenuation region becomes longer than the one in base case. In order to get the system back to normal, several methods can be done. Firstly to increase the winder speed; secondly to increase cooling water flow rate in order to cool down the bushing plate. Other situations are similar.

Obviously, it is desirable to regulate the burner to bring the process back to the design conditions, but the thermal time constants are very long in these systems and it was proposed that a coordinated controller that can manipulate both the winder speed and the burner firing rate be developed to allow greater flexibility and more accurate quality control. Further work focused on the modeling of the furnace and burner, and the development of a comprehensive controller for the system.

\subsection{Estimator Based LQR Control Glass Furnace Model}

In the production of continuous fibers, temperature of the molten glass layer contacting the bushing plate is essential for the quality of fibers. However, the temperature is sensitive to conditions like ambient temperature, molten glass depth in the furnace and others. If some disturbance happens, instabilities occur which cause variation in the final glass fiber and interruption of the process when fibers break. 
While there have been studies on temperature control in huge furnaces in the open literature, no studies have been published on the multivariable control of the glass temperature for the small furnace in fiber-glass manufacture.

In the previous work, the parametric analysis has been done for the glass fiber drawing process in order to perform effective control. In this chapter, a LQR control model is developed based on reduced order estimator for small glass furnace. Based on the model, multivariable control analysis is performed to obtain the desired molten glass temperature near to the bushing plate and winder speed when common disturbances occur such as changes in ambient temperature or glass depth in the furnace.

\subsubsection{Control Model for the Glass Furnace}

\subsubsection{Simplified Glass Furnace Model}

In Figure 2.5 black body radiation spectrum (reproduced from [2.14]), it is obvious that at different temperatures, energy in different wavelength range is different. Calculated by our blackbody spectrum model (Please check the Appendix D Black Body Spectrum Calculation for detail), at no preheat condition (around 2100K), there is $76.17 \%$ energy in the wavelength range from 0 to $3 \mu \mathrm{m}$, and $16.19 \%$ energy in the range from 3 to $5 \mu \mathrm{m}$, and only $7.62 \%$ energy in the range from $5 \mu \mathrm{m}$ to infinity.

Optical thickness is introduced in Chapter 2, and it is used to define molten glass layers in our furnace model. According to Figure 2.4 Gardon’s Spectral Absorption 
Coefficients of Window Glass[2.12], Figure 2.5 black body radiation spectrum [2.14] and Figure 2.7 Prokhorenko 's data [2.15], average optical thickness values can be gotten for three wavelength ranges 0-3 $\mu \mathrm{m}, 3-5 \mu \mathrm{m}, 5-\infty \mu \mathrm{m}$. By using energy percentage for each wavelength range, I can approximately get average optical thickness $3.85 \mathrm{~cm}$ for whole spectrum.

In our case, glass furnaces are small and periodically-fed type, based on a sensor that measures melt depth. Only less than $1 \%$ of the whole glass in the furnace is fed into the furnace in one cycle. So it is reasonable to consider that glass furnaces in my case are continuous type. Each feeding definitely gives some disturbance to my control system, which will be considered as molten glass depth variation later in my control analysis.

The furnaces are cylinder-shape with ellipse cross sections. In the normal condition, molten glass depth is about $10.2 \mathrm{~cm}$ ( 4 inches).

A simplified analytical model was developed by defining several layers or zones in glass furnaces. In the furnace, all the combustion gas volume is defined as Zone a. The rest part in the furnace is molten glass, which absorbs heat energy mainly by radiation heat transfer from the burner and combustion gas. Because of optical thickness property, molten glass doesn't absorb heat energy uniformly in different depths. By using optical thickness value, three glass layers were defined as b, c, d from top to bottom with thickness $3.85 \mathrm{~cm}, 3.85 \mathrm{~cm}, 2.46 \mathrm{~cm}$ respectively. There is a refractory layer as furnace outside shell. The last zone is the bushing plate. So there are six zones or layers totally in my simplified furnace model. 


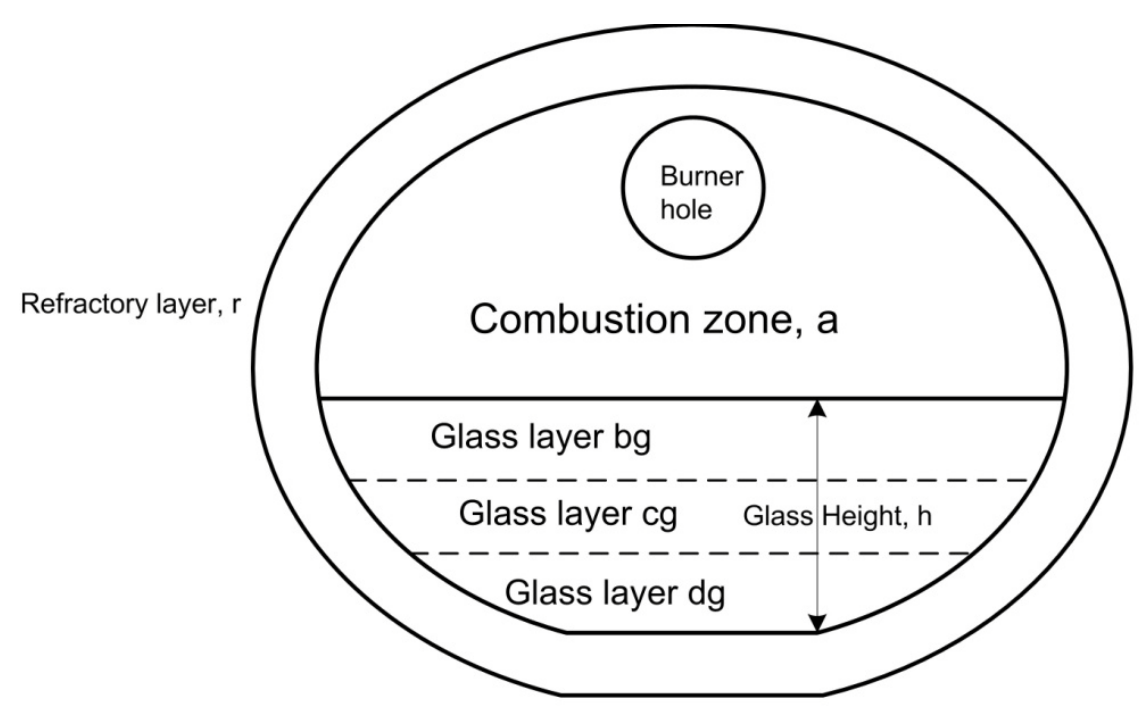

View from feed end

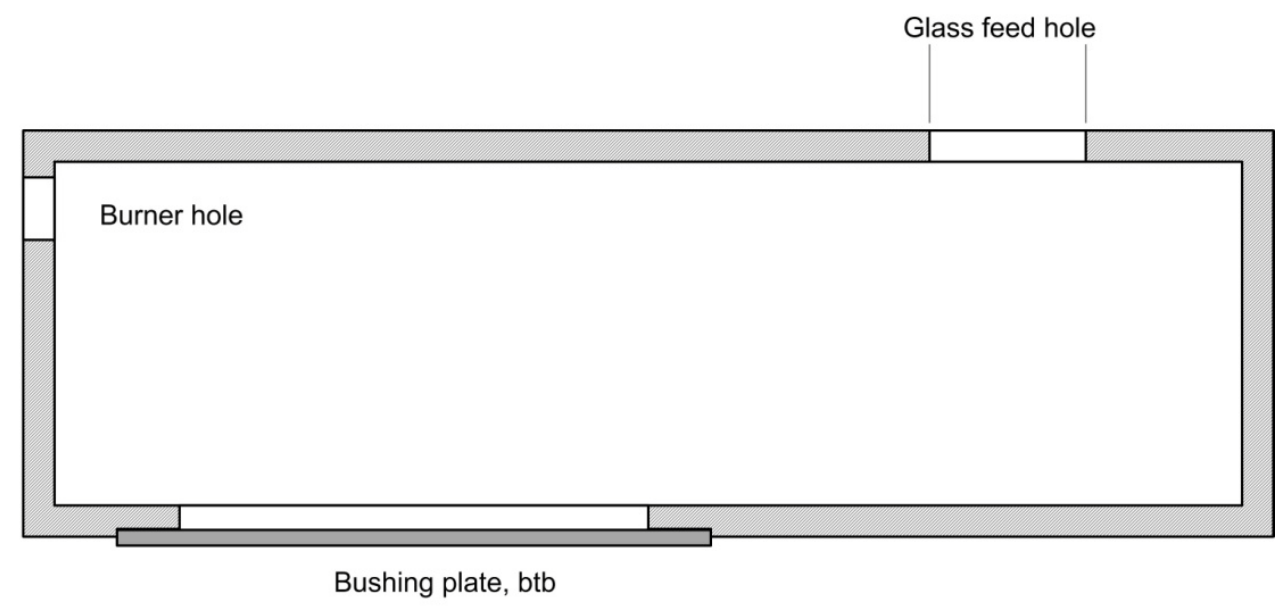

Side View, sectioned through center

\section{Figure 3.19 Small Fiber Glass Furnace with Zones}

Effectively controlling the glass temperature near the bottom of the furnace, which is $d$ glass layer temperature $T_{d g}$, is the main aim in my control system model. Currently in the object company, only the crown temperature $T_{a}$ is measured by using thermocouples. However, the difference between $T_{d g}$ and $T_{a}$ can be large, due to the much longer time constants for the glass temperature versus the crown temperature, and due to heat loss from the bushing plate from radiation and convection. The 
temperature of the glass is the critical process parameter, rather than the temperature of the crown. However, existing technology required to measure the glass temperature directly is expensive. For example, infrared temperature sensing systems capable of the necessary temperature range cost in the order of $\$ 10,000-12,000$ per furnace to implement. In addition, the sensors should be protected from high process temperatures, usually with a compressed air supply, adding to the maintenance cost of the system [2.43]. All the expense would not be feasible for small glass companies, so an estimator based control method is a good choice for them.

In our case, an estimator was designed based on available temperature of combustion gas in the crown $T_{a}$ and the bushing plate temperature $T_{b t b} \cdot T_{a}$ was measured by installing some thermocouples in the combustion zone, while $\mathrm{T}_{\mathrm{btb}}$ was measured by some infrared sensors pointing to some representative points on the bushing plate. $\mathrm{T}_{\text {btb }}$ was measured using an infrared (IR) camera (Mikron Technologies model 7515). The camera is able to measure temperatures up to $2500 \mathrm{~F}$ with a resolution of 1 F. Spot checks also were made using an IR Pyrometer (Minolta/Land model Cyclops 152), but the camera provided imaging capability that was very useful in assessing the influence of water flow rate on the temperature distribution of the bushing plate. Figure 3.20 is one of the bushing plate temperature distribution images taken with the IR camera. 


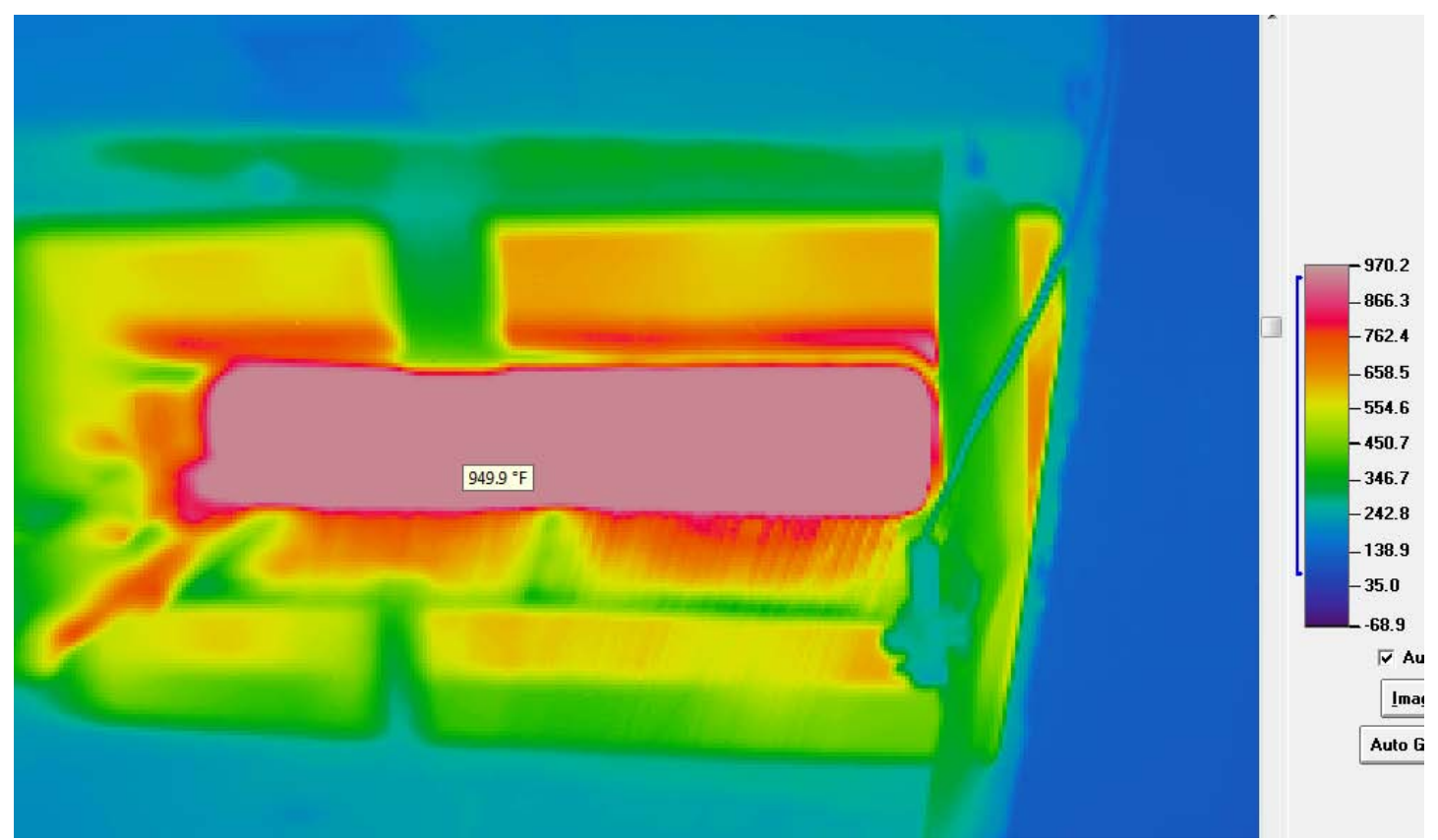

Figure 3.20 Testing Picture from the Mikron Infrared Camera

According to those measurement data, other temperatures in the model can be estimated by an estimator.

\subsubsection{State Space Model for the Glass Furnace}

Before development of state space model, the following assumptions are made:

1. In the furnace, there are three glass layers and one zone, and temperature is uniform in each volume. Constant molten glass transfers from high temperature layer to low temperature layer during the process, and assume that it changes to low layer temperature in a very short time.

2. Assume that temperature $\operatorname{Tr}$ is uniform in refractory layer. Outside refractory layer, assume that there is a perfect thermal insulation layer and no heat transfer between the refractory layer and the thermal insulation layer.

3. Temperature is uniform on the bushing plate as $\mathrm{T}_{\mathrm{btb}}$. 
4. Convection heat transfer effect in molten glass is counted in conduction by increasing conduction coefficient.

5. Glass mass flow rate and molten glass depth in the furnace are assumed constant in simulation because matrix $A$ is not sensitive to small glass flow rate changes. (Please check Appendix E for details)

Following with Holladay's and Morris's idea, the radiation heat transfer equation was linearized. The heat transfer equations are:

$$
\begin{array}{cc}
Q=C \frac{d T}{d t}=\frac{A}{R}(S F)\left(T_{1}-T_{2}\right) & R=\frac{1}{4 \sigma \varepsilon \bar{T}^{3}} \quad \bar{T}=0.5\left(T_{1}+T_{2}\right) \\
Q=C \frac{d T}{d t}=\frac{A}{R^{\prime}}\left(T_{1}-T_{2}\right) & R^{\prime}=\frac{L}{k} \\
Q=C \frac{d T}{d t}=\frac{A}{R^{\prime \prime}}\left(T_{1}-T_{2}\right) & R^{\prime \prime}=\frac{1}{\bar{h}}
\end{array}
$$

where SF is shape factor, $\varepsilon$ is glass emissivity , $\sigma$ is the Stefan-Boltzmann constant, $5.67 \times 10^{-8} \mathrm{~W} / \mathrm{m}^{2} * \mathrm{~K}^{4}$. L is length of two ends, $\mathrm{k}$ is glass thermal conductivity coefficient $\mathrm{W} / \mathrm{m}^{2} * \mathrm{~K}^{4}, \bar{h}$ is average air convection coefficient $\mathrm{W} / \mathrm{m}^{2} * \mathrm{~K}^{4}$.

There is a gas burner in combustion zone a, so the combustion equation is $\dot{Q}_{\text {fuel }}=\dot{Q}_{\text {comb }}-\dot{Q}_{\text {loss }}$

$$
\dot{Q}_{\text {fuel }}=\dot{m}_{\text {fuel }}\left[L H V-\left(1+\frac{A}{F}\right) c_{a}\left(T_{a}-T_{\infty}\right)\right]
$$

where $\dot{Q}_{\text {comb }}$ is the energy available from combustion $\mathrm{J}, \dot{Q}_{\text {loss }}$ is the stack energy loss, $\dot{Q}_{\text {fuel }}$ is the energy available to the process, Ta is the measured temperature of the combustion (stack) gases, LHV is the lower heating value of methane $(49770 \mathrm{~kJ} / \mathrm{kg})$, $\mathrm{A} / \mathrm{F}$ is the air fuel ratio. The stoichiometric value of 19.0 was used for the simulations. 
$\mathrm{c}_{\mathrm{a}}$ is the approximated specific heat of the combustion gas.

In order to develop state space representation and simplify the model, I chose six state variables as $\mathrm{Tbg}^{*}=\mathrm{Tbg}-\mathrm{T} \infty, \mathrm{Tcg}{ }^{*}=\mathrm{Tcg}-\mathrm{T} \infty, \mathrm{Tdg}^{*}=\mathrm{Tdg}-\mathrm{T} \infty, \mathrm{Tr}{ }^{*}=\mathrm{Tr}-\mathrm{T} \infty$, Ta*=Ta $-\mathrm{T} \infty$, Tbtb*=Tbtb - T $\infty$. After linearization at the steady point $\left(\dot{m}_{\text {fuel }}, T_{a}^{*}\right)=(\mathrm{h}$,

i) for (3-16), I set $\dot{m}_{\text {fuel }} *=\dot{m}_{\text {fuel }}+\frac{\left(1+\frac{A}{F}\right) h i c_{a}}{L H V-\left(1+\frac{A}{F}\right) i c_{a}}=\dot{m}_{\text {fuel }}+\dot{m} c$ as our input, then got

$$
\begin{aligned}
& \dot{Q}_{\text {fuel }}=\left[L H V-\left(1+\frac{A}{F}\right) c_{p s} i\right] \dot{m}_{\text {fuel }}-\left(1+\frac{A}{F}\right) c_{p s} h T_{a} *+\left(1+\frac{A}{F}\right) c_{p s} h i \\
& =\left[L H V-\left(1+\frac{A}{F}\right) c_{p s} i\right] \dot{m}_{\text {fuel }} *-\left(1+\frac{A}{F}\right) c_{p s} h T_{a} *
\end{aligned}
$$

where $\mathrm{h}$ is fuel flow rate at the steady state, $\mathrm{kg} / \mathrm{s}, \mathrm{i}$ is Ta* value at the steady state.

In the combustion gas layer a, the energy equation is :

$$
\begin{aligned}
& \frac{d T_{a} *}{d t}=\frac{A_{a-b g}}{R_{a-b g} C_{a}}\left(S F_{a-b g}\right) T_{b g} *+\frac{A_{a-s a}}{R_{a-s a} C_{a}}\left(S F_{a-s a}\right) T_{r} *- \\
& {\left[\frac{A_{a-b g}}{R_{a-b g}}\left(S F_{a-b g}\right)+\left(1+\frac{A}{F}\right) C_{a} h+\frac{A_{a-s a}}{R_{a-s a} C_{a}}\left(S F_{a-s a}\right)\right] \frac{T_{a} *}{C_{a}}+\left[L H V-\left(1+\frac{A}{F}\right) C_{a} i\right] \frac{\dot{m}_{\text {fuel }}}{C_{a}}}
\end{aligned}
$$

where $\dot{m}_{\text {fuel }}=h=0.00012603 \mathrm{~kg} / \mathrm{s}, \mathrm{Ta}=1240 \mathrm{~K}, \mathrm{~T} \infty=300 \mathrm{~K}, \mathrm{Ta} * \mathrm{i}=\mathrm{Ta}-\mathrm{T} \infty=940 \mathrm{~K}$, $\mathrm{Ca}=\mathrm{ca} * \mathrm{ma}$, ca is combustion gas specific heat, $\mathrm{J} / \mathrm{kg} \operatorname{deg} \mathrm{K}$.

There are still another five energy equations corresponding to another five state variables (please check Appendix F for detail). Then we put all six equations to get state space representation [3.9]:

$$
\dot{x}=A x+B u \quad y=C x+D u \quad z=G x+H u
$$

The state variable vector $\dot{x}$ is $\left[T_{b g} *, T_{c g} *, T_{d g} *, T_{r} *, T_{a} *, T_{b t b} *\right.$ ]', and the input 
vector is $\mathrm{u}=\left[\begin{array}{r}\dot{m}_{\text {fuel }} \\ ]\end{array}\right]$, the measured output vector is $\mathrm{y}=\left[T_{a} *, T_{b t b} *\right]$ ', the controlled output vector is $\mathrm{z}=\left[T_{d g} *\right]$. So matrix $\mathrm{A}$ is $6 \times 6$ size , $\mathrm{B}$ is $6 \times 1, \mathrm{C}$ is $2 \times 6$, D is $2 \times$ 1 null matrix, $\mathrm{G}$ is $1 \times 6, \mathrm{H}$ is $1 \times 1$. According to our experiment data, at the steady state, Tbg=1209K, Tcg=1195K, Tdg=1177K, Tr=1236K, Ta=1240K, Tbtb=1173K. We set normal initial condition X1 [900;850;800;800;900;800] for the state variable vector, which is near to steady state values of state variables. Then we set another four initial condition vectors $\mathrm{X} 2, \mathrm{X} 3, \mathrm{X} 4, \mathrm{X} 5$. X2, X3 are 10 degree higher or lower than $\mathrm{X} 1$, and X4, X5 are 50 degree higher or lower than X1.

There were six differential equations and state space representation was used to build the model. First of all, A,B,C,D needed to be calculated. Steady state value for fuel flow rate h was difficult to get. So a simple Simulink ${ }^{\mathrm{TM}}$ model was developed, shown in Figure 3.21. By using constant fuel flow rate as input, we got all the temperature values when the system was in steady state. According to above temperature values at steady state, we got h value after several simulations. 


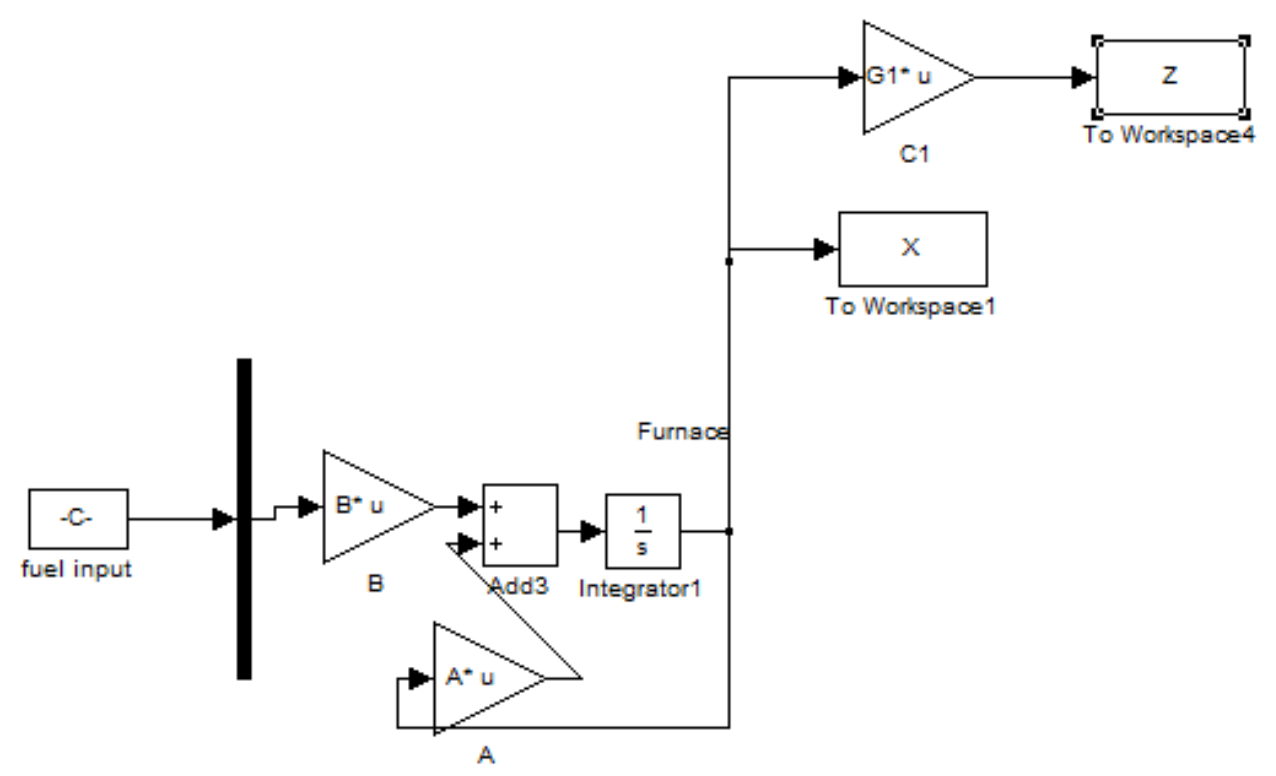

Figure 3.21 Simulink ${ }^{\mathrm{TM}}$ Model for Temperature Verification in the Steady State

\subsubsection{LQR Controller with a Reference Input}

After state space model was developed, control strategy was chosen. Poiseuille’s Law (or Hagen-Poiseuille Law) may be expressed in the following form [2.17]:

$$
\phi=\frac{d V}{d t}=\bar{v} \pi R^{2}=\frac{\pi R^{4}}{8 \eta}\left(\frac{-\Delta P}{\Delta x}\right)=\frac{\pi R^{4}}{8 \eta} \frac{|\Delta P|}{l}
$$

where $\mathrm{l}$ is the total length of the tube in the $\mathrm{x}$ direction, $\mathrm{mm}$; $\mathrm{R}$ is radius of nozzles, $\mathrm{cm} ; \quad \eta$ is the dynamic fluid viscosity in the nozzle, Pa*sec. $\eta$ is a strong function of temperature of the lowest molten glass zone (Tdg in my case) and final size of glass fibers is determined by flow rate calculated by Equation 2-9 and the winder speed. So Tdg is very important for the quality of glass fibers. I had to control Tdg and kept it to the set point in order to get desired final diameter for glass fibers.

After simplification, my system was SISO, one input ( $\dot{m}_{\text {fuel }}$, fuel flow rate) one 
output (Tdg, temperature of d glass zone). We used Linear Quadratic Regulation (LQR) with reference input to design the controller. LQR is a most effective and widely used technique of linear control systems. The standard form is [3.10]:

$$
J=\int_{0}^{\infty}\left(x^{T} Q x+u^{T} R u\right) d t
$$

$\mathrm{r}=1177 \mathrm{~K}$ was given as a set-point for state variable Tdg, and LQR controller was design to drive Tdg to converge as fast as possible to r, not zero. This can be achieved by making the state $\mathrm{x}$ and the input $\mathrm{u}$ of the process (3-21) converge to value $\mathrm{x}^{*}$ and $\mathrm{u}^{*}$ for which [3.9]

$$
\begin{aligned}
& A x^{*}+B u^{*}=0, \quad r=G x^{*}+H u^{*} \\
& {\left[\begin{array}{ll}
A & B \\
G & H
\end{array}\right]\left[\begin{array}{l}
x^{*} \\
u^{*}
\end{array}\right]=\left[\begin{array}{l}
0 \\
r
\end{array}\right]}
\end{aligned}
$$

Given the desired set-point $\mathrm{r}$ for $\mathrm{x}$, in general $\mathrm{x}^{*}$ and $\mathrm{u}^{*}$ can be calculated as:

$$
x^{*}=\mathrm{Fr}, \quad u^{*}=\mathrm{Nr}
$$

When the number of inputs to the process $\mathrm{m}$ is equal to the number of controlled outputs l, it is [3.9]

$$
\left[\begin{array}{l}
x^{*} \\
u^{*}
\end{array}\right]=\left[\begin{array}{ll}
A & B \\
G & H
\end{array}\right]^{-1}\left[\begin{array}{l}
0 \\
r
\end{array}\right]=S\left[\begin{array}{l}
0 \\
r
\end{array}\right]
$$

where $\mathrm{F}$ is an $\mathrm{n} \times \mathrm{l}$ matrix given by the top $\mathrm{n}$ rows and right-most $\mathrm{l}$ columns of $\mathrm{S}$ and $\mathrm{N}$ is an $\mathrm{m} \times \mathrm{l}$ matrix given by the bottom $\mathrm{m}$ rows and right-most $\mathrm{l}$ columns of $\mathrm{S}$.

The state-feedback controller with a reference input $r$ should be [3.9]:

$$
u=-K\left(x-x^{*}\right)+u^{*}=-K x+(K F+N) r
$$

where $\mathrm{K}$ is the LQR gain. The corresponding control architecture is shown in Figure 3.22 . 


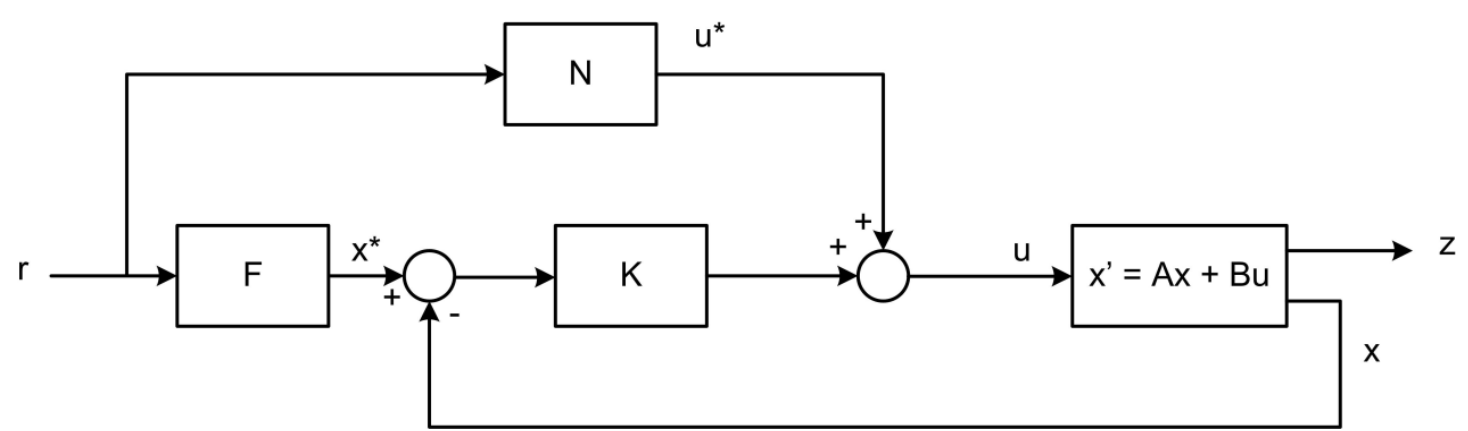

Figure 3.22 Linear Quadratic Set-point Control with State Feedback [3.9]

There was physical limitation for fuel flow control valve in the real system, so I

added a saturation block with max and min values for fuel flow rates. At the same time, a proportional gain block was added in order to get better dynamic response instead of an integral gain block. The control part is illustrated in Figure 3.23

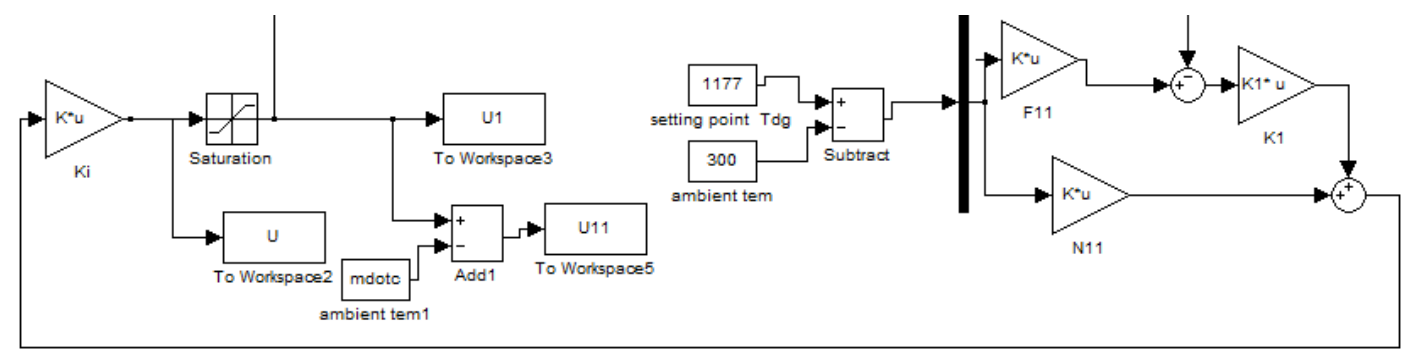

Figure 3.23 the LQR Control Part with a Reference Input

Choosing different $\mathrm{Q}$ and $\mathrm{R}$ in the command $\mathrm{K}=\mathrm{LQR}(\mathrm{A}, \mathrm{B}, \mathrm{Q}, \mathrm{R})$ in $\mathrm{MATLAB}^{\mathrm{TM}}$, I can get different LQR gains $\mathrm{K}$. In my case, $\mathrm{Q}$ is $6 \times 6$ matrix with only non- zero value in $\mathrm{Q}(3,3)$ position, zeroes in other else positions and $\mathrm{R}$ is a scalar. $\mathrm{Q}$ is related to error between state variable values and reference set point. Tdg is the only temperature I would like to control, so only $\mathrm{Q}(3,3)$ is kept non-zero. Finally I found that 3000 and 6000 were good choices for $\mathrm{Q}(3,3)$ element after lots of try, which minimized error in a short time. $\mathrm{R}$ is response for control effort. In other words, it means how hard to achieve the control object. Very big control gains are not desirable in real control design, so $\mathrm{R}$ was kept as 1 after lots of try. In order to achieve an 
acceptable trade-off between performance and control effort, finally I chose control gain $\mathrm{K} 1$ got from $\mathrm{Q}(3,3)=3000, \mathrm{R}=1$, and $\mathrm{K} 2$ got from $\mathrm{Q}(3,3)=6000, \mathrm{R}=1$ to design control system.

\subsubsection{Reduced-Order Estimator}

During the LQR controller design in our model, it was assumed that all state variables were available to measure. Actually only combustion layer temperature Ta (Ta*) and the bushing plate temperature Tbtb (Tbtb*) can be measured directly. So an estimator needs to design to estimate other four state variables $\mathrm{Tbg}^{*}, \mathrm{Tcg}^{*}, \mathrm{Tdg}^{*}, \mathrm{Tr}^{*}$ in the control process.

If a system is observable, it is possible to design a full order estimator. It is better to implement a full-order estimator if there is significant noise on the measurements because, in addition to estimating unmeasured state variables, the estimator filters the measurements. If the sensors have no noise, then a full-order estimator contains redundancies, and it seems reasonable to question the necessity for estimating state variables that are measured directly. In my model, there are six state variables in the system. Among them, combustion layer temperature Ta $\left(\mathrm{Ta}^{*}\right)$ and the bushing plate temperature Tbtb (Tbtb*) can be measured directly by thermal couples in the furnace and infrared cameras respectively. So only a four-order estimator is needed in my case and the choice for full-order estimator is unnecessary. In addition the sensors for measurement have no noise, and redundancies caused by a full-order estimator possibly are not good for control process. So a reduced-order estimator was 
designed in my control system.

Given a state space representation (3-21), if outputs are measured, and if $\operatorname{Rank}(\mathrm{C})=\mathrm{p}$ and $\mathrm{n}$ is the number of all state variables, it should be possible to design a reduced-order estimator with (n-p) poles only and use the measurable state variables directly.

Algorithm was as follow [3.11]:

$$
\begin{aligned}
& \overrightarrow{\dot{x}}=\left[\begin{array}{l}
\overrightarrow{\dot{x}}_{1} \\
\frac{\dot{x}_{2}}{}
\end{array}\right]=\left[\begin{array}{ll}
A_{11} & A_{12} \\
A_{21} & A_{22}
\end{array}\right]\left[\frac{\vec{x}_{1}}{\vec{x}_{2}}\right]+\left[\frac{B_{1}}{B_{2}}\right] \vec{u} \\
& \vec{y}=\left[\begin{array}{ll}
C_{1} & C_{2}
\end{array}\right]\left[\begin{array}{l}
\vec{x}_{1} \\
\vec{x}_{2}
\end{array}\right]
\end{aligned}
$$

$\vec{x} \in R^{n}, \quad \vec{u} \in R^{m}, \quad \vec{y} \in R^{p}, \quad \vec{x}_{1} \in R^{n-p}, \quad \vec{x}_{2} \in R^{p}$

where $\mathbf{x}_{\mathbf{1}}$ is a vector including all the state variables need to be estimated, $\mathbf{x}_{\mathbf{2}}$ is a vector including all the state variables which can be measured directly.

Then following transformation was applied:

$$
\begin{aligned}
& T=\left[\begin{array}{cc}
I^{(n-p)} & \phi \\
C_{1} & C_{2}
\end{array}\right], T^{-1}=\left[\begin{array}{cc}
I^{(n-p)} & \phi \\
-C_{2}^{-1} C_{1} & C_{2}^{-1}
\end{array}\right] \\
& \vec{\xi}=T \vec{x}=\left[\begin{array}{cc}
I^{(n-p)} & \phi \\
C_{1} & C_{2}
\end{array}\right]\left[\begin{array}{l}
\vec{x}_{1} \\
\vec{x}_{2}
\end{array}\right]=\left[\begin{array}{c}
\vec{x}_{1} \\
\vec{y}
\end{array}\right] \\
& \hat{A}=\left[\begin{array}{cc}
P & Q \\
R & S
\end{array}\right] ; \quad \hat{B}=\left[\begin{array}{c}
B_{1} \\
\hat{B}_{2}
\end{array}\right] \\
& \vec{\xi}=\hat{A} \vec{\xi}+\hat{B} \vec{u}=T A T^{-1} \vec{\xi}+T B \vec{u}=\left[\begin{array}{ll}
P & Q \\
R & S
\end{array}\right] \vec{\xi}+\left[\begin{array}{c}
B_{1} \\
\hat{B}_{2}
\end{array}\right] \vec{u} \\
& P=A_{11}-A_{12} C_{2}^{-1} C_{1} \\
& Q=A_{12} C_{2}^{-1} \\
& \text { where: } S=\left(C_{1} A_{12}+C_{2} A_{22}\right) C_{2}^{-1} \\
& R=C_{1} A_{11}+C_{2} A_{21}-S C_{1} \\
& \hat{B}_{2}=C_{1} B_{1}+C_{2} B_{2}
\end{aligned}
$$




$$
\begin{gathered}
\hat{C}=\left[\begin{array}{ll}
\phi & I^{(p)}
\end{array}\right] \\
\vec{y}=\hat{C} \vec{\xi}=C T^{-1} \vec{\xi}=\left[\begin{array}{ll}
\phi & I^{(p)}
\end{array}\right] \vec{\xi}
\end{gathered}
$$

According to duality character, we performed pole placement to design an estimator by using controller design method in its dual system in order to get estimator gain $\mathrm{N}$.

Finally it was obtained:

$$
\begin{aligned}
& \overrightarrow{\dot{w}}=M \vec{w}+L \vec{u}+K \vec{y} \\
& \text { The reduced-order estimator: } \overrightarrow{\hat{x}}_{1}=\vec{w}+N \vec{y} \\
& \overrightarrow{\hat{x}}_{2}=C_{2}^{-1} \vec{y}-C_{2}^{-1} C_{1} \overrightarrow{\hat{x}}_{1} \\
& M=P-N R \\
& \text { where : } K=Q+M N-N S \\
& L=B_{1}-N \hat{B}_{2}
\end{aligned}
$$

In our case, the reduced-order estimator has four poles. There is error between the actual values of state variables and the estimated ones. Good poles for estimators always drive error to go to zero fast. However, those good poles always bring the huge estimator gains, which transfer big noise to control part. So there is compromise when estimator gains are chosen.

For Tbg*,Tcg*,Tdg*,Tr* which need to be estimated, there is no specific requirement for their response except that it is desirable to drive error of Tdg* to zero in a short time. Starting for wide guess, we chose the first pole vector for my estimator $\mathrm{EP}_{0}=[-0.015+0.025 \mathrm{i} ;-0.015-0.025 \mathrm{i} ;-0.002+0.002 \mathrm{i} ;-0.002-0.002 \mathrm{i}]$ and did the first simulation. Please see the result in Figure 3.24. 


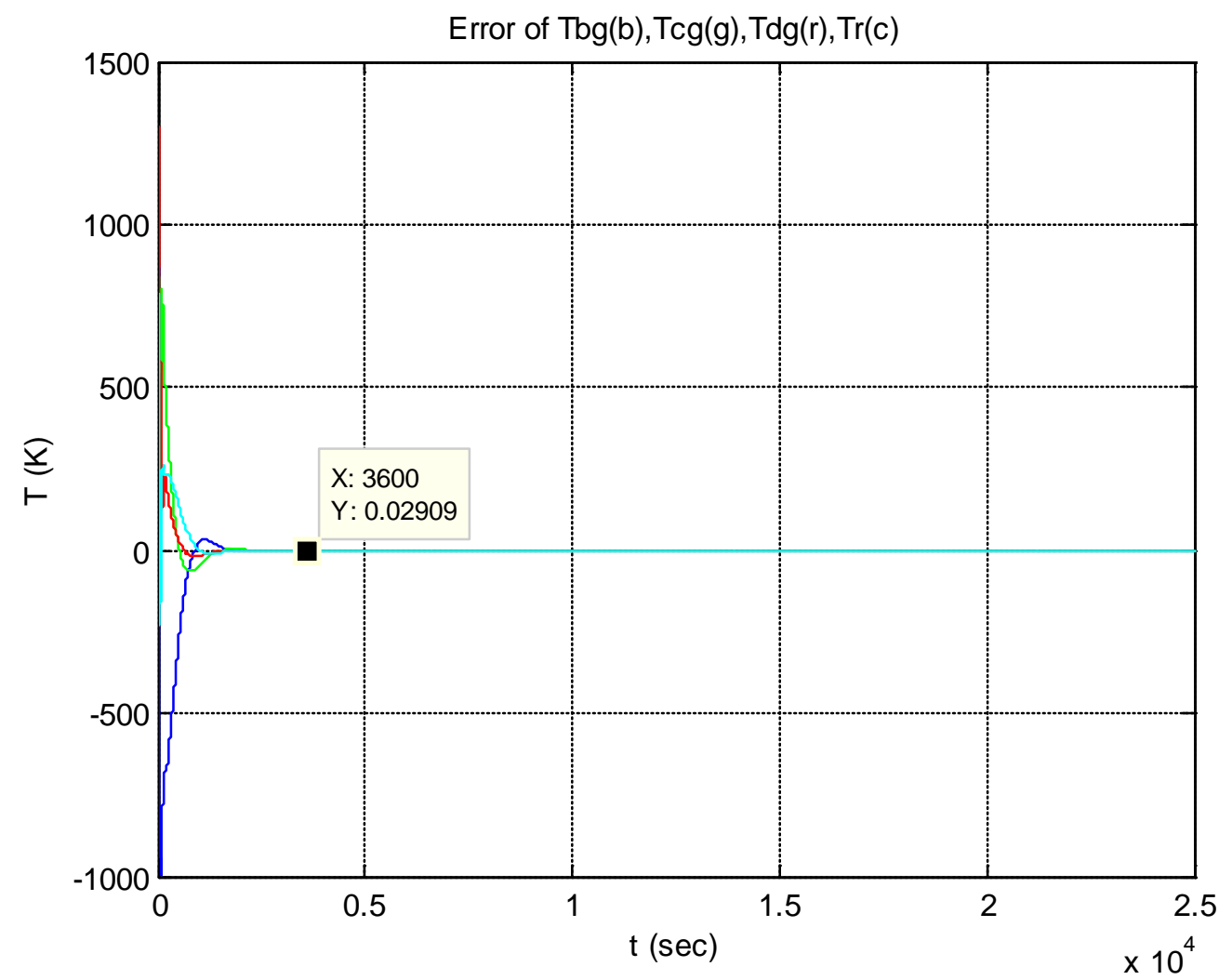

Figure 3.24 Error Response of the Reduced-order Estimator with the Pole Vector EP0

Generally it took about 1 hour (3600 seconds) to drive error to zero, which was not good. So we tried to decrease the values for first two poles by 0.005 and kept others the same values to do the simulation. Then we increased the first two poles by 0.005 and did the simulation again. By comparing the simulation results with the previous ones, we drew the conclusion approximately that how to change the poles of the estimator can drive error to zero quickly. In fact, there is no direct method which can help to design the best pole vector for estimators because there is always a compromise between the speed to drive error to zero and the noise caused by huge gains. In real situation with special requirement, trial and error method is a general way to design pole vector for estimators. After lots of simulations by the trial and 
error method, we finally got three of the best pole vectors:

$\mathrm{EP} 1=[\quad-0.015+0.025 \mathrm{i} ;-0.015-0.025 \mathrm{i} ;-0.002+0.002 \mathrm{i} ; \quad-0.002-0.002 \mathrm{i}], \quad \mathrm{EP} 2=$

$[-0.0075+0.0125 \mathrm{i} ;-0.0075-0.0125 \mathrm{i} ;-0.004+0.004 \mathrm{i}$;

$-0.004-0.004 \mathrm{i}]$ and EP3 $=[-0.03+0.05 \mathrm{i} ;-0.03-0.05 \mathrm{i} ;-0.004+0.004 \mathrm{i} ;-0.004-0.004 \mathrm{i}]$.

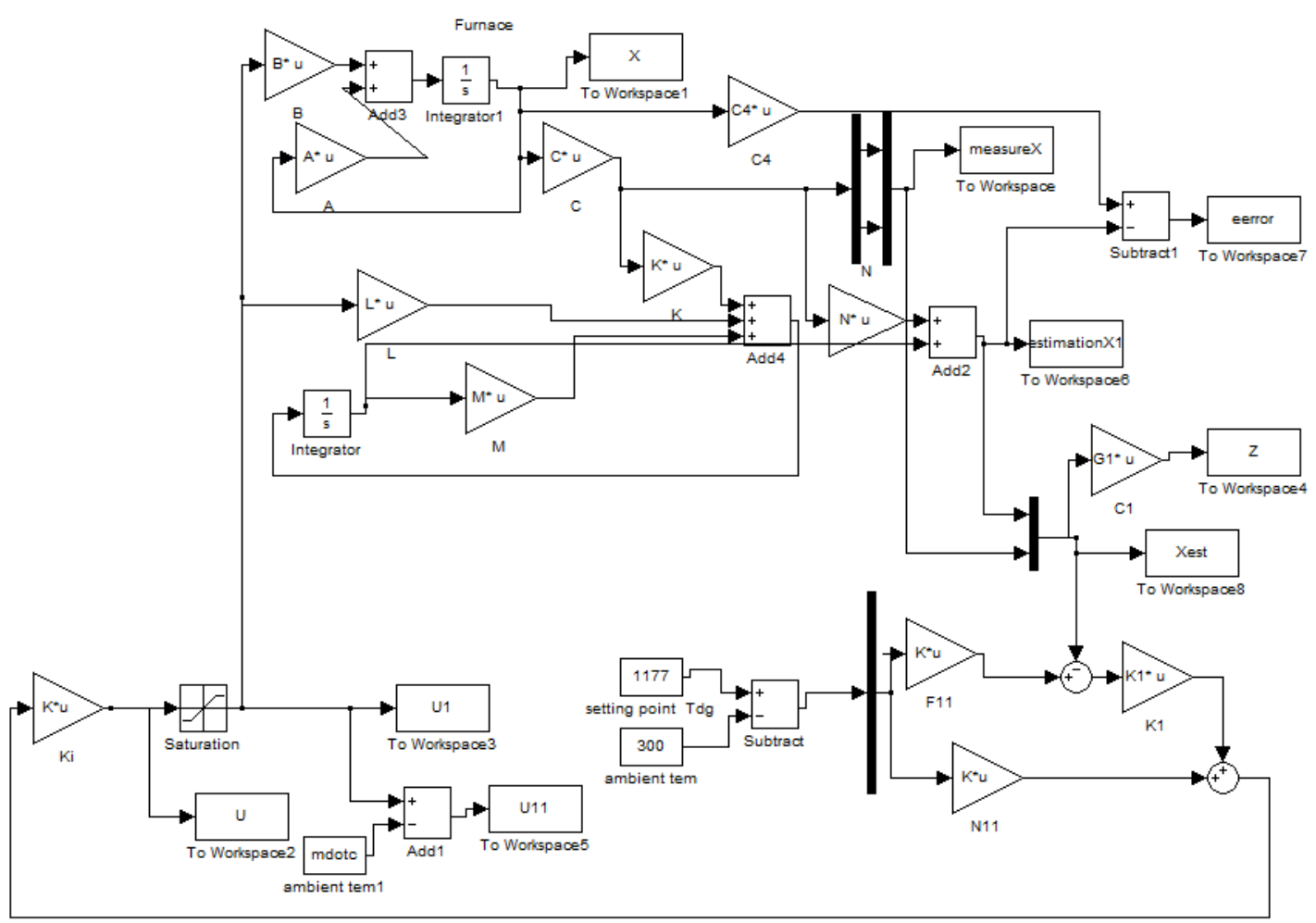

Figure 3.25 the LQR Control Model with a Reference Input and an Estimator

Finally a Simulink ${ }^{\mathrm{TM}}$ model with a reduced-order estimator based LQR controller was developed. It is illustrated in Figure 3.25.

\subsubsection{Winder Speed Control}

The temperature of the lowest glass layer Tdg needs to be controlled to the set point in order to get the desired final diameter for glass fibers. While even with a good controller, it still takes some time for Tdg to reach the desired status in such a 
thermal system. During this process, Tdg changes with time and so does the molten glass viscosity in the nozzles. From Poiseuille's Law, it is known that glass flow rate changes when other factors are the same.

About relation between glass flow rate and winder speed, Loewenstein concluded that the rate of fiber manufacture from a given bushing is entirely a function of the rate of the flow of glass through the nozzles and is independent of the rate of attenuation, i.e. of the diameter of the fiber made [2.16]. His idea was that the molten glass flow rate through a nozzle has nothing to do with the drawing force from the drum, and can be described by

$$
w \propto \frac{R^{4} H}{L \eta}
$$

Where $\mathrm{w}$ is the molten glass flow rate, $\mathrm{g} / \mathrm{s}$; $\mathrm{R}$ is the radius of the nozzle bore in its narrowest cylindrical section, mm; $\mathrm{H}$ is the molten glass height above the nozzle, $\mathrm{mm}$; $\mathrm{L}$ is length of this cylindrical section, $\mathrm{mm} ; \quad \eta \quad$ is the dynamic fluid viscosity in the nozzle, Pa*sec. From Poiseuille’s Law and glass flow rate equation, we can get :

$$
\pi r^{2} V \rho=C \frac{\pi R^{4} \rho^{2} g H}{8 \eta l}
$$

where $\mathrm{V}$ is the winder speed, $\mathrm{r}$ is the final radius of glass fibers, $\mathrm{C}$ is a constant. Changes in the molten glass depth $\mathrm{H}$ and dynamic fluid viscosity $\eta$ on the right side of Equation 3-29 cause changes in final radius $\mathrm{r}$ or the winder speed V on the left side. In normal case, $\mathrm{V}$ is $13.6 \mathrm{~m} / \mathrm{s}$ and $\mathrm{r}$ is 15 microns.

It is assumed that there are two different cases in the process, case 1 and case 2 with different $\mathrm{V}, \mathrm{H}$ and $\eta$ having the sub number 1 or 2 , but the same final radius 
$r$ if the final radius of glass fibers should be kept constant. In each case, their relationship still can be expressed in Equation 3-29 and other parameters are the same in both two cases. After cancellation for those two equations, we got:

$$
V_{2}=\frac{V_{1} \eta_{1} H_{2}}{\eta_{2} H_{1}}
$$

It is shown in Equation 3-30 that even if the glass flow rate changes with Tdg when the system is not at steady state, the final radius of the glass fibers can be kept constant by controlling the winder speed accordingly during the process. Please check the following Figure 3.26 for the complete model:

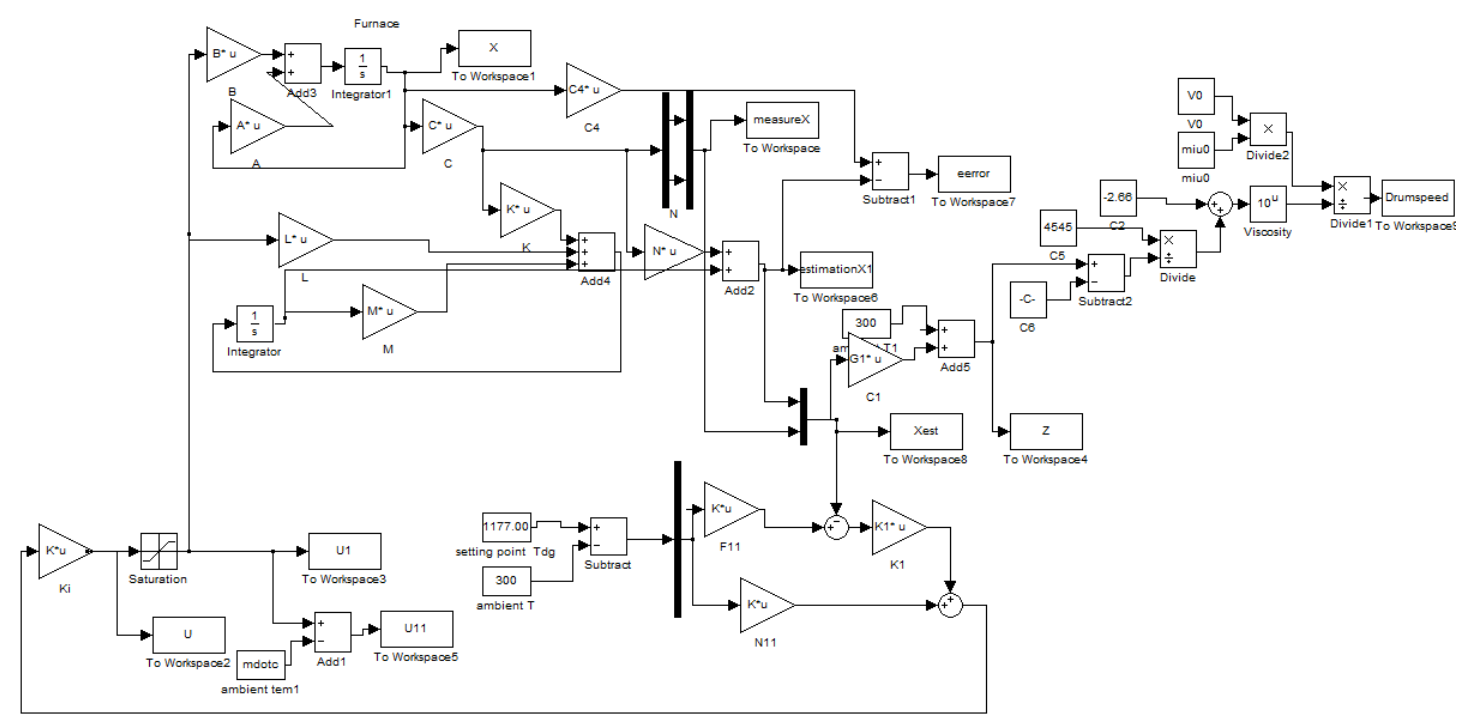

Figure 3.26 the LQR Controller with Winder Speed Control

\subsubsection{Multivariable Control Analysis}

The model is developed by using Matlab /Simulink ${ }^{\mathrm{TM}}$. A "normal case” was computed for a furnace molten glass depth of $10.2 \mathrm{~cm}$ and ambient temperature $300 \mathrm{~K}$. The lowest glass layer temperature Tdg is the controlled object, which will decide the glass flow rate through nozzles on the bushing plate. A set point $1177 \mathrm{~K}$ for Tdg from 
measurement was used in normal case. It was also assumed that the initial temperature of the glass is $1177 \mathrm{~K}$ in the normal case. After the model was developed, we got control gains $\mathrm{K} 1$ and K2, estimator pole vector EP1,EP2,EP3. Before doing the control analysis in different conditions, we had to choose the best combination of control gain and estimator pole vector among those.

\subsubsection{Choice of Control Gains and Estimator Poles}

Settling time, one of the important specifications in control performance, is the time it takes the system transients to decay, within $\pm 1 \%$ of the steady state value [3.10]. In our case, the steady state value for Tdg was $1177 \mathrm{~K}$. We calculated settling time when Tdg response was within $\pm 5 \mathrm{~K}$ of $1177 \mathrm{~K}$, that was a range from $1172 \mathrm{~K}$ to $1182 \mathrm{~K}$.

The Integral of Time multiply by Absolute Error (ITAE) index is a popular performance criterion used for control system design. Absolute error between the real Tdg and the estimated Tdg is used in calculation of the ITAE during the simulations.

ITAE and Settling time were calculated and used as standards to choose the best combination of those control gains and estimator poles. Simulations were run for the normal case with five initial conditions X1 to X5 (Please check Appendix G for detailed information in each case). Table 3.1 shows the five initial conditions from X1 to X5. 


\begin{tabular}{|l|r|r|r|r|r|r|}
\hline Unit K & \multicolumn{1}{l|}{ Tbg* } & \multicolumn{1}{l|}{ Tcg* } & \multicolumn{1}{l|}{ Tdg* } & \multicolumn{1}{l|}{ Tr* } & Ta* & \multicolumn{1}{l|}{ Tbtb* } \\
\hline X1 & 900 & 850 & 800 & 800 & 900 & 800 \\
\hline X2 & 910 & 860 & 810 & 810 & 910 & 810 \\
\hline X3 & 890 & 840 & 790 & 790 & 890 & 790 \\
\hline X4 & 950 & 900 & 850 & 850 & 950 & 850 \\
\hline X5 & 850 & 800 & 750 & 750 & 850 & 750 \\
\hline
\end{tabular}

Table 3.3 Five Initial Conditions in the Normal Case

\begin{tabular}{|c|c|c|c|c|}
\hline $\mathrm{T}=300 \mathrm{~K}, \mathrm{H}=10.2 \mathrm{~cm}$ & $\begin{array}{l}\text { estimator } \\
\text { poleEP1 }\end{array}$ & $\begin{array}{l}\text { estimator } \\
\text { poleEP2 }\end{array}$ & $\begin{array}{l}\text { estimator } \\
\text { poleEP3 }\end{array}$ & $\begin{array}{l}\text { Initial } \\
\text { condition }\end{array}$ \\
\hline $\mathrm{Q}(3,3)=3000, \mathrm{R}=1$ & 2720 & 2880 & 2487 & $\mathrm{X} 1$ \\
\hline \multirow[t]{4}{*}{ settling $\mathrm{t}(\mathrm{sec})$} & 2208 & 2264 & 2798 & $\mathrm{X} 2$ \\
\hline & 1626 & 3657 & 5121 & X3 \\
\hline & 4579 & 60.89 & 103.4 & $\mathrm{X} 4$ \\
\hline & 3046 & 6193 & 8018 & $\mathrm{X} 5$ \\
\hline Average time & 2835.8 & 3010.978 & 3705.48 & \\
\hline $\mathrm{Q}(3,3)=6000, \quad \mathrm{R}=1$ & 976.9 & 4869 & 4053 & $\mathrm{X} 1$ \\
\hline \multirow[t]{4}{*}{ settling $\mathrm{t}(\mathrm{sec})$} & 2294 & 2306 & 1690 & $\mathrm{X} 2$ \\
\hline & 1732 & 3638 & 4951 & X3 \\
\hline & 4397 & 117.4 & 55.86 & $\mathrm{X} 4$ \\
\hline & 3116 & 6111 & 7843 & $\mathrm{X} 5$ \\
\hline Average time & 2503.18 & 3408.28 & 3718.572 & \\
\hline
\end{tabular}

Table 3.4 Settling Time for Tdg in the Normal Case

In Table 3.2, the first column shows two control gains K1 and K2, calculated by corresponding Q and R groups. There are three estimator poles EP1, EP2 and EP3 in the first row. The last column shows the five initial conditions from X1 toX5. The settling time for Tdg response with different control gains, estimator poles and initial conditions are shown in Table 3.2. Average settling times for five initial conditions in all combinations were calculated. It is obvious that the K2 and EP1 combination 
gave smallest average settling time value of the six combinations.

\begin{tabular}{|l|r|r|r|l|}
\hline T =300K, H=10.2cm & $\begin{array}{l}\text { estimator } \\
\text { poleEP1 }\end{array}$ & $\begin{array}{l}\text { estimator } \\
\text { poleEP2 }\end{array}$ & $\begin{array}{l}\text { estimator } \\
\text { poleEP3 }\end{array}$ & $\begin{array}{l}\text { Initial } \\
\text { condition }\end{array}$ \\
\hline Q $(3,3)=3000, \mathrm{R}=1$ & $2.77 \mathrm{E}+08$ & $6.31 \mathrm{E}+08$ & $5.13 \mathrm{E}+08$ & X1 \\
\hline $\begin{array}{l}\text { ITAE after } \\
25000 \text { second }\end{array}$ & $3.26 \mathrm{E}+08$ & $4.77 \mathrm{E}+08$ & $3.39 \mathrm{E}+08$ & X2 \\
\hline & $2.54 \mathrm{E}+08$ & $7.87 \mathrm{E}+08$ & $6.79 \mathrm{E}+08$ & X3 \\
\hline & $1.07 \mathrm{E}+09$ & $1.70 \mathrm{E}+08$ & $1.53 \mathrm{E}+08$ & X4 \\
\hline & $4.27 \mathrm{E}+08$ & $1.33 \mathrm{E}+09$ & $1.24 \mathrm{E}+09$ & X5 \\
\hline Average & $4.70 \mathrm{E}+08$ & $6.78 \mathrm{E}+08$ & $5.84 \mathrm{E}+08$ & \\
\hline Q $(3,3)=6000, \mathrm{R}=1$ & $2.41 \mathrm{E}+08$ & $6.20 \mathrm{E}+08$ & $4.99 \mathrm{E}+08$ & X1 \\
\hline $\begin{array}{l}\text { ITAE after } \\
25000 \text { second }\end{array}$ & $2.92 \mathrm{E}+08$ & $4.60 \mathrm{E}+08$ & $3.16 \mathrm{E}+08$ & X2 \\
\hline & $2.17 \mathrm{E}+08$ & $7.81 \mathrm{E}+08$ & $6.71 \mathrm{E}+08$ & X3 \\
\hline & $1.05 \mathrm{E}+09$ & $1.26 \mathrm{E}+08$ & $1.09 \mathrm{E}+08$ & X4 \\
\hline & $4.05 \mathrm{E}+08$ & $1.33 \mathrm{E}+09$ & $1.25 \mathrm{E}+09$ & X5 \\
\hline Average & $4.40 \mathrm{E}+08$ & $6.64 \mathrm{E}+08$ & $5.68 \mathrm{E}+08$ & \\
\hline
\end{tabular}

Table 3.5 ITAE Values for Tdg in the Normal Case

In Table 3.3, the first column shows two control gains K1 and K2, calculated by corresponding Q and R groups. There are three estimator poles EP1, EP2 and EP3 in the first row. The last column shows the five initial conditions from X1 toX5. The ITAE values for Tdg response with different control gains, estimator poles and initial conditions are shown in Table 3.3. Average ITAE values for five initial conditions in all combinations were calculated. It is obvious that K2 and EP1 combination gave the smallest average ITAE value of those combinations. So the control gain vector

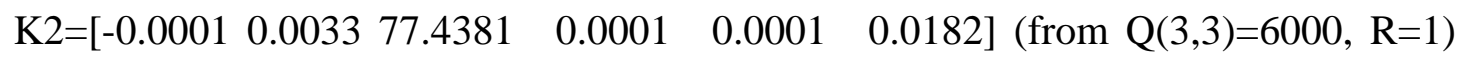
and estimator pole vector $E P 1=[-0.015+0.025 i ;-0.015-0.025 i ;-0.002+0.002 i$; -0.002-0.002i] were chosen to use in the model.

Figure 3.27, 3.28, 3.29, 3.30, 3.31 show the simulation results for the normal 
case. After almost 1 hour simulation, Tdg reached the set point and the fuel flow rate was gotten in the steady state. At the same time, the winder speed was controlled as expected.

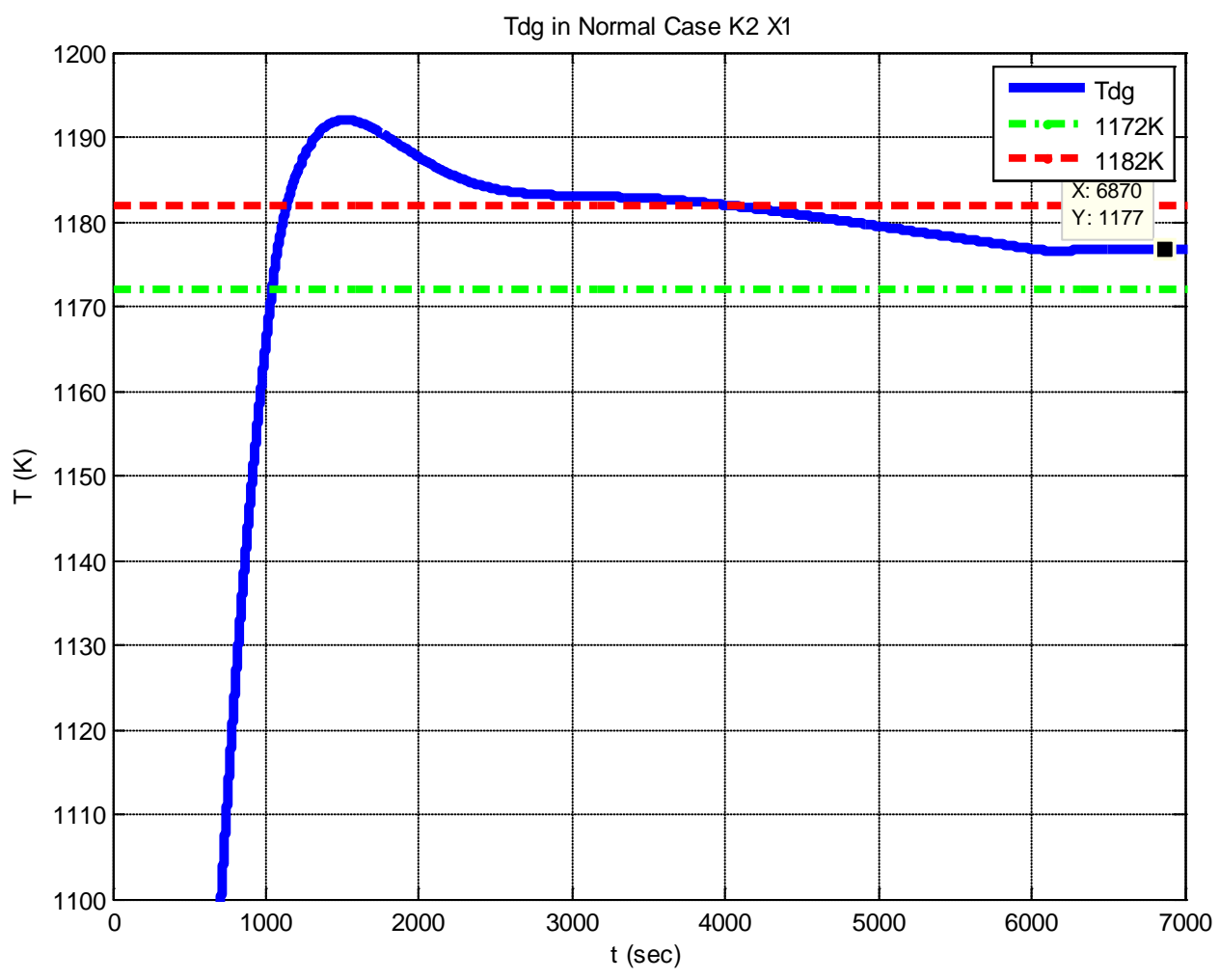

Figure 3.27 Tdg with the Control Gain K2 and the Estimator Pole EP1 


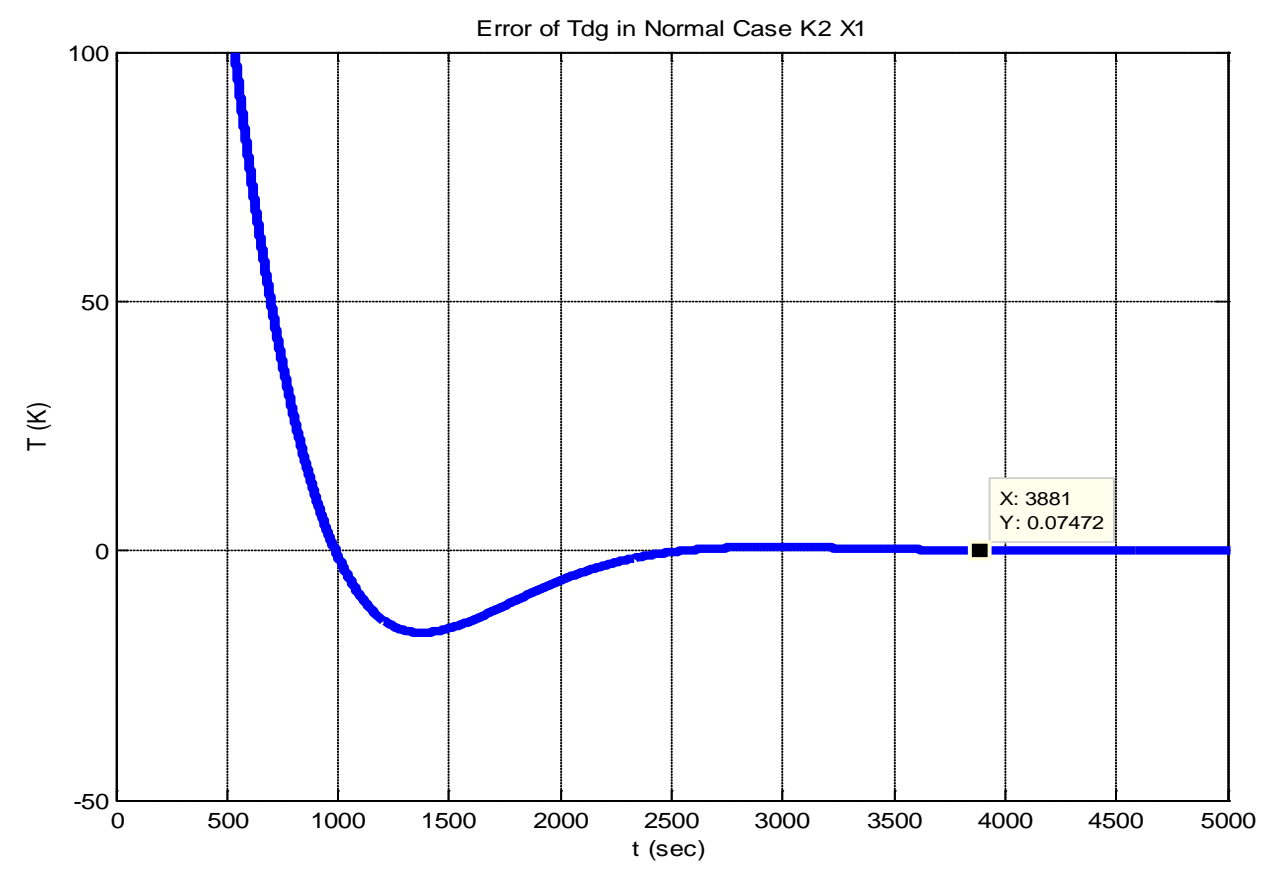

Figure 3.28 Error of Tdg in the Normal Case
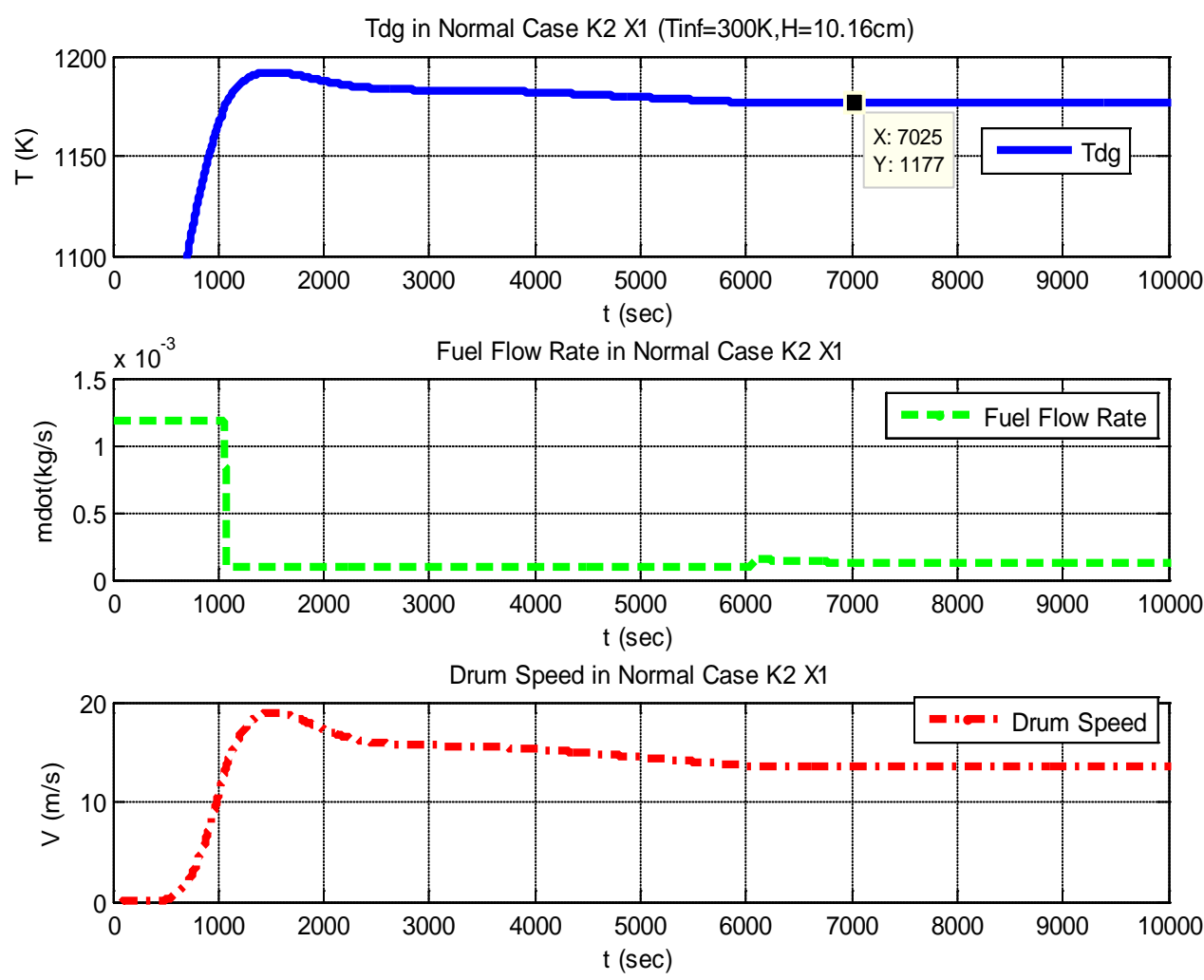

Figure 3.29 Tdg, Fuel Flow Rate and Winder Speed in the Normal Case (1) 

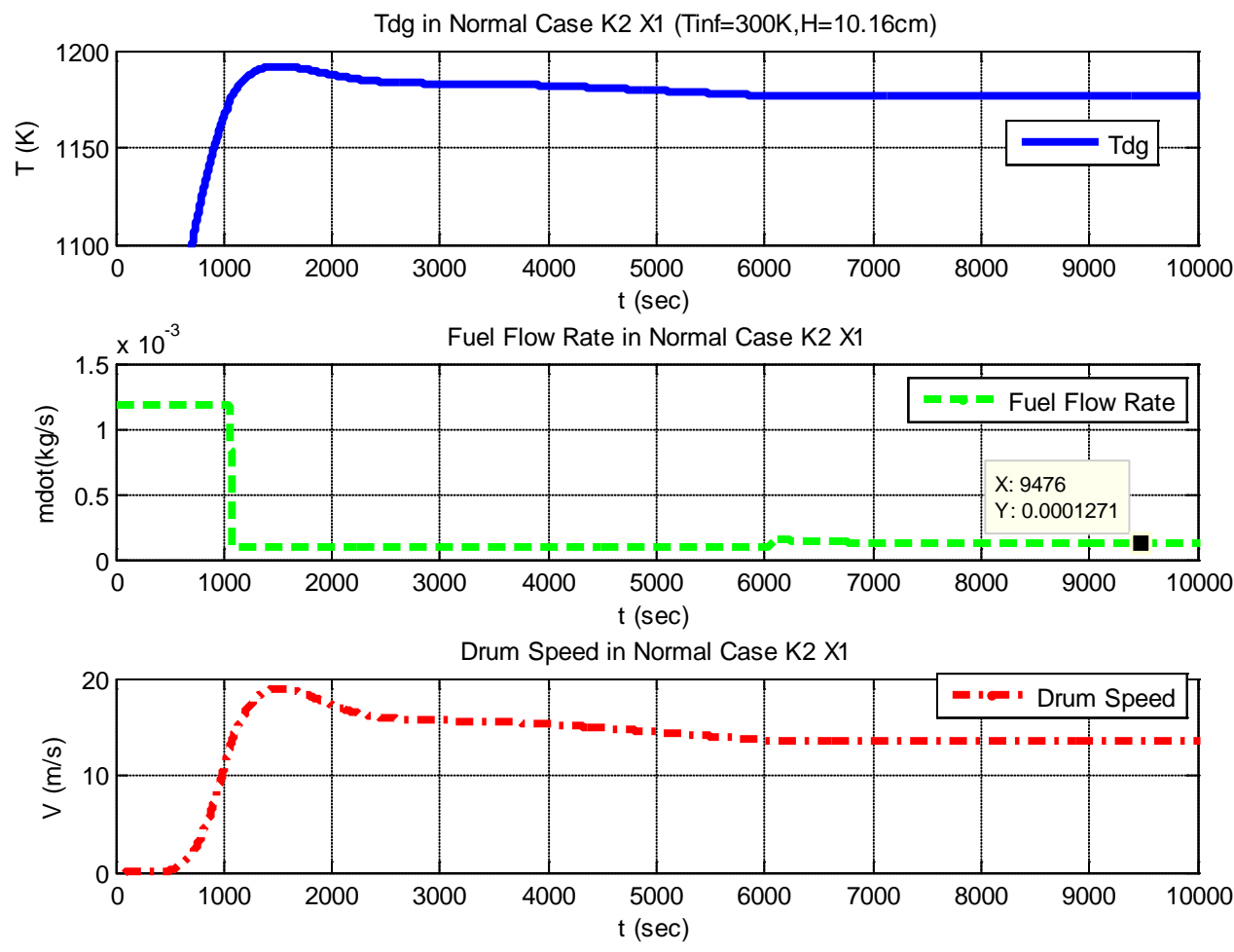

Figure 3.30 Tdg, Fuel Flow Rate and Winder Speed in the Normal Case (2)
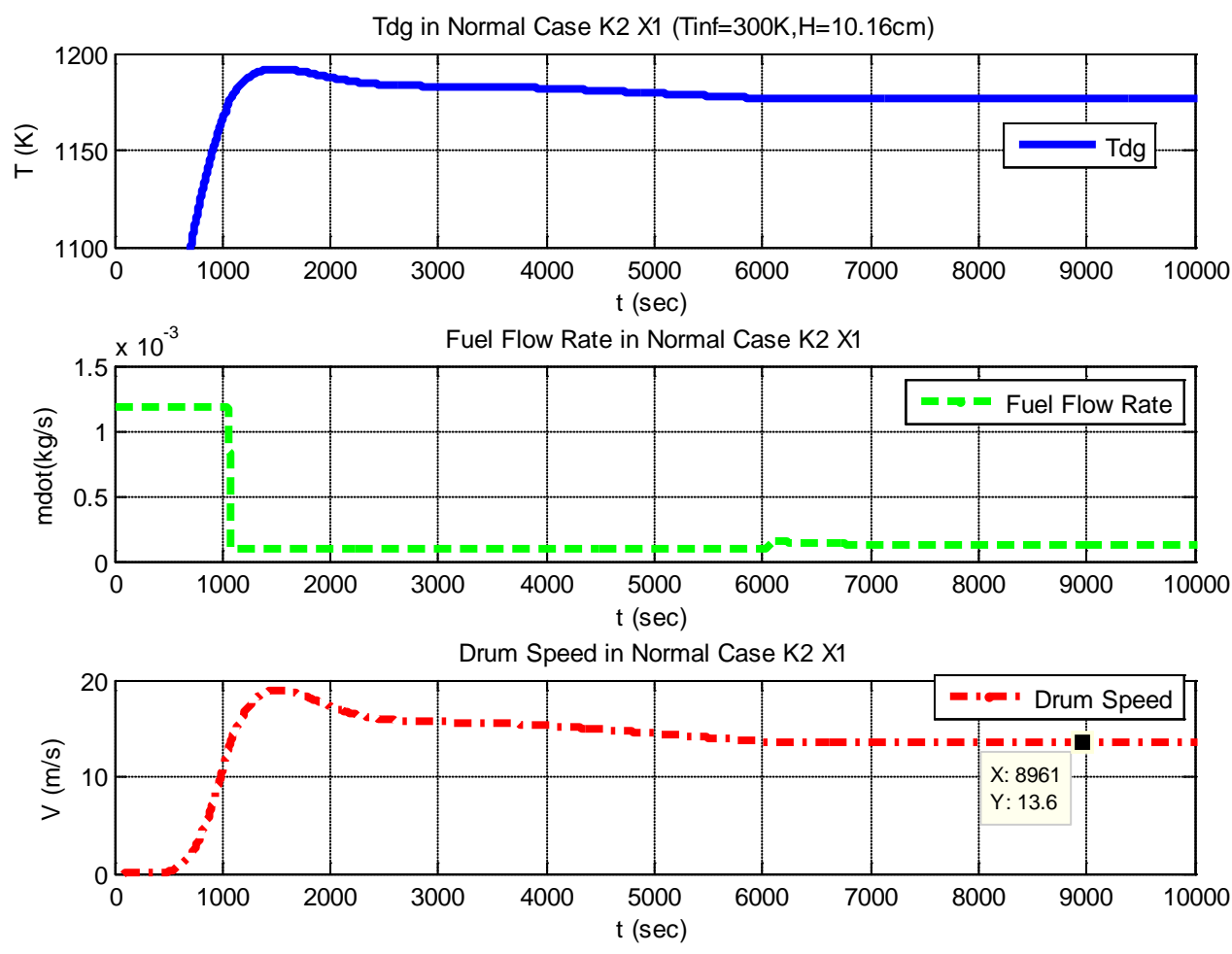

Figure 3.31 Tdg, Fuel Flow Rate and Winder Speed in Normal Case (3)

There are some transient points in fuel flow rate response plot. It is because of 
setting of the saturation block in front of fuel flow output. Different upper and lower limits give different plots for fuel flow rate. There are no transient points in plot for some suitable setting of the saturation block smooth in the Simulink ${ }^{\mathrm{TM}}$ model. Please check it in appendix $\mathrm{H}$ for detail.

In addition, I also tried to change the set point (1177K ) to $1160 \mathrm{~K}$ and $1190 \mathrm{~K}$ for test, and still got desired performance. Please check Figure 3.32 and 3.33 for the simulation results.

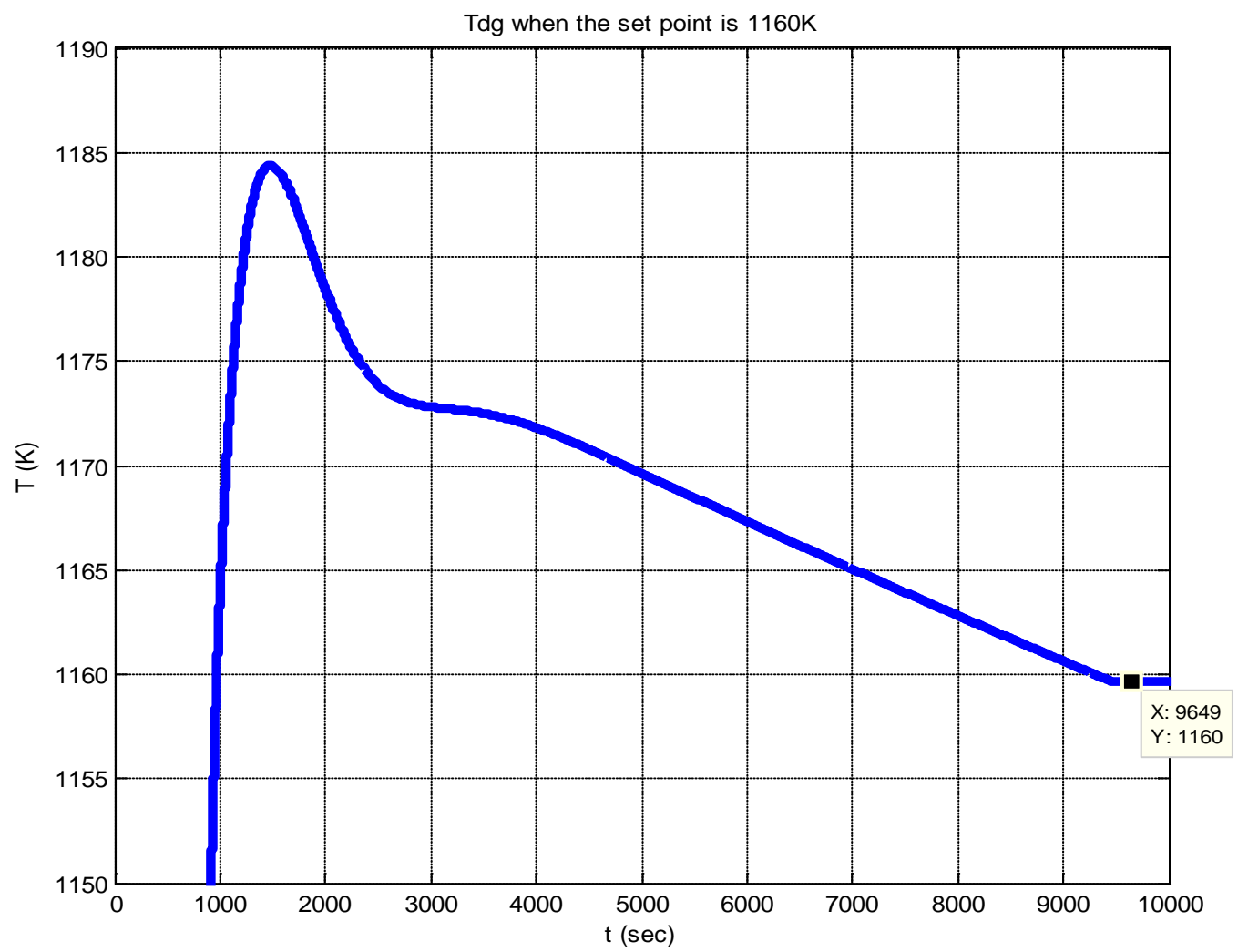

Figure 3.32 Tdg with the Set Point 1160K in the Normal Case 


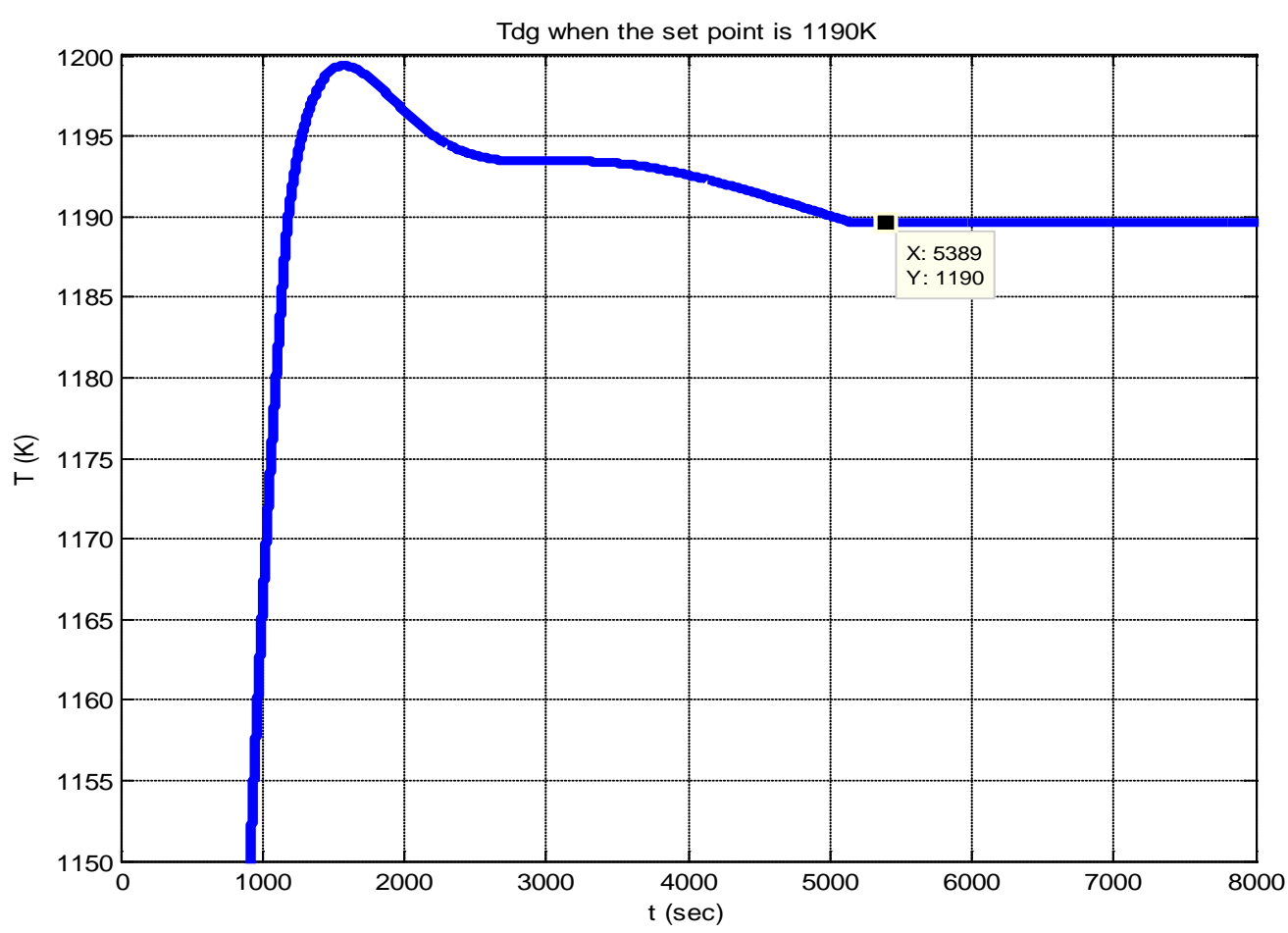

Figure 3.33 Tdg with the Set Point 1190K in the Normal Case

\subsubsection{Ambient Temperature Variation}

We developed the model in the "normal case", in which ambient temperature is $300 \mathrm{~K}$ and molten glass depth is $10.2 \mathrm{~cm}$. In the actual condition the ambient temperature and molten glass depth are affected by several factors so they are not as the same as those in normal case. In fact they are disturbance variables and model uncertainty. We have to make sure that my model can still achieve desired performance when those parameters are different from values in the normal case.

The ambient temperature is $300 \mathrm{~K}$ for the normal case, but $\mathrm{T} \infty$ changes with weather, season and many other factors. In fact, ambient temperature is a bounded uncertainty, and it is assumed that To changes from $285 \mathrm{~K}$ to $315 \mathrm{~K}$. State variables are 
$\mathrm{T}^{*}=\mathrm{T}-\mathrm{T} \infty$ in the model, so they change when ambient temperature changes. At the same time, all the other values including steady state value of the fuel flow rate, and $h$, the molten glass depth were kept the same as those in the normal case. The set point of Tdg is kept as $1177 \mathrm{~K}$ and the initial temperature for the glass flow rate is still 1177K. In each case, simulations were carried on five different initial conditions X1 to X5. There are four cases, from case 1 to case 4 , in ambient temperature change condition.

Besides Tdg temperature control in the model, the winder speed control was performed in the whole process at the same time. In the ambient temperature change case, the molten glass depth is assumed constant at $10.2 \mathrm{~cm}$, the same as one in the normal case. In the normal case, the winder speed is V1=13.6 m/s when Tdg reaches 1177K. According to Equation 3-30, we can control the winder speed in order to keep the same final diameter glass fibers even if Tdg changes before it becomes stable. Only the winder speed control in case 3 is shown but other results for the winder speed control are similar.

Case 1: Constant ambient temperature 315K. In this case, the control system with all the normal case settings starts from ambient temperature 315K. Check the following Figure 3.34 and we found that the control system can still do its work well even if there is ambient temperature disturbance at the beginning of the process. 


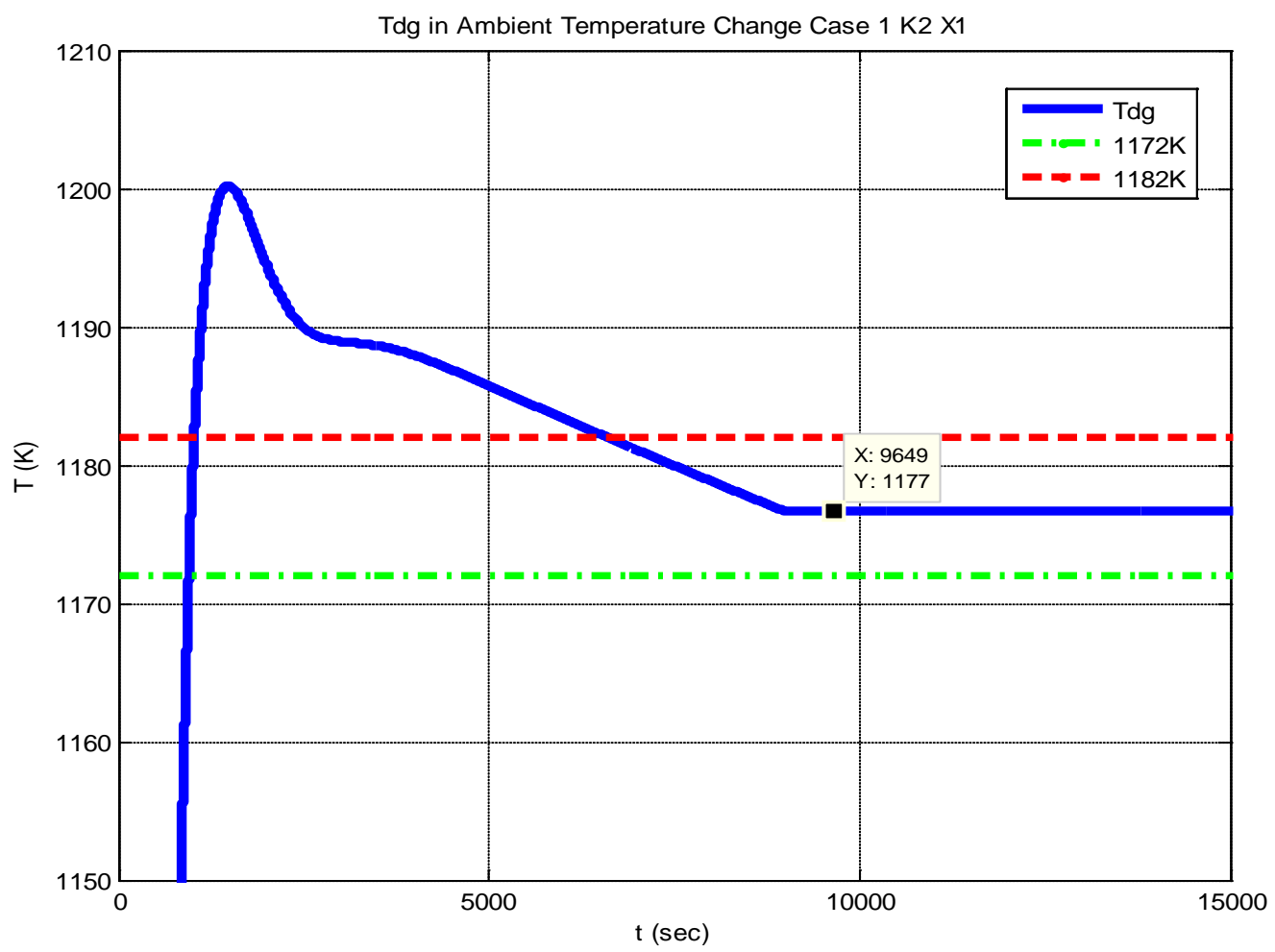

Figure 3.34 Tdg in Ambient Temperature Change Case 1 K2 X1

Case2: Constant ambient temperature 285K. In the case 2, the control system with all the normal case settings starts from ambient temperature 285K. Figure 3.35 shows that the control system can still work well even if there is an ambient temperature disturbance at the beginning of the process. 


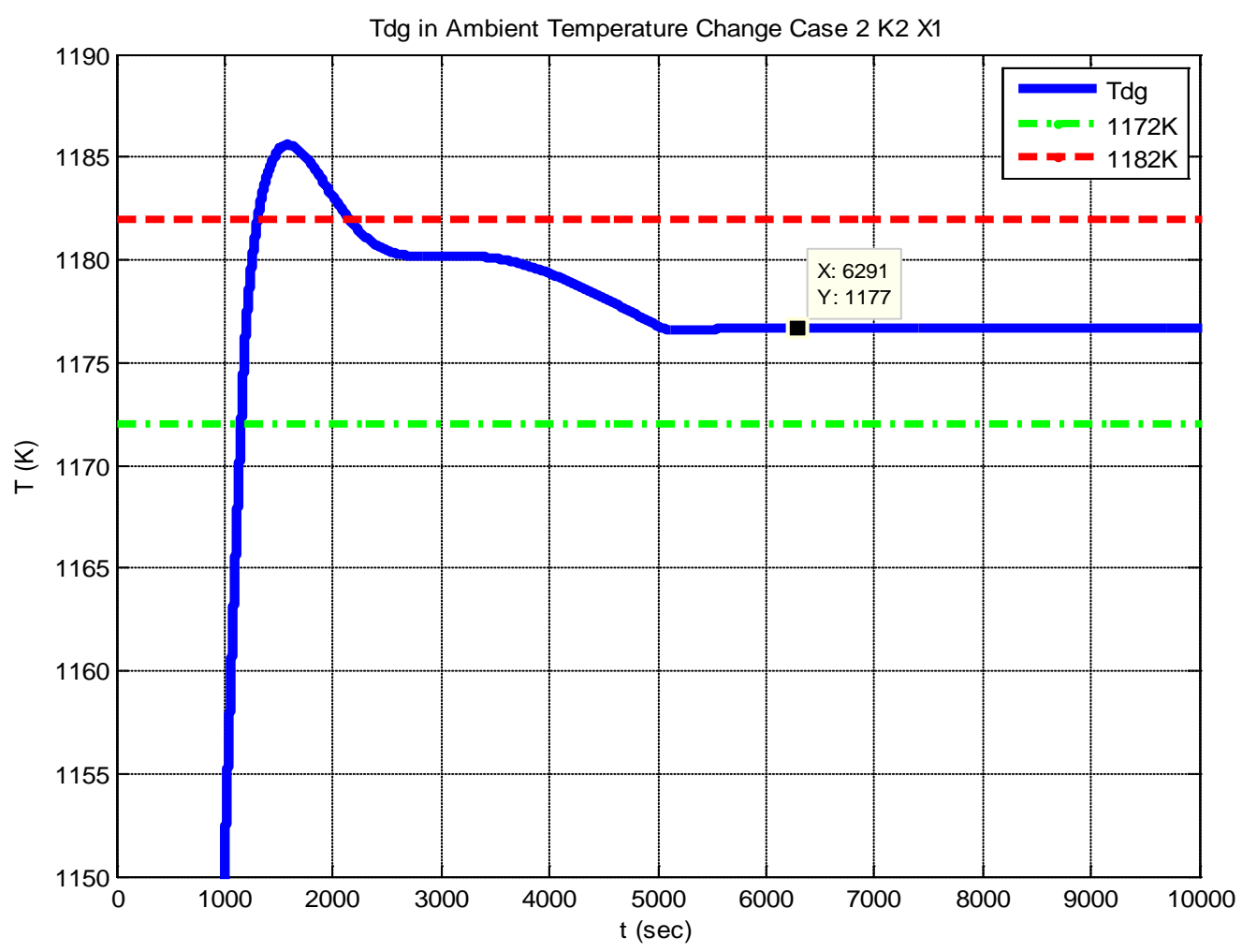

Figure 3.35 Tdg in Ambient Temperature Change Case 2 K2 X1

Case 3: Ambient temperature variation during operation. Starting from 300K, the ambient temperature was increased from $300 \mathrm{~K}$ to $315 \mathrm{~K}$ at a rate of $0.003 \mathrm{~K} /$ second, then held at 315 K. Figures 3.36, 3.37 demonstrates that the control system can still work well even there is an ambient temperature disturbance during the process. 


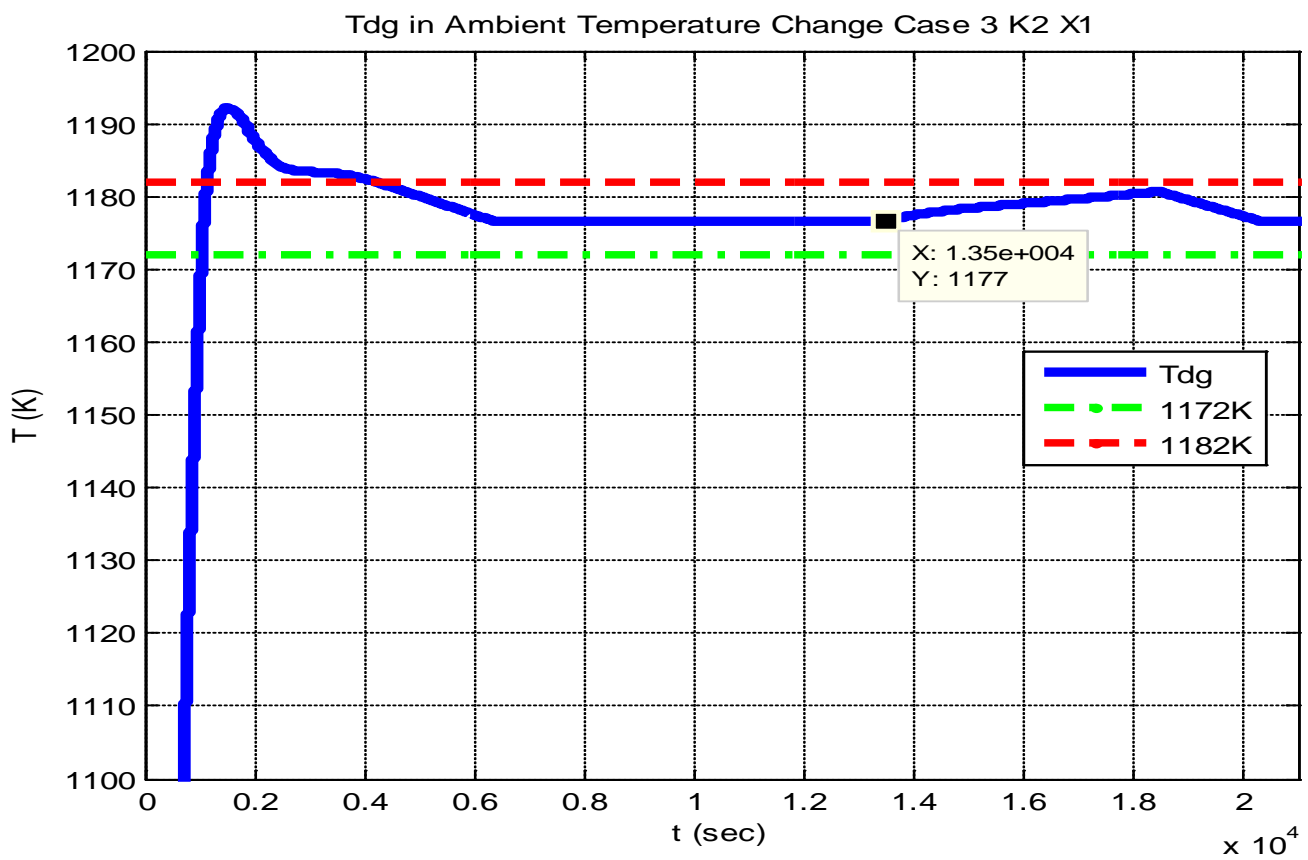

Figure 3.36 Tdg in Ambient Temperature Change Case 3 K2 X1

(1)

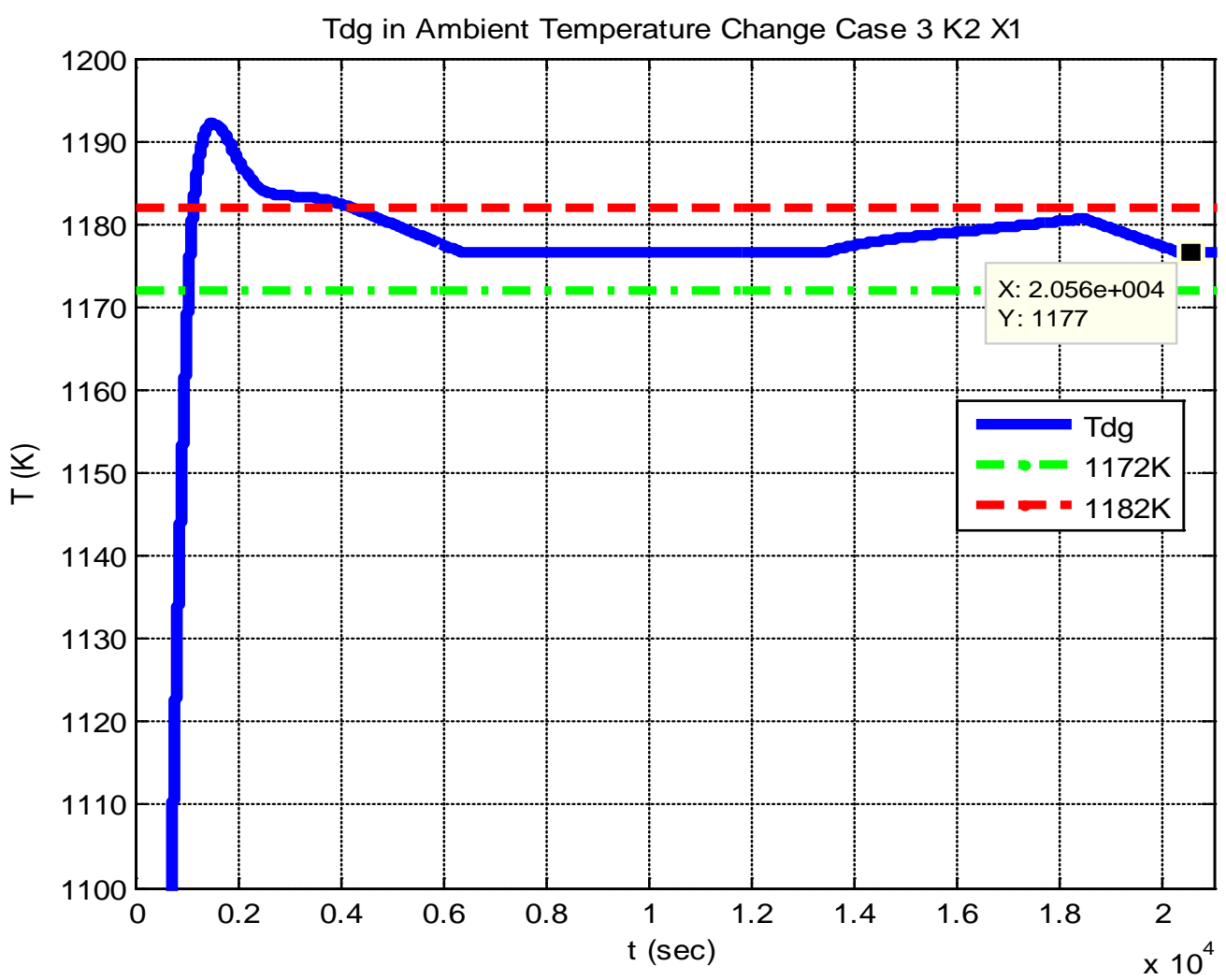

Figure 3.37 Tdg in Ambient Temperature Change Case 3 K2 X1 (2) 

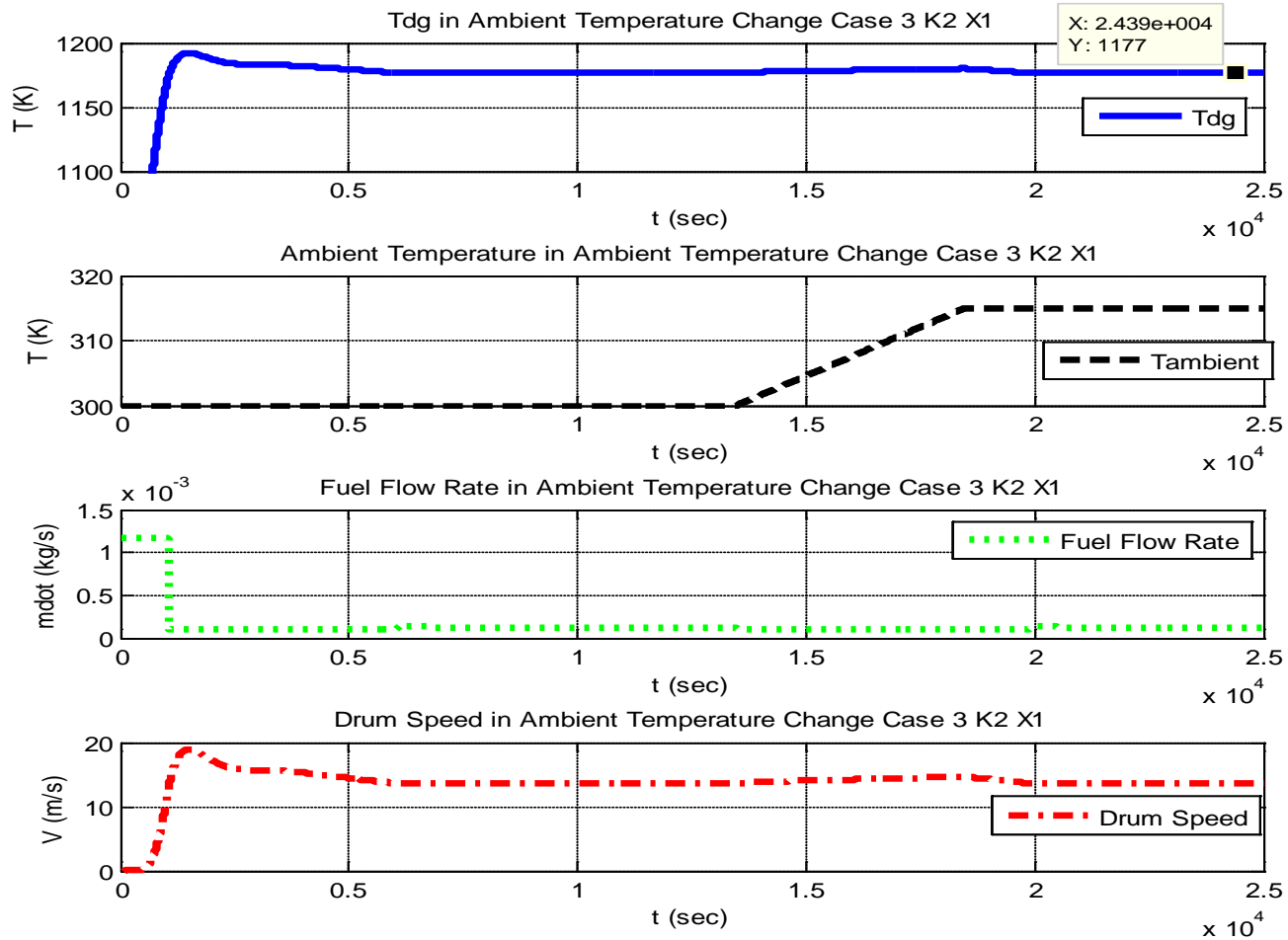

Figure 3.38 Tdg,Tळ,Fuel Flow Rate and Winder Speed in Ambient Temperature Change Case 3 K2 X1 (1)
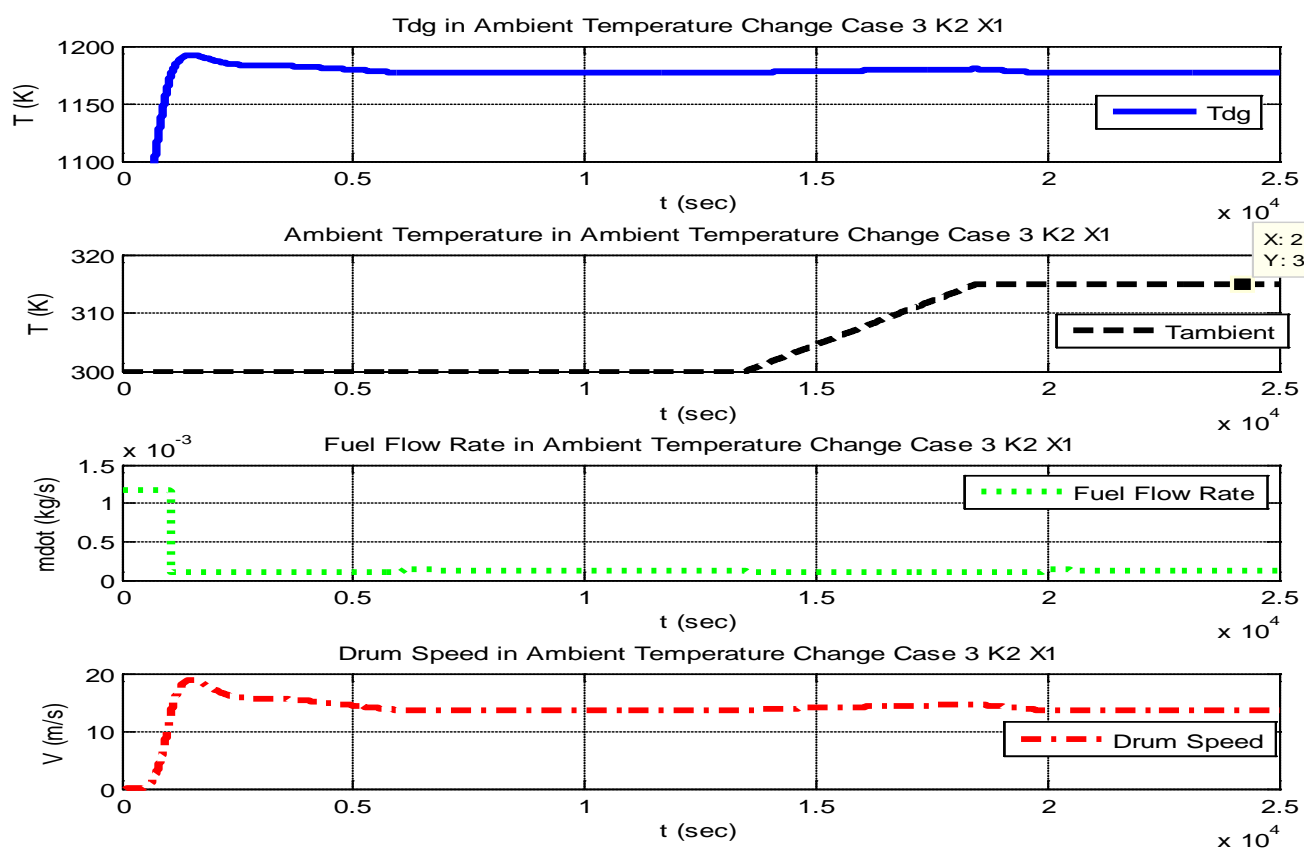

Figure 3.39 Tdg,T $\infty$,Fuel Flow Rate and Winder Speed in Ambient Temperature Change Case 3 K2 X1 (2) 

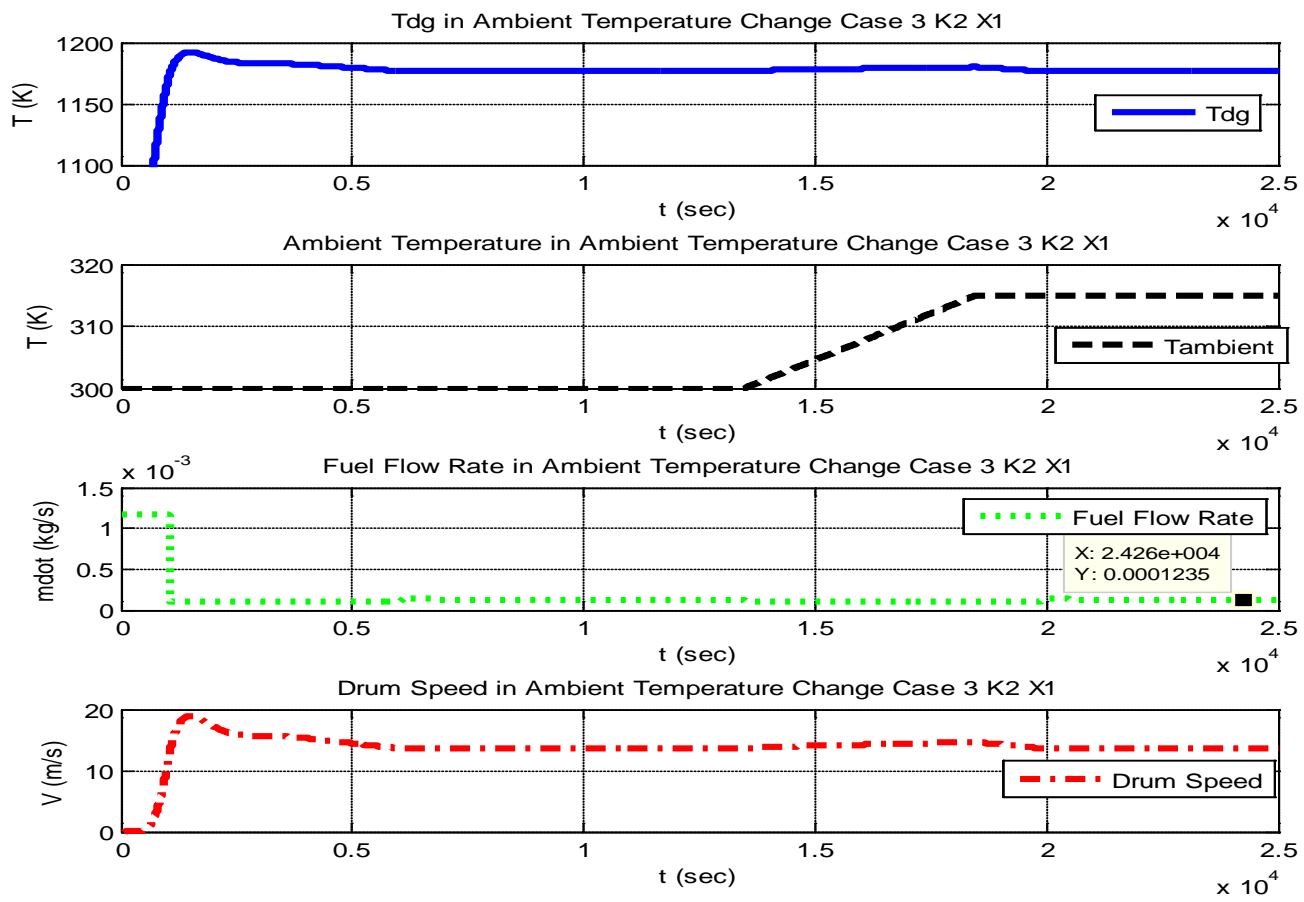

Figure 3.40 Tdg,T $\infty$,Fuel Flow Rate and Winder Speed in Ambient Temperature Change Case 3 K2 X1 (3)
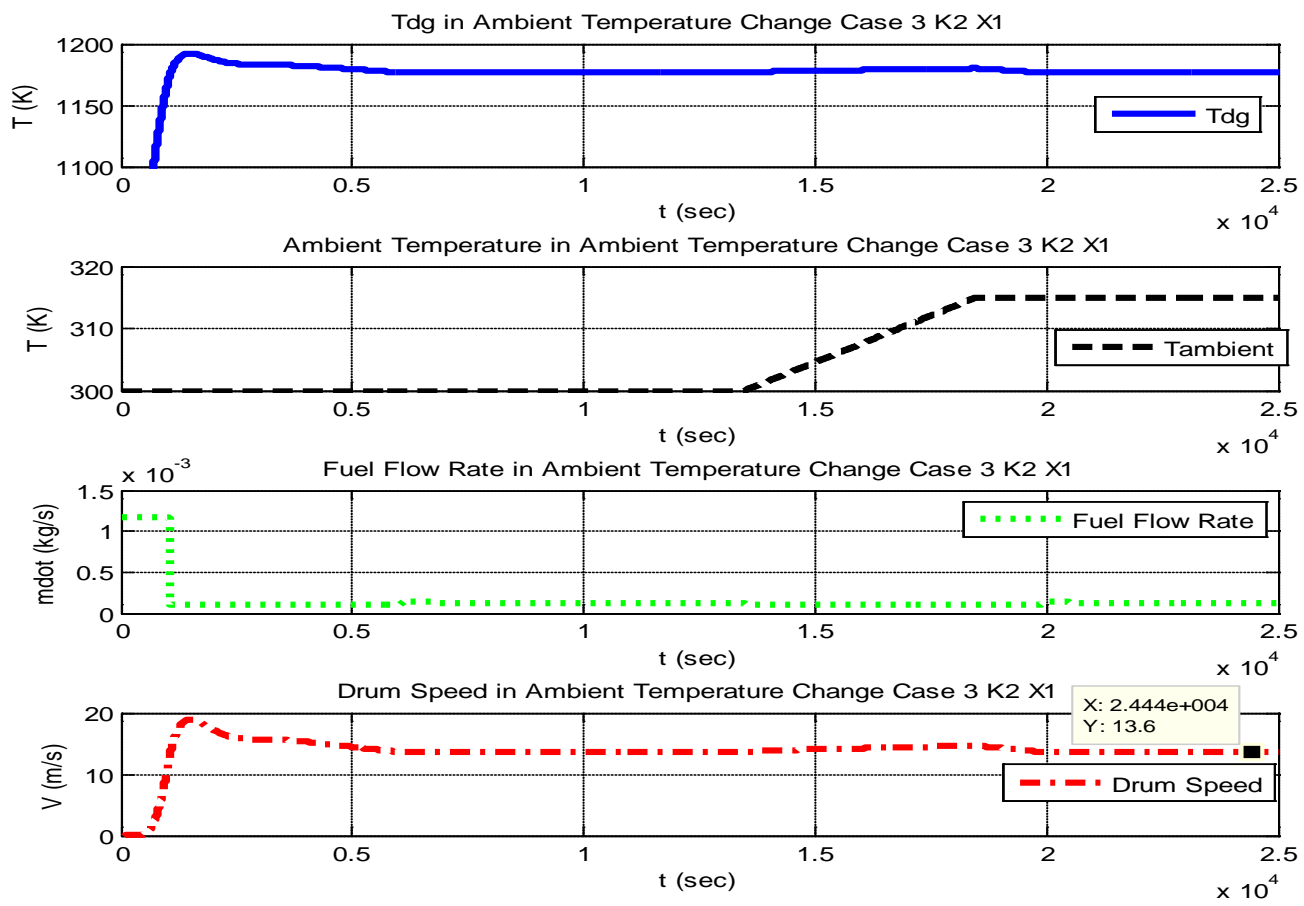

Figure 3.41 Tdg,T $\infty$,Fuel Flow Rate and Winder Speed in Ambient Temperature Change Case 3 K2 X1 (4)

Case 4: Ambient temperature variation during operation. Starting from 300K, 
the ambient temperature was decreased from $300 \mathrm{~K}$ to $285 \mathrm{~K}$ at a rate of $-0.012 \mathrm{~K} / \mathrm{second}$, then held at $285 \mathrm{~K}$. Figure 3.36 demonstrate that the control system can still work well even there is an ambient temperature disturbance during the process.

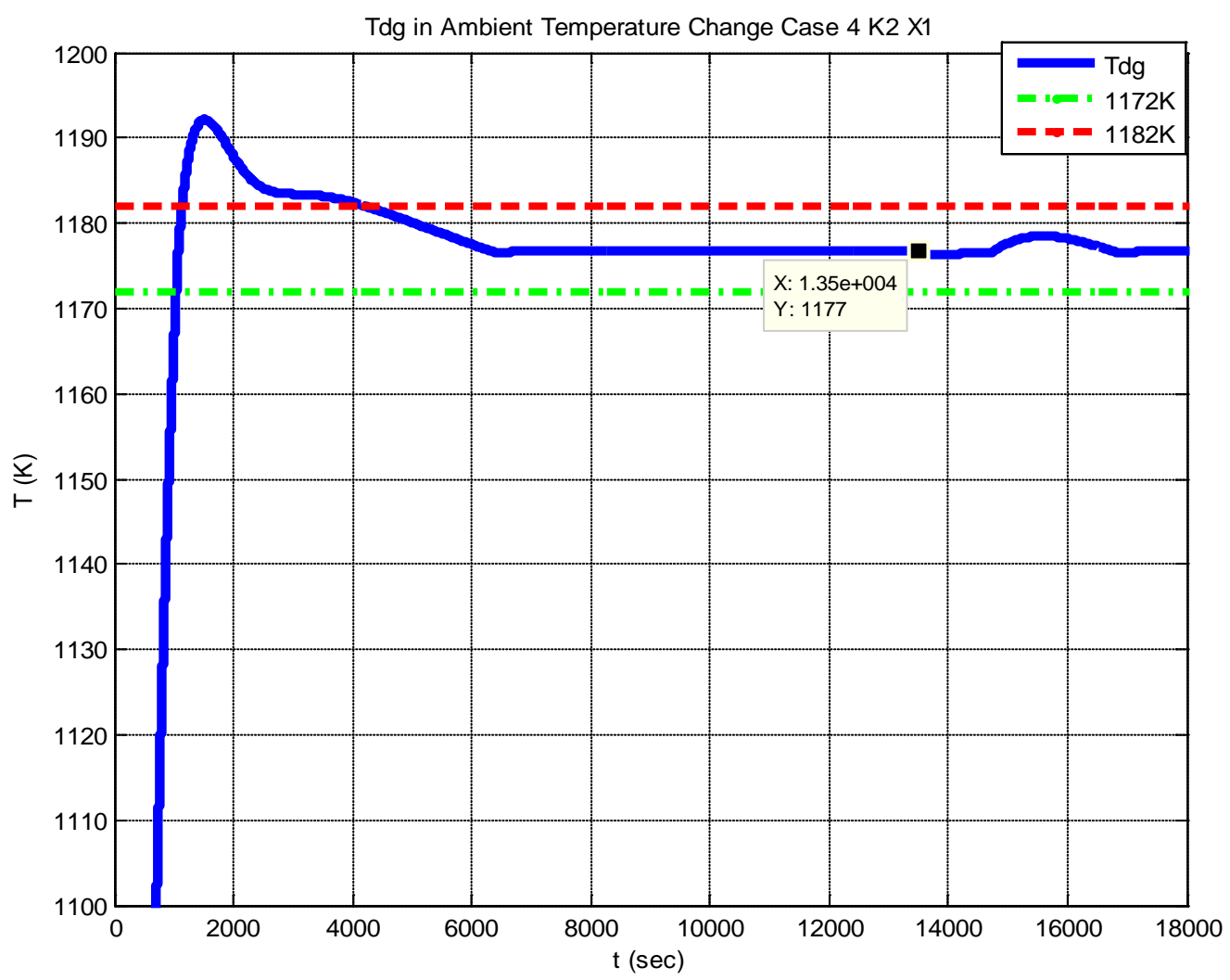

Figure 3.42 Tdg in Ambient Temperature Change Case 4 K2 X1 (1) 


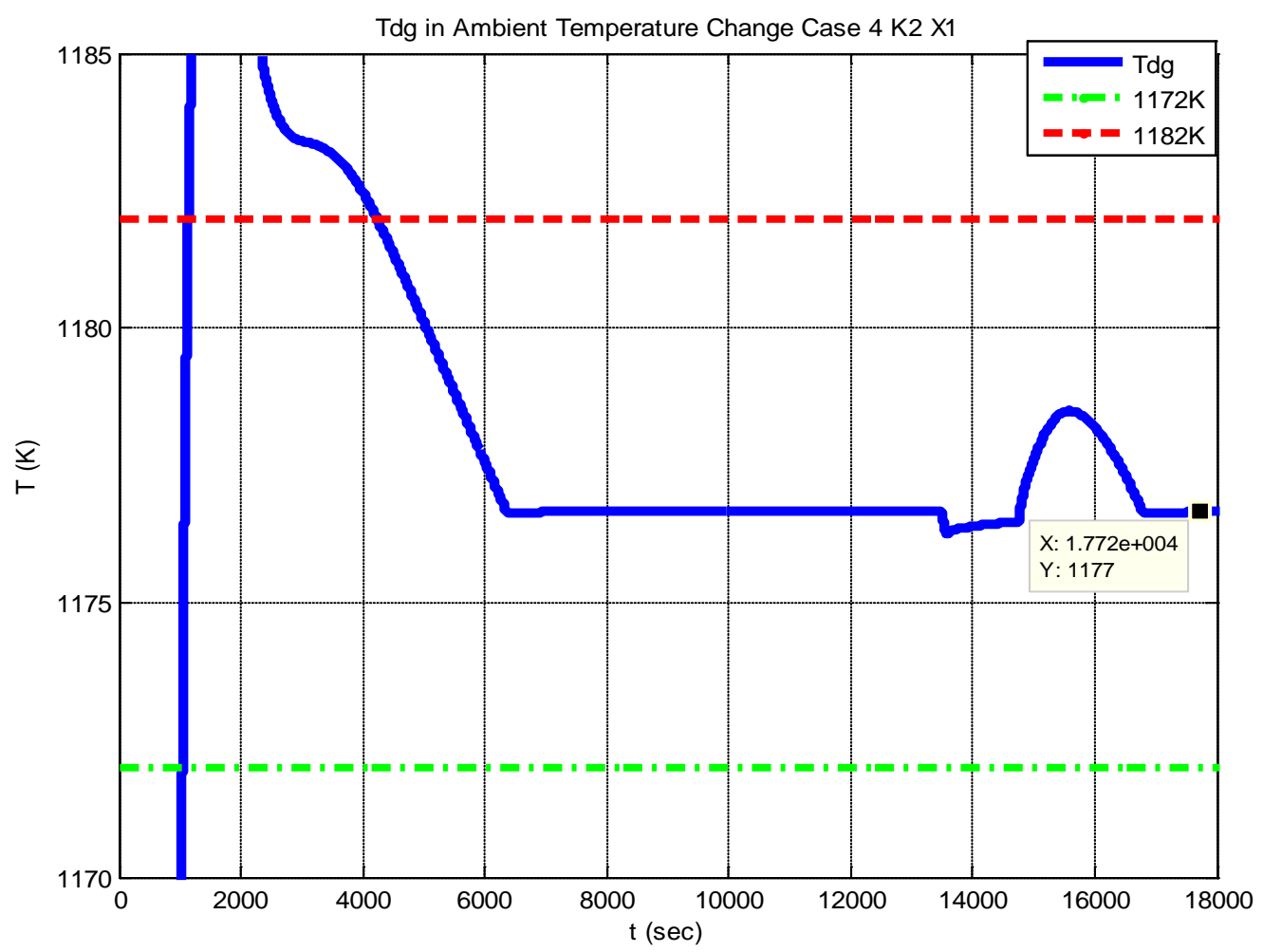

Figure 3.43 Tdg in Ambient Temperature Change Case 4 K2 X1 (2)

From above figures, the LQR controller can regulate the controlled variable Tdg back to the chosen set point despite disturbances in the ambient temperature. At the same time, the winder speed controller works in the whole process to keep the final glass fibers at the desired size. The control model presents good performance in the bounded ambient temperature variation cases.

\subsubsection{Molten Glass Depth Variation}

In the normal case, the molten glass depth in the furnace was assumed constant at $10.2 \mathrm{~cm}$, which is the average value. In reality situation, the furnace glass depth is changing slightly all the time, due to the "batch" nature of glass additions and the constant flow of glass out through the bushing plate. According to Poiseuille's Law [2.17], glass depth directly affects the glass flow rate, so a study of the furnace glass 
depth uncertainty was conducted. The glass depth before and after feeding should be the minimum value and the maximum value respectively. Depth probably does not vary by more than a few millimeters, but for this study, the molten glass depth uncertainty range is assumed to be from $9.2 \mathrm{~cm}$ to $11.2 \mathrm{~cm}$. In each case, $\mathrm{H}$ was changed and thickness of the lowest glass layer in the furnace was changed accordingly. All other parameters including ambient temperature and the set point for Tdg were kept as the same as in the normal case. Simulations were carried on five different initial conditions X1 to X5 in each case. Winder speed control plots are only shown for case 1 , but those in all other cases are similar.

Case 1: Molten glass depth was constant at $11.2 \mathrm{~cm}$. In this case, the initial temperature for the Tdg is still $1177 \mathrm{~K}$. During the simulation, the winder speed was controlled to change with changes in Tdg. The winder speed stabilized at $14.94 \mathrm{~m} / \mathrm{s}$ to keep the final diameter of the glass fibers at 30 microns. 


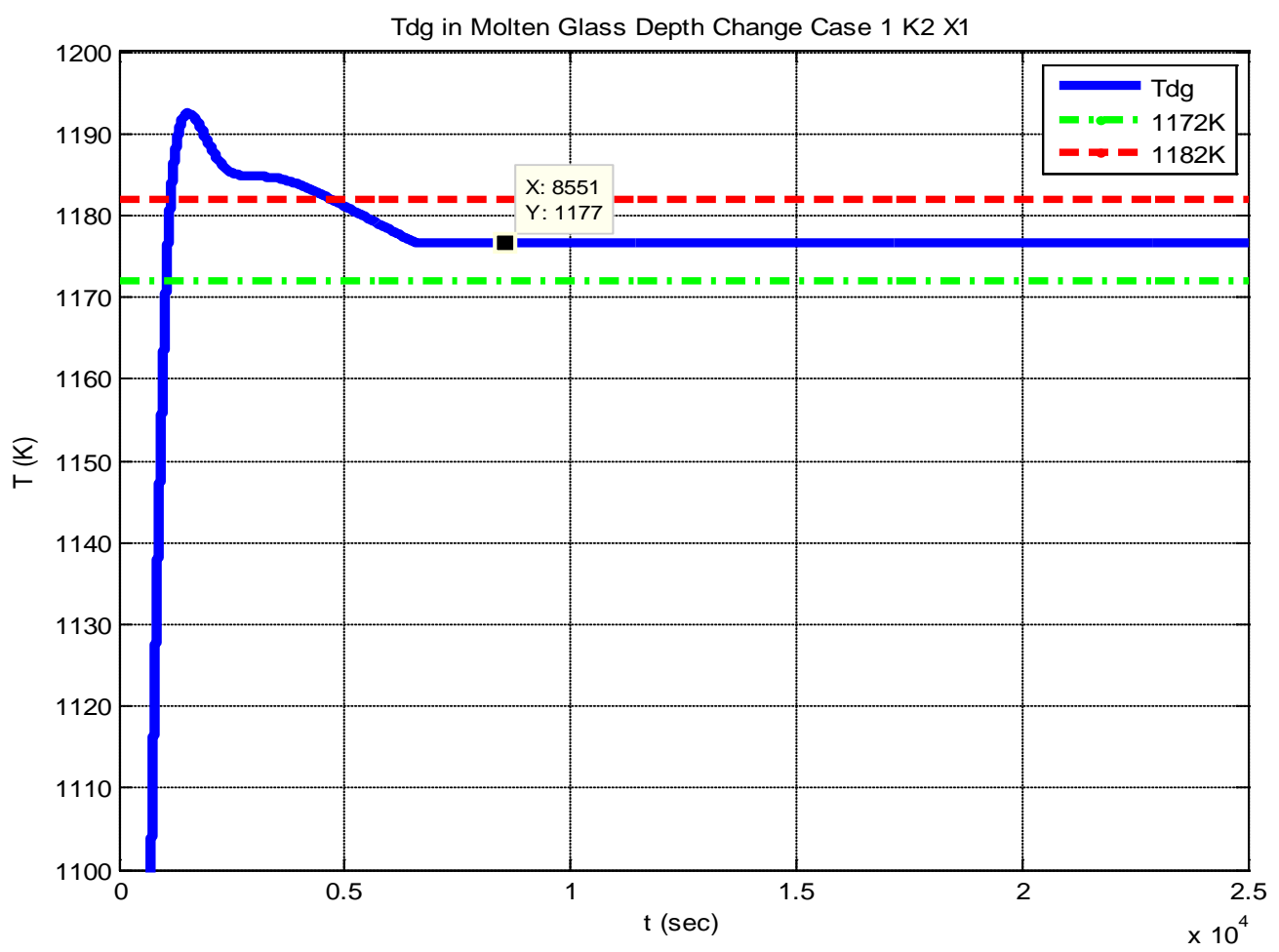

Figure 3.44 Tdg in Molten Glass Depth Change Case 1 K2 X1
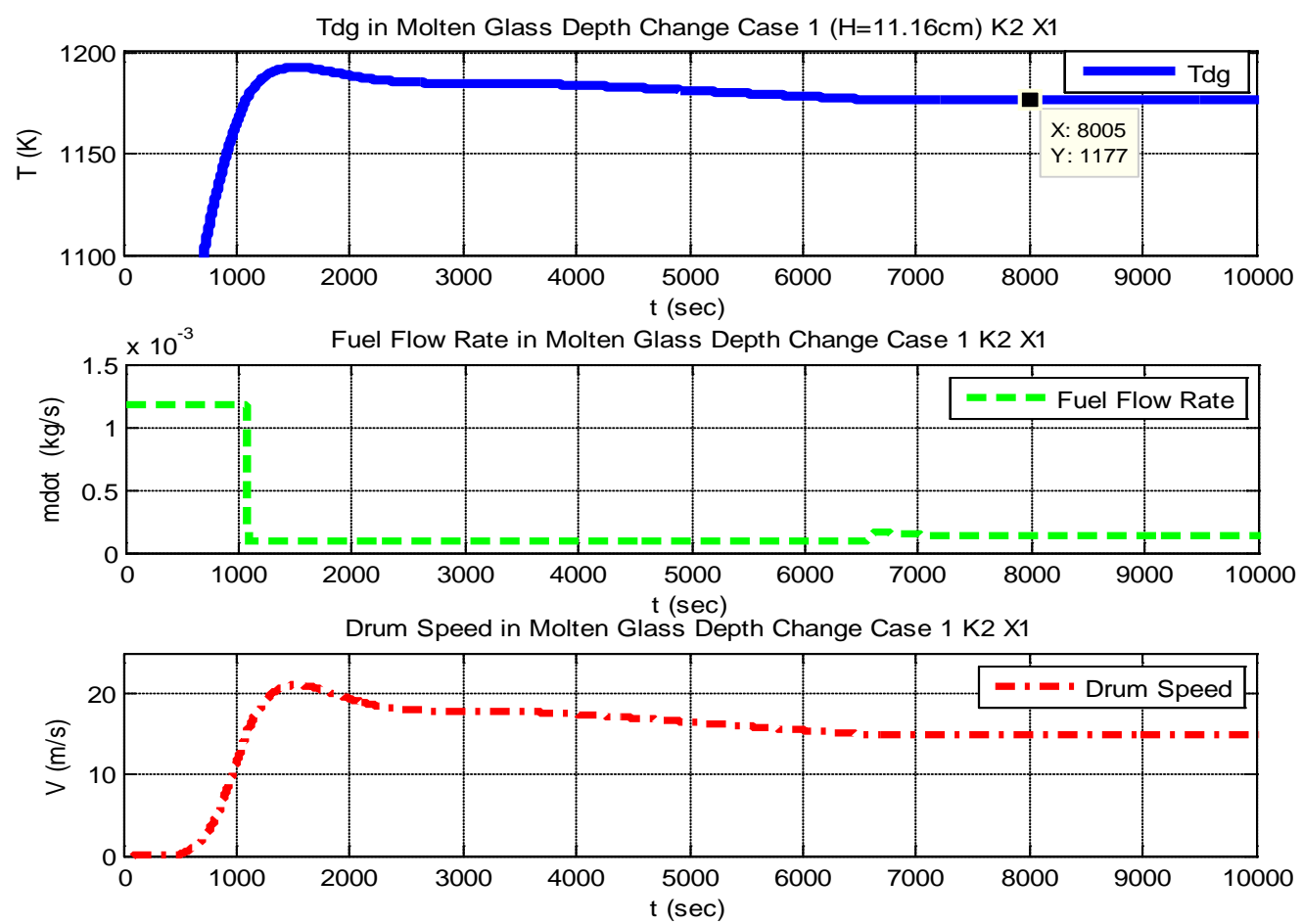

Figure 3.45 Tdg, Fuel Flow Rate in Molten Glass Depth Change Case 1 K2 X1(1) 

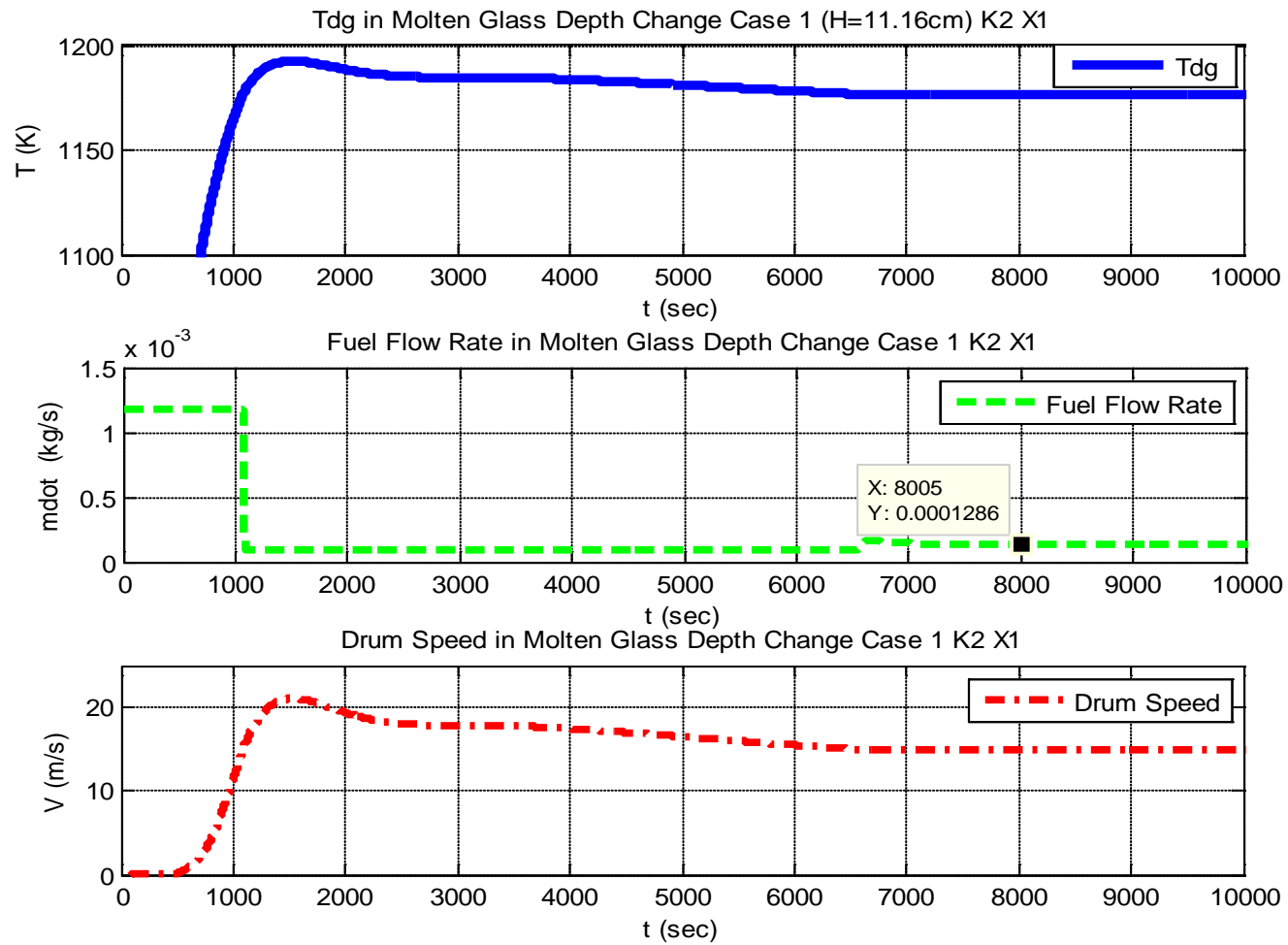

Figure 3.46 Tdg, Fuel Flow Rate in Molten Glass Depth Change Case 1 K2 X1(2)
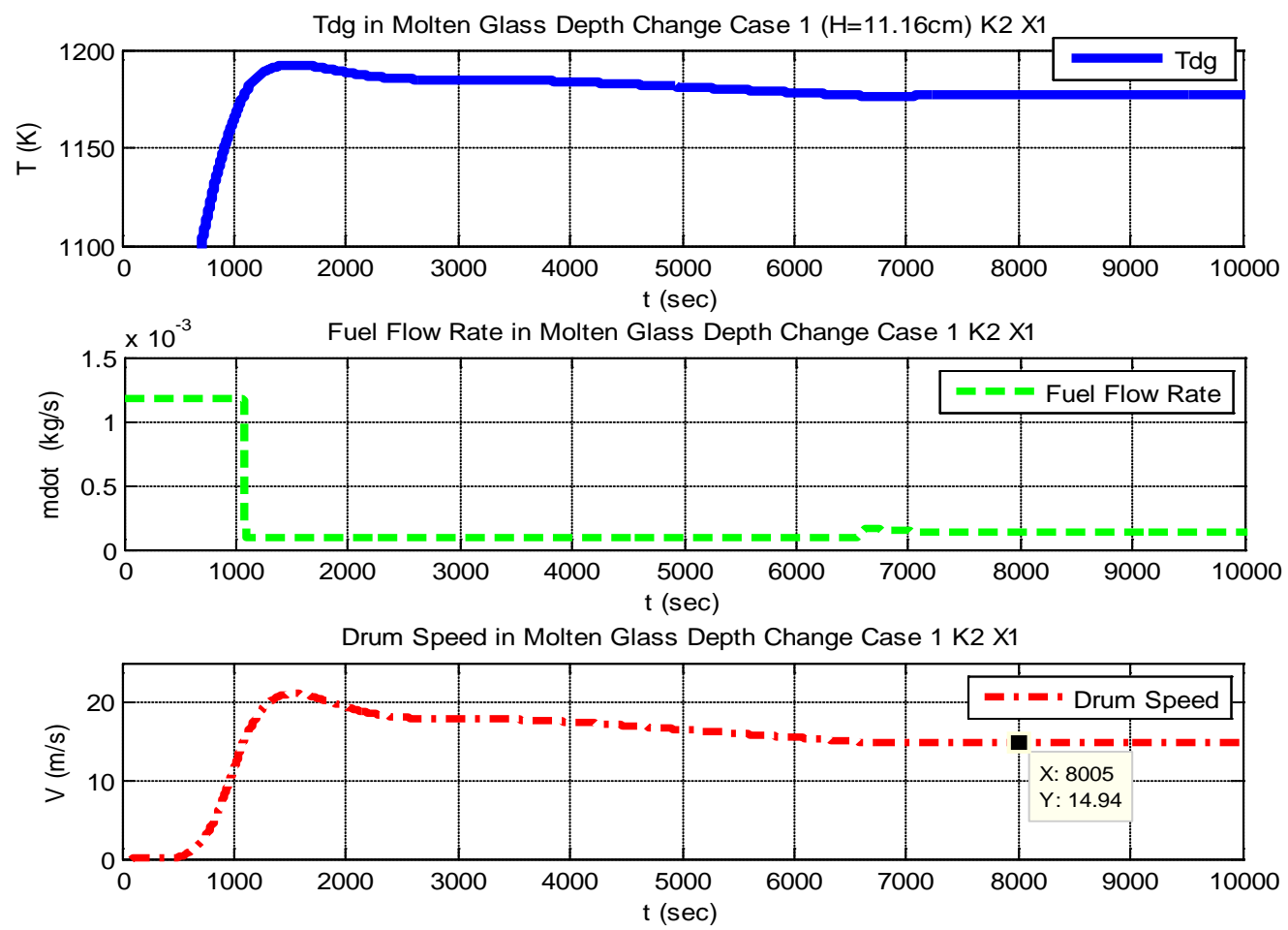

Figure 3.47 Tdg, Fuel Flow Rate in Molten Glass Depth Change Case 1 K2 X1(3) 
Case 2: Molten glass depth was constant at $9.2 \mathrm{~cm}$.

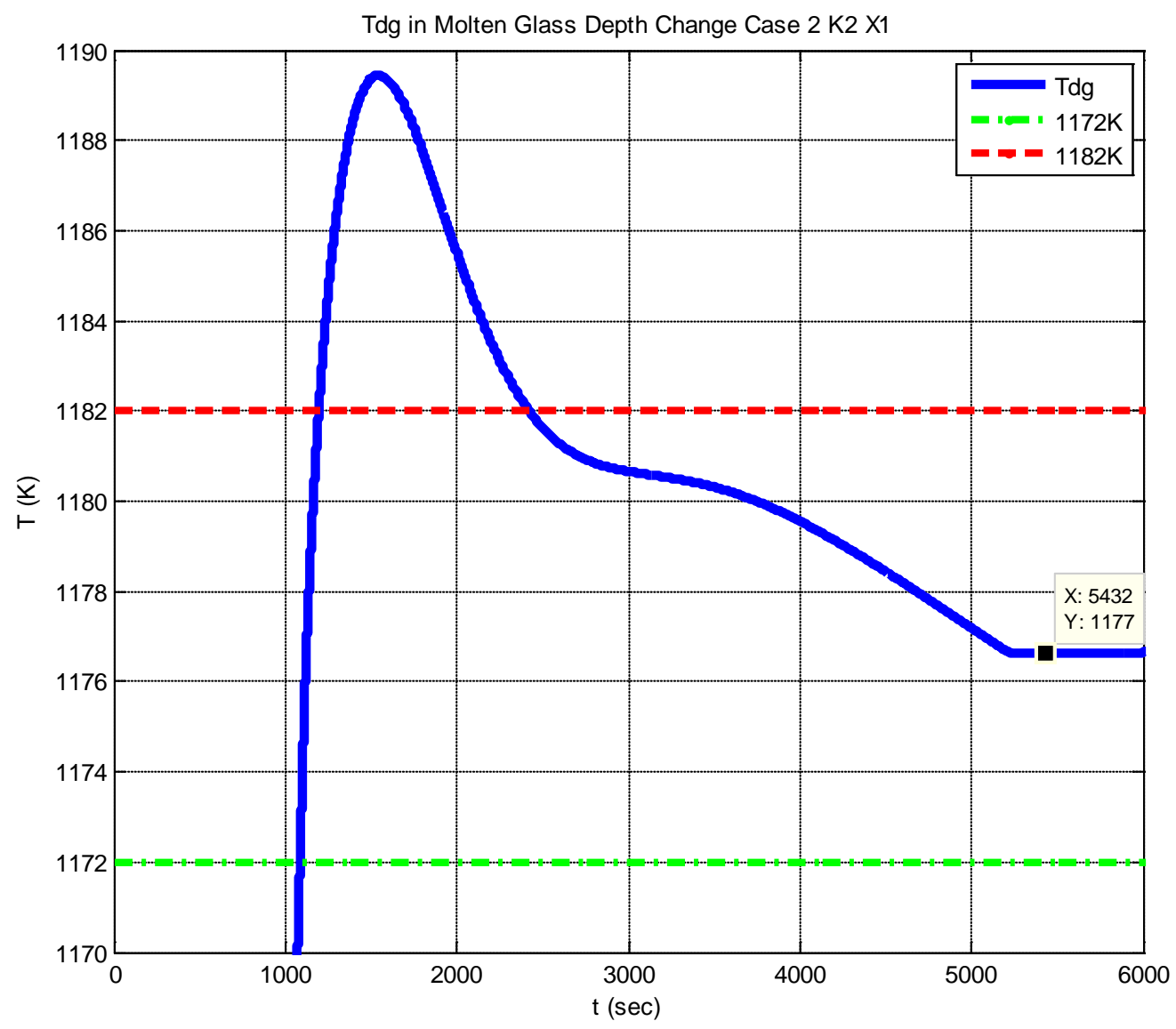

Figure 3.48 Tdg in Molten Glass Depth Change Case 2 K2 X1

For the "worst- case" uncertainty of molten glass depth $9.2 \mathrm{~cm}$ and $11.2 \mathrm{~cm}$,

LQR control model still can present desired performance for Tdg and winder speed. 


\section{Conclusions and Future Work}

Two models were developed in this study. The first one is the glass fiber drawing process model. I modeled the central attenuation region of glass fibers in the drawing process and did parametric analysis to find the relationship among the key process parameters, which is important for developing the second control model.

The second model is a LQR control model using a reduced order estimator for control of the glass furnace. It can estimate molten glass temperatures in different depths based on measurement of the combustion gas temperature and the bushing plate temperature. What is more, it can effectively control the bottom glass temperature to a desired set point by regulating the input fuel flow rate, which is essential to glass fiber production and quality. The temperature controller is able to reject disturbances in the ambient temperature over the expected range of temperatures in the factory. At the same time, the winder speed controller can guarantee the same final diameter of glass fibers in the whole process. This is important to maintain product quality during the very slow system response to temperature upsets. In addition, the control system shows good performance in handling molten glass depth uncertainty.

Some real experiments are needed to tune the controllers and refine my model. From Poiseuille's Law, the glass mass flow rate through one nozzle is only a function 
of the viscosity of the glass in the nozzle when the glass depth in the furnace, the radius and length of the nozzles are constant. Because there is temperature variance across the bushing plate, there is variance in the glass mass flow rate through different nozzles. In the future, experiments will be done using different cooling water rates, different winder speeds and different furnace temperatures to assess the influence of these parameters on the bushing plate temperature and on the temperature distribution on the bushing plates. If there is some similar pattern for the temperature distribution, I may use it to modify the diameters of the nozzles in order to get the same glass mass flow rate through each nozzle on the bushing plate to keep the final diameters of glass fibers in an acceptable range and to reduce the variance of the fiber diameters.

For the disturbance control analysis, I only considered ambient temperature and molten glass depth. Currently I just used settling time and ITAE to choose poles and gains. It is important to find a better way to figure out better gain and estimator pole combination in order to meet real requirement. Since Hळ is better than LQR in robust control, it is a good idea to apply $\mathrm{H} \infty$ to this model in the future work. 


\section{Bibliography}

[1.1] Glicksman, L.R.,’The Dynamics of a Heated Free Jet of Variable Viscosity Liquid at Low Reynolds Numbers”, Trans, ASME, J.Basic Eng., 343-354 (September, 1968)

[1.2] Purnode, B.A., Y. Bubin. "Two-dimensional finite element analysis of glass fiber forming”, Proc. XVIIIth Int. Congress Glass, San Francisco; California (1988)

[2.1] Morey, G.W. The Properties of Glass, Reinhold, New York, $2^{\text {nd }}$., 1954

[2.2] Varshneya, Arun K. Fundamentals of Inorganic Glass, Academic Press.Inc.,San Diego,CA,1993 ISBN 0-12-714970-8

[2.3] Tooley, Fay V. The Handbook of Glass Manufacture, V.1 ,2nd, Ashlee Publishing Co.Inc., New York, NY, 1984 ISBN 0-911993-21-5

[2.4] Babcock, C.L. J.Am.Ceram.Soc., 17,329(1934)

[2.5] "Borosilicate Glass Properties”, Cambridge, http://www.camglassblowing.co.uk/gproperties.htm. May 30, 2010.

[2.6] “Soda Lime Flat Float Glass ”, Valley Design Corp,

http://www.valleydesign.com/sodalime.htm. May 30, 2010.

[2.7] "Lead Glass for X-Ray/Radiation Shielding”, a-fabco,Inc, http://www.afabxray.com/Lead\%20Glass\%20for\%20Radiation\%20Shielding\%20Doc.htm May 30, 2010.

[2.8] “Lead Glass”, Wapedia. http://wapedia.mobi/en/Lead_glass. May 30, 2010.

[2.9] “Temperature dependence of liquid viscosity”, Wikipedia, http://en.wikipedia.org/wiki/Temperature_dependence_of_liquid_viscosity, February 28, 2008

[2.10] Purnode, B.A., Y. Rubin. “Two-dimensional finite element analysis of glass fiber forming”, Proc.XVIIIth Int.Congress Glass, San Francisco; California (1998)

[2.11] POLYFLOW 3.11 User's Guide, 10.2 Theory and Equation, March 14,2007: 10-9

[2.12] Gardon, R., "Calculation of Temperature Distribution in Glass Plates Undergoing Heat-Treatment”, Journal of the American Ceramic Society, Vol.41, No.6,1985:200-209

[2.13] “Optical thickness”, Encyclopedia of Laser Physics and Technology, http://www.rp-photonics.com/optical_thickness.html, May 30, 2010.

[2.14] “Black body radiation spectrum”, A course in Consciousness by Stanley 
Sobottka, www.faculty.virginia.edu/consciousness/new_page_6.htm, June 13, 2010.

[2.15] Prokhorenko,Oleg A., "Radiative Thermal Conductivity of Melts”, High Temperature Glass Melt Property Database for Process Modeling, Edited by Seward, Thomas P., Vascott, Terese., The American Ceramic Society, Westerville, Ohio, 2005:95-117

[2.16] Loewenstein,K.L., The Manufacturing Technology of Continuous Glass Fibers, Elsevier Scientific Publishing company, New York, 1973 ISBN 0-444-41109-7

[2.17] “Poiseuille’s law”, Wikipedia, http://en.wikipedia.org/wiki/Poiseuille_law, March 30, 2008

[2.18] Siegel, Melvin W., Reed H. Grundy. “Apparatus and methods for measuring the diameter of a moving elongated”, Patent Storm, http://www.patentstorm.us/patents/5015867-fulltext.html, March 29,2008.

[2.19] Hearle, J.W.S., High-performance fibers, Woodhead Publishing Ltd and CRC Press LLC, New York, 2001 Woodhead Publishing ISBN 185573539 3, CRC Press ISBN 0-8493-1304-X

[2.20] Rekhson, Simon., Jim Leonard and Philip Sanger. “Attenuation and Breakage in the Continuous Glass Fiber Drawing Process”, Ceramic Engineering and Science Proceedings, Vol.25, No.1,2004:179-190.

[2.21] Anderegg, F.O., “Strength of Glass Fiber”, Industrial and Engineering Chemistry, Vol.31, No.3, March,1939: 290-298

[2.22] Paek, U.C., “High-Speed High-Strength Fiber Drawing”, Journal of Lightwave Technology,Vol.LT-4, No.8, August, 1986:1048-1060

[2.23] Zhang, G., M.R. Thompson. "Reduced Fiber Breakage in a Glass-fiber Reinforced Thermoplastic through Foaming”, Composites Science and Technology, Vol 65, Issue 14, Nov, 2005:2240-2249

[2.24] Anderson, O.L., "Cooling Time of Strong Glass Fibers”, Journal of Applied Physics, Vol. 29, No.1, January 1958:9-12

[2.25] Otto, W.H., "Relationship of Tensile Strength of Glass Fiber to Diameter," Journal of the American Ceramic Society, Vol.38,No.3, March, 1955:122-124

[2.26] Bateson,S., "Critical Study of the Optical and Mechanical Properties of Glass Fibers”, Journal of Applied Physics, Vol.29,No.1, January 1958:13-21

[2.27] Bartenev,G..M., “The Structure and Strength of Glass Fibers”, Journal of Non-Crystalline Solids 1, North-Holland Publishing Co. Amsterdam, 1968:69-90

[2.28] Petrie, C.J.S, M.M. Denn. "Instabilities in polymer processing”, AIChE J., 22, 209-236 (1976)

[2.29] Shah, Y.T., Pearson, J.R.A., “On the stability of non-isothermal fiber spinning ”Ind. Eng. Chem. Fundam., 11[2].145-149(1972)

[2.30] Mashkar, R.D., Y.T. Shah. "Stability analysis of glass fiber spinning”, Glass Tech., 18,152-158 (1977)

[2.31] Denn, M.M., C.J.S. Petrie, P. Avenas. "Mechanics of steady spinning of a 
viscoelastic liquid”, AIChE., J.21, 791-798(1975)

[2.32] Schultz, W.W., "Slender Viscoelastic fiber flow” J.Rheol, 31[8],733-750 (1987)

[2.33] Wang,Q., M.G. Forrest. "Numerical Simulation of non-isothermal fiber spinning processes” Num. Methods Non-Newt. Fluid Dynamics, FED-179, 11-20(1994)

[2.34] Gupta,G.K., W.W. Schultz, E.M. Arruda, X. Lu. “Non-isothermal model of glass fiber drawing stability”, Rheol.Acta, 35,584-596(1996)

[2.35] Purnode, B.A., “Transient Axisymmetric Study of Glass Fiber Forming”, Proceedings of FEDSM’00, ASME 2000 Fluids Engineering Division Summer Meeting, Boston, Massachusetts, June 11-15, 2000

[2.36]“Single Glass Fiber Drawing ”, FLUENT, http://www.fluent.com/solutions/examples/x30.htm , April 13,2008

[2.37] Gough, B., P. Eng, D. Matovich. "Predictive-Adaptive Temperature Control of Molten Glass”, Dynamic Modeling Control Applications for Industry Workshop,1997., IEEE Industry Applications Society, May, 1997:51-55

[2.38] Dzyuzer,V.Ya., V.S. Shvydkii, V.N. Klimychev. "Methods for Controlling Thermal Performance of the Glass-Melting Furnace”, Glass and Ceramics, Vol.62, Nos. 3-4, 2005:105-108

[2.39] Moon, U., K.Y. Lee. “Temperature Control of Glass Melting Furnace with Fuzzy Logic and Conventional PI Control”, Proceeding of the American Control Conference, Chicago, Illinois, June,2000:2720-2724

[2.40] Moon, U., K.Y. Lee. "Hybrid Algorithm with Fuzzy System and Conventional PI Control of TV Glass Furnace”, IEEE Transactions on Control Systems Technology, Vol.11, No.4, July 2003:548-554

[2.41] Moon, U., K.Y. Lee. "Multi-Loop Control of Temperature for TV Glass Furnace”, Proceedings of the $39^{\text {th }}$ IEEE Conference on Decision and Control, Sydney, Australia, December, 2000: 4550-4555

[2.42] Wertz, V., M. Gevers, J.-F. Simon. “Adaptive Control of the Temperature of a Glass Furnace”, Adaptive Systems in Control and Signal Processing 1992: selected papers from the $4^{\text {th }}$ IFAC symposium, Grenoble, France, 1-3 July 1992/IFAC symposia series, Vol.8. 1993:331-316

[2.43] Holladay, Andrea. Rae.(2005)., "Modeling and Control of a Small Glass Furnace”. Master's Thesis, West Virginia University,[On-line Abstract]. Available:https://eidr.wvu.edu/files/4324Holladay_Andrea_thesis.pdf

[2.44] Morris, Heath. A .(2007). “Advanced Modeling for Small Glass Furnaces”. Master's Thesis, West Virginia University,[On-line Abstract].Available: https://eidr.wvu.edu/eidr/documentdata.eIDR?documentid=5066

[3.1] Fox, Robert W., Alan T. Mcdonald. Introduction to Fluid Mechanics, $2^{\text {nd }}$, John Wiley\&Sons, Inc., New York, 1978 ISBN 0-471-01909-7:35

[3.2] Kreith, Frank., Principles of Heat Transfer, $3^{\text {rd }}$, IEP-A DUN-DONNELLEY PUBLISHER., New York, 1976 ISBN 0-7002-2422-X:

[3.3] Morris, G. J., J.L. Loth, and R.E. Bond, “Cooling Rate of a Filament”, Final Contract Report to PPG Industries, Inc. 1997.

[3.4] Morris G..J.,, J.L. Loth, R.E. Bond, and A.J. Cragg, Cooling Rate of a Drawn 
Glass Filament, Final Contract Report to PPG Industries, Inc. 1999.

[3.5] Glauert, M.B. and M.J. Lighthill , The Axisymmetric Boundary Layer on a Long Thin Cylinder, Proceedings of Royal Society, Series A.P.188. (1955)

[3.6] Glicksman, L.R., The Cooling of Glass Fibres, Glass Technology, 9[5] 131 (1968)

[3.7] Xiong,Daxi., (2002). “An Experimental and Theoretical Study of the Cooling of a Thin Glass Fiber during the Formation Process”.Ph.D’s Thesis, Massachusetts Institute of Technology.

[3.8] Tooley, Fay V., The Handbook of Glass Manufacture, V.1 ed, Ashlee Publishing Co.Inc., New York, NY, 1984 ISBN 0-911993-21-5

[3.9]“LQG/LQR CONTROLLER DESIGN”, http://www.ece.ucsb.edu/ roy/classnotes/147c/lqrlqgnotes.pdf , December 12, 2009 [3.10] Franklin, Gene F., Powell, J.David., Emami-Naeini, Abbas., Feedback Control of Dynamic Systems, fifth edition, Pearson Education, In, Upper Saddle River, New Jersey 2006 ISBN 0-13-149930-0

[3.11] "Pole placement for MIMO system"

http://www.ece.arizona.edu/ cellier/ece501_ln19.pdf , December 12,2009 


\section{Appendix A. Comparison of Conduction, Radiation and Forced Convection in the Central Attenuation Region}

During the drawing process, glass fibers exchange heat energy with air by conduction, convection and radiation. At the winder speed $13.6 \mathrm{~m} / \mathrm{s}$, glass fibers are drawn from the nozzle to the drum and create forced convection heat transfer. In Glicksman's paper [1], he assumed that in the central attenuation region, radiation and conduction heat transfer are negligible compared to forced convection. In the central region of glass fiber drawing process, it is known that the Biot number for glass is less than 0.1 , which means the temperature distribution inside the glass fiber in the central region is pretty flat. The conduction we are concerned with is from glass to air and because the conduction heat transfer coefficient between air and glass is so small, it is reasonable to neglect the conduction part. Given a constant mass flow rate, I would like to verify this assumption by calculating the key parameter, the forced convective heat transfer coefficient, using a cylinder model to compare the powers of the forced convection and radiation.

The heat-transfer phenomena for these systems, as for those in which a fluid flows inside a duct or along a flat plate, are closely related to the nature of the flow. 
Kreith [2] thought the most important difference between the flow over a bluff body and the flow over a flat plate or a streamlined body lies in the behavior of the boundary layer. Analyses of the boundary-layer growth and the variation of the local unit-surface conductance with angular position around circular cylinders and spheres have been only partially successful. Over the forward portion of the cylinder ( $0<\theta<80 \mathrm{deg}$ ), the empirical equation for $h_{c \theta}$, the local value of the unit-surface conductance at $\theta$, has been found to agree satisfactorily [3] with experimental data.

$$
\frac{h_{c \theta} D_{o}}{K_{f}}=1.14\left(\frac{V_{\infty} D_{o}}{v_{f}}\right)^{0.5} \operatorname{Pr}_{f}^{0.4}\left[1-\left(\frac{\theta}{90}\right)^{3}\right]
$$

where $\rho_{\infty}=$ free-stream density, in $l b_{m} /$ cuft ;

$V_{\infty}=$ free-stream velocity, in $\mathrm{ft} / \mathrm{sec}$;

$D_{o}=$ outside diameter, in $\mathrm{ft}$.

For air, Equation A-1 can be written in the form

$$
h_{c \theta}=0.194 T_{f}^{0.49}\left(V_{\infty} \rho_{\infty} / D_{o}\right)^{0.5}\left[1-(\theta / 90)^{3}\right]
$$

where $T_{f}$ is the arithmetic average of the absolute temperatures of the free stream and of the surface in degrees Rankine R. It is apparent from the foregoing discussion that the variation of the unit-surface conductance around a cylinder or a sphere is a very complex problem. For many practical applications it is fortunately not necessary to know the local value $h_{c \theta}$, but sufficient to evaluate the average value of the conductance around the body. A number of observers have measured mean conductance for flow over single cylinders and spheres. Hilpert [4] accurately measured the average conductance for air flowing over cylinders of diameters ranging from 0.008 to nearly 6 in. His data can be correlated by the equation 


$$
\frac{\overline{h_{c}} D_{o}}{K_{f}}=C\left(\frac{V_{\infty} D_{o}}{v_{f}}\right)^{n}
$$

where $\mathrm{C}$ and $\mathrm{n}$ are empirical constants whose numerical values vary with the Reynolds number. This empirical correlation agrees with the data results within 15 percent, which is within the accuracy of the experimental data.

For liquids flowing over a single tube or wire, McAdams [5] suggests that the right-hand side of Equation A-3 be multiplied by the factor $1.1 \operatorname{Pr}_{f}^{0.31}$, that is ,

$$
\frac{\overline{h_{c}} D_{o}}{K_{f}}=1.1 C\left(\frac{V_{\infty} D_{o}}{v_{f}}\right)^{n} \operatorname{Pr}_{f}^{0.31}
$$

In my experiment, the mass flow rate is constant. Different drawing velocities correspond to different diameters of the samples. According to the different temperatures, velocities and kinematics viscosity coefficients of air, I can get different Reynolds numbers, and the corresponding values of $\mathrm{C}$ and $\mathrm{n}$ by using following table.

\begin{tabular}{|l|r|r|}
\hline Re Df & \multicolumn{1}{|l|}{ C } & \multicolumn{1}{l|}{. } \\
\hline $0.4-4$ & 0.891 & 0.33 \\
\hline $4-40$ & 0.821 & 0.385 \\
\hline $40-4000$ & 0.615 & 0.466 \\
\hline $4000-40000$ & 0.174 & 0.618 \\
\hline $40000-400000$ & 0.0239 & 0.805 \\
\hline
\end{tabular}

Table A.1 Coefficients for Calculation of Average Heat Transfer Coefficient of a Circular Cylinder in Air Flowing Normal to Its Axis by Equation A-3 and A-4[Kreith]

There is some difference between my case and the case in Equation A-4. In the drawing process, the air flows over the surface of glass fibers along the axial direction like flowing over streamlined bodies while Equation A-4 is for air flowing over the surface in the direction normal to the glass fibers axis. Obviously, the forced convection from the direction normal to the axis is stronger than the one along the 
axis. So the actual forced convection power is smaller than the result from Equation A-4.

First, I would like to use Equation A-4 to calculate average forced convective heat transfer coefficient. Because glass fibers in the central region have the shape gradient less than 0.1 , I approximated them as a glass cylinder with length $\mathrm{L}$, diameter $\mathrm{D}$ and temperature T. Then I compute the Reynolds number and air conductive heat transfer coefficient, air kinematic viscosity and Prandtl number at $\mathrm{T}$ in order to get the convective coefficient from Equation A-4. After that, I compared the power of forced convection with the power of radiation. The diameter $\mathrm{D}$ of the cylinder is varied from 0.007in to $0.0000984 \mathrm{in}$, and temperature $\mathrm{T}$ is varied from $100^{\circ} \mathrm{C}$ to $950^{\circ} \mathrm{C}$ because currently I am not sure about the average diameters and temperatures of glass fibers in the central region and the actual values should be covered in those experiment data.

Please see Figure A.1, it can be seen that given a constant mass flow rate, for some temperature, ratios of forced convection to radiation increase with the decrease of sample diameters; for some constant diameter of sample, ratios increase when I decreased the temperature of samples. It is obvious that during the diameter range of 0.0018in to $0.007 \mathrm{in}$, no matter what temperature I set from $100^{\circ} \mathrm{C}$ to $950^{\circ} \mathrm{C}$, the ratios always are less than 50. Under this condition, radiation should not be neglected comparing with forced convection. But when the diameter is small enough and the temperature is low enough, the ratios can be high enough to let me neglect the radiation. For example, when the temperature is $100^{\circ} \mathrm{C}$ and the diameter is only 0.0000984 in, the ratio of forced convection to radiation is 326. Most important of all, 
the actual forced convection is weaker than what I calculated here, so probably the actual ratio plots should be lower than the ones in Figure A.1.

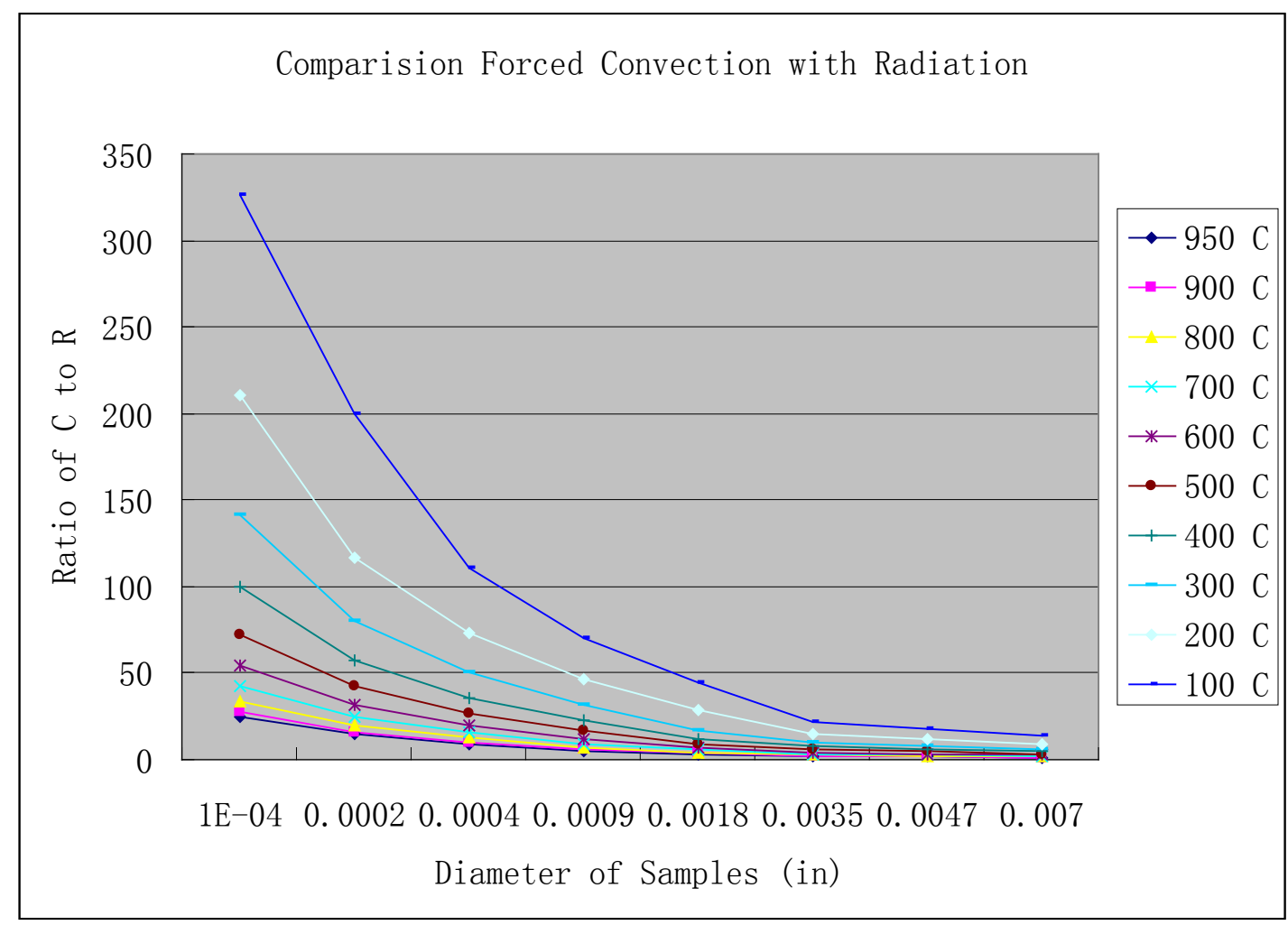

Figure A.1.Comparison of Forced Convection and Radiation

Anyway whether the radiation should be neglected or not compared with the forced convection in the central attenuation region, depends on the actual average diameter and average temperature of glass fibers. Given the results of this investigation, it was decided to include a radiation heat transfer term in the glass fiber drawing process model. 
[1] Glicksman, L.R.,’The Dynamics of a Heated Free Jet of Variable Viscosity Liquid at Low Reynolds Numbers”, Trans, ASME, J.Basic Eng., 343-54 (1968)

[2] Kreith, Frank., Principles of Heat Transfer, 3rd, IEP-A DUN-DONNELLEY PUBLISHER., New York, 1976 ISBN 0-7002-2422-X: 457.

[3]Martinelli,R.C., Guibert,A.G.., Morin,E.H., and Boelter,L.M.K., “An Investigation of Aircraft Heaters VIII-A Simplified Method for Calculating the Unit-Surface Conductance over Wings,” NACA ARR, March, 1943.

[4]Hilpert,R., “Warmeabgabe von geheizten Drahten und Rohren,” Forsch.Gebiete Ingenieurw., Vol.4(1933),p.215.

[5] McAdams, W.H., Heat Transmission, 3d ed. (New York: McGraw Hill Book Company, Inc., 1953.)

[6] Kreith, Frank., Principles of Heat Transfer, 3rd, IEP-A DUN-DONNELLEY PUBLISHER., New York, 1976 ISBN 0-7002-2422-X: 468. 


\section{Appendix B Comparison of Gravity Force with Surface Tension}

Poiseuille's Law (or Hagen-Poiseuille Law) is the physical law concerning the voluminal laminar stationary flow $\Phi$ of an incompressible uniform viscous liquid (so called Newtonian fluid) through a cylindrical tube with constant circular cross-section. It may be expressed in the following form:

$$
\phi=\frac{d V}{d t}=v \pi R^{2}=\frac{\pi R^{4}}{8 \eta}\left(\frac{-\Delta P}{\Delta x}\right)=\frac{\pi R^{4}}{8 \eta} \frac{|\Delta P|}{L}
$$

where $\mathrm{V}$ is a volume of the liquid, flowing in the time unit $\mathrm{t}, \mathrm{v}$ the mean fluid velocity along the length of the tube (given in meters/second), $\mathrm{x}$ the direction of flow, $\mathrm{R}$ the internal radius of the tube (given in meters), $\Delta P$ the pressure difference between the two ends (given in $\mathrm{mmHg}$ ), $\eta$ the dynamic fluid viscosity (given in cPs, or centi-Poisseuille's), and $\mathrm{L}$ the total length of the tube in the $\mathrm{x}$ direction (given in meters) [1].

Generally, the law is used for the horizontal tube or cylinder case. In the glass fiber drawing process, the Poiseuille Law is applied to calculate the flow rate through the single nozzle on the bushing plate. Hearle thought the rate of fiber production at the nozzle is a function of the rate of flow of glass, not the rate of attenuation, which only determines final diameter of the fiber [2]. This means the rate of attenuation, or the drawing force from the winder, has nothing to do with the flow rate, only with the 
final dimension of the glass fibers. According to the Hagen-Poiseuille Law, Rekhson concluded the flow rate through the nozzles is higher in the middle of the bushing plate and lower on the periphery because the glass melt is cooler at the walls of the bushing and hotter in the middle. He modified the Hagen-Poiseuille equation and got this mass flow rate in a nozzle:

$$
V_{0}=\left(\rho g H+\sigma_{0}\right) R_{0}^{2} /\left[8 L_{0} \eta_{0}\left(1+\frac{3 \pi R_{0}}{8 L_{0}}\right)\right]
$$

where $\mathrm{V}_{\mathrm{o}}=$ flow rate in the nozzle; g=gravity constant; $\mathrm{H}=$ molten glass depth; $\sigma_{0}=$ stress from the winder; $R_{0}, L_{0}=$ nozzle radius, nozzle length; $\eta_{0}=$ dynamic fluid viscosity in the nozzle [3].

Rekhson modified the Poiseuille Law and gave another explanation of the $\Delta P$. He thought the drawing force should contribute to the pressure difference, and for the vertical cylinder case, the drawing force on the fibers also plays a role on the flow rate through the single nozzle.

Molten glass is a laminar fluid, and the drawing force depends on the surface tension to pull the glass down. So we need to compare the gravity force ( $\left.\rho g \mathrm{H}^{*} \mathrm{~S}\right)$ with the surface tension on the corresponding single cross section in order to get the right explanation of the $\Delta P$.

Tooley concluded that commercial glasses possess surface-tension values at $1200^{\circ} \mathrm{C}$, which usually lies in the range of about 245 to 320 dynes per cm per ${ }^{\circ} \mathrm{C}$. The temperature coefficient is usually from -0.02 to $-0.04[4]$ (Page 36). And the ratio of gravity force to the surface tension can be expressed: 


$$
R=\frac{\rho g H \pi r^{2}}{2 \alpha \pi r \cos \theta}=\frac{\rho g H r}{2 \alpha \cos \theta}
$$

where $\mathrm{R}$ is the ratio, $\mathrm{H}(\mathrm{m})$ is the distance from the molten glass top surface to the point where we calculate, $r(m)$ is the radius of glass fiber where we calculate, $\alpha(\mathrm{N} / \mathrm{m})$ is the surface tension coefficient, $\theta$ (radian) is the angle between the tangent to the jet surface, and the axial direction in the r-z plane.

The analysis was conducted by making reasonable assumption about $\mathrm{T}(\mathrm{z}), \mathrm{R}(\mathrm{z})$ from measurements and photographs. For several scenarios, the ratio of gravity forces to surface tension forces was computed. The results were consistent across different assumed functions of R (z) and T (z). A typical plot is shown in Figure B.1.

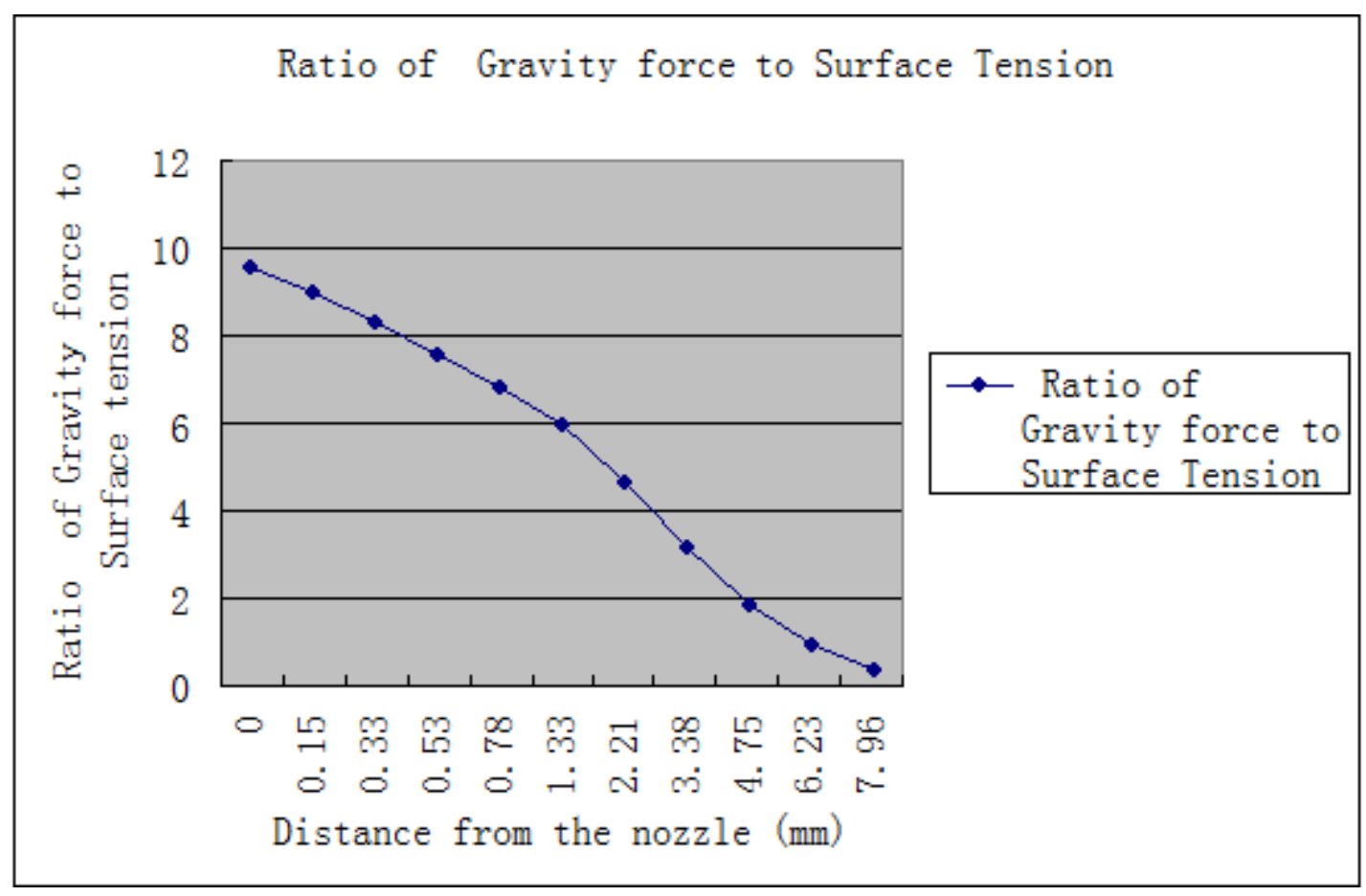

Figure B.1 Ratio of Gravity to Surface Tension

From the figure above, it can be seen easily that the nearer the cross section is to the nozzle, the bigger the ratio is. According to Glicksman, the upper attenuation region is the distance from the nozzle to the 3 or 4 times of radius of the nozzle, where the absolute value of slope of the jet shape is greater than one tenth [5]. In my 
case, the radius of the nozzle is $2.135 \mathrm{~mm}$, so the range for the upper part should be from $0 \mathrm{~mm}$ to $6.405 \mathrm{~mm}$ or $8.54 \mathrm{~mm}$. In Figure B.1, all the testing points are in the upper meniscus region, and the ratio changes from 9.57 to 0.38 . The surface tension is small enough to be neglected compared with the gravity force near the nozzle in the upper meniscus region. When the distance from the nozzle becomes long until the fibers stick to the winder, the ratio shows the surface tension is dominant to the gravity force. So Loewenstein, Hearle and other researchers agree to use the Poiseuille's Law to calculate the flow rate through the single nozzle and conclude that the rate of attenuation or the drawing force has nothing to do with the flow rate. The drawing speed thus affects the fiber final diameter but not the mass flow rate through the nozzle.

[1] “Poiseuille’s law”, Wikipedia, http://en.wikipedia.org/wiki/Poiseuille_law, March 30, 2008

[2] Hearle,J W S., High-performance Fibers, Woodhead Publishing Ltd and CRC Press LLC, New York, 2001 Woodhead Publishing ISBN 185573539 3, CRC Press ISBN 0-8493-1304-X

[3] Rekhson, Simon., Leonard, Jim., and Sanger, Philip., “Attenuation and Breakage in the Continuous Glass Fiber Drawing Process”, Ceramic Engineering and Science Proceedings, Vol.25, No.1,2004:179-190.

[4]Tooley, Fay V., The Handbook of Glass Manufacture, V.1 ed, Ashlee Publishing Co.Inc., New York, NY, 1984 ISBN 0-911993-21-5

[5] Glicksman, L.R.,’The Dynamics of a Heated Free Jet of Variable Viscosity Liquid at Low Reynolds Numbers”, Trans, ASME, J.Basic Eng., 343-54 (1968) 


\section{Appendix C Parametric Analysis for the} Glass Fiber Model in the Drawing

\section{Process}

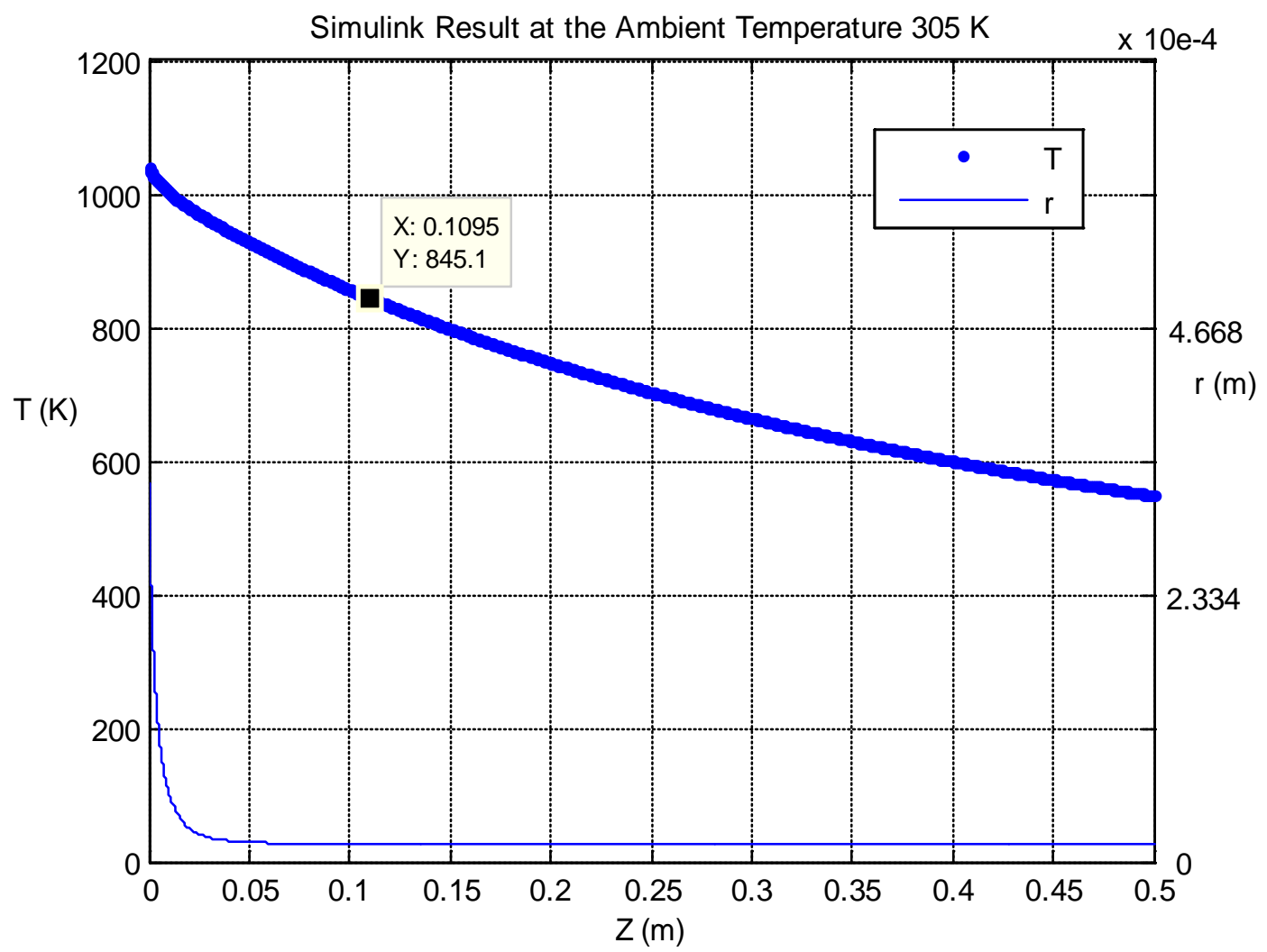

Figure C.1 Fiber Radius and Temperature as Functions of $\mathrm{z}$ for $\mathrm{Ta}=305 \mathrm{~K}$ 


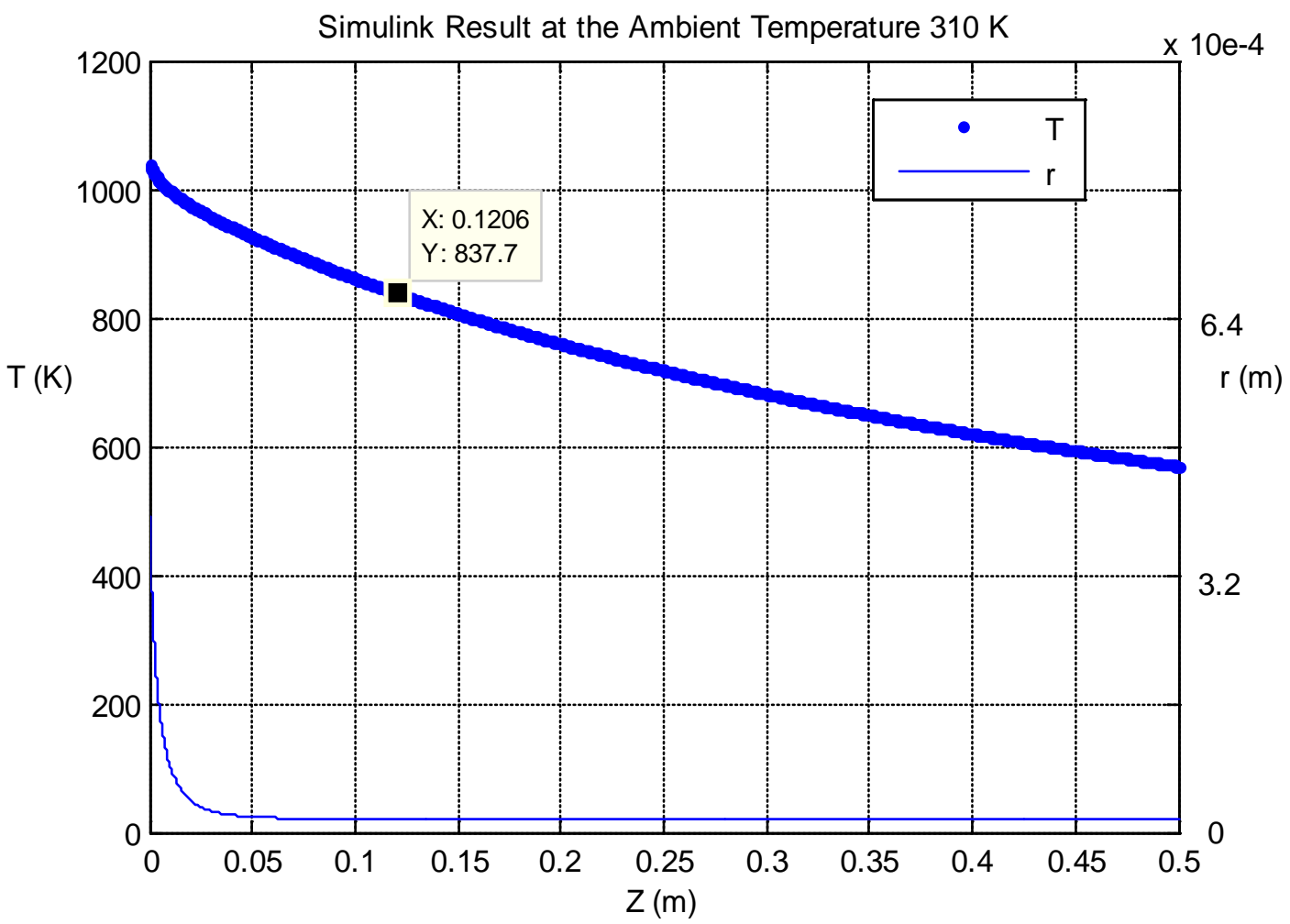

Figure C.2 Fiber Radius and Temperature as Functions of $\mathrm{z}$ for Ta=310K

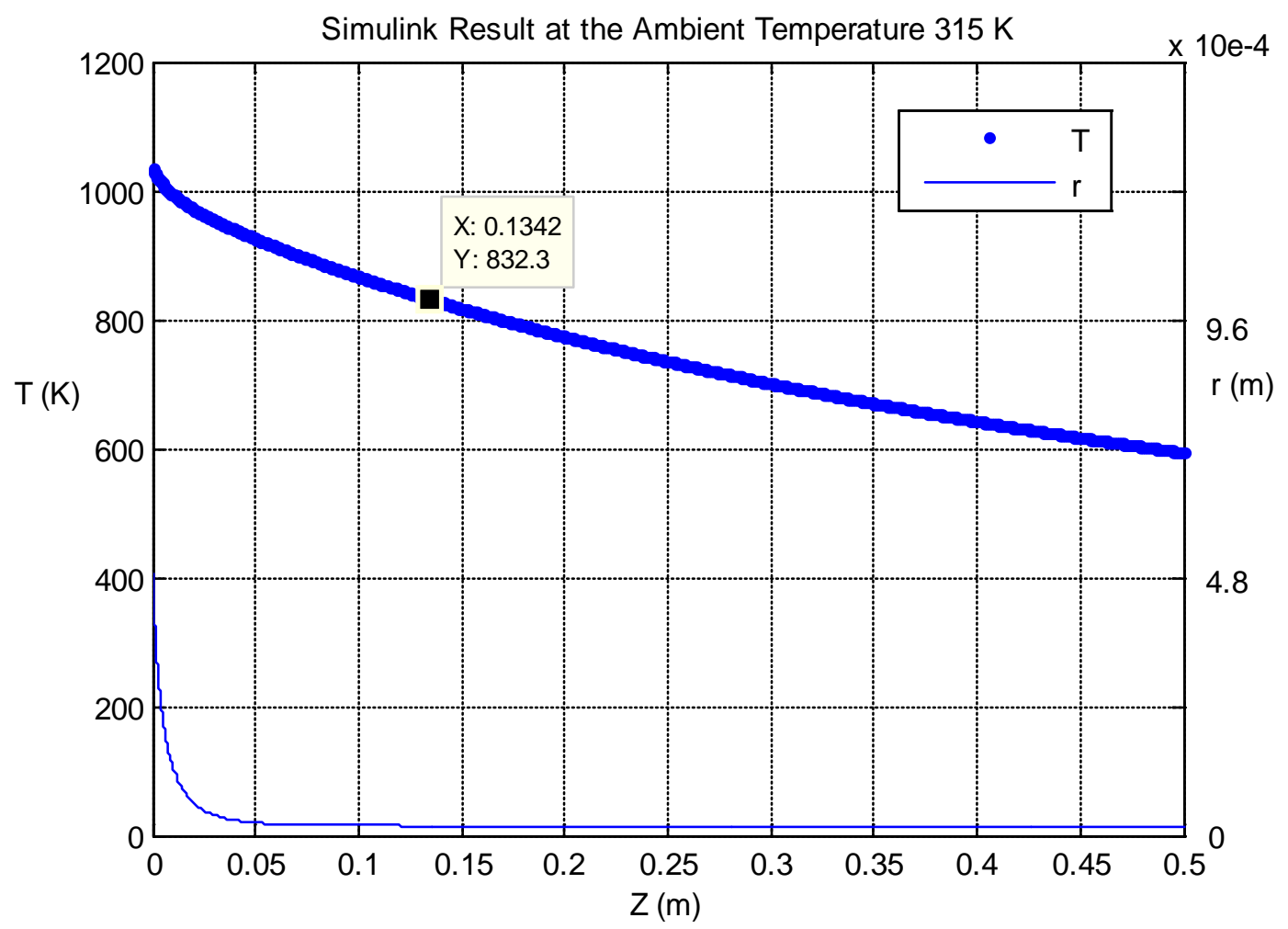

Figure C.3 Fiber Radius and Temperature as Functions of $\mathrm{z}$ for Ta=315K 


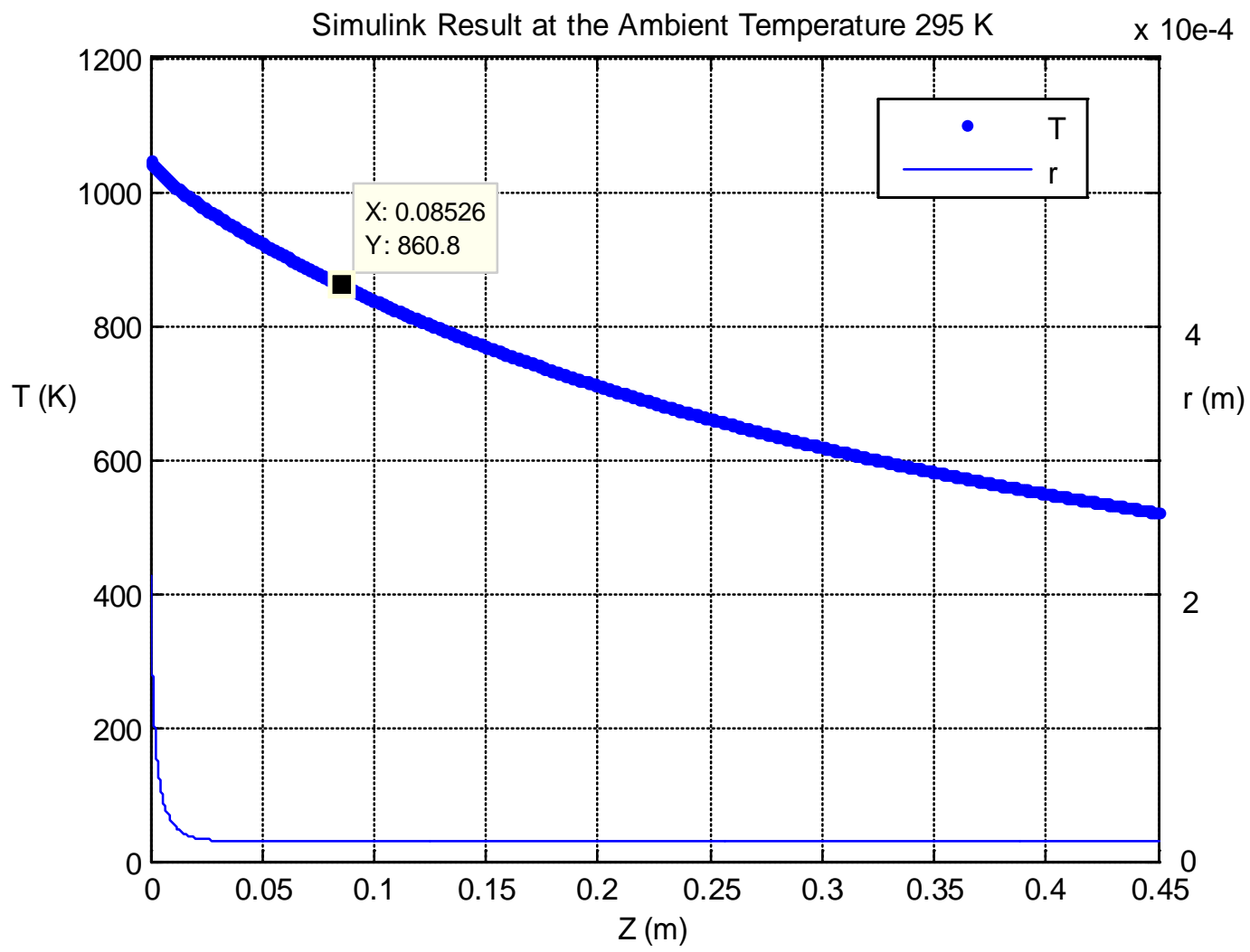

Figure C.4 Fiber Radius and Temperature as Functions of $\mathrm{z}$ for $\mathrm{Ta}=\mathbf{2 9 5 K}$

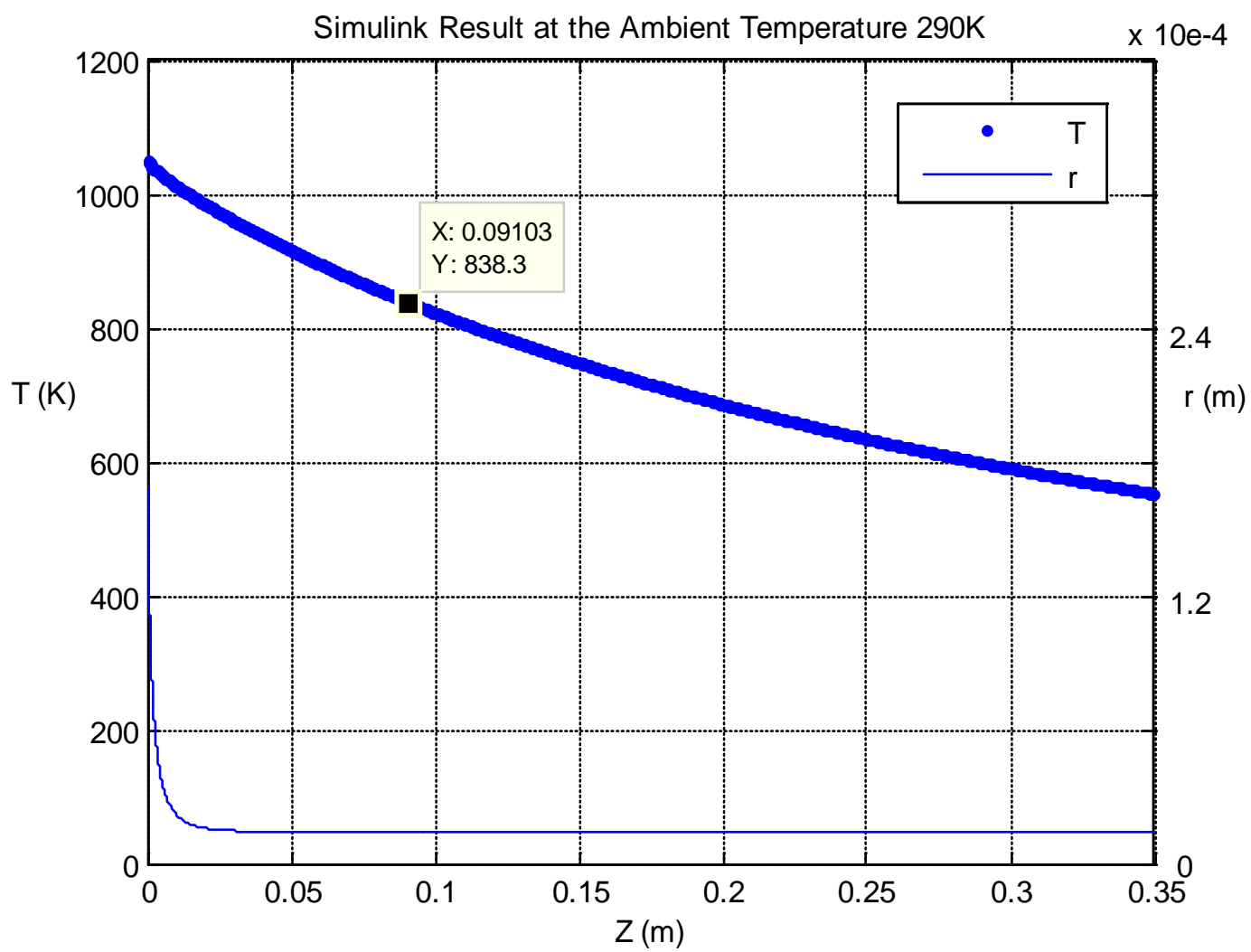

Figure C.5 Fiber Radius and Temperature as Functions of $\mathrm{z}$ for $\mathrm{Ta}=290 \mathrm{~K}$ 


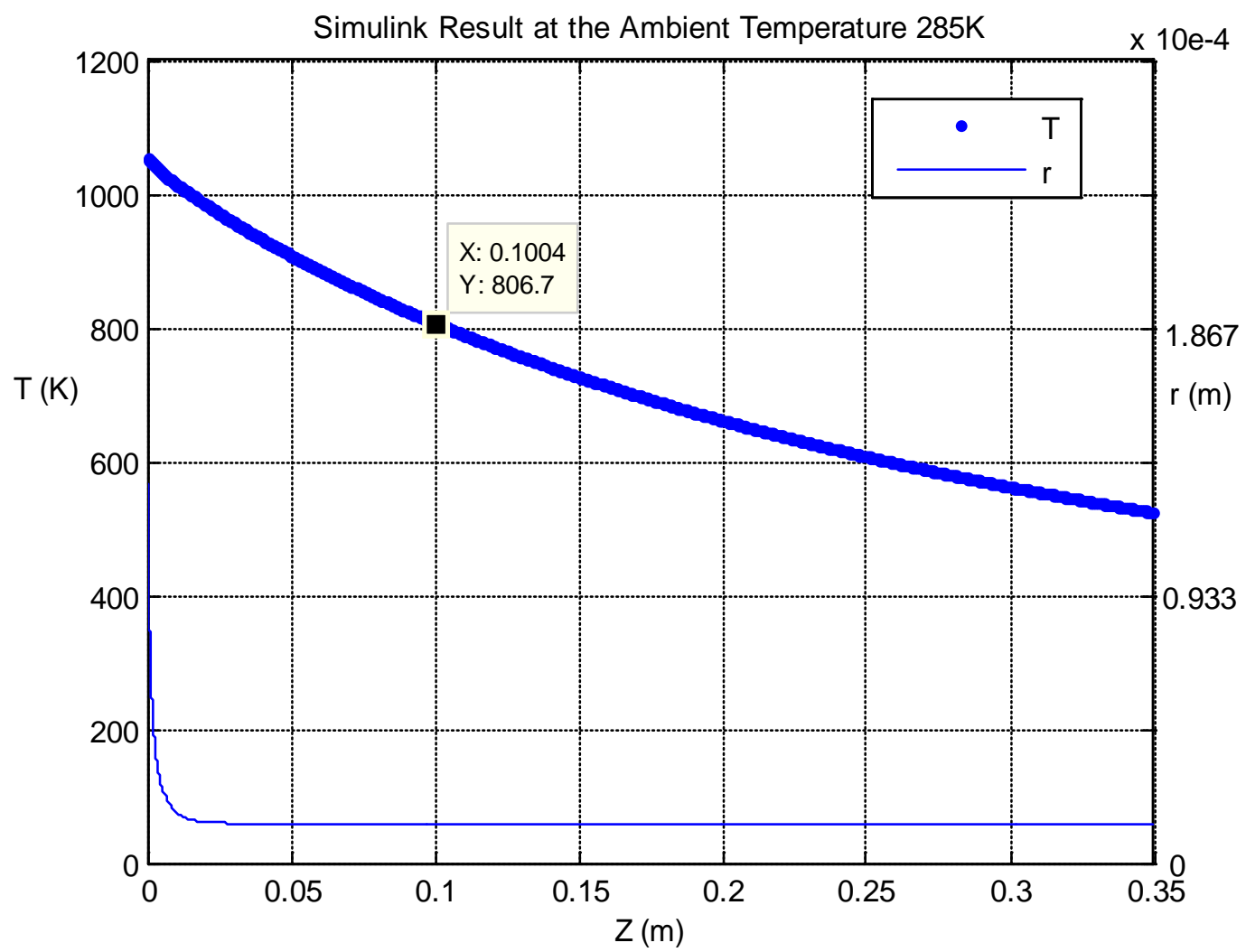

Figure C.6 Fiber Radius and Temperature as Functions of $\mathrm{z}$ for $\mathrm{Ta}=\mathbf{2 8 5 K}$

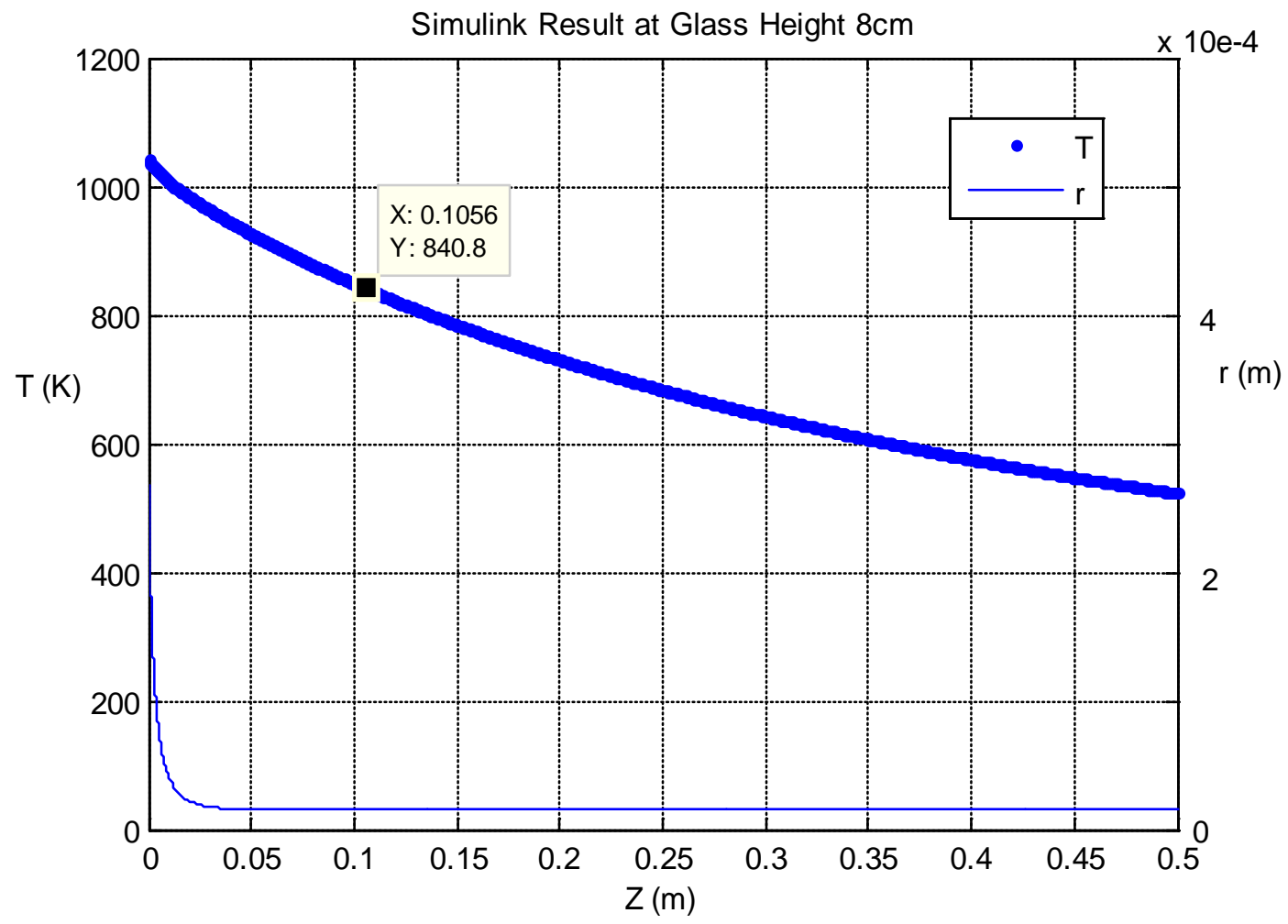

Figure C.7 Variation of T (z) and r (z) with Glass Height $8 \mathrm{~cm}$ 


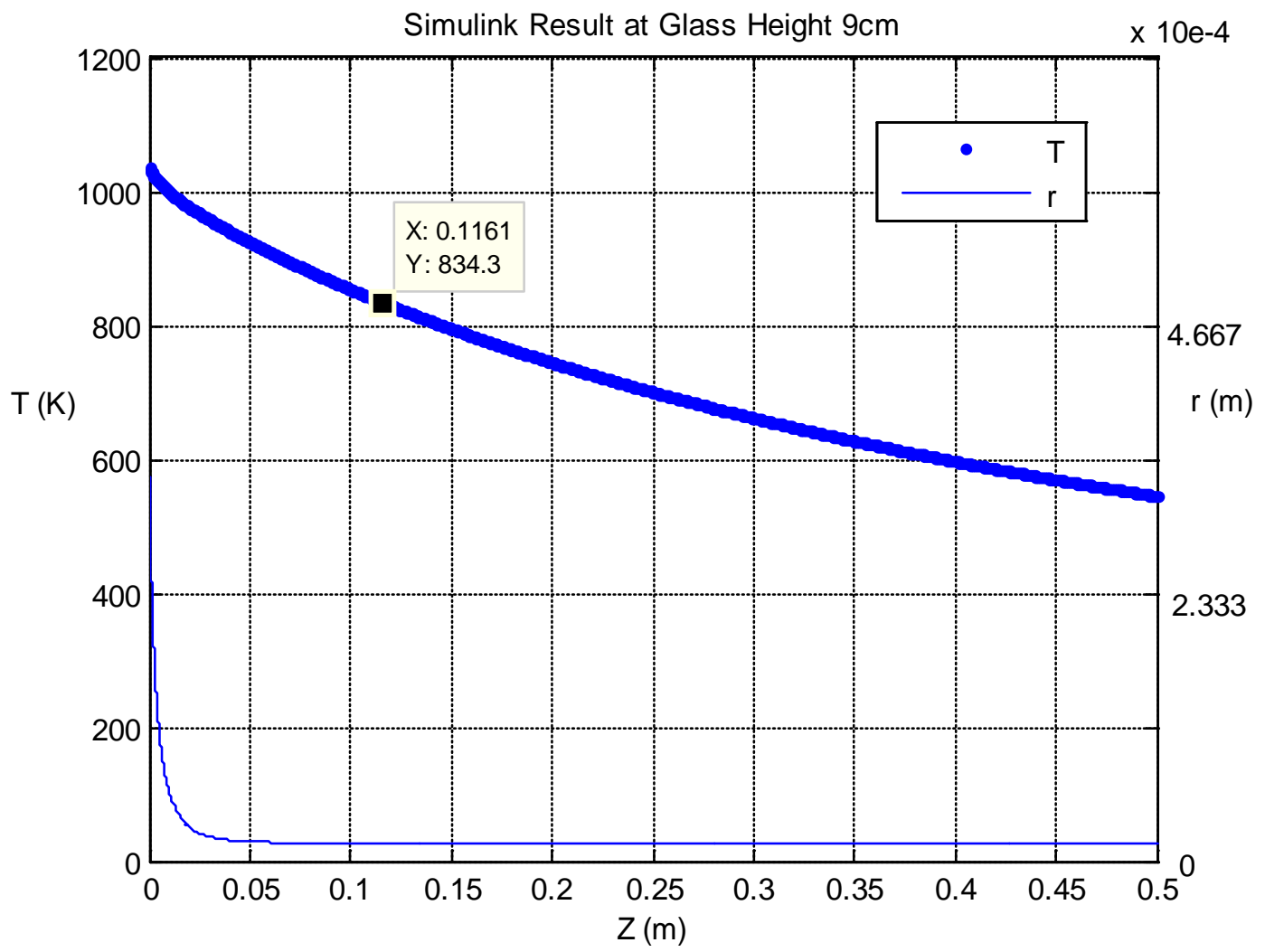

Figure C.8 Variation of T (z) and r (z) with Glass Height $9 \mathrm{~cm}$

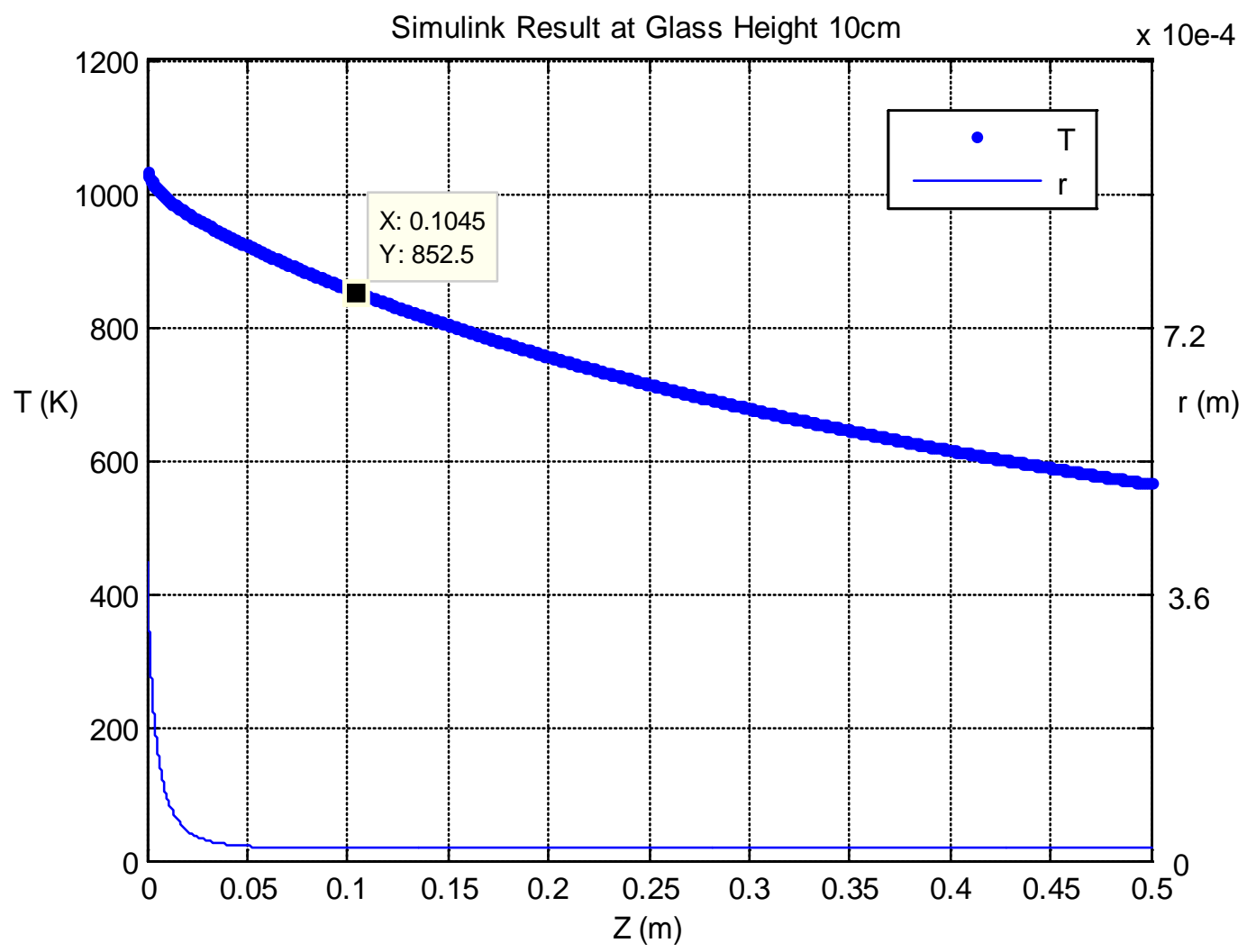

Figure C.9 Variation of $T(z)$ and $r(z)$ with Glass Height $10 \mathrm{~cm}$ 


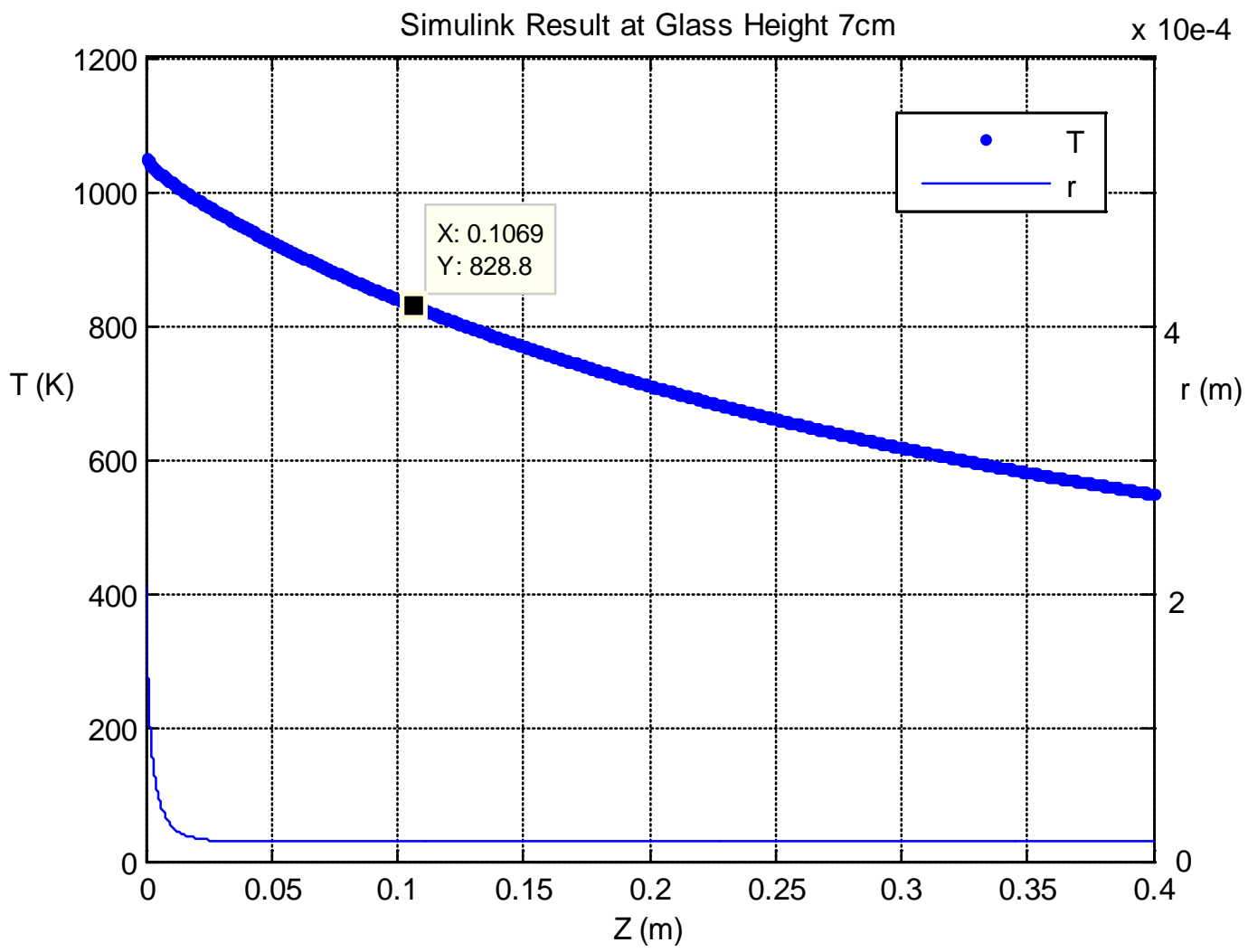

Figure C.10 Variation of $T(z)$ and $r(z)$ with Glass Height $7 \mathrm{~cm}$

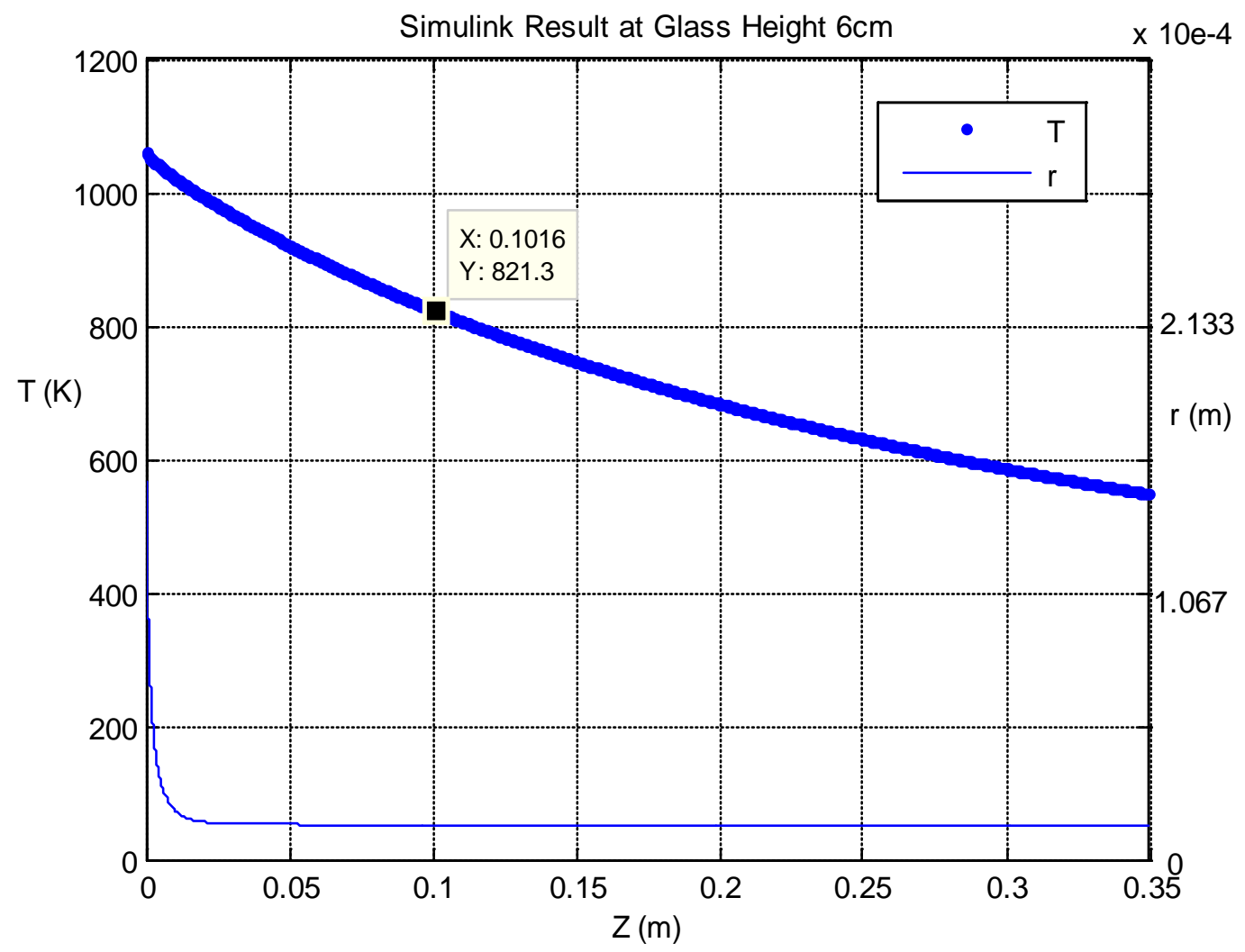

Figure C.11 Variation of $T(z)$ and $r(z)$ with Glass Height $6 \mathrm{~cm}$ 


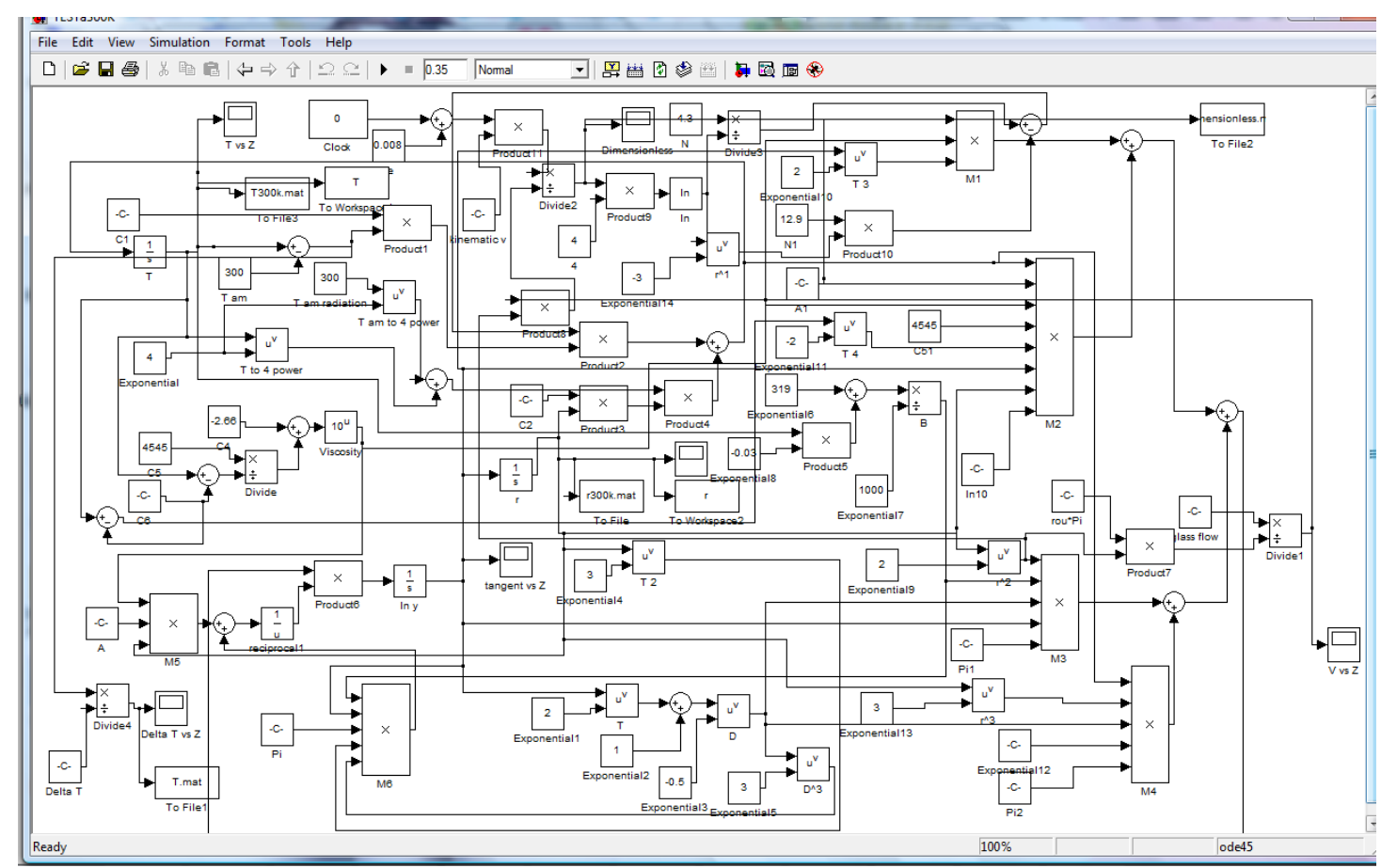

Figure C.12 Simulink Diagram for Glass Fiber Model

$\%$ M-file of Te calculation for the glass fiber model in drawing process $\mathrm{v}=149 * 5.4854 / 60 ; \%$ winder speed $\mathrm{m} /$ second $\mathrm{df}=3 \mathrm{e}-05 ; \quad \%$ final diameter of glass fiber $\mathrm{s}=\mathrm{pi} * \mathrm{df} * \mathrm{df} / 4 ; \quad \%$ area of final glass fiber rou $=2475 ; \%$ density of glass fiber $\mathrm{w} 1=\mathrm{s} * \mathrm{v} * \mathrm{rou} ; \quad \%$ the mass flow rate $2.3831 \mathrm{e}-005 \mathrm{~kg} / \mathrm{sec}$ c4=-2.66; \% Fulcher constants in Fulcher law c5=4545; \% Fulcher constants in Fulcher law c6=216.6; \% Fulcher constants in Fulcher law $\mathrm{T} 0=900 ; \quad \%$ average temperature on the bushing plate miu $0=10^{\wedge}(\mathrm{c} 4+\mathrm{c} 5 /(\mathrm{T} 01-\mathrm{c} 6)) ; \quad \%$ viscosity calculated by Fulcher law ST0 $=(283-0.03 *(\mathrm{~T} 0-1200)) * 0.001 ; \quad \%$ surface tension thita $0=-88 * \mathrm{pi} / 180 ; \quad \%$ angle between the tangent to the fiber surface at the nozzle position.

thitae=-0.0996686525; \% angle between the tangent to the fiber surface at the start point of the central attenuation region.

$\mathrm{B} 1=-1 * 6 * \mathrm{w} 2 * 10 \wedge(\mathrm{c} 4+\mathrm{c} 5 /(\mathrm{T} 0-\mathrm{c} 6)) * \tan ($ thita 0$) / \mathrm{rou} / \mathrm{r} 0 ; \quad \%$ using constant tension assumption to calculate Te.

$\mathrm{B} 2=\mathrm{pi}{ }^{*} \mathrm{r} 0 * \mathrm{ST} 0 * \cos ($ thita 0$)$;

$\mathrm{B} 3=0.6 * \mathrm{w} 2 / \mathrm{rou} / \mathrm{re}$;

B4=pi*re* $\cos$ (thitae);

Te=fzero(@(x)B3*10^(c4+c5/(x-c6))+B4*(283-0.03*(x-1200))*0.001-B1-B2,T0);

\% Using constant tension assumption to calculate Te

$\mathrm{Te}=\mathrm{Te}+273.15 ; \quad \% \mathrm{Te}$ in Kelvin 


\section{Appendix D Black Body Spectrum Calculation in Our Model}

According to the Planck's Law [1]:

$$
\begin{gathered}
E_{b \lambda}(\lambda, T)=\frac{C_{1}}{\lambda^{5}\left(e^{C_{2} / \lambda T}-1\right)} \\
C_{1}=8 \pi h c \\
C_{2}=\frac{h c}{k}
\end{gathered}
$$

where $E_{\mathrm{b} \lambda}=$ monochromatic (wavelength $\lambda$ ) emissive power of a blackbody at temperature $\mathrm{T}$ in $\mathrm{W} / \mathrm{m}^{3}$

$$
\begin{aligned}
& \lambda=\text { wavelength in } \mathrm{m} \\
& \mathrm{T}=\text { absolute temperature of the body in degree } \mathrm{K} \\
& \mathrm{C} 1=374.15 \times 10^{-18} \mathrm{~W} \mathrm{~m}^{2} \\
& \mathrm{C} 2=14.388 \times 10^{-3} \mathrm{~m} \mathrm{~K} \\
& \mathrm{~h}=\text { Planck constant, } 6.62606896 \times 10^{-34} \mathrm{~J} \mathrm{~s} \\
& \mathrm{c}=\text { speed of light, } 2.99792458 \times 10^{8} \mathrm{~m} / \mathrm{s} \\
& \mathrm{k}=\text { Boltzmann constant, } 1.3806504 \times 10^{-23} \mathrm{~J} / \mathrm{K}
\end{aligned}
$$

The radiance emitted over a frequency range [f1 , f2] or a wave length range $[\lambda 2, \lambda 1]=[\mathrm{c} / \mathrm{f} 2, \mathrm{c} / \mathrm{f} 1]$ can be obtained by integrating the respective functions at some $\mathrm{T}$. At T,

$$
P_{\lambda 2-\lambda 1}=\int_{\lambda 2}^{\lambda 1} E(\lambda, T) d \lambda=\int_{\lambda 2}^{\lambda 1} \frac{8 \pi h c}{\lambda^{5}\left(e^{\frac{h c}{\lambda k T}}-1\right)} d \lambda
$$

where $\mathrm{P}_{\lambda 2-\lambda 1}$ is the unit spectral energy density within the band defined by $\lambda 2, \lambda 1$, 
unit is $\mathrm{W} / \mathrm{m}^{2}$.

And $\mathrm{P}_{0-\infty}$ is the unit spectral energy density within the whole band.

$$
R=\frac{P_{\lambda 2-\lambda 1}}{P_{0-\infty}} \times 100 \%
$$

From help file of MATLAB'M 7.6.0 (R2008a), "The quadgk function may be most efficient for high accuracies and oscillatory integrands.”

At 2100K temperature, non- preheated air

Energy: $\quad P_{0-\infty}=2.9472 \times 10^{21} \mathrm{~W} / \mathrm{m}^{2}$ within the whole band of wavelength,

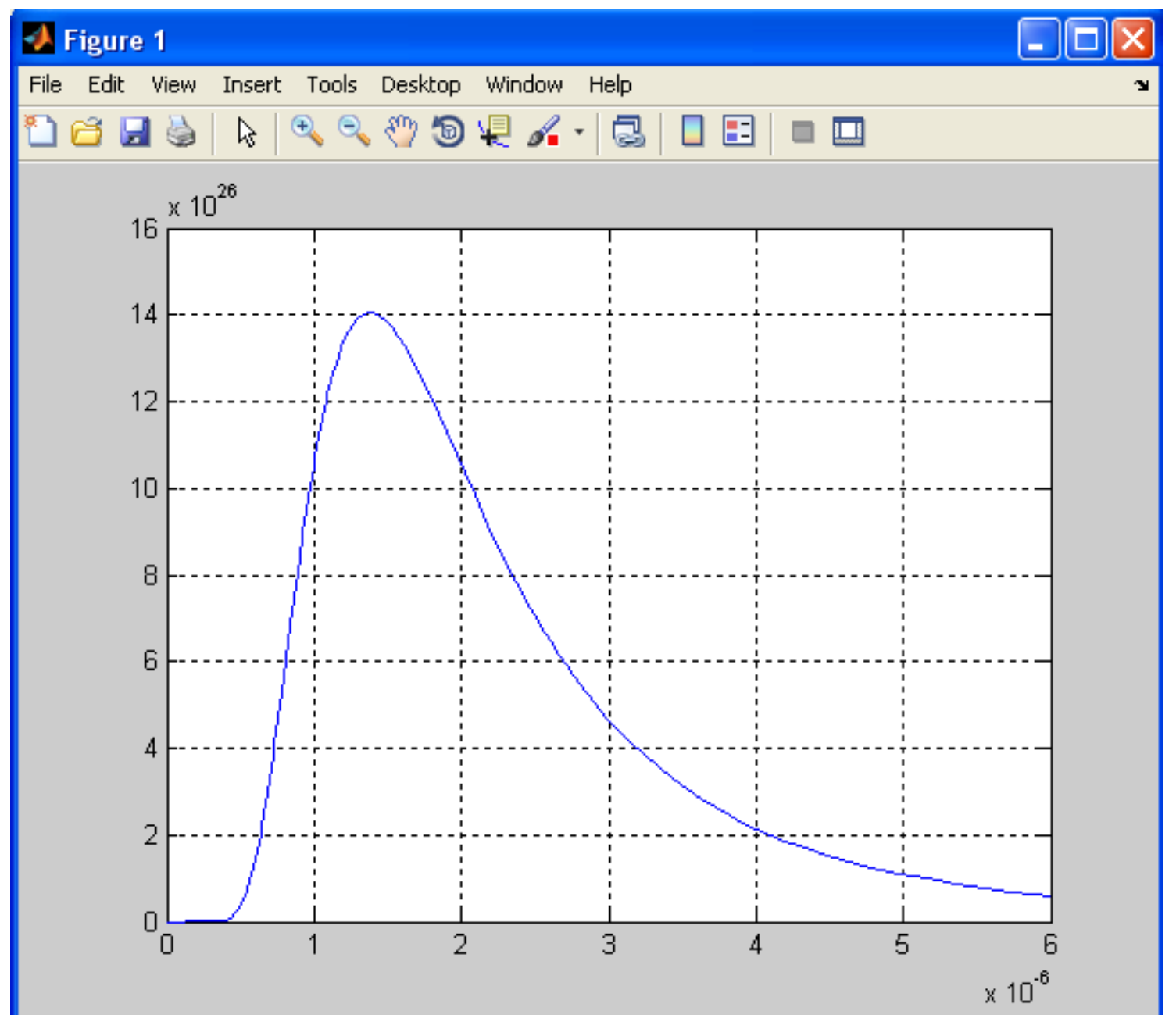

FigureD.1 Radiation Energy in Light at Wavelengths for 0 Micron to 50 Micron

Energy $\mathrm{P}_{0-\infty}=2.9472 \times 10^{21}$, and $\mathrm{P}_{0-3 \mu \mathrm{m}}=2.2452 \times 10^{21}$, Ratio $\mathrm{R}$ of $\mathrm{P}_{0-3 \mu \mathrm{m}}$ to $\mathrm{P}_{0-\infty}$ is $76.18 \%$. 


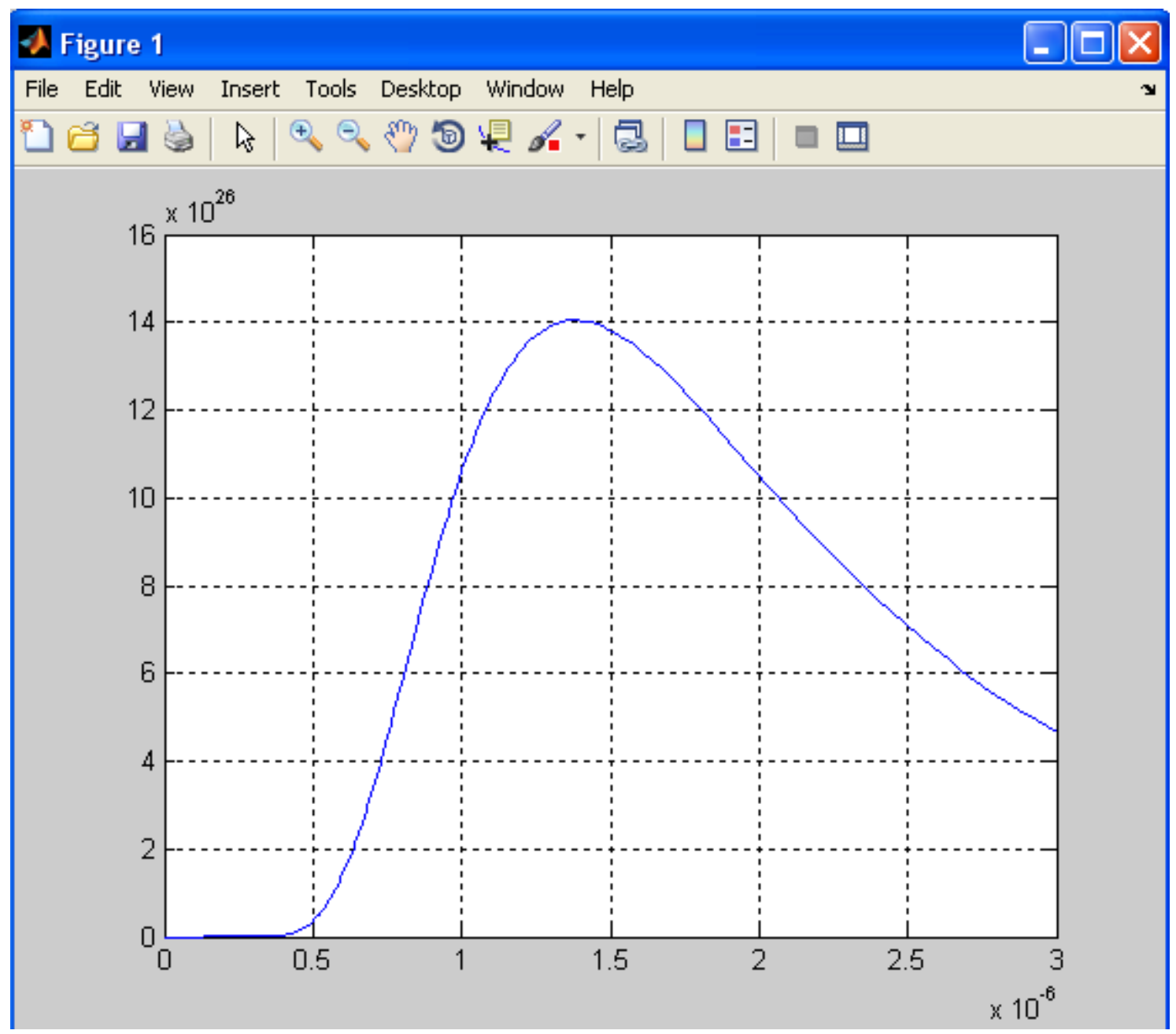

Figure D.2 Radiation Energy in Light at Wavelengths for 0 Micron to 3 Micron

Energy $\quad \mathrm{P}_{0-\infty}=2.9472 \times 10^{21} \mathrm{~W} / \mathrm{m}^{2}$, and $\quad \mathrm{P}_{3-5 \mu \mathrm{m}}=4.7705 \times 10^{20} \mathrm{~W} / \mathrm{m}^{2}$, Ratio $\mathrm{R}$ of $\mathrm{P}_{3-5 \mu}$ $\mathrm{m}$ to $\mathrm{P}_{0-\infty}$ is $16.19 \%$ 


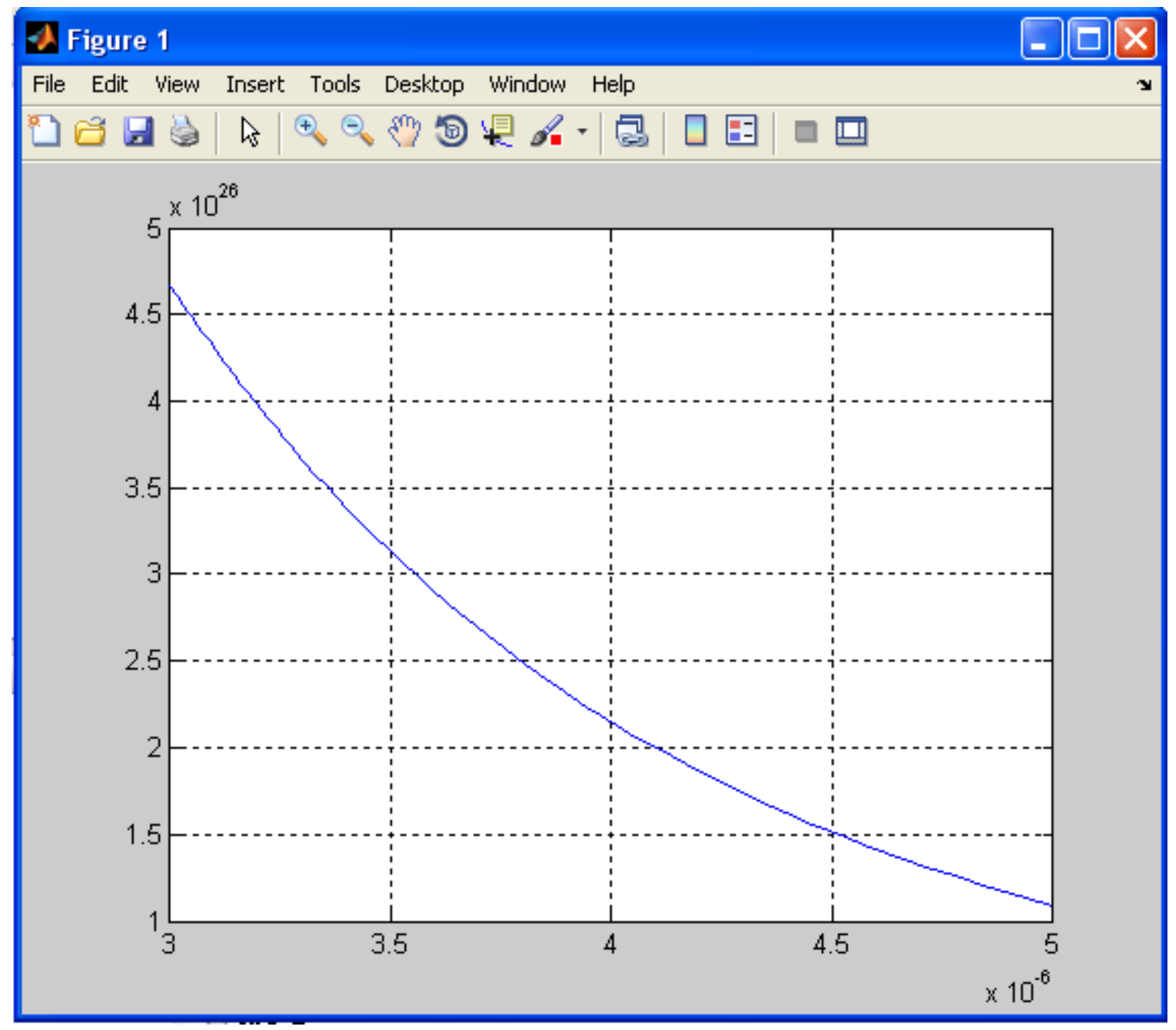

Figure D.3 Radiation Energy in Light at Wavelengths for 3 Micron to 5 Micron

Energy $\mathrm{P}_{0-\infty}=2.9472 \times 10^{21} \mathrm{~W} / \mathrm{m}^{2}$, and $\quad \mathrm{P}_{5-50 \mu \mathrm{m}}=2.2497 \times 10^{20} \mathrm{~W} / \mathrm{m}^{2}$, Ratio R of $\mathrm{P}_{5-50}$ u $\mathrm{m}$ to $\mathrm{P}_{0-\infty}$ is $7.63 \%$. 


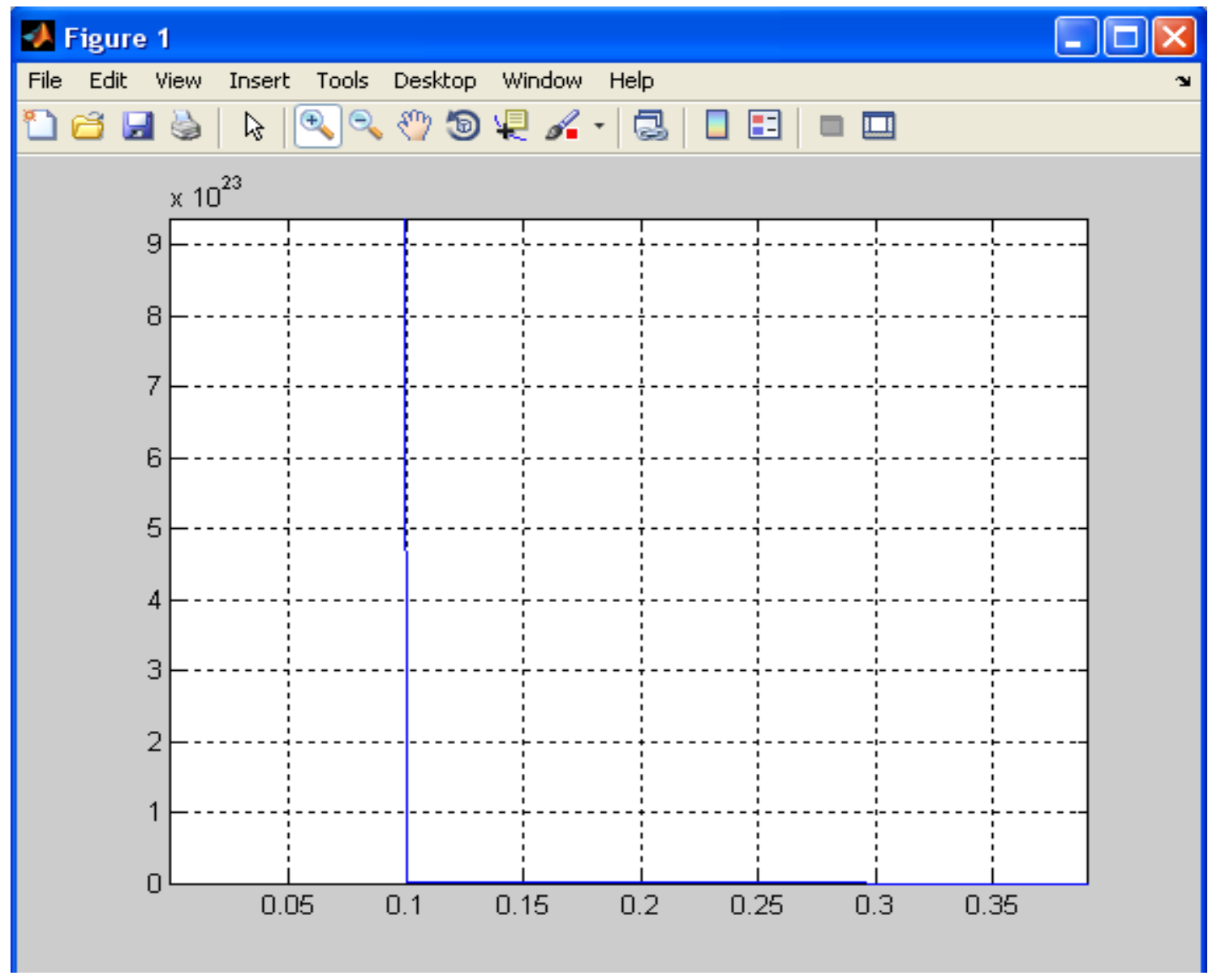

Figure D.4 Radiation Energy in Light at Wavelengths for 5 Micron to 50 Micron

\begin{tabular}{|l|l|l|}
\hline $\mathrm{P}_{0-\infty}$ & $\mathrm{P}_{0-3 \mu \mathrm{m}}$ & Ratio R \\
\hline $2.9472 \times 10^{21}\left(\mathrm{~W} / \mathrm{m}^{2}\right)$ & $2.2452 \times 10^{21}\left(\mathrm{~W} / \mathrm{m}^{2}\right)$ & $76.18 \%$ \\
\hline $\mathrm{P}_{0-\infty}$ & $\mathrm{P}_{3-5 \mu \mathrm{m}}$ & Ratio R \\
\hline $2.9472 \times 10^{21}\left(\mathrm{~W} / \mathrm{m}^{2}\right)$ & $4.7705 \times 10^{20}\left(\mathrm{~W} / \mathrm{m}^{2}\right)$ & $16.19 \%$ \\
\hline $\mathrm{P}_{0-\infty}$ & $\mathrm{P}_{5-50 \mu \mathrm{m}}$ & Ratio R \\
\hline $2.9472 \times 10^{21}\left(\mathrm{~W} / \mathrm{m}^{2}\right)$ & $2.2497 \times 10^{20}\left(\mathrm{~W} / \mathrm{m}^{2}\right)$ & $7.63 \%$ \\
\hline
\end{tabular}

Table D.1 Energy Ratios in Different Light Wavelength Ranges

$\%$ M-file of calculation for the glass fiber model in drawing process

$\%$ using quadgk non-preheated air at temperature $2100 \mathrm{~K}$

$\mathrm{h}=6.62606896 \mathrm{e}-34 ; \quad \%$ Planck constant, joule-seconds(J*s )

$\mathrm{c}=2.99792458 \mathrm{e}+8 ; \quad \%$ speed of light, meters per second $(\mathrm{m} / \mathrm{s})$

$\mathrm{k}=1.3806504 \mathrm{e}-23 ; \quad \%$ Boltzmann constant, joules per kelvin $(\mathrm{J} / \mathrm{K})$

$\mathrm{T}=2100 ; \quad \%$ combustion temperature with non-preheated air

$\mathrm{A}=8 * \mathrm{pi}^{*} \mathrm{~h} * \mathrm{c}$; 
$\mathrm{B}=\mathrm{h} * \mathrm{c} / \mathrm{k} / \mathrm{T}$

syms $\mathrm{x} \%$ function head

$\mathrm{f}=@(\mathrm{x}) 1 . /(\mathrm{x} . \wedge 5) . /(\exp (\mathrm{B} . / \mathrm{x})-1) ; \%$ Plank's law

p1=quadgk(f,0,3e-6); \% integration for light wavelength from 0 to 3 micron meter

fplot(f,[0 3e-6]); \% blackbody spectrum for light wavelength from 0 to 3 micron meter

p2=quadgk(f,3e-6,5e-6); \% integration for light wavelength from 3 to 5 micron meter fplot(f,[3e-6 5e-6]); \% blackbody spectrum for light wavelength from 3 to 5

micron meter

p3=quadgk(f,5e-6,50); \% integration for light wavelength from 5 to 50 micron meter(approximate $\infty$ wavelength)

fplot(f,[5e-6 50]); \% blackbody spectrum for light wavelength from 5 to 50

micron meter (approximate $\infty$ wavelength)

$\mathrm{p}=$ quadgk(f,0,50); \% integration for light wavelength from 0 to 50 micron

meter(approximate $\infty$ wavelength)

fplot(f,[0 6e-6]); \% black spectrum for light wavelength from 0 to $\infty$ wavelength, only shown from 0 to 6 micron meter

grid on

[1] Kreith, Frank., Principles of Heat Transfer, 3rd, IEP-A DUN-DONNELLEY

PUBLISHER., New York, 1976 ISBN 0-7002-2422-X: 468. 


\section{Appendix E Assumption for Constant Glass Mass Flow Rate and Constant Molten Glass Depth in Simulation}

Before developing state space model for the glass furnace, I assumed that the mass flow rate in simulation is constant, so matrix A in state space representation is constant. In fact, before Tdg reaches the set point, Tdg changes with time and even has the maximum value about $1200 \mathrm{~K}$. Change in the glass temperature near the bushing plate causes change in the glass mass flow rate through nozzles according to the Poiseuille's Law. Actually it is an adaptive control problem because matrix A in the model changes with time.

However, if change in matrix A doesn't cause significant change in final control model, I can assume that the glass flow rate in simulation doesn't change with variation of Tdg when there is no disturbance from changes in ambient temperature and molten glass depth.

Now I am going to calculate the different matrix A when Tdg is a different value.

When Tdg is $1177 \mathrm{~K}, \mathrm{H}$ is $10.16 \mathrm{~cm}$. The following is matrix A and Poles of A. $\mathrm{A}=$

$\begin{array}{cccccc}-0.0045 & 0.0025 & 0.0000 & 0.0019 & 0 & 0 \\ 0.0024 & -0.0066 & 0.0035 & 0.0001 & 0.0006 & 0 \\ -0.0003 & 0.0082 & -0.0533 & 0.0002 & 0.0003 & 0.0449 \\ 0.0000 & 0.0000 & 0.0000 & -0.0013 & 0.0012 & 0.0001\end{array}$




$\begin{array}{rrrrrr}11.6351 & 0 & 0 & 20.0911 & -32.0463 & 0 \\ -0.0006 & 0 & 0.6106 & 0.0086 & 0.0006 & -0.6225\end{array}$

$\operatorname{eig}(A)=[-32.0471,-0.6672,-0.0133,-0.0055,-2.3843 e-005,-0.0015]$ '

Then I used the maximum value $1200 \mathrm{~K}$ of Tdg (in fact, it is only $1192 \mathrm{~K}$ ), $\mathrm{H}$ is $10.16 \mathrm{~cm}$

$\mathrm{A}=$

$\begin{array}{rrrrrr}-0.0045 & 0.0025 & 0.0000 & 0.0019 & 0 & 0 \\ 0.0024 & -0.0066 & 0.0035 & 0.0001 & 0.0006 & 0 \\ -0.0003 & 0.0083 & -0.0534 & 0.0002 & 0.0003 & 0.0449 \\ 0.0000 & 0.0000 & 0.0000 & -0.0013 & 0.0012 & 0.0001 \\ 11.6351 & 0 & 0 & 20.0911 & -32.0463 & 0 \\ -0.0006 & 0 & 0.6110 & 0.0086 & 0.0006 & -0.6229\end{array}$

$\operatorname{eig}(A)=[-32.0471,-0.6676,-0.0133,-0.0055,-2.5278 e-005,-2.5278 e-005]$ '

I also tried to let Tdg be $1240 \mathrm{~K}$, which is impossible because $1240 \mathrm{~K}$ is the normal value for Ta, $\mathrm{H}$ is $10.16 \mathrm{~cm}$. Then I got:

$\mathrm{A}=$

$\begin{array}{rrrccc}-0.0045 & 0.0025 & 0.0000 & 0.0019 & 0 & 0 \\ 0.0024 & -0.0067 & 0.0035 & 0.0001 & 0.0006 & 0 \\ -0.0003 & 0.0084 & -0.0534 & 0.0002 & 0.0003 & 0.0449 \\ 0.0000 & 0.0000 & 0.0000 & -0.0013 & 0.0012 & 0.0001 \\ 11.6351 & 0 & 0 & 20.0911 & -32.0463 & 0 \\ -0.0006 & 0 & 0.6123 & 0.0086 & 0.0006 & -0.6241\end{array}$

$\operatorname{eig}(A)=[-32.0471,-0.6688,-0.0134,-0.0055,-2.9617 e-005,-0.0015]$ '.

Table E.1 shows the different poles of matrix A in different condition.

\begin{tabular}{|r|c|l|l|l|l|l|l|}
\hline Tdg $(\mathrm{K})$ & $\mathrm{H}(\mathrm{cm})$ & Pole1 & Pole2 & Pole3 & Pole4 & Pole5 & Pole6 \\
\hline 1177 & 10.16 & -32.0471 & -0.6672 & -0.0133 & -0.0055 & $-2.38 \mathrm{E}-05$ & -0.0015 \\
\hline 1200 & 10.16 & -32.0471 & -0.6676 & -0.0133 & -0.0055 & $-2.53 \mathrm{E}-05$ & -0.0015 \\
\hline 1240 & 10.16 & -32.0471 & -0.6688 & -0.0134 & -0.0055 & $-2.96 \mathrm{E}-05$ & -0.0015 \\
\hline
\end{tabular}

Table E.1 Comparison of Poles of Matrix A when Tdg Changes

Based on above analysis, it is known that with some small changes of Tdg, the poles of A are still negative, which means that the system is still stable. And only two 
pole 2 and pole 3, of six poles change slightly. So the assumption of constant glass mass flow rate is reasonable.

A similar analysis was done to see if the assumption of constant glass depth can be made. In fact, molten glass depth changes with time, reaching a maximum value after glass feeding and a minimum value before glass feeding. But the difference between the average value and the maximum one (or the minimum one) is much less than $1 \mathrm{~cm}$. So I have to prove that there is no big difference in the matrix A even if there is $1 \mathrm{~cm}$ depth difference.

For $\mathrm{H}=10.16 \mathrm{~cm}, \mathrm{~T}=1177 \mathrm{~K}$,

$\begin{array}{crrrrr}\mathrm{A}= & & & & \\ & & & & & \\ -0.0045 & 0.0025 & 0.0000 & 0.0019 & 0 & 0 \\ 0.0024 & -0.0066 & 0.0035 & 0.0001 & 0.0006 & 0 \\ -0.0003 & 0.0082 & -0.0533 & 0.0002 & 0.0003 & 0.0449 \\ 0.0000 & 0.0000 & 0.0000 & -0.0013 & 0.0012 & 0.0001 \\ 11.6351 & 0 & 0 & 20.0911 & -32.0463 & 0 \\ -0.0006 & 0 & 0.6106 & 0.0086 & 0.0006 & -0.6225\end{array}$

$\operatorname{eig}(A)=[-32.0471,-0.6672,-0.0133,-0.0055,-2.3843 e-005,-0.0015]$ '

For $\mathrm{H}=11.16 \mathrm{~cm}, \mathrm{~T}=1177 \mathrm{~K}$,

$\mathrm{A}=$

$\begin{array}{rrrrrr}-0.0045 & 0.0026 & 0.0000 & 0.0019 & 0 & 0 \\ 0.0023 & -0.0067 & 0.0037 & 0.0000 & 0.0006 & 0 \\ -0.0002 & 0.0077 & -0.0453 & 0.0001 & 0.0002 & 0.0375 \\ 0.0000 & 0.0000 & 0.0000 & -0.0014 & 0.0013 & 0.0001 \\ 11.6857 & 0 & 0 & 20.0911 & -32.0969 & 0 \\ -0.0010 & 0 & 0.6107 & 0.0086 & 0.0010 & -0.6225\end{array}$

$\operatorname{eig}(A)=[-32.0977,-0.6598,-0.0129,-0.0053,-2.3950 \mathrm{e}-05,-0.0015]$ 
For $\mathrm{H}=9.16 \mathrm{~cm}, \mathrm{~T}=1177 \mathrm{~K}$,

$\mathrm{A}=$

$\begin{array}{rrrrrr}-0.0045 & 0.0025 & 0.0000 & 0.0019 & 0 & 0 \\ 0.0025 & -0.0065 & 0.0033 & 0.0001 & 0.0007 & 0 \\ -0.0002 & 0.0097 & -0.0706 & 0.0004 & 0.0002 & 0.0605 \\ 0.0000 & 0.0000 & 0.0000 & -0.0012 & 0.0011 & 0.0001 \\ 11.5231 & 0 & 0 & 20.0911 & -31.9343 & 0 \\ -0.0005 & 0 & 0.6105 & 0.0086 & 0.0005 & -0.6224\end{array}$

$\operatorname{eig}(A)=[-31.9350,-0.6827,-0.0144,-0.0057,-2.2942 \mathrm{e}-05,-0.0016]$ ’

\begin{tabular}{|r|r|l|l|l|l|l|l|}
\hline Tdg $(\mathrm{K})$ & $\mathrm{H}(\mathrm{cm})$ & Pole1 & Pole2 & Pole3 & Pole4 & Pole5 & Pole6 \\
\hline 1177 & 10.16 & -32.0471 & -0.6672 & -0.0133 & -0.0055 & $-2.38 \mathrm{E}-05$ & -0.0015 \\
\hline 1177 & 11.16 & -32.0977 & -0.6598 & -0.0129 & -0.0053 & $-2.40 \mathrm{E}-05$ & -0.0015 \\
\hline 1177 & 9.16 & -31.935 & -0.6827 & -0.0144 & -0.0057 & $-2.29 \mathrm{E}-05$ & -0.0016 \\
\hline
\end{tabular}

Table E.2 Comparison of Poles of Matrix A when Molten Glass Depth Changes

From above analysis, it is known that with some small changes of $\mathrm{H}$, the poles of A are still negative, which means that the system is still stable. And only small changes of some poles happen. So assumption of constant molten glass depth is reasonable. 


\section{Appendix F Differential Equations for Our Fiber Glass Furnace Model}

Equation 1

$$
\begin{aligned}
& \frac{d T_{b g} *}{d t}=-\left[\left(1-\frac{1}{e}\right) \frac{A_{a-b g}}{R_{a-b g}}\left(S F_{a-b g}\right)+c_{g} m_{g}+\frac{A_{b g-c g}}{R_{b g-c g}^{\prime}}+\frac{A_{b g-s b}}{R_{b g-s b}^{\prime}}\right] \frac{T_{b g} *}{C_{b g}}+\frac{A_{b g-c g}}{R_{b g-c g}^{\prime} C_{b g}} T_{c g} * \\
& +\frac{A_{b g-s b}}{R_{b g-s b}^{\prime} C_{b g}} T_{r} *+\left(1-\frac{1}{e}\right) \frac{A_{a-b g}}{R_{a-b g}}\left(S F_{a-b g}\right) \frac{T_{a} *}{C_{b g}}
\end{aligned}
$$

Equation 2

$$
\begin{aligned}
& \frac{d T_{c g} *}{d t}=\left[\frac{A_{b g-c g}}{R_{b g-c g}^{\prime}}-\left(\frac{1}{e}-\frac{1}{e^{2}}\right) \frac{A_{a-b g} M_{s b}}{R_{a-b g}}\left(S F_{a-b g}\right)+c_{g} m_{g}\right] \frac{T_{b g} *}{C_{c g}}-\left(c_{g} m_{g}+\frac{A_{c g-d g}}{R_{c g-d g}^{\prime}}+\frac{A_{b g-c g}}{R_{b g-c g}^{\prime}}+\frac{A_{c g-s c}}{R_{c g-s c}^{\prime}}\right) \frac{T_{c g} *}{C_{c g}}+ \\
& \frac{A_{c g-d g}}{R_{c g-d g}^{\prime} C_{c g}} T_{d g} *+\frac{A_{c g-s c}}{R_{c g-s c}^{\prime} C_{c g}} T_{r} *+\left(\frac{1}{e}-\frac{1}{e^{2}}\right) \frac{A_{a-b g} M_{s b}}{R_{a-b g} C_{c g}}\left(S F_{a-b g}\right) T_{a} *
\end{aligned}
$$

Equation 3

$$
\begin{aligned}
& \frac{d T_{d g} *}{d t}=-\left(\frac{1}{e^{2}}-\frac{1}{e^{2.63896}}\right) \frac{A_{a-b g} M_{s b} M_{s c}}{R_{a-b g} C_{d g}}\left(S F_{a-b g}\right) T_{b g} *+\left(\frac{A_{c g-d g}}{R_{c g-d g}^{\prime}}+c_{g} m_{g}\right) \frac{T_{c g} *}{C_{d g}}- \\
& \left(\frac{A_{c g-d g}}{R_{c g-d g}^{\prime}}+c_{g} m_{g}+\frac{A_{d g-b t} M_{b t b}}{R_{d g-b t b}^{\prime}}+\frac{A_{d g-s d}}{R_{d g-s d}^{\prime}}\right) \frac{T_{d g} *}{C_{d g}}+\frac{A_{d g-s d}}{R_{d g-s d}^{\prime} C_{d g}} T_{r} *\left(\frac{1}{e^{2}}-\frac{1}{e^{2.63896}}\right) \frac{A_{a-b g} M_{s b} M_{s c}}{R_{a-b g} C_{d g}}\left(S F_{a-b g}\right) T_{a} * \\
& +\frac{A_{d g-b t} M_{b t b}}{R_{d g-b t b}^{\prime} C_{d g}} T_{b t b} *
\end{aligned}
$$

Equation 4 


$$
\begin{aligned}
& \frac{d T_{r} *}{d t}=\frac{A_{b g-s b}}{R_{b g-s b}^{\prime}} \frac{T_{b g}}{C_{r}}+\frac{A_{c g-s c}}{R_{c g-s c}^{\prime}} \frac{T_{c g} *}{C_{r}}+\frac{A_{d g-s d}}{R_{d g-s d}^{\prime}} \frac{T_{d g} *}{C_{r}}- \\
& {\left[\frac{A_{b g-s b}}{R_{b g-s b}^{\prime}}+\frac{A_{c g-s c}}{R_{c g-s c}^{\prime}}+\frac{A_{d g-s d}}{R_{d g-s d}^{\prime}}+\frac{A_{a-s a}}{R_{a-s a}}\left(S F_{a-s a}\right)+\frac{A_{b t r-b t b}}{R_{b t r-b t b}^{\prime}}\right] \frac{T_{r}}{C_{r}}+\frac{A_{a-s a}}{R_{a-s a} C_{r}}\left(S F_{a-s a}\right) T_{a} *+\frac{A_{b t r-b t b}}{R_{b t r-b t b}^{\prime}} \frac{T_{b t b}}{C_{r}}}
\end{aligned}
$$

Equation 5

$$
\begin{aligned}
& \frac{d T_{a}^{*}}{d t}=\frac{A_{a-b g}}{R_{a-b g} C_{a}}\left(S F_{a-b g}\right) T_{b g} *+\frac{A_{a-s a}}{R_{a-s a} C_{a}}\left(S F_{a-s a}\right) T_{r} *-\left[\frac{A_{a-b g}}{R_{a-b g}}\left(S F_{a-b g}\right)+\left(1+\frac{A}{F}\right) C_{a} h+\frac{A_{a-s a}}{R_{a-s a} C_{a}}\left(S F_{a-s a}\right)\right] \frac{T_{a} *}{C_{a}} \\
& +\left[L H V-\left(1+\frac{A}{F}\right) C_{a} i\right] \frac{\dot{m}_{f u e l}}{C_{a}}
\end{aligned}
$$

At the operation point of linearization:

$$
\dot{m}_{\text {fuel }}=h=1.2603 \times 10^{-4} \mathrm{~kg} / \mathrm{s}, \dot{m}_{\text {fuel }} *=\dot{m}_{\text {fuel }}+m d o c=2.1085 \times 10^{-4} \mathrm{~kg} / \mathrm{s}, \mathrm{Ta}=1240 \mathrm{~K} \text {, }
$$

$\mathrm{T} \infty=300 \mathrm{~K}, \mathrm{Ta} *=\mathrm{i}=1240-300=940 \mathrm{~K}$

\section{Equation 6}

$$
\begin{aligned}
& \frac{d T_{b t b} *}{d t}=-\frac{M_{b t b} M_{s b} M_{s c} M_{s d}}{e^{2.63896}} \frac{A_{a-b g}}{R_{a-b g} C_{b t b}}\left(S F_{a-b g}\right) T_{b g} *+\left(\frac{M_{b t b} A_{d g-b t}}{R_{d g-b t b}^{\prime}}+c_{g} m_{g}\right) \frac{T_{d g} *}{C_{b t b}}+ \\
& \frac{A_{b t r-b t b}}{R_{b t r-b t b}^{\prime} C_{b t b}} T_{r} * \frac{M_{b t b} M_{s b} M_{s c} M_{s d}}{e^{2.63896}} \frac{A_{a-b g}}{R_{a-b g} C_{b t b}}\left(S F_{a-b g}\right) T_{a} * \\
& -\left(\frac{M_{b t b} A_{d g-b t}}{R_{d g-b t b}^{\prime}}+\frac{M_{b t b} A_{b t-\infty}}{R_{b t b-\infty}^{\prime \prime}}+\frac{M_{b t b} A_{b t-\infty}}{R_{b t b-\infty}}\left(S F_{b t b-\infty}\right)+\frac{A_{b t r-b t b}}{R_{b t r-b t b}^{\prime}}+c_{g} m_{g}\right) \frac{T_{b t b} *}{C_{b t b}}
\end{aligned}
$$




\section{Appendix G Methods of Choosing Control Gains and Estimator Poles in Our Model}

Settling time is the time it takes the system transient to decay. Generally, $1 \%$ of the response in the steady state is used [1]. Since the set point for Tdg is $1177 \mathrm{~K}$, temperature range within $1 \%$ error is $1165.2 \mathrm{~K}$ to $1188.8 \mathrm{~K}$. In my model, I would like to set the temperature range within $\pm 5 \mathrm{~K}$ for settling time.

The ambient temperature is $300 \mathrm{~K}$ and molten glass depth is $10.2 \mathrm{~cm}$ in the normal case. Combinations between control gain $\mathrm{K}$ and estimator poles EP will be simulated, and in each combination case, all five initial conditions will be used. Please check the following table $\mathrm{G}$ for initial conditions.

\begin{tabular}{|l|r|r|r|r|r|r|}
\hline Unit K & \multicolumn{1}{l|}{ Tbg* } & \multicolumn{1}{l|}{ Tcg* } & \multicolumn{1}{l|}{ Tdg* } & \multicolumn{1}{l|}{ Tr* } & \multicolumn{1}{l|}{ Ta* } & \multicolumn{1}{l|}{ Tbtb* } \\
\hline X1 & 900 & 850 & 800 & 800 & 900 & 800 \\
\hline X2 & 910 & 860 & 810 & 810 & 910 & 810 \\
\hline X3 & 890 & 840 & 790 & 790 & 890 & 790 \\
\hline X4 & 950 & 900 & 850 & 850 & 950 & 850 \\
\hline X5 & 850 & 800 & 750 & 750 & 850 & 750 \\
\hline
\end{tabular}

Table G.1 Five Initial Conditions in the Normal Case

Using $\mathrm{Q}(3,3)=3000$ and $\mathrm{R}=1$, I got the control gain $\mathrm{K} 1$.

$\mathrm{K} 1=\left[\begin{array}{llllll}-0.0001 & 0.0028 & 54.7541 & 0.0001 & 0.0001 & 0.0153\end{array}\right]$

Using $\mathrm{Q}(3,3)=6000$ and $\mathrm{R}=1$, I got the control gain $\mathrm{K} 2$.

$\mathrm{K} 2=\left[\begin{array}{llllll}-0.0001 & 0.0033 & 77.4381 & 0.0001 & 0.0001 & 0.0182\end{array}\right]$

EP1, EP2 and EP3 are the estimator pole vectors chosen in my model. 
EP1=[ -0.015+0.025i;-0.015-0.025i;-0.002+0.002i;-0.002-0.002i];

$E P 2=[-0.0075+0.0125 \mathrm{i} ;-0.0075-0.0125 \mathrm{i} ;-0.004+0.004 \mathrm{i} ;-0.004-0.004 \mathrm{i}]$

EP3=[ -0.03+0.05i;-0.03-0.05i;-0.004+0.004i;-0.004-0.004i];

Please check some of the simulation result.

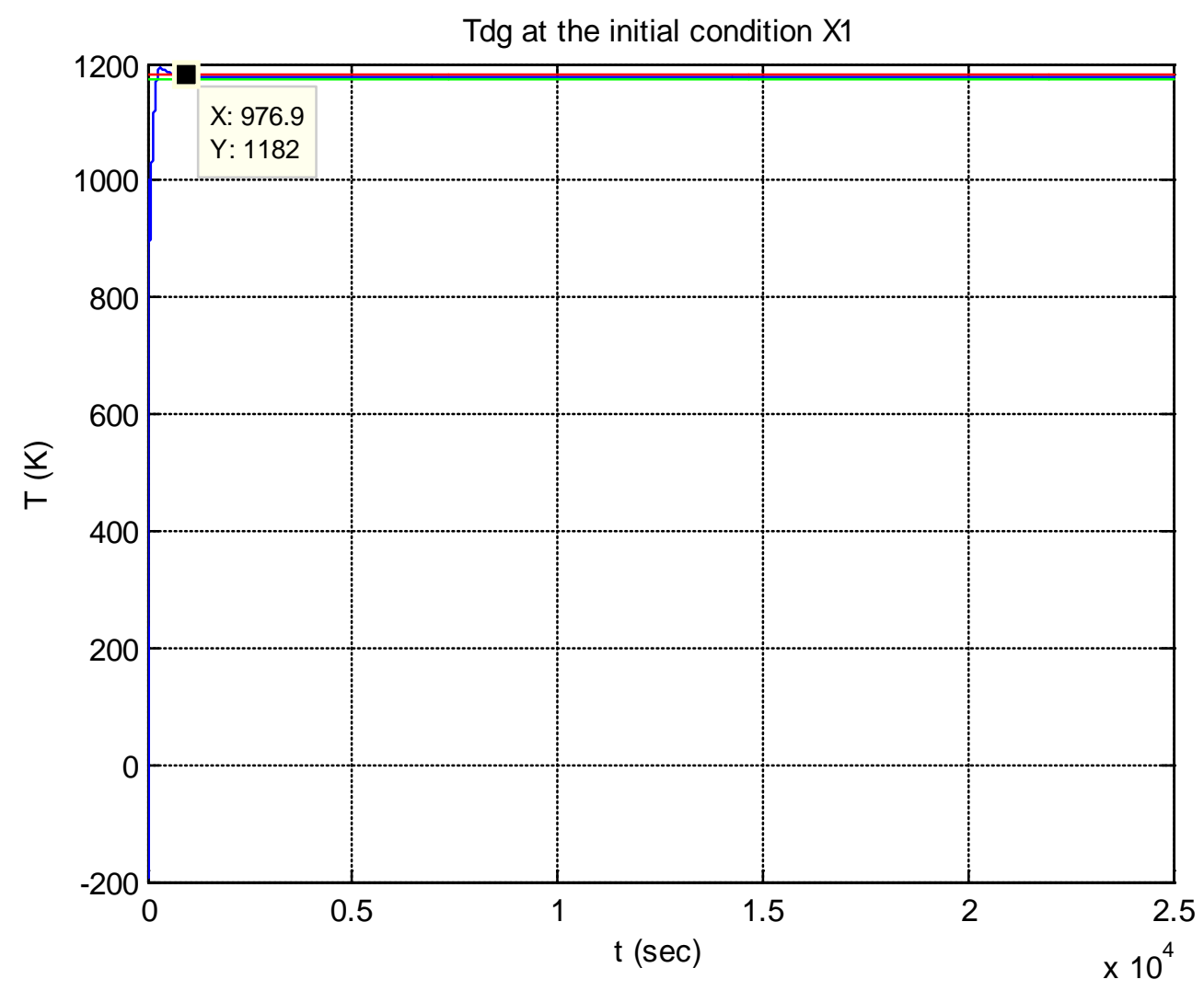

Figure G.1 Tdg Response with Control Gain K2 and Estimator Pole EP1 at Initial Condition X1 


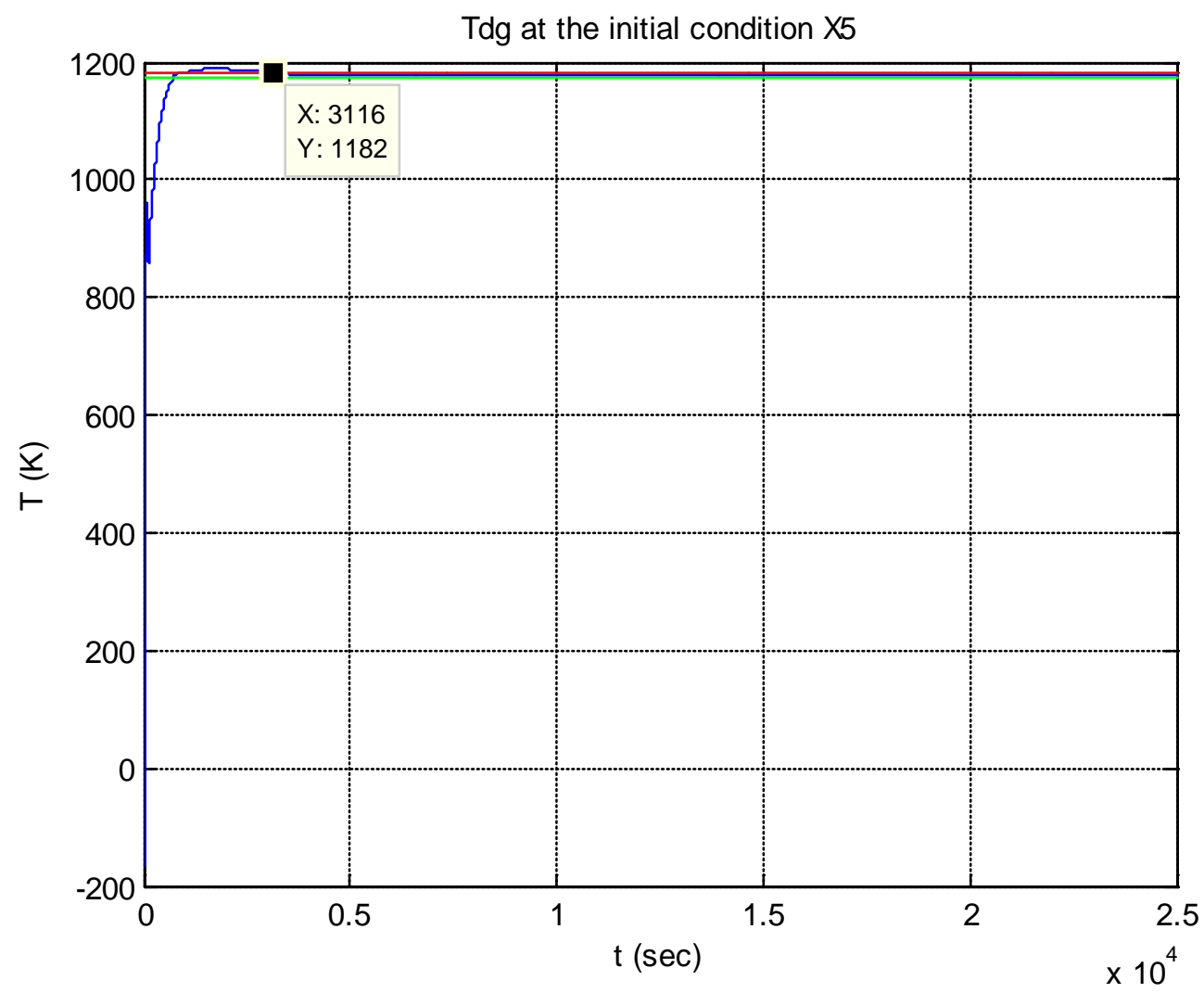

Figure G.2 Tdg Response with Control Gain K2 and Estimator Pole EP1 at Initial Condition X5

\begin{tabular}{|l|r|r|r|l|}
\hline T =300K, H=10.2cm & $\begin{array}{l}\text { estimator } \\
\text { poleEP1 }\end{array}$ & $\begin{array}{l}\text { estimator } \\
\text { poleEP2 }\end{array}$ & $\begin{array}{l}\text { estimator } \\
\text { poleEP3 }\end{array}$ & $\begin{array}{l}\text { Initial } \\
\text { condition }\end{array}$ \\
\hline $\mathrm{Q}(3,3)=3000, \mathrm{R}=1$ & 2720 & 2880 & 2487 & $\mathrm{X} 1$ \\
\hline settling t $(\mathrm{sec})$ & 2208 & 2264 & 2798 & $\mathrm{X} 2$ \\
\hline & 1626 & 3657 & 5121 & $\mathrm{X} 3$ \\
\hline & 4579 & 60.89 & 103.4 & $\mathrm{X} 4$ \\
\hline & 3046 & 6193 & 8018 & $\mathrm{X} 5$ \\
\hline Average time & 2835.8 & 3010.978 & 3705.48 & \\
\hline $\mathrm{Q}(3,3)=6000, \mathrm{R}=1$ & 976.9 & 4869 & 4053 & $\mathrm{X} 1$ \\
\hline sett1ing t $(\mathrm{sec})$ & 2294 & 2306 & 1690 & $\mathrm{X} 2$ \\
\hline & 1732 & 3638 & 4951 & $\mathrm{X} 3$ \\
\hline & 4397 & 117.4 & 55.86 & $\mathrm{X} 4$ \\
\hline & 3116 & 6111 & 7843 & $\mathrm{X} 5$ \\
\hline Average time & 2503.18 & 3408.28 & 3718.572 & \\
\hline
\end{tabular}

Table G.2 Settling Time for Tdg in the Normal Case

From the above Table G.2, it is clear that combination of K2 and EP1 is the best combination for average settling time. 
Beside using rising time to choose poles, I also used ITAE definition as standard to choose combination of gains and poles. ITAE means that integration of result of that $t$ times absolute value of errors. So the less ITAE value, the better performance the system has.

I simulated all the combinations and in each combination, there are five different initial conditions. Please check some simulation results:

$\mathrm{K} 2(\mathrm{Q}(3,3)=6000, \mathrm{R}=1)$ : Control gain $\mathrm{K} 2$ estimator pole EP1 at the initial conditionX1

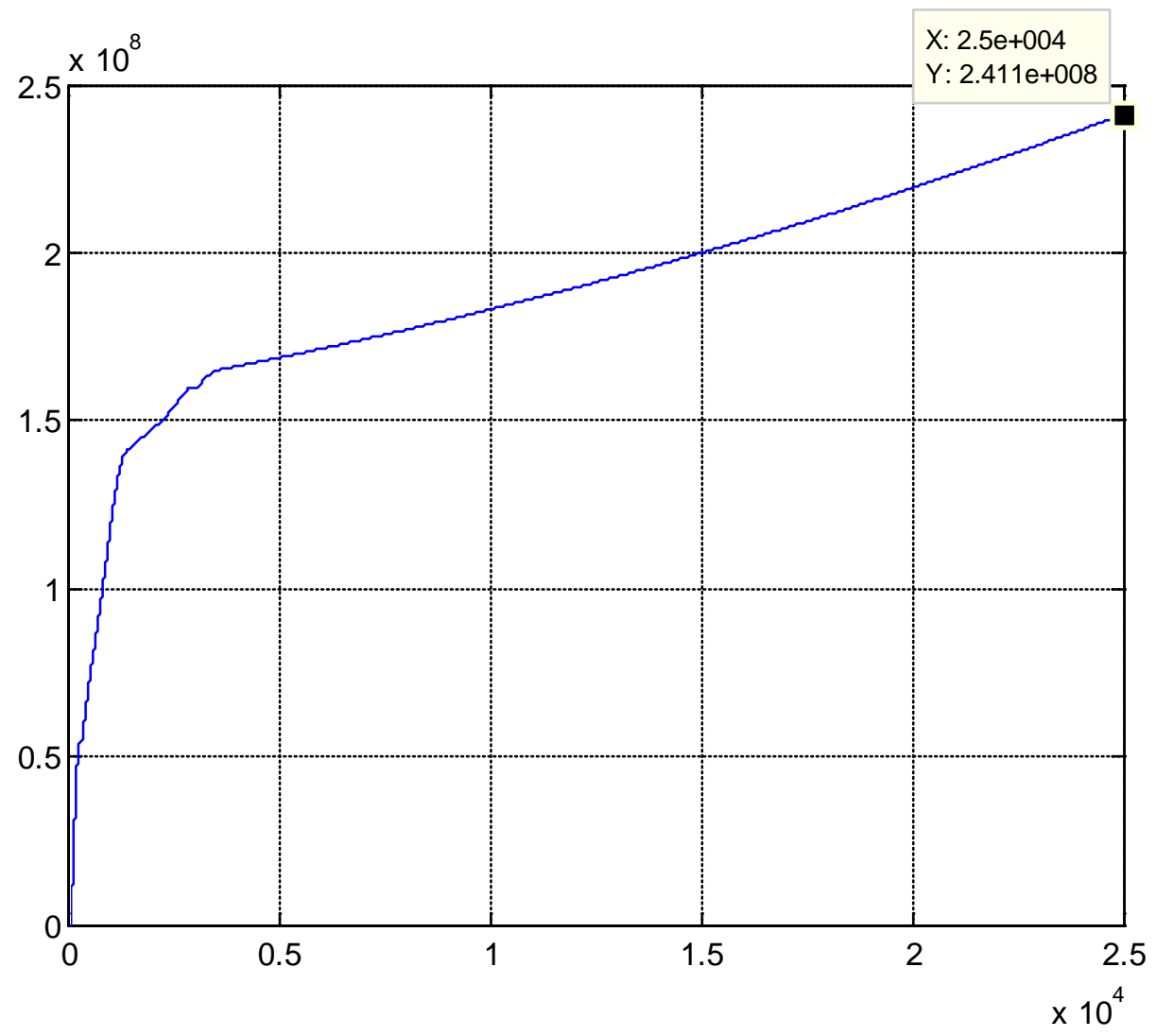

Figure G.3 ITAE Values of Tdg with Control Gain K2 and Estimator Pole EP1 at Initial Condition X1

Control gain K2 estimator pole EP1 at the initial condition X5 


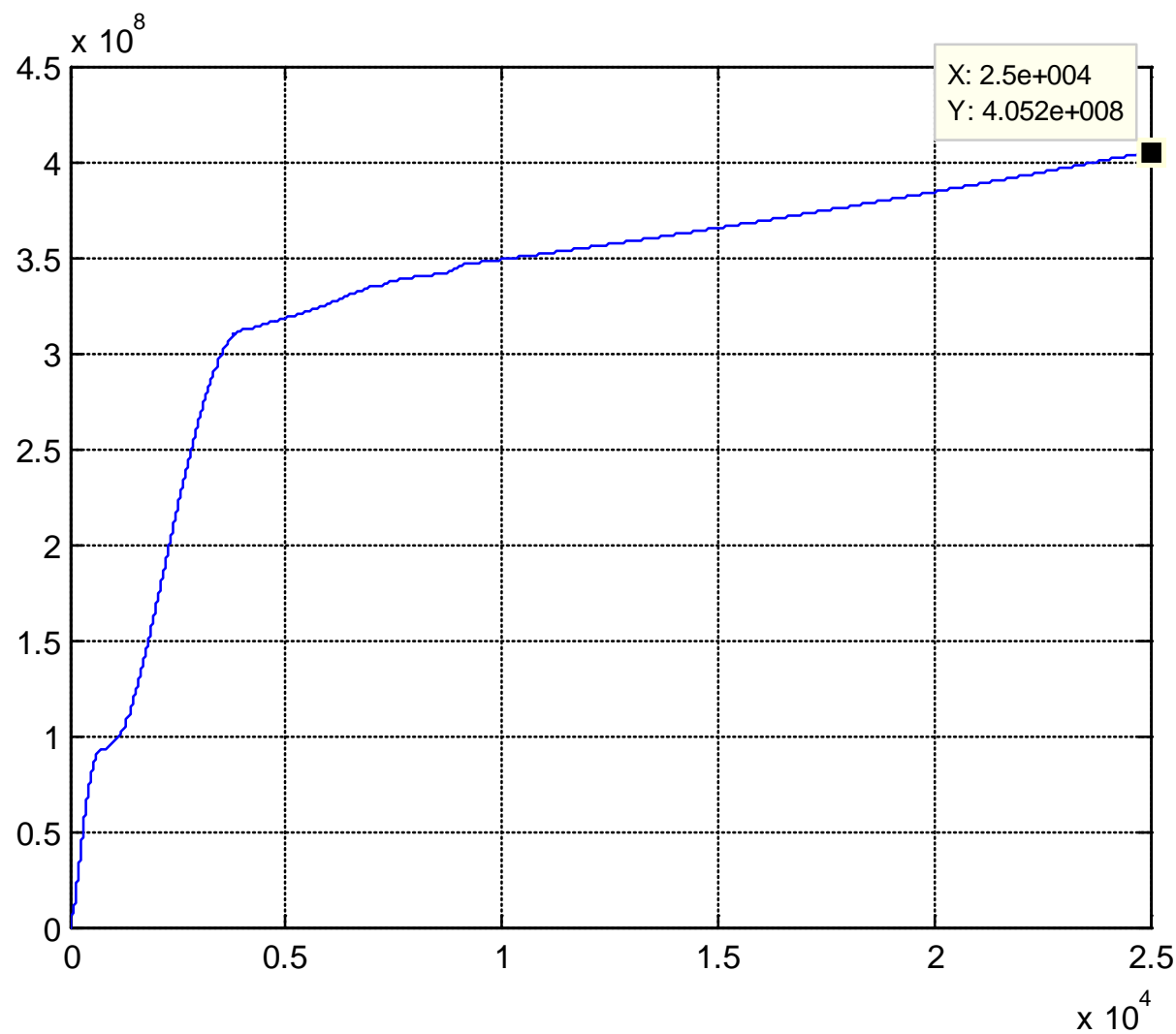

Figure G.4 ITAE Values of Tdg with Control Gain K2 and Estimator Pole EP1 at Initial Condition X5

\begin{tabular}{|l|r|r|r|l|}
\hline T =300K, H=10.2cm & $\begin{array}{l}\text { estimator } \\
\text { poleEP1 }\end{array}$ & $\begin{array}{l}\text { estimator } \\
\text { poleEP2 }\end{array}$ & $\begin{array}{l}\text { estimator } \\
\text { poleEP3 }\end{array}$ & $\begin{array}{l}\text { Initial } \\
\text { condition }\end{array}$ \\
\hline Q $(3,3)=3000, \mathrm{R}=1$ & $2.77 \mathrm{E}+08$ & $6.31 \mathrm{E}+08$ & $5.13 \mathrm{E}+08$ & X1 \\
\hline $\begin{array}{l}\text { ITAE after } \\
25000 \text { second }\end{array}$ & $3.26 \mathrm{E}+08$ & $4.77 \mathrm{E}+08$ & $3.39 \mathrm{E}+08$ & X2 \\
\hline & $2.54 \mathrm{E}+08$ & $7.87 \mathrm{E}+08$ & $6.79 \mathrm{E}+08$ & X3 \\
\hline & $1.07 \mathrm{E}+09$ & $1.70 \mathrm{E}+08$ & $1.53 \mathrm{E}+08$ & X4 \\
\hline & $4.27 \mathrm{E}+08$ & $1.33 \mathrm{E}+09$ & $1.24 \mathrm{E}+09$ & X5 \\
\hline Average & $4.70 \mathrm{E}+08$ & $6.78 \mathrm{E}+08$ & $5.84 \mathrm{E}+08$ & \\
\hline Q $(3,3)=6000, \mathrm{R}=1$ & $2.41 \mathrm{E}+08$ & $6.20 \mathrm{E}+08$ & $4.99 \mathrm{E}+08$ & X1 \\
\hline $\begin{array}{l}\text { ITAE after } \\
25000 \text { second }\end{array}$ & $2.92 \mathrm{E}+08$ & $4.60 \mathrm{E}+08$ & $3.16 \mathrm{E}+08$ & X2 \\
\hline & $2.17 \mathrm{E}+08$ & $7.81 \mathrm{E}+08$ & $6.71 \mathrm{E}+08$ & X3 \\
\hline & $1.05 \mathrm{E}+09$ & $1.26 \mathrm{E}+08$ & $1.09 \mathrm{E}+08$ & X4 \\
\hline & $4.05 \mathrm{E}+08$ & $1.33 \mathrm{E}+09$ & $1.25 \mathrm{E}+09$ & X5 \\
\hline Average & $4.40 \mathrm{E}+08$ & $6.64 \mathrm{E}+08$ & $5.68 \mathrm{E}+08$ & \\
\hline
\end{tabular}

Table G.3 ITAE values for Tdg in the Normal Case

In Table G.3, combination of K2 and EP1 is the best one which makes the least 
ITAE value among the three poles in normal situation. By using settling time and

ITAE methods, I found that combination of K2 and EP1 is the best choice for the control system, and used it in the further simulation.

[1] Franklin, Gene F., Powell, J.David., Emami-Naeini, Abbas., Feedback Control of Dynamic Systems, fifth edition, Pearson Education, In, Upper Saddle River, New Jersey 2006 ISBN 0-13-149930-0 


\section{Appendix $H$ Effect of Setting for the Saturation Block in the Simulink ${ }^{\mathrm{TM}}$ Model to the Fuel Flow Rate Plot}

There is a saturation block in front of the fuel flow rate output in the glass furnace model. Different setting for the saturation block, that is different upper limits and lower limits, presents different fuel flow rate plots. Sometimes, the plot is smooth without any sharp turning points with one setting. With another setting, there may be some sharp turning points on the fuel flow rate plot.

For example, in ambient temperature change case 3, there were two cases for different settings for the saturation block in the glass furnace model. In case 1, upper limit was set to $1.26 \times 10^{-3} \mathrm{~kg} / \mathrm{s}$, and lower limit was $1.85 \times 10^{-4} \mathrm{~kg} / \mathrm{s}$. The simulation result about the fuel flow rate is shown in Figure H.1. There are some sharp turning points on the plot. In case 2 , upper limit was set to $1.26 \times 10^{-2} \mathrm{~kg} / \mathrm{s}$, and lower limit was $5.05 \times 10^{-4} \mathrm{~kg} / \mathrm{s}$. The simulation result about the fuel flow rate is shown in Figure H.2. The plot is smooth without any sharp turning points.

Suitable setting of saturation block gives the smooth plot for the fuel flow rate in simulation. Real situation about fuel flow valves decide the upper and lower limits of saturation blocks in the model. 


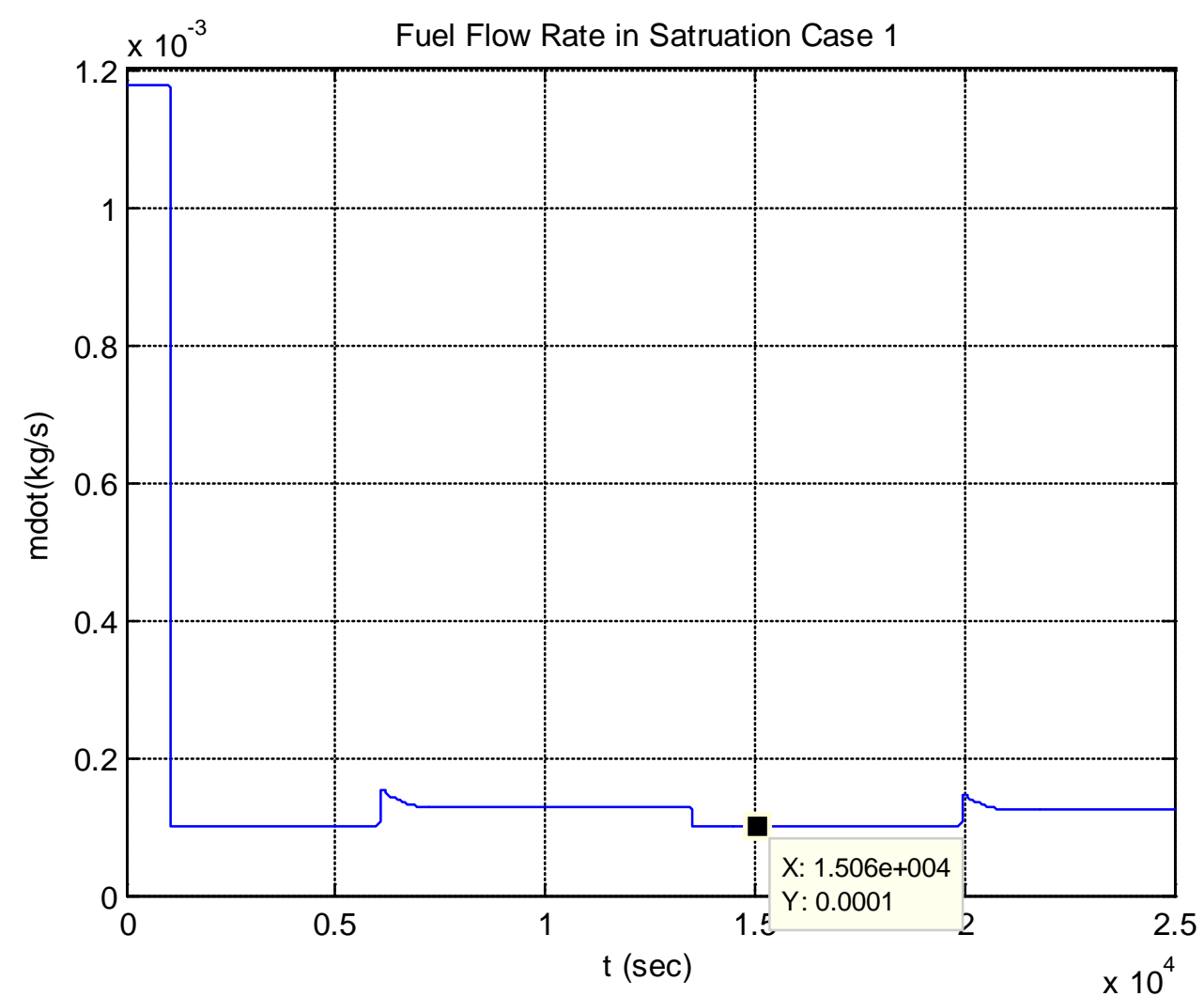

Figure H.1 Fuel Flow Rate in Saturation Case 1

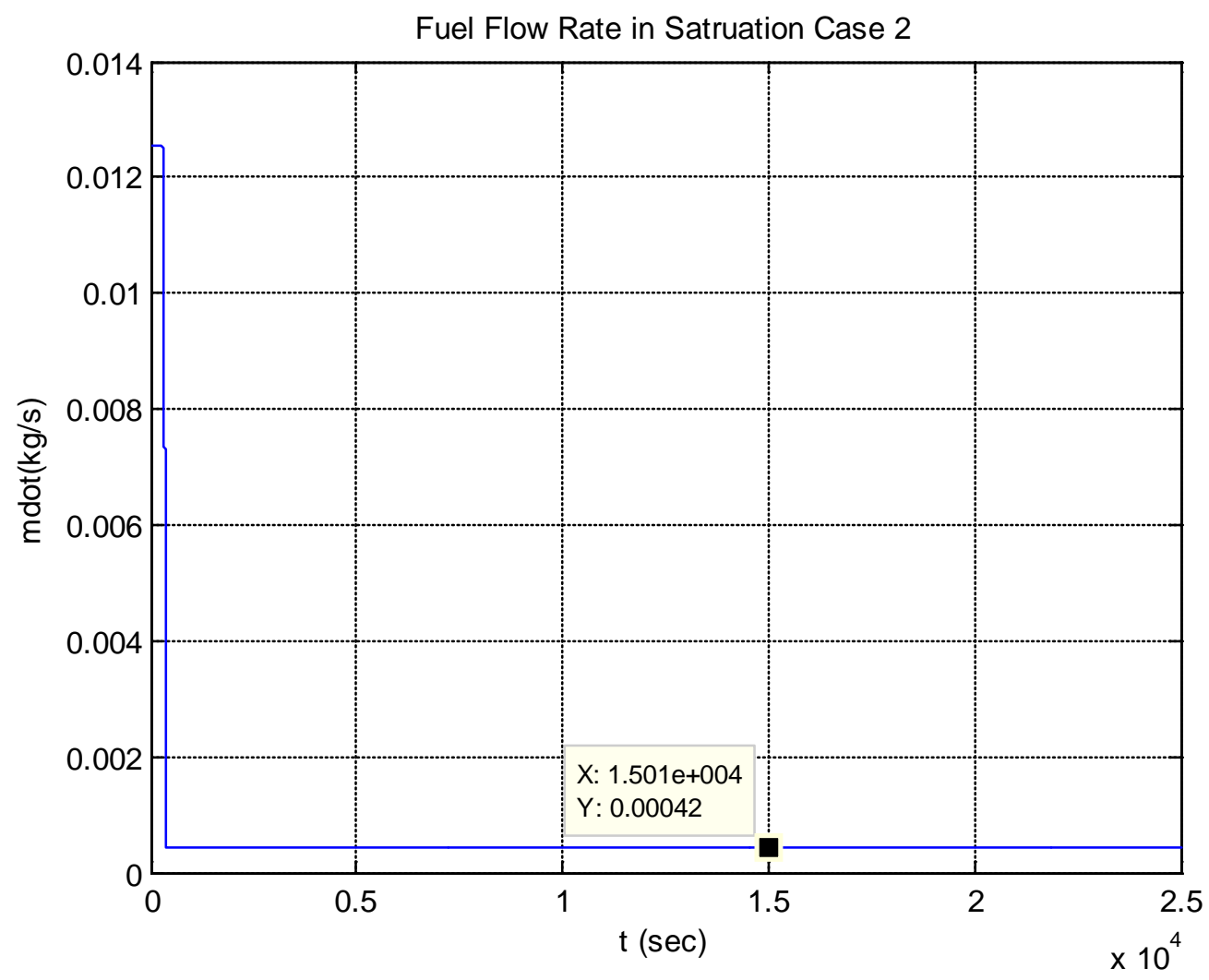

Figure H.2 Fuel Flow Rate in Saturation Case 2 


\section{Appendix I M file for the Multivariable Control Model for Fiber Glass Furnace Systems in Matlab ${ }^{\mathrm{TM}}$}

rfinal=1.5e-05; \% final glass fiber radius, meter

$\mathrm{V} 0=13.6 ; \quad \%$ drum speed at the normal situation, $\mathrm{m} / \mathrm{s}$

rou_g=2430; \% density of glass fiber, $\mathrm{kg} / \mathrm{m}^{3}$

$\mathrm{N}=294 ; \quad \% \quad$ number of nozzles on the bushing plate

$\mathrm{H}=0.1016 ; \quad \% \quad$ normal molten glass depth in the furnace, meter

$\mathrm{T} 0=1177 ; \quad \% \quad \mathrm{~K}$ which will make drum speed control as $13.5 \mathrm{~m} / \mathrm{s}$

c4=-2.66; \% Fulcher constant

c5=4545; \% Fulcher constant

c6=489.75; \% Fulcher constant, temperature unit Kelvin

miu $0=10^{\wedge}(\mathrm{c} 4+\mathrm{c} 5 /(\mathrm{T} 0-\mathrm{c} 6)) ; \quad \%$ viscosity calculated by Fulcher law

$\mathrm{L}=0.0035$; $\quad \%$ length of mzzles onthe buhing phte, $\mathrm{m}$

$\mathrm{R}=0.002135 ; \quad \%$ radius ofnozzles on the bushing plate, $\mathrm{m}$

$\mathrm{CmC}=\mathrm{R} \wedge 4 * 9.8 *$ rou_g/8/L; \% glass flow rate through one nozzle by Poiseullle law m_g=N*pi*R^4*rou_g^2*9.8*H/8/miu0/L; \% glass flow ate hrough he whole bushing plate, $\mathrm{kg} / \mathrm{s}$

$\%$ ellipse cross section area and arc length calculation

$\mathrm{I}=0.1524 ; \quad \%$ long axis for the ellipse, $\mathrm{m}$

$\mathrm{J}=0.1219235$; \% short axie fr he ellipse, $\mathrm{m}$

opth $=0.0385$; \% average optical thickness, $m$

$\mathrm{l}=0.9652 ; \quad \%$ length of inside furnace, $\mathrm{m}$

$\mathrm{yb}=0.0114265 ; \quad \%$ distance from the top glass layer to the long axis, $\mathrm{m}$

$\mathrm{xb}=\left(\mathrm{I} \wedge 2-\mathrm{I}^{\wedge} 2 * \mathrm{yb} \wedge 2 / \mathrm{J} \wedge 2\right)^{\wedge} .5 ; \quad \% \quad \mathrm{xb}=0.1517$

$\mathrm{yc}=\mathrm{yb}+$ opth; $\quad \% 0.0499 \mathrm{~m}$

$\mathrm{xc}=\left(\mathrm{I}^{\wedge} 2-\mathrm{I} \wedge 2^{*} \mathrm{yc}^{\wedge} 2 / \mathrm{J} \wedge 2\right)^{\wedge} .5 ; \quad \% \quad \mathrm{xc}=0.1390$

yd=yc+opth; $\quad \% 0.0884 \mathrm{~m}$

$\mathrm{xd}=\left(\mathrm{I}^{\wedge} 2-\mathrm{I}^{\wedge} 2 * \mathrm{yd}^{\wedge} \mathrm{2} / \mathrm{J} \wedge 2\right)^{\wedge} .5 ; \quad \% \quad \mathrm{xd}=0.1049$

$\mathrm{tb}=\mathrm{asin}(\mathrm{yb} / \mathrm{J})$;

$\mathrm{tc}=\operatorname{asin}(\mathrm{yc} / \mathrm{J})$;

eccen $=\left(I^{\wedge} 2-\mathrm{J} \wedge 2\right)^{\wedge} .5 / \mathrm{I}$;

syms $\mathrm{x}$

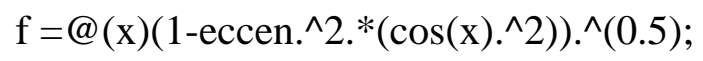

$\mathrm{pbc}=$ quadl(f,tb,tc);

arclength_sb=2*I*pbc; \% arc length fr cross section of Zone bg,

arclength_sb $=0.0816 \mathrm{~m}$

$\mathrm{Msb}=2 * \mathrm{xc} /(2 * \mathrm{xc}+$ arclength_sb); $\%$ area ratio of Ac to Ac+Asb, $\quad \mathrm{Msb}=0.7731$ $\mathrm{td}=\operatorname{asin}(\mathrm{yd} / \mathrm{J})$; 
syms $\mathrm{x}$

$\mathrm{f}=@(\mathrm{x})\left(1-\right.$ eccen. $\left.{ }^{\wedge} 2 .^{*}(\cos (\mathrm{x}) \cdot \wedge 2)\right) \cdot \wedge(0.5)$;

pcd=quadl(f,tc,td);

arclength_sc $=2 * I *$ pcd; $\%$ arc length for cross section of Zone cg,

arclength_sc $=0.1036 \mathrm{~m}$

Msc $=2 * x d /(2 * x d+$ arclength_sc $) ; \quad \%$ rea ntio of Ad $\mathrm{b}$ Ad+Asc

Msc $=0.6695$

$\mathrm{ybt}=\mathrm{yd}+0.0246 ; \quad \% \quad 0.1130 \mathrm{~m}$

tbt=asin(ybt/J);

syms $\mathrm{x}$

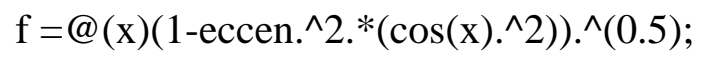

pdbt=quadl(f,td,tbt);

arclength_sd=2*I*pdbt; \% arc length fr cross section of Zone dg,

arclength_sd $=0.1080 \mathrm{~m}$

$\mathrm{xbt}=0.05715$;

Msd $=2 * x b t /(2 * x b t+$ arclength_sd $) ; \quad \%$ area ratio of Abt to Abt+Asd

Msd $=0.5142$

$\%$ Calculation for all areas in heat transfer

ycr $=0.0806485$; $\quad \%$ crown y coordinator for Zone a, refractory

$0.1219235-0.041275, \mathrm{~m}$

$\mathrm{xCr}=\left(\mathrm{I} \wedge 2-\mathrm{I}^{\wedge} 2 * \mathrm{ycr}^{\wedge} 2 / \mathrm{J} \wedge 2\right)^{\wedge} .5 ; \quad \%$ rown $\mathrm{x}$ oordinator, $\mathrm{xa}=0.1143 \mathrm{~m}$

$a=2 * 0.1517=0.3034, b=0.9652, S=a * b, c=y c r+y b=0.0921$, for calculation of shape

factor cr-bg

$\mathrm{t} 1=\mathrm{a} \sin (\mathrm{ycr} / \mathrm{J})$

eccen $=(I \wedge 2-\mathrm{J} \wedge 2)^{\wedge} .5 / \mathrm{I}$;

syms $\mathrm{X}$

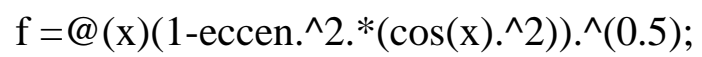

$\mathrm{p} 1=$ quadl(f,t1,pi/2);

arclength_cr $=2 * I^{*} \mathrm{p} 1 ; \quad \%$ ac length for cross section of crown in Zone a,

arclength_cr $=0.2485 \mathrm{~m}$

$\mathrm{l}=0.9652 ; \quad \%$ length of inside furnace, $\mathrm{m}$

Aa_cr1=arclength_cr*l-pi*0.0635*0.0635; \% Aa_cr1, m2

Aa_cr2=pi*I*J-(I*J*(pi/2+asin $\left.\left.(\mathrm{ycr} / \mathrm{J}))+\mathrm{I}^{*} \mathrm{ycr} *((\mathrm{~J} \wedge 2-\mathrm{ycr} \wedge 2))\right)^{\wedge} .5 / \mathrm{J}\right) ; \%$ Aa_cr2, m^2

Aa_cr3 $=$ Aa_cr2-pi*0.028575*0.028575*0.5; \% Aa_cr3, m^2

Aa_cr $=$ Aa_cr1+Aa_cr2+Aa_cr3; $\%$ heat transfer area from Zone a to crown, $\mathrm{m} \wedge 2$ \%\%\%\%\%\%\%\%\%\%\%\%\%\%\%\%\%\%\%\%\%\%\%\%\%\%\%\%\%\%\%\%\%\%\%\%\%\%\%\%\%

$\mathrm{d} 2=0.0114265 ; \quad \% \mathrm{~m}$

$\mathrm{t} 2=\operatorname{asin}(\mathrm{d} 2 / \mathrm{J})$;

syms $\mathrm{x}$

$\mathrm{f}=@(\mathrm{x})\left(1\right.$-eccen. $\left.{ }^{\wedge} 2{ }^{*}(\cos (\mathrm{x}) \cdot \wedge 2)\right) \cdot \wedge(0.5)$;

$\mathrm{p} 2=$ quadl $(\mathrm{f}, 0, \mathrm{t} 2)$;

p3=quadl $(\mathrm{f}, 0, \mathrm{t} 1)$;

arclength_sa $=2 * I *(p 2+p 3) ; \quad \%$ arc length for cross section of Zone a, $\quad 0.2067 \mathrm{~m}$ Aa_sa1=arclength_sa*l; $\%$ Aa_sa1 $=0.1995 \mathrm{~m} 2$ 
Aa_sa2 $=$ pi*I*J-(I*J*(pi/2+asin(-d2/J))+I*(-d2)*((J^2-d2^2))^.5/J)-Aa_cr2; \% Aa_sa2 $=0.0261, \mathrm{~m}^{\wedge} 2$ Aa_sa3 $=$ Aa_sa2-pi $* 0.028575 * 0.028575 * 0.5 ; \quad \%$ Aa_sa3 $=0.0248, \mathrm{~m}^{\wedge} 2$

Aa_sa=Aa_sa1+Aa_sa2+Aa_sa3+Aa_cr; $\%$ heat transfer area in Zone a, $\mathrm{m}^{\wedge} 2$ \%\%\%\%\%\%\%\%\%\%\%\%\%\%\%\%\%\%\%\%\%\%\%\%\%\%\%\%\%\%\%\%\%\%\%\%\%\%\%\%\% Aa_bg $=2 * x b *$; $\quad \%$ heat transfer area from Zone a to Zone bg,Aa_bg $=0.2929 \mathrm{~m} \wedge 2$ \%\%\%\%\%\%\%\%\%\%\%\%\%\%\%\%\%\%\%\%\%\%\%\%\%\%\%\%\%\%\%\%\%\%\%\%\%\%\%\%\% Abg_sb1 $=\left(I^{*} \mathrm{~J}^{*}(\mathrm{pi} / 2+\mathrm{asin}(-\mathrm{yb} / \mathrm{J}))+\mathrm{I} *(-\mathrm{yb}) *((\mathrm{~J} \wedge 2-\mathrm{yb} \wedge 2)) \wedge .5 / \mathrm{J}\right)-(\mathrm{I} * \mathrm{~J} *(\mathrm{pi} / 2+\mathrm{asin}(-\mathrm{yc} / \mathrm{J}))+$ $\left.\mathrm{I}^{*}(-\mathrm{yc}) *\left(\left(\mathrm{~J} \wedge 2-\mathrm{yc}^{\wedge} 2\right)\right)^{\wedge} .5 / \mathrm{J}\right) ; \quad \%$ Abg_sb1, $\mathrm{m}^{\wedge} 2$

Abg_sb2=arclength_sb*l; \% Abg_sb2, $\mathrm{m}^{\wedge} 2$

Abg_sb=2*Abg_sb1+Abg_sb2; \% heat transfer area from bg layer to refractory sb, $\mathrm{m}^{\wedge} 2$

\%\%\%\%\%\%\%\%\%\%\%\%\%\%\%\%\%\%\%\%\%\%\%\%\%\%\%\%\%\%\%\%\%\%\%\%\%\%\%\%\%

Abg_cg $=2 * \mathrm{xc} * \mathrm{l} ; \quad \%$ heat transfer area from bg to cg, $\mathrm{m}^{\wedge} 2$

\%\%\%\%\%\%\%\%\%\%\%\%\%\%\%\%\%\%\%\%\%\%\%\%\%\%\%\%\%\%\%\%\%\%\%\%\%\%\%\%\%

Acg_dg=2*xd*l; $\quad \%$ heat transfer area from cg to dg, $\mathrm{m}^{\wedge} 2$

\%\%\%\%\%\%\%\%\%\%\%\%\%\%\%\%\%\%\%\%\%\%\%\%\%\%\%\%\%\%\%\%\%\%\%\%\%\%\%\%\%

Acg_sc1 $=\left(I^{*} \mathrm{~J}^{*}(\mathrm{pi} / 2+\mathrm{asin}(-\mathrm{yc} / \mathrm{J}))+\mathrm{I}^{*}(-\mathrm{yc})^{*}((\mathrm{~J} \wedge 2-\mathrm{yc} \wedge 2))^{\wedge} .5 / \mathrm{J}\right)-\left(\mathrm{I}^{*} \mathrm{~J} *(\mathrm{pi} / 2+\mathrm{asin}(-\mathrm{yd} / \mathrm{J}))+\mathrm{I}\right.$ $\left.*(-\mathrm{yd}) *\left(\left(\mathrm{~J} \wedge 2-\mathrm{yd}^{\wedge} \mathrm{2}\right)\right)^{\wedge} .5 / \mathrm{J}\right) ; \quad \% \mathrm{~m}^{\wedge} 2$

Acg_sc2=arclength_sc*l; \% $\mathrm{m}^{\wedge} 2$

Acg_sc=2*Acg_sc1+Acg_sc2; \% heat transfer area from cg layer to refractory sc, $\mathrm{m} \wedge 2$

\%\%\%\%\%\%\%\%\%\%\%\%\%\%\%\%\%\%\%\%\%\%\%\%\%\%\%\%\%\%\%\%\%\%\%\%\%\%\%\%\%

A_bushing $=0.381 * 0.0889 ; \quad \%$ area of the bushing plate, $\mathrm{m}^{\wedge} 2$

Abtr_btb $=2 *(0.4318+0.1143) * 0.005 ; \quad \%$ contact area between the bushing plate and refractory layer, $\mathrm{m}^{\wedge} 2$

A_bottom $=1 * 0.1143 ; \quad \%$ area of the bottom of the furnace, $\mathrm{m}^{\wedge} 2$

Mbtb=A_bushing/A_bottom; \% area ratio

Adg_bt=A_bottom; $\quad \%$ heat transfer area from dg to bottom, $\mathrm{m}^{\wedge} 2$

Abt_inf $=$ A_bottom; $\quad \%$ heat transfer area from bottom to air, $\mathrm{m}^{\wedge} 2$

\%\%\%\%\%\%\%\%\%\%\%\%\%\%\%\%\%\%\%\%\%\%\%\%\%\%\%\%\%\%\%\%\%\%\%\%\%\%\%\%\%

Adg_sd1 $=\left(I^{*} \mathrm{~J} *(\mathrm{pi} / 2+\mathrm{asin}(-\mathrm{yd} / \mathrm{J}))+\mathrm{I}^{*}(-\mathrm{yd}) *((\mathrm{~J} \wedge 2-\mathrm{yd} \wedge 2)) \wedge .5 / \mathrm{J}\right)-\left(\mathrm{I}^{*} \mathrm{~J} *(\mathrm{pi} / 2+\mathrm{asin}(-\mathrm{ybt} / \mathrm{J}))\right.$ $\left.+\mathrm{I}^{*}(-\mathrm{ybt})^{*}((\mathrm{~J} \wedge 2-\mathrm{ybt} \wedge 2))^{\wedge} .5 / \mathrm{J}\right) ; \% \quad \mathrm{~m}^{\wedge} 2$

Adg_sd2=arclength_sd*l; \% $\mathrm{m}^{\wedge} 2$

Adg_sd=2*Adg_sd1+Adg_sd2+Adg_bt*(1-Mbtb); \% heat transfer area from dg layer to refractory $\mathrm{sd}, \quad \mathrm{m}^{\wedge} 2$

\%\%\%\%\%\%\%\%\%\%\%\%\%\%\%\%\%\%\%\%\%\%\%\%\%\%\%\%\%\%\%\%\%\%\%\%\%\%\%\%\%

SF_a_sa $=1 ; \quad \%$ shape factor for radiation from a to refractory sa

SF_a_bg $=1 ; \quad \%$ shape factor for radiation from a to glass layer bg

SF_btb_inf $=1$; $\%$ shape factor for radiation from the bushing plate to air \%\%\%\%\%\%\%\%\%\%\%\%\%\%\%\%\%\%\%\%\%\%\%\%\%\%\%\%\%\%\%\%\%\%\%\%\%\%\%\%\% thickness $=0.0254$; $\%$ refractory thickness, $\mathrm{m}$ c_a=1025; \% heat capacitance for air $\mathrm{J} / \mathrm{kg} \mathrm{K}$ P_a=101325; \% air pressure $\mathrm{N} / \mathrm{m} 2$ 
R_a $=274.57 ; \%$ constant

$\mathrm{d} 2=0.0114265 ; \quad \% \quad \mathrm{~m}$

$\mathrm{I}=0.1524 ; \quad \%$ long axis of ellipse cross section for the furnace $\mathrm{m}$

$\mathrm{J}=0.1219235$; \% hort axis of ellipse cross section for the furnace $\mathrm{m}$

$\mathrm{l}=0.9652 ; \quad \% \quad \mathrm{~m}$

V_a $=\left(\mathrm{pi}^{*} \mathrm{I}^{*} \mathrm{~J}-\left(\mathrm{I}^{*} \mathrm{~J}^{*}(\mathrm{pi} / 2+\mathrm{asin}(-\mathrm{d} 2 / \mathrm{J}))+\mathrm{I}^{*}(-\mathrm{d} 2)^{*}((\mathrm{~J} \wedge 2-\mathrm{d} 2 \wedge 2))^{\wedge} .5 / \mathrm{J}\right)\right)^{*} \mathrm{l} ; \quad \%$ volume of the furnace, $\mathrm{m}^{\wedge} 3$

T_a1=1422; $\quad \%$ average temperature, $\mathrm{K}$

m_a=P_a*V_a/R_a/T_a1; \% mass of mixed combustion gas, $\mathrm{kg}$

$\mathrm{Ca}=\mathrm{c} \_\mathrm{a} * \mathrm{~m} \_\mathrm{a} ; \quad \%$ heat capacitance for gas in Zone a , $\mathrm{J} / \mathrm{K}$

\%\%\%\%\%\%\%\%\%\%\%\%\%\%\%\%\%\%\%\%\%\%\%\%\%\%\%\%\%\%\%\%\%\%\%\%\%\%\%\%\%

$\mathrm{d} 2=0.0114265 ; \quad \% \quad \mathrm{~m}$

$\mathrm{t} 2=\mathrm{asin}(\mathrm{d} 2 / \mathrm{J})$;

syms $\mathrm{x}$

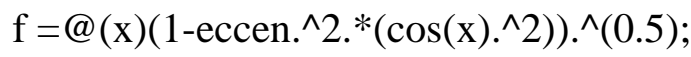

p2=quadl(f,0,t2);

$\mathrm{p} 3=$ quadl $(\mathrm{f}, 0, \mathrm{t} 1)$;

arclength_sa $=2 * I^{*}(\mathrm{p} 2+\mathrm{p} 3) ; \quad \%$ ac length, $\mathrm{m}$

V_sa=thickness*Aa_sa; $\%$ volume,_ $\mathrm{m}^{\wedge} 3$

m_sa=rou_r*V_sa; $\quad \%$ mass , kg

Csa $=$ C_r*m_sa; $\quad \%$ heat capacitance of sidewall refractory in $\mathrm{A}, \mathrm{J} / \mathrm{K}$

\%\%\%\%\%\%\%\%\%\%\%\%\%\%\%\%\%\%\%\%\%\%\%\%\%\%\%\%\%\%\%\%\%\%\%\%\%\%\%\%\%

c_g $=1240 ; \quad \%$ glass specific heat, $\mathrm{J} / \mathrm{kg}^{*} \mathrm{~K}$

rou_g $=2430 ; \quad \%$ density of glass, $\mathrm{kg} / \mathrm{m}^{\wedge} 3$

Abg_sb1 $=\left(I^{*} \mathrm{~J} *(\mathrm{pi} / 2+\mathrm{asin}(-\mathrm{yb} / \mathrm{J}))+\mathrm{I} *(-\mathrm{yb}) *((\mathrm{~J} \wedge 2-\mathrm{yb} \wedge 2)) \wedge .5 / \mathrm{J}\right)-(\mathrm{I} * \mathrm{~J} *(\mathrm{pi} / 2+\mathrm{asin}(-\mathrm{yc} / \mathrm{J}))+$ $\left.\mathrm{I}^{*}(-\mathrm{yc}) *\left(\left(\mathrm{~J} \wedge 2-\mathrm{yc}^{\wedge} 2\right)\right)^{\wedge} .5 / \mathrm{J}\right) ; \quad \% \quad$ area, $\mathrm{m}^{\wedge} 2$

V_bg=Abg_sb1*l; \% volume, $\mathrm{m}^{\wedge} 3$,

m_bg=rou_g*V_bg; \% mass of glass layer bg, m_bg=26.5110 kg

Cbg=c_g*m_bg; $\quad \%$ heat capacitance of glass layer bg, $\quad \mathrm{J} / \mathrm{K}$

\%\%\%\%\%\%\%\%\%\%\%\%\%\%\%\%\%\%\%\%\%\%\%\%\%\%\%\%\%\%\%\%\%\%\%\%\%\%\%\%\%

c_r $=1180 ; \quad \% \quad$ refractory specific heat, $\mathrm{J} / \mathrm{kg} * \mathrm{~K}$

rou_r $=3810 ; \quad \%$ density of glass, $\mathrm{kg} / \mathrm{m}^{\wedge} 3$

$\mathrm{tb}=\mathrm{asin}(\mathrm{yb} / \mathrm{J})$;

$\mathrm{tc}=\operatorname{asin}(\mathrm{yc} / \mathrm{J})$;

eccen $=(\mathrm{I} \wedge 2-\mathrm{J} \wedge 2) \wedge .5 / \mathrm{I}$;

syms $\mathrm{x}$

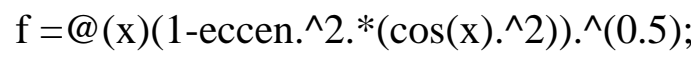

$\mathrm{pbc}=$ quadl $(\mathrm{f}, \mathrm{tb}, \mathrm{tc})$;

arclength_sb $=2 * I * p b c ; \quad \%$ arc length, $m$

V_sb=thickness*Abg_sb; \%volume, $\mathrm{m}^{\wedge} 3$

$\mathrm{m} \_s b=r o u \_r * V \_s b ; \quad \%$ mass of sidewall refractory in bg layer, $\mathrm{kg}$

Csb=c_r*m_sb; $\quad \%$ heat capacitance of sidewall refractory in bg layer, $\mathrm{J} / \mathrm{K}$

\%\%\%\%\%\%\%\%\%\%\%\%\%\%\%\%\%\%\%\%\%\%\%\%\%\%\%\%\%\%\%\%\%\%\%\%\%\%\%\%\%

c_g=1240; $\quad \%$ glass specific heat, $\quad \mathrm{J} / \mathrm{kg}^{*} \mathrm{~K}$ 
rou_g $=2430 ; \quad \%$ density of glass, $\mathrm{kg} / \mathrm{m}^{\wedge} 3$

Acg_sc1 $=\left(\mathrm{I}^{*} \mathrm{~J} *(\mathrm{pi} / 2+\mathrm{asin}(-\mathrm{yc} / \mathrm{J}))+\mathrm{I} *(-\mathrm{yc}) *((\mathrm{~J} \wedge 2-\mathrm{yc} \wedge 2)) \wedge .5 / \mathrm{J}\right)-(\mathrm{I} * \mathrm{~J} *(\mathrm{pi} / 2+\mathrm{asin}(-\mathrm{yd} / \mathrm{J}))+\mathrm{I}$ $*(-\mathrm{yd}) *((\mathrm{~J} \wedge 2-\mathrm{yd} \wedge 2)) \wedge .5 / \mathrm{J}) ; \quad \%$ area, $\mathrm{m}^{\wedge} 2$

V_cg=Acg_sc $1 * \mathrm{l} ; \quad \%$ volume, $\mathrm{m}^{\wedge} 3$

m_cg=rou_g*V_cg; \% mass, kg

Ccg=c_g*m_cg; $\%$ heat capacitance of glass layer cg, $\mathrm{J} / \mathrm{K}$

\%\%\%\%\%\%\%\%\%\%\%\%\%\%\%\%\%\%\%\%\%\%\%\%\%\%\%\%\%\%\%\%\%\%\%\%\%\%\%\%\%

$\mathrm{td}=\mathrm{asin}(\mathrm{yd} / \mathrm{J})$;

syms $\mathrm{x}$

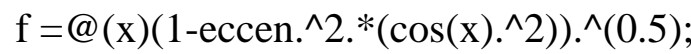

pcd=quadl(f,tc,td);

arclength_sc $=2 * I *$ pcd; $\%$ arc length, $\mathrm{m}$

V_sc=thickness*Acg_sc; \% volume, $\mathrm{m}^{\wedge} 3$

m_sc $=$ rou_r*V_sc; $\quad \%$ mass, $\mathrm{kg}$

Csc $=$ c_r*m_sc; $\quad \%$ heat capacitance of sidewall refractory in cg layer , J/K

\%\%\%\%\%\%\%\%\%\%\%\%\%\%\%\%\%\%\%\%\%\%\%\%\%\%\%\%\%\%\%\%\%\%\%\%\%\%\%\%\%

$\mathrm{xbt}=0.05715$

Adg_sd1 $=\left(I^{*} \mathrm{~J}^{*}(\mathrm{pi} / 2+\mathrm{asin}(-\mathrm{yd} / \mathrm{J}))+\mathrm{I}^{*}(-\mathrm{yd}) *((\mathrm{~J} \wedge 2-\mathrm{yd} \wedge 2))^{\wedge} \cdot 5 / \mathrm{J}\right)-\left(\mathrm{I}^{*} \mathrm{~J} *(\mathrm{pi} / 2+\mathrm{asin}(-\mathrm{ybt} / \mathrm{J}))\right.$

$\left.+\mathrm{I}^{*}(-\mathrm{ybt}) *((\mathrm{~J} \wedge 2-\mathrm{ybt} \wedge 2))^{\wedge} \cdot 5 / \mathrm{J}\right) ; \quad \%$ area, $\mathrm{m}^{\wedge} 2$

V_dg=Adg_sd1*l; \% volume, $\mathrm{m}^{\wedge} 3$,

m_dg=rou_g*V_dg; \% mass, kg

Cdg=c_g*m_dg; $\quad \%$ heat capacitance of glass layer dg, J/K

\%\%\%\%\%\%\%\%\%\%\%\%\%\%\%\%\%\%\%\%\%\%\%\%\%\%\%\%\%\%\%\%\%\%\%\%\%\%\%\%\%

$\mathrm{tbt}=\mathrm{asin}(\mathrm{ybt} / \mathrm{J})$;

syms $\mathrm{x}$

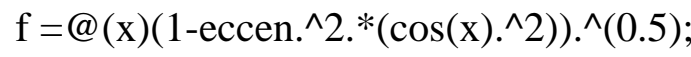

pdbt=quadl(f,td,tbt);

arclength_sd $=2 * I *$ pdbt; $\%$ arc length, $\mathrm{m}$

V_sd=thickness*Adg_sd; $\%$ vdume, $\mathrm{m}^{\wedge} 3$

m_sd=rou_r*V_sd; \% mass, kg

Csd=c_r*m_sd; $\quad \% \quad$ heat capacitance of sidewall refractory in dg layer, $\mathrm{J} / \mathrm{K}$

\%\%\%\%\%\%\%\%\%\%\%\%\%\%\%\%\%\%\%\%\%\%\%\%\%\%\%\%\%\%\%\%\%\%\%\%\%\%\%\%\%

A_bushing $=0.4318 * 0.1143 ; \quad \%$ aea of the bushing plate, $\quad \mathrm{m}^{\wedge} 2$

Abtb_inf $=$ A_bushing; $\%$ heat transfer area from the bushing plate to air, $\mathrm{m}^{\wedge} 2$

A_bottom $=\mathrm{l}^{*} 0.1143 ; \quad \% \quad$ area of the bottom of the furnace, $\mathrm{m}^{\wedge} 2$

A_btr=A_bottom-A_bushing; \% area of refractory at the bottom of the furnace, $\mathrm{m} \wedge 2$

V_btr=A_btr*thickness; $\quad \%$ volıme, $\mathrm{m}^{\wedge} \mathrm{3}$

m_btr=rou_r*V_btr; $\quad \%$ mass, $\mathrm{kg}$

Cbtr $=$ c_r ${ }^{*}$ m_btr; $\%$ heat capacitance of refractory at the bottom of glass furnace , $\mathrm{J} / \mathrm{K}$

\%\%\%\%\%\%\%\%\%\%\%\%\%\%\%\%\%\%\%\%\%\%\%\%\%\%\%\%\%\%\%\%\%\%\%\%\%\%\%\%\%

rou_btb=7817.008; $\quad \%$ \$ainless \$eel density, $\mathrm{kg} / \mathrm{m}^{\wedge} 3$

V_btb=A_bushing*0.005; \% volıme, $\mathrm{m}^{\wedge}$ 3

m_btb=rou_btb*V_btb; \% mass, kg

c_btb=460.548; $\quad \%$ specific heat for the bushing plate, $\mathrm{J} / \mathrm{kg} / \mathrm{K}$ 
Cbtb=c_btb*m_btb; $\quad \%$ heat capacitance of the bushing plate , J/K \%\%\%\%\%\%\%\%\%\%\%\%\%\%\%\%\%\%\%\%\%\%\%\%\%\%\%\%\%\%\%\%\%\%\%\%\%\%\%\%\% $\mathrm{Cr}=\mathrm{Ccr}+\mathrm{Csa}+\mathrm{Csb}+\mathrm{Csc}+\mathrm{Csd}+\mathrm{Cbtr} ; \quad \%$ heat capacitance for the refractory layer, $\mathrm{J} / \mathrm{K}$ \%\%\%\%\%\%\%\%\%\%\%\%\%\%\%\%\%\%\%\%\%\%\%\%\%\%\%\%\%\%\%\%\%\%\%\%\%\%\%\%\% epsilon=0.8; $\%$ glass emissivity constant sigma $=5.6704 \mathrm{e}-8 ; \quad \%$ Stephan-boltzmann constant, $\quad \mathrm{W} / \mathrm{m}^{\wedge} 2 / \mathrm{K}^{\wedge} 4$ $\mathrm{Ta} 0=1240$; $\quad \%$ average temperature in Zone a at steady state, $\mathrm{K}$ Tbg0=1209; \% average temperature in Zone bg at steady state, $\mathrm{K}$ Tav_a_bg $=0.5 *(\mathrm{Ta} 0+\mathrm{Tbg} 0) ; \quad \%$ average temperature, $\mathrm{K}$

Ra_bg=0.25/epsilon/sigma/Tav_a_bg^3; \% radiation from Zone a to glass layer bg , $\mathrm{W}^{*} \mathrm{~m} \wedge 2 * \mathrm{~K}$

\%\%\%\%\%\%\%\%\%\%\%\%\%\%\%\%\%\%\%\%\%\%\%\%\%\%\%\%\%\%\%\%\%\%\%\%\%\%\%\%\% $\mathrm{Tr} 0=1236 ; \quad \% \quad$ average temperature in refractory layer $\mathrm{r}$ at steady state, $\mathrm{K}$ Tav_a_sa $=0.5 *(\mathrm{Ta} 0+\operatorname{Tr} 0) ; \quad \%$ average temperature, $\mathrm{K}$

Ra_sa=0.25/epsilon/sigma/Tav_a_sa^3; \% radiation from Zone a to refractory layer $\mathrm{r}$, $\mathrm{W}^{*} \mathrm{~m} \wedge 2 * \mathrm{~K}$

\%\%\%\%\%\%\%\%\%\%\%\%\%\%\%\%\%\%\%\%\%\%\%\%\%\%\%\%\%\%\%\%\%\%\%\%\%\%\%\%\% Tbtb0=1173; \% average temperature in bushing plate layer btb at steady state, $\mathrm{K}$ Tav_btb_inf $=0.5 *($ Tbtb0 +300$) ; \quad \%$ average temperature, $\mathrm{K}$

Rbtb_inf $=(0.25 /$ epsilon/sigma/Tav_btb_inf $\wedge 3)$; \% radiation from bushing plate layer btb to air, $\mathrm{W}^{*} \mathrm{~m} \wedge 2 * \mathrm{~K}$

\%\%\%\%\%\%\%\%\%\%\%\%\%\%\%\%\%\%\%\%\%\%\%\%\%\%\%\%\%\%\%\%\%\%\%\%\%\%\%\%\% Lbg_sb $=0.0254 ; \quad \%$ thickness of refractory layer, $\mathrm{m}$ k_bg_sb=0.3; \% conduction oefficient for refractory, W/m.K R_bg_sb=Lbg_sb/k_bg_sb; \% conduction from glass layer bg to refractory layer $\mathrm{r}$, $\mathrm{W} / \mathrm{K}$

\%\%\%\%\%\%\%\%\%\%\%\%\%\%\%\%\%\%\%\%\%\%\%\%\%\%\%\%\%\%\%\%\%\%\%\%\%\%\%\%\% Lbg_cg=opth; $\quad \% \quad$ average optical thickness, $m$ k_bg_cg=12; \% conduction coefficient for glass, W/m.K R_bg_cg=Lbg_cg/k_bg_cg; \% conduction from glass layer bg to layer cg , W/K \%\%\%\%\%\%\%\%\%\%\%\%\%\%\%\%\%\%\%\%\%\%\%\%\%\%\%\%\%\%\%\%\%\%\%\%\%\%\%\%\% Lcg_dg=0.0246; $\quad \%$ average opical hickness, $m$ k_cg_dg=12; $\quad \%$ onduction coefficient for glass, W/m.K R_cg_dg=Lcg_dg/k_cg_dg; \% conduction from glass layer cg to layer dg, W/K \%\%\%\%\%\%\%\%\%\%\%\%\%\%\%\%\%\%\%\%\%\%\%\%\%\%\%\%\%\%\%\%\%\%\%\%\%\%\%\%\% Lcg_sc $=0.0254 ; \quad \%$ thickness of refractory, $m$ k_cg_sc $=0.3 ; \quad \%$ conduction oefficient for refractory , W/m.K R_cg_sc=Lcg_sc/k_cg_sc; \% conduction from glass layer cg to refractory layer $\mathrm{r}$, $\mathrm{W} / \mathrm{K}$

\%\%\%\%\%\%\%\%\%\%\%\%\%\%\%\%\%\%\%\%\%\%\%\%\%\%\%\%\%\%\%\%\%\%\%\%\%\%\%\%\% Ldg_btr $=0.0254 ; \%$ thickness of refractory, $m$ k_dg_btr=0.3; \% conduction coefficient for refractory R_dg_btr=Ldg_btr/k_dg_btr; \% conduction from glass layer $\mathrm{d}$ to refractory layer $\mathrm{r}$, $\mathrm{W} / \mathrm{K}$ 
\%\%\%\%\%\%\%\%\%\%\%\%\%\%\%\%\%\%\%\%\%\%\%\%\%\%\%\%\%\%\%\%\%\%\%\%\%\%\%\%\% Ldg_btb $=0.005 ; \quad \%$ thickness ofthe bushing plate, $m$ k_dg_btb=80; \% conduction coefficient for the bushing plate R_dg_btb=Ldg_btb/k_dg_btb; \% conduction from glass layer dg to the bushing plate layer btb, $\mathrm{W} * \mathrm{~K}$ \%\%\%\%\%\%\%\%\%\%\%\%\%\%\%\%\%\%\%\%\%\%\%\%\%\%\%\%\%\%\%\%\%\%\%\%\%\%\%\%\% Ldg_sd $=0.0254 ; \quad \% \quad$ thickness of the refractory , $m$ k_dg_sd=0.3; \% onduction oefficient fr efractory R_dg_sd=Ldg_sd/k_dg_sd; \% conduction from glass layer dg to the refractory layer $\mathrm{r}, \mathrm{W} / \mathrm{K}$

\%\%\%\%\%\%\%\%\%\%\%\%\%\%\%\%\%\%\%\%\%\%\%\%\%\%\%\%\%\%\%\%\%\%\%\%\%\%\%\%\% Lbtr_btb $=0.05715 ; \quad \% \mathrm{~m}$ k_btr_btb=80; \% conduction coefficient for the bushing plate, $\mathrm{W} / \mathrm{m} / \mathrm{K}$ R_btr_btb=Lbtr_btb/k_btr_btb; \% conduction from the refractory layer $\mathrm{r}$ to the bushing plate layer btb , W/K

\%\%\%\%\%\%\%\%\%\%\%\%\%\%\%\%\%\%\%\%\%\%\%\%\%\%\%\%\%\%\%\%\%\%\%\%\%\%\%\%\% h_btb=12.51455; $\quad \% \quad$ forced convection coefficient, $\mathrm{W} / \mathrm{m}^{\wedge} 2 / \mathrm{K}$ $\mathrm{R} \_\mathrm{btb}=1 / \mathrm{h} \_\mathrm{btb} ; \quad \%$ convection from the bushing plate to air , $\mathrm{m} \wedge 2 * \mathrm{~K} / \mathrm{W}$ \%\%\%\%\%\%\%\%\%\%\%\%\%\%\%\%\%\%\%\%\%\%\%\%\%\%\%\%\%\%\%\%\%\%\%\%\%\%\%\%\% $\mathrm{A}=$ zeros(6,6); \% set A, B ,C, D to zero matrix

$\mathrm{B}=\mathrm{zeros}(6,1)$;

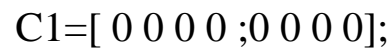

$\mathrm{C} 2=\left[\begin{array}{lll}1 & 0 ; 0 & 1\end{array}\right]$;

$\mathrm{C}=[\mathrm{C} 1 \mathrm{C} 2]$;

$\mathrm{D}=[0 ; 0]$;

$\mathrm{h}=1.2603 \mathrm{e}-004$; \% forced convection coefficient, $\mathrm{kg} / \mathrm{s}$ $\mathrm{i}=1240-300 ; \quad \%$ steady state value for temperature in Zone a, $\mathrm{K}$

$\mathrm{LHV}=49770000$; \% the lower heating value of methane, $\mathrm{J} / \mathrm{kg}$ A_F $=19.78 ; \%$ ratio of air to fuel mdotc $=\left(1+A \_F\right) * c \_a * h * i /\left(L H V-\left(1+A \_F\right) * c \_a * i\right) ; \quad \%$ mass fuel flow rate, $\mathrm{kg} / \mathrm{s}$ $\%$ energy equation for glass layer bg, 1st row of $\mathrm{A}$

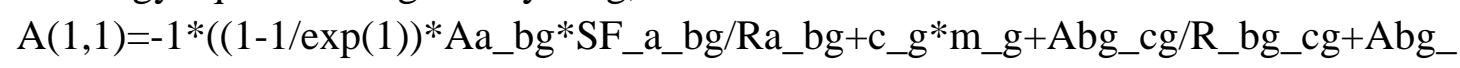
sb/R_bg_sb)/Cbg; \% coefficient for Tbg* $\mathrm{A}(1,2)=\mathrm{Abg} \_c g / \mathrm{R} \_b g \_c g / C b g ; \%$ coefficient for Tcg* $\mathrm{A}(1,3)=$ Abg_sb/R_bg_sb/Cbg; \% coefficient for Tr* $\mathrm{A}(1,4)=(1-1 / \exp (1)) * A a \_b g * S F \_a \_b g / R a \_b g / C b g ; \%$ coefficient for Ta* $\%$ energy equation for glass layer cg, 2st ow ofA $\mathrm{A}(2,1)=($ Abg_cg/R_bg_cg-(1/exp(1)-1/exp(2))*Aa_bg*Msb*SF_a_bg/Ra_bg+c_g*m g)/Ccg; \% coefficient for Tbg* $\mathrm{A}(2,2)=-1 *\left(c \_g * m \_g+A c g \_d g / R \_c g \_d g+A b g \_c g / R \_b g \_c g+A c g \_s c / R \_c g \_s c\right) / C c g ;$ $\%$ coefficient for Tcg* A(2,3)=Acg_dg/R_cg_dg/Ccg;\% coefficient for Tdg* $\mathrm{A}(2,4)=$ Acg_sc/R_cg_sc/Ccg; $\%$ coefficient for $\mathrm{Tr}^{*}$ $\mathrm{A}(2,5)=(1 / \exp (1)-1 / \exp (2)) * A a \_b g * M s b * S F \_a \_b g / R a \_b g / C c g ; \%$ coefficient for Ta* 
$\%$ energy equation for glass layer dg, 3st row of A

$\mathrm{A}(3,1)=-1 *(1 / \exp (2)-1 / \exp (2.63896)) * A a \_b g * M s b * M s c * S F \_a \_b g / R a \_b g / C d g ;$

$\%$ coefficient for Tbg*

$\mathrm{A}(3,2)=($ Acg_dg/R_cg_dg+c_g*m_g)/Cdg; \% coefficient for Tcg*

$\mathrm{A}(3,3)=-1 *$ (Acg_dg/R_cg_dg+c_g*m_g+Mbtb*Adg_bt/R_dg_btb+Adg_sd/R_dg_sd)

/Cdg; \% coefficient for Tdg*

$\mathrm{A}(3,4)=$ Adg_sd/R_dg_sd/Cdg; \% coefficient for $\mathrm{Tr} *$

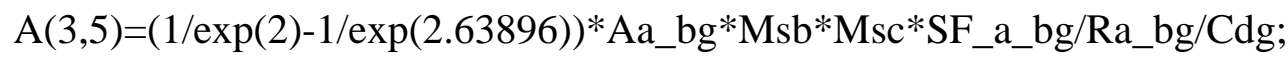

$\%$ coefficient for $\mathrm{Ta}^{*}$

A(3,6)=Mbtb*Adg_bt/R_dg_btb/Cdg; \% coefficient for Tbtb*

$\%$ energy equation for refractory layer $\mathrm{r}$, 4st row of $\mathrm{A}$

A(4,1)=Abg_sb/R_bg_sb/Cr; \% coefficient br Tbg*

$\mathrm{A}(4,2)=$ Acg_sc/R_cg_sc/Cr; \% coefficient for Tcg*

A(4,3)=Adg_sd/R_dg_sd/Cr; \% coefficient for Tdg*

$A(4,4)=-\left(A b g \_s b / R \_b g \_s b+A c g \_s c / R \_c g \_s c+A d g \_s d / R \_d g \_s d+A a \_s a * S F \_a \_s a / R a\right.$ _ sa+Abtr_btb/R_btr_btb)/Cr; \% coefficient for Tr*

$\mathrm{A}(4,5)=A a \_s a * S F$ a_sa/Ra_sa/Cr; $\%$ coefficient for Ta*

$\mathrm{A}(4,6)=\mathrm{Abtr} \_b t b / \mathrm{R} \_b t r \_b t b / C r ; \quad \%$ coefficient for Tbtb*

$\%$ energy equation for Zone a, 5st row of $\mathrm{A}$

A(5,1)=Aa_bg*SF_a_bg/Ca/Ra_bg; \% coefficient for Tbg*

$\mathrm{A}(5,4)=A a \_s a * S F$ _a_sa/Ra_sa/Ca; $\%$ coefficient for $\mathrm{Tr}$ *

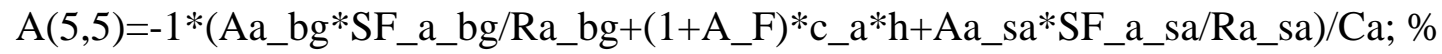
coefficient for Ta*

$\% 5$ st row of $\mathrm{B}$

$\mathrm{B}(5,1)=\left(\mathrm{LHV}-\left(1+\mathrm{A} \_\mathrm{F}\right){ }^{*} \mathrm{C} \_\mathrm{a}{ }^{*} \mathrm{i}\right) / \mathrm{Ca} ; \quad$ \% coefficient for mdotc*

$\%$ energy equation for the bushing plate layer btb , 6st row of $\mathrm{A}$

$\mathrm{A}(6,1)=-1 *$ Mbtb*Msb*Msc*Msd*Aa_bg*SF_a_bg/exp(2.63896)/Ra_bg/Cbtb; \% coefficient for Tbg*

A(6,3) $=($ Mbtb*Adg_bt/R_dg_btb+c_g*m_g)/Cbtb; \% coefficient fr Tdg*

A(6,4) =Abtr_btb/R_btr_btb/Cbtb; \% coefficient for Tr*

A(6,5)=Mbtb*Msb*Msc*Msd*Aa_bg*SF_a_bg/exp(2.63896)/Ra_bg/Cbtb;

$\%$ coefficient for Ta*

$\mathrm{A}(6,6)=-1 *(\mathrm{Mbtb} *$ Adg_bt/R_dg_btb+Mbtb*Abt_inf/R_btb+c_g*m_g+Mbtb*Abt_i nf*SF_btb_inf/Rbtb_inf+Abtr_btb/R_btr_btb)/Cbtb; \% coefficient for Tbtb*

\%\%\%\%\%\%\%\%\%\%\%\%\%\%\%\%\%\%\%\%\%\%\%\%\%\%\%\%\%\%\%\%\%\%\%\%\%\%\%\%\%

$\mathrm{Xi}=[900 ; 850 ; 800 ; 800 ; 900 ; 800] ; \quad \%$ normal initial condition, $\mathrm{K}$

$\% \mathrm{Xi}=[910 ; 860 ; 810 ; 810 ; 910 ; 810]$; initial condition 2, K

$\% \mathrm{Xi}=[890 ; 840 ; 790 ; 790 ; 890 ; 790]$; initial condition 3, K

$\% \mathrm{Xi}=[950 ; 900 ; 850 ; 850 ; 950 ; 850]$; initial condition 4, K

$\% \mathrm{Xi}=[850 ; 800 ; 750 ; 750 ; 850 ; 750]$; initial condition 5, K

$\mathrm{G} 1=$ zeros $(1,6)$;

$\mathrm{G} 1(1,3)=1$;

$\mathrm{H} 1=0$;

$\mathrm{O} 1=\left[\begin{array}{lll}\mathrm{A} & \mathrm{B} ; \mathrm{G} 1 \mathrm{H} 1\end{array}\right]$; 


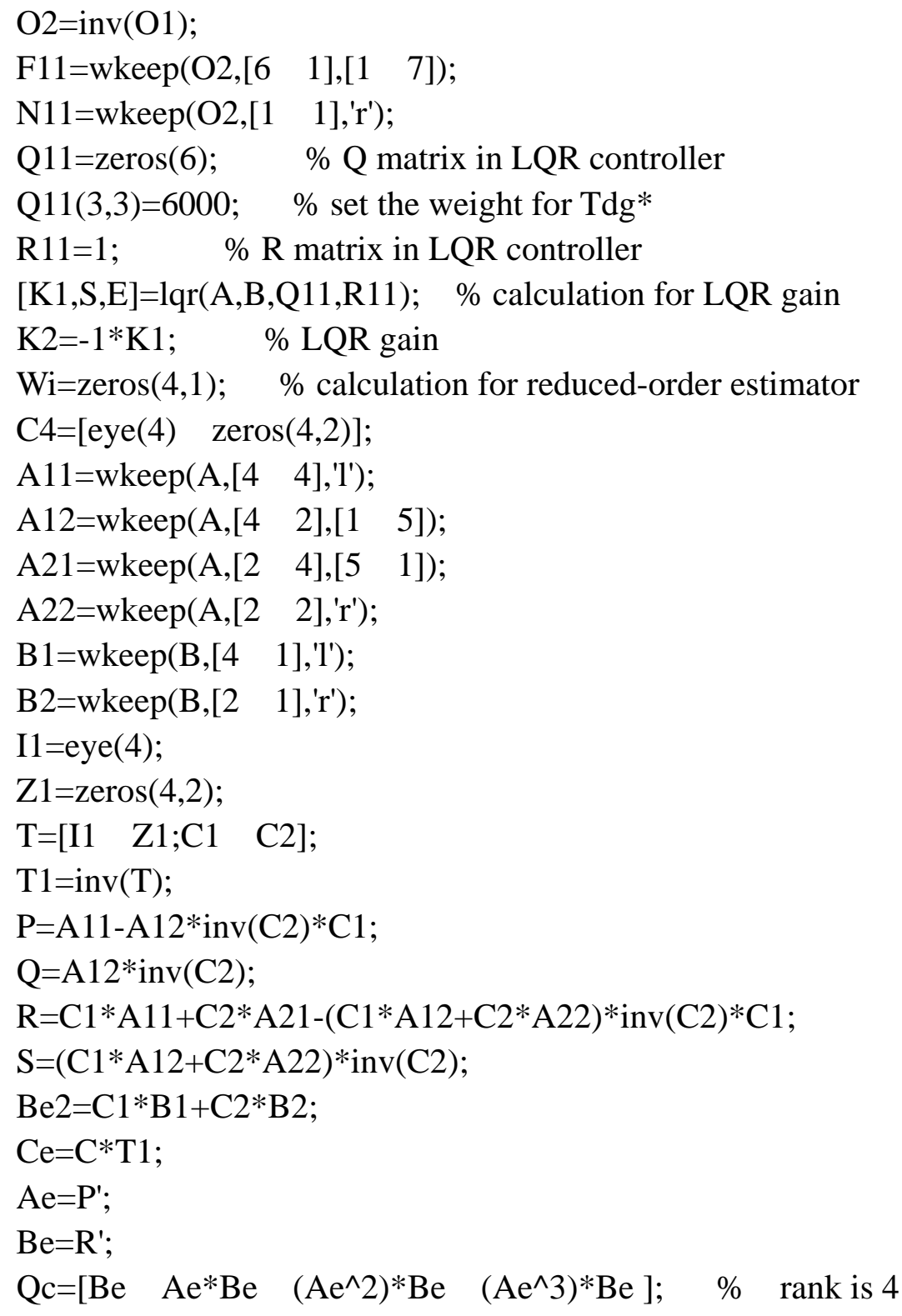

$\mathrm{CONT}=\mathrm{ctrb}(\mathrm{Ae}, \mathrm{Be}) ; \quad \%$ rank is 4

OBSER $=\operatorname{obsv}\left(\mathrm{Ae}, \mathrm{B} 11^{\prime}\right) ; \%$ rank is onl 6

$\mathrm{EP}=[-0.015+0.025 \mathrm{i} ;-0.015-0.025 \mathrm{i} ;-0.002+0.002 \mathrm{i} ;-0.002-0.002 \mathrm{i}]$; \% estimator pole vector 1

$\%$ EP=[ -0.0075+0.0125i;-0.0075-0.0125i;-0.004+0.004i;-0.004-0.004i];

$\%$ estimator pole vector 2

$\%$ EP=[ -0.03+0.05i;-0.03-0.05i;-0.004+0.004i;-0.004-0.004i];

$\%$ estimator pole vector 3

$\mathrm{F}=$ place(Ae,Be,EP);

$\mathrm{N}=\mathrm{F}^{\prime} ; \quad$ \% in the dual system, the estimator gain

$\mathrm{M}=\mathrm{P}-\mathrm{N} * \mathrm{R} ; \quad \%$ other gains in estimator system $\quad$ wdot $=\mathrm{Mw}+\mathrm{Lu}+\mathrm{Ky}$

$\mathrm{K}=\mathrm{Q}+\mathrm{M} * \mathrm{~N}-\mathrm{N} * \mathrm{~S} ; \% \mathrm{X} 1 \mathrm{e}=\mathrm{w}+\mathrm{Ny}$

$\mathrm{L}=\mathrm{B} 1-\mathrm{N} * \mathrm{Be} 2 ; \quad \% \quad$ wdot $=\mathrm{Mw}+\mathrm{Lu}+\mathrm{Ky}$

errorTbg=eerror(:,1); \% error of Tbg between estimator and real data

errorTcg=eerror(:,2); \% error of Tcg between estimator and real data 
errorTdg=eerror(:,3); \% error of Tdg between estimator and real data

errorTr=eerror(:,4); \% error of $\mathrm{Tr}$ between estimator and real data

figure

time1 = linspace(0,10000,93463); \% error plots for all the estimated temperatures

plot(time1,errorTbg,'b',time1,errorTcg,'g',time1,errorTdg,'r',time1,errorTr,'c');

grid on

mdotnr=U(:,1)-mdotc; \% mass fuel flow rate, $\mathrm{kg} / \mathrm{s}$

mdotstarr=U1(:,1);

mdotr=U11(:,1);

figure

time2 = linspace(0,25000,62887);

plot(time2,Tdg);

grid on

$\operatorname{Tdg}=\mathrm{Z}(:, 1)$;

Y2=1182*ones(length(Tdg),1); \% max limit for settling time

Y1=1172*ones(length(Tdg),1); \% min limit for settling time

figure

time2 = linspace(0,25000,length(Tdg));

plot(time2,Tdg,'b',time2,Y1,'g',time2,Y2,'r'); \% plot Tdg response with settling time limits

grid on

drumspeed=Drumspeed(:,1);

figure

time2 = linspace $(0,25000$,length(drumspeed)); \% winder speed control plots

plot(time2,drumspeed);

grid on

$\operatorname{Tdg}=\mathrm{Z}(:, 1)$;

mdotr=U11(:,1);

drumspeed=Drumspeed(:,1);

ambient $\mathrm{T}=$ Ambient $\mathrm{T}(:, 1)$;

figure

time2 = linspace $(0,25000$,length(Tdg)); \% plot Tdg, ambient temperature, mass

fuel flow rate and winder speed in the same figure

subplot(4,1,1);

plot(time2,Tdg,'b');

grid on

subplot $(4,1,2)$;

plot(time2,ambientT,'k');

grid on

subplot(4,1,3);

plot(time2,mdotr,'g');

grid on

subplot(4,1,4);

plot(time2,drumspeed,'r'); 
grid on

(It is similar to those program codes in molten glass depth variation cases.)

John $\mathrm{H}$. 